LIDIANE SANTANA OLIVEIRA

AVALIAÇÃO DO CICLO DE VIDA DE BLOCOS DE CONCRETO DO MERCADO BRASILEIRO: ALVENARIA E PAVIMENTAÇÃO

SÃO PAULO

2015 
LIDIANE SANTANA OLIVEIRA

AVALIAÇÃO DO CICLO DE VIDA DE BLOCOS DE CONCRETO DO MERCADO BRASILEIRO: ALVENARIA E PAVIMENTAÇÃO

Dissertação apresentada à Escola Politécnica da Universidade de São Paulo para obtenção do título de Mestre em Engenharia Civil.

SÃO PAULO

2015 
LIDIANE SANTANA OLIVEIRA

\section{AVALIAÇÃO DO CICLO DE VIDA DE BLOCOS DE CONCRETO DO MERCADO BRASILEIRO: ALVENARIA E PAVIMENTAÇÃO}

Dissertação apresentada à Escola Politécnica da Universidade de São Paulo para obtenção do título de Mestre em Engenharia Civil.

Área de concentração: Engenharia de Construção Civil e Urbana

Orientador: Prof. Dr. Vanderley M. John

SÃO PAULO

2015 
Este exemplar foi revisado e corrigido em relação à versão original,

sob

responsabilidade única do autor e com a anuência de seu orientador.

$-.$.

Assinatura do autor:

Assinatura do orientador:

Catalogação-na-publicação

Oliveira, Lidiane Santana

Avaliação do ciclo de vida de blocos de concreto do mercado brasileiro: alvenaria e pavimentação / L. S. Oliveira -- versão corr. -- São Paulo, 2015. $155 \mathrm{p}$.

Dissertação (Mestrado) - Escola Politécnica da Universidade de São Paulo. Departamento de Engenharia de Construção Civil.

1.Construção Civil 2.Ciclo de vida (Avaliação) 3.Sustentabilidade 4.Bloco de concreto 5.Dióxido de carbono (Emissão) I.Universidade de São Paulo. Escola Politécnica. Departamento de Engenharia de Construção Civil II.t. 
Dedico esse trabalho a meus pais, Geraldo e Maria José, minhas maiores inspirações. 


\section{AGRADECIMENTOS}

Primeiramente agradeço a Deus, sem o qual não teria conseguido concluir mais essa etapa na minha vida.

Aos meus amados pais, Geraldo e Maria José, minha base e meus eternos professores, onde sempre encontro apoio e forças para ir adiante. Aos meus amados irmãos, que sempre me deram forças e incentivo; João pelo apoio a distância e Liliane pela acolhida e suporte durante esse período, em especial nos difíceis primeiros meses.

Ao Prof. Vanderley John pela orientação, por proporcionar minha participação nesse projeto, por todo conhecimento compartilhado, pelas discussões e incentivos no decorrer desses últimos anos.

Ao CBCS por possibilitar minha participação no Projeto ACV Modular, assim como a $\mathrm{ABCP}$ e a BlocoBrasil, parceiras fundamentais nessa empreitada. A equipe e parceiros do projeto, todas as discussões foram de grande aprendizado: Érica Campos, Katia Punhagui, Prof. Sérgio Pacca, Prof. Sergio Angulo, Yazmin Mack, Cláudio Silva e Carlos Tauil. A todas as empresas que participaram dessa etapa do projeto ACV-m, pela colaboração e contínua comunicação: Arevale, Aroucatec, Blojaf, Calblock, Casalite, Civil, Exactomm, FLG, Glasser, Intercity, JB Blocos, Kerber, Original, Oterprem, Pavibloco, Pavimenti, Vale do Selke, Pentágono, Piuca, Prensil, Presto, Prontomix, Quitaúna, Sigma, Tatu, Tecmold, Tecpaver, Tinari, Uni Stein, Valleblock, Gai e Blocolit/Votorantim.

A todos os professores da Poli com quem tive o privilégio de conviver nesse período. Aos funcionários pelo apoio, em especial a Engracia, Wandréa, Patrícia e Eliana.

A CAPES, ao CBCS e a FDTE pelo auxílio financeiro.

Às amigas que o mestrado colocou no meu caminho e que levarei para vida: Katia Punhagui, Vanessa Heinrich, Débora Cavalheiro, Ana Werle, Isabela Libório, Marylinda de França, Camila Numazawa. As risadas e os desabafos foram essenciais para chegar ao final dessa jornada

Aos amigos conquistados no decorrer desse ciclo, especialmente ao pessoal da sala Asteroide, pelas conversas e cafezinhos de incentivo: Thiago, Winnie, Eliane, Juliana, Ricardo Alferes, Ricardo Cruvinel, Yazmin, Felipe, Alan, Delver, Fabricio, 
Carol, Débora Costa, Karen, Karolyne, Renata, Leonardo, Christian.

A todos os amigos que apoiaram e incentivaram de longe essa jornada, em especial a Kátia Ribeiro, Aline Souza, Leísa Cunha e Ana Cristina.

A Ulysses Oliveira, pela acolhida e convívio nos primeiros anos dessa aventura.

A família Projete Liberdade Capoeira, pelos encontros que sempre me deram ânimo pra continuar.

A meus tios Vadinho, Cida e Amintas e a todos os meus primos por todo amparo e acolhida em São Paulo.

A meus tios e primos pela torcida, em especial tias Ana, Lourdes, Rita e Neyde. A minha avó Alaíde, mesmo tendo partido no finalzinho dessa etapa, sempre foi e será para mim grande exemplo de mulher forte e perseverante. 
"Se Deus tivesse, na sua mão direita, a verdade toda, e na sua mão esquerda a infinita busca da verdade, sem nunca chegar a ela, e me dissesse: 'Escolha!', eu diria:'Dá-me a tua mão esquerda porque a verdade é para ti somente'." 


\section{RESUMO}

A construção civil é responsável por relevante impacto ao meio ambiente, da extração das materiais-primas até a disposição dos seus resíduos em aterros. A avaliação do ciclo de vida (ACV) é uma ferramenta que possibilita a estimativa dos impactos ambientais potenciais do setor de forma sistemática. A simplificação da $A C V$, pelo uso de dados secundários e redução do escopo do estudo, facilita sua implementação como ferramenta de promoção da sustentabilidade. O objetivo dessa dissertação é estimar faixas dos cinco principais indicadores do setor de blocos de concreto do mercado brasileiro pela simplificação da ACV: consumo de materiais, energia incorporada, emissão de $\mathrm{CO}_{2}$, água e geração de resíduos. Este estudo foi o piloto do Projeto ACV Modular, iniciativa do Conselho Brasileiro de Construção Sustentável em parceria da Associação Brasileira de Cimento Portland e da Associação Brasileira da Indústria de Blocos de Concreto. O inventário foi desenvolvido com 33 fábricas localizadas em diferentes regiões do Brasil, estas sendo responsáveis por aproximadamente $50 \%$ da produção nacional. Os produtos selecionados foram blocos para pavimentação e alvenaria (estruturais e de vedação) considerados mais representativos no mercado. A fronteira do sistema adotada foi do berço ao portão da fábrica. $O$ indicador de consumo de materiais não foi apresentado para garantir a confidencialidade dos dados das empresas, pois o teor de cimento foi dado direto informado no formulário. $O$ indicador de resíduos não pode ser gerado devido a diferentes interpretações adotadas pelos fabricantes ao registrar seus dados. $O$ indicador de água, apesar de incluir todo o consumo informado pela fábrica, apresentou valores muito baixos, alguns próximos a zero. $\mathrm{O}$ consumo de cimento, não o teor de clínquer, foi responsável por parcela significativa do $\mathrm{CO}_{2}$ e da energia incorporada do bloco, com participação de 62 a 99\% das emissões de $\mathrm{CO}_{2}$. Assim, entre as empresas analisadas, mesmo com igual rota tecnológica, os insumos utilizados, a formulação do concreto, a eficiência de compactação da vibro prensa e o sistema produtivo tiveram maior influência nos indicadores de materiais, energia e $\mathrm{CO}_{2}$.

Palavras-Chave: Avaliação do Ciclo de Vida. Sustentabilidade. Blocos de concreto. Emissão de $\mathrm{CO}_{2}$. Energia incorporada. 


\begin{abstract}
The civil construction is responsible for significant environmental impact from the extraction of raw materials to the disposal of their waste in landfills. The life cycle assessment (LCA) is a tool that enables the estimative of the potential environmental impacts of a sector systematically. Simplification of LCA, the use of secondary data and reduce the scope of the study, facilitates its implementation as a tool for promoting sustainability. The purpose of this dissertation is to estimate ranges of the five main indicators of the concrete block industry in the Brazilian market by simplifying the LCA: consumption of materials, embodied energy, $\mathrm{CO}_{2}$ emissions, water and waste generation. This study was the pilot of Modular LCA Project, an initiative of the Brazilian Council for Sustainable Construction (CBCS) in partnership with the Brazilian Portland Cement Association (ABCP) and the Brazilian Association of Concrete Blocks Industry (BlocoBrasil). The inventory was raised from 33 factories located in different regions of Brazil, that accounting for approximately $50 \%$ of national production. The products selected were paving and masonry blocks considered most representative in the market. The boundary system adopted was from cradle to factory gate. The indicator material consumption has been omitted to ensure the confidentiality of company data, as the cement content was raised directly by the companies. The waste indicator cannot be generated due to different interpretations adopted by companies to register their data. The water indicator, although it includes all the consumption reported by the factory, showed very low values, some near zero. Cement consumption, not the clinker content, accounted for a significant portion of $\mathrm{CO}_{2}$ emission and embodied energy, accounting $62-99 \%$ of $\mathrm{CO}_{2}$. Thus, among the analyzed factories, even with the same technological route, the inputs, the concrete formulation, the compression efficiency of vibro press and the production system had a greater influence on indicators of materials, energy and $\mathrm{CO}_{2}$.
\end{abstract}

Keywords: Life Cycle Assessment. Sustainability. Concrete blocks. $\mathrm{CO}_{2}$ emission. Embodied energy. 


\section{LISTA DE FIGURAS}

Figura 1 - Esquema das etapas de uma ACV. Fonte: Modificado da NBR 14040 (ABNT, 2009b)...

Figura 2 - Fluxograma do processo produtivo de blocos de concreto. Fonte: (JOHN et al., 2014) .....

Figura 3 - Tipos de vibro-prensas utilizadas para a produção de blocos e pisos de concreto.

Figura 4 - Possibilidades de embalagem dos produtos para entrega ao consumidor, registrados entre as empresas participantes do estudo: (a) uso de plástico e pallets; (b) uso de plástico apenas.

Figura 5 - Comparação entre o consumo de água de dois produtores de agregados e cimento no ano de 2011.

Figura 6 - Fluxograma do consumo de água em uma fábrica de blocos de concreto.

Figura 7 - Emissão de $\mathrm{CO}_{2}$ média brasileira de acordo com o teor de clínquer permitido por tipo de cimento (pontos sobre a reta limitados pelas faixas coloridas) e faixa de emissão média de três empresas nacionais (faixa cinza). Fonte: Oliveira (2015). .52

Figura 8 - Delimitação da fronteira do sistema estudado - fabricação de blocos de concreto.

Figura 9 - Comparação entre a massa de cimento utilizada na fabricação dos produtos analisados com a massa de cimento total utilizada na fábrica e a porcentagem que os produtos analisados representam na massa total dos produtos.

Figura 10 - Comparação entre a massa de agregados utilizada na fabricação dos produtos analisados com a massa total de agregados usados na fábrica e a porcentagem que os produtos analisados representam na massa total dos produtos.

Figura 11 - Comparação entre a massa de materiais secos utilizados na fabricação dos produtos analisados com a massa total de materiais secos utilizados na fábrica e a porcentagem que os produtos analisados representam na massa total dos produtos.

Figura 12 - Variação da massa informada e dado da ABCP - Bloco retangular para pavimento (35 MPa). A variabilidade é função da variação da densidade das formulações e dos agregados.

Figura 13 - Variação da massa informada - Blocos para pavimento de 16 faces (35 $\mathrm{MPa}$ ). A variabilidade é função da variação das dimensões das peças e da variação da densidade das formulações e dos agregados.

Figura 14 - Variação da massa informada - Blocos estruturais. A variabilidade é função da variação da densidade das formulações e dos agregados. Desgaste de formas é fator importante. .90

Figura 15 - Variação da massa informada - Blocos de vedação. A variação é associada à espessura de parede, além dos fatores de densidade. $O$ dado referente 
ao bloco de $9 \mathrm{~cm}$ com massa de $13 \mathrm{~kg}$ pertence à empresa 19, que forneceu o mesmo valor para blocos de 14 e $9 \mathrm{~cm}$ - acredita-se que seja erro de inventário....91

Figura 16 - Gráfico de distribuição acumulada do teor de água de composição do concreto que foi informada pelas empresas. O teor típico para a produção de blocos indicado pela $\mathrm{ABCP}$ é de $6 \%$ da massa seca. 100

Figura 17 - Fontes de água utilizadas por fábrica participante do projeto. A empresa 29 não informou dados de consumo de água. 103

Figura 18 - Fontes de água utilizadas pelas empresas participantes. 103

Figura 19 - Distribuição do teor de cimento levantado a partir dos dados informados pelas empresas participantes. 105

Figura 20 - Distribuição das perdas de produção informadas pelas empresas

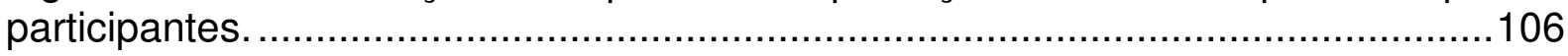

Figura 21 - Distribuição da energia incorporada mínima calculada por bloco. .......106

Figura 22 - Distribuição da energia incorporada máxima calculada por bloco. ......107

Figura 23 - Distribuição da emissão de $\mathrm{CO}_{2}$ mínima calculada por bloco..............107

Figura 24 - Distribuição da emissão de $\mathrm{CO}_{2}$ máxima calculada por bloco .............108

Figura 25 - Indicador de energia incorporada - Blocos para pavimento (35 MPa). Alguns resultados não foram considerados por serem julgados produtos de erro de inventário.

Figura 26 - Indicador de energia incorporada - Blocos estruturais e de vedação. Alguns resultados não foram considerados por serem julgados produtos de erro de inventário

Figura 27 - Indicador de emissão de $\mathrm{CO}_{2}$ - Blocos para pavimento ( $35 \mathrm{MPa}$ ). Alguns resultados não foram considerados por serem julgados produtos de erro de inventário.

Figura 28 - Indicador de emissão de $\mathrm{CO}_{2}$ - Blocos estruturais e de vedação. Alguns resultados não foram considerados por serem julgados produtos de erro de inventário.

Figura 29 - Gráfico de distribuição do consumo total de água das fábricas alocado nos blocos pela massa da peça.

Figura 30 - Indicador de consumo total de água da fábrica dos blocos para

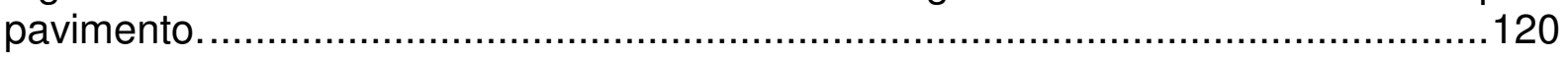

Figura 31 - Indicador de consumo total de água da fábrica dos blocos para alvenaria. 120

Figura 32 - Faixas da energia incorporada dos blocos para pavimento com mediana/média por tipo de cimento.

Figura 33 - Faixas da energia incorporada dos blocos para alvenaria com mediana/média por tipo de cimento.

Figura 34 - Faixas da emissão de $\mathrm{CO}_{2}$ dos blocos para pavimento com mediana/média por tipo de cimento.

Figura 35 - Faixas da emissão de $\mathrm{CO}_{2}$ dos blocos para alvenaria com mediana/média por tipo de cimento. 
Figura 36 - Faixas da energia incorporada dos blocos para pavimento, considerando a variabilidade entre as empresas e do transporte e as incertezas da energia dos insumos.

Figura 37 - Faixas da emissão de $\mathrm{CO}_{2}$ dos blocos para pavimento, considerando a variabilidade entre as empresas e do transporte e as incertezas dos fatores de emissão dos insumos.

Figura 38 - Faixas da energia incorporada dos blocos estruturais, considerando a variabilidade entre as empresas e do transporte e as incertezas da energia dos insumos.

Figura 39 - Faixas da emissão de $\mathrm{CO}_{2}$ dos blocos estruturais, considerando a variabilidade entre as empresas e do transporte e as incertezas dos fatores de emissão dos insumos. 130

Figura 40 - Faixas da energia incorporada dos blocos de vedação, considerando a variabilidade entre as empresas e do transporte e as incertezas da energia dos insumos. 130

Figura 41 - Faixas da emissão de $\mathrm{CO}_{2}$ dos blocos de vedação, considerando a variabilidade entre as empresas e do transporte e as incertezas dos fatores de emissão dos insumos.

Figura 42 - Curva de frequência acumulada versus a distância média ponderada dos insumos. 132

Figura 43 - Distância média ponderada dos insumos pela quantidade utilizada nos blocos. 133

Figura 44 - Relação entre a distância média ponderada e a emissão de $\mathrm{CO}_{2}$, por $\mathrm{m}^{2}$ para os blocos para pavimento e por peça para os blocos para alvenaria: (a) blocos para pavimento; (b) blocos estruturais; (c) blocos de vedação. 


\section{LISTA DE TABELAS}

Tabela 1 - Dados de blocos de concreto levantados em literatura, sendo os seis primeiros estudos nacionais. Os resultados seguem métodos de cálculo diferentes e não podem ser comparados. O número de dígitos significativos é o da publicação. 35

Tabela 2 - Comparação superficial entre os dados de blocos levantados na literatura. Como os estudos consideraram métodos de cálculo diferentes, essa comparação não é correta. O número de dígitos significativos é o da publicação....36

Tabela 3 - Composição do cimento de acordo com as normas (\% em massa). Fonte: Oliveira (2015).

Tabela 4 - Energia incorporada e emissão de $\mathrm{CO}_{2}$ unitárias por tipo de cimento. Emissão de $\mathrm{CO}_{2}$ estimada por Oliveira et al. (2014) e energia incorporada calculada a partir dos teores de clínquer permitidos por norma e do consumo energético publicado pelo WBCSD.

Tabela 5 - Emissão de $\mathrm{CO}_{2}$ e energia incorporada dos agregados levantados nesse estudo.

Tabela 6 - Fator de emissão de $\mathrm{CO}_{2}$ e energia incorporada dos insumos energéticos por unidade de referência (Und).

Tabela 7 - Lista das empresas participantes, por estado da federação. 60

Tabela 8 - Características dos blocos de concreto para pavimentos selecionados para o estudo.

Tabela 9 - Características dos blocos estruturais e de vedação selecionados para o estudo.

Tabela 10 - Comparação entre os formulários teste e final para a coleta de dados. 63 Tabela 11 - Dados adotados para as conversões das unidades dos insumos informados e as respectivas unidades estabelecidas como padrão para o cálculo dos indicadores.

Tabela 12 - Unidades referentes às produções informadas. Os números sublinhados referem-se às empresas que utilizaram uma unidade para os blocos para pavimentação e outra referente aos blocos para alvenaria. 69

Tabela 13 - Unidades de consumo de cimento informadas por tipo de produto.......69 Tabela 14 - Unidades de água de composição do concreto informadas pelas empresas por tipo de produto.

Tabela 15 - Unidades de produção utilizadas pelas empresas para informar o total da fábrica. A fábrica 32 não informou sua produção total. .71

Tabela 16 - Análises do consumo de cimento: comparação entre consumo total na fábrica e consumo nos produtos analisados.

Tabela 17 - Análises de consumo de agregados: comparação na fábrica e nos produtos analisados.

Tabela 18 - Análises de consumo de materiais secos: comparação na fábrica e nos produtos analisados.

Tabela 19 - Comparação entre as perdas de produção dos produtos analisados e as perdas/resíduos de produção total da empresa. As empresas podem ter feito 
diferentes considerações neste último valor, incluindo dados referentes a perdas de produção que não se convertem em resíduos.

Tabela 20 - Destinação das perdas de produção. As perdas que retornam para a fabricação de outros produtos sem que sofram qualquer processamento (ainda no estado fresco) podem não ter sido classificados de resíduos.

Tabela 21 - Destinação dos resíduos do processo de produção dos blocos de concreto - RR para resíduo reciclado ou reutilizado e Des para resíduo descartado.

Tabela 22 - Tipos de cimento utilizados pelas empresas associado ao uso de cura térmica.

Tabela 23 - Quantidade de água de composição do concreto informada para os blocos para pavimento (35 MPa)

Tabela 24 - Quantidade de água de composição do concreto informada para os blocos estruturais e de vedação.

Tabela 25 - Consumo de água total da fábrica por fonte de origem. A empresa 29 não informou dados sobre o consumo de água pela fábrica.

Tabela 26 - Comparação da água total da fábrica alocada nos produtos analisados com a água média de composição do concreto informada pelas empresas.

Tabela 27 - Consumo de água total da fábrica para os blocos para pavimento (35 $\mathrm{MPa})$

Tabela 28 - Consumo de água total da fábrica para os blocos estruturais. 116

Tabela 29 - Consumo de água total da fábrica para os blocos de vedação com 14 $\mathrm{cm}$ de largura.

Tabela 30 - Consumo de água total da fábrica para os blocos de vedação com $9 \mathrm{~cm}$ de largura.

Tabela 31 - Participação de cada etapa da ACV dos blocos de concreto na energia incorporada e na emissão de $\mathrm{CO}_{2}$.

Tabela 32 - Tipo de cimento associado aos valores mínimos e máximos de consumo de cimento, energia incorporada e emissão de $\mathrm{CO}_{2}$. 126

Tabela 33 - Variação dos fatores de emissão de $\mathrm{CO}_{2}$ e da energia incorporada dos insumos. 


\section{LISTA DE SIGLAS}

\begin{tabular}{|c|c|}
\hline $\mathrm{ABCP}$ & Associação Brasileira de Cimento Portland \\
\hline ABNT & Associação Brasileira de Normas Técnicas \\
\hline ACV & Avaliação do Ciclo de Vida \\
\hline ACV-m & Avaliação do Ciclo de Vida Modular \\
\hline AICV & Avaliação do Impacto do Ciclo de Vida \\
\hline ANEPAC & $\begin{array}{l}\text { Associação Nacional das Entidades de Produtores de Agregados para a Constru- } \\
\text { ção Civil }\end{array}$ \\
\hline ANICER & Associação Nacional da Indústria Cerâmica \\
\hline ANTT & Agência Nacional de Transportes Terrestres \\
\hline BEES & Building for Environmental and Economic Sustainability \\
\hline BEN & Balanço Energético Nacional \\
\hline BlocoBrasil & Associação Brasileira da Indústria de Blocos de Concreto \\
\hline$B R E$ & Building Research Establishment \\
\hline CAPES & Coordenação de Aperfeiçoamento de Pessoal de Nível Superior \\
\hline$C B A$ & Concrete Block Association \\
\hline CBCS & Conselho Brasileiro de Construção Sustentável \\
\hline CERIB & Centre d'Etudes \& de Recherches de l'Industrie Du Béton \\
\hline CONMETRO & Conselho Nacional de Metrologia, Normalização e Qualidade Industrial \\
\hline CSI & Cement Sustainability Initative \\
\hline DNPM & Departamento Nacional de Produção Mineral \\
\hline$E L C D$ & European Reference Life Cycle Database \\
\hline$E P D$ & Product Category Rules \\
\hline EPE & Empresa de Pesquisa Energética \\
\hline$E U$ & European Union \\
\hline GEE & Gases do Efeito Estufa \\
\hline$G R I$ & Global Reporting Initiative \\
\hline IEMA & Instituto Estadual de Meio Ambiente \\
\hline IPCC & Intergovernmental Panel on Climate Change \\
\hline ISO & International Organization for Standardization \\
\hline ITeC & Institut de Tecnologia de la Construcció de Catalunya \\
\hline MCT & Ministério da Ciência e Tecnologia \\
\hline MME & Ministério de Minas e Energia \\
\hline NCMA & National Concrete Masonry Association \\
\hline NREL & National Renewable Energy Laboratory \\
\hline PBACV & Programa Brasileiro de Avaliação do Ciclo de Vida \\
\hline$P C A$ & Portland Cement Association \\
\hline$P C R$ & Product Category Rule \\
\hline SENAI & Serviço Nacional de Aprendizagem Industrial \\
\hline SETAC & Society for Environmental Toxicology and Chemistry \\
\hline SINDIBRITA & Sindicato da Indústria de Mineração de Brita do Estado do RJ \\
\hline SNIC & Sindicato Nacional da Indústria do Cimento \\
\hline UNEP & United Nations Environment Programme \\
\hline WBCSD & World Business Council for Sustainable Development \\
\hline WRI & World Resources Institute \\
\hline
\end{tabular}




\section{LISTA DE ABREVIATURAS}

$\%$ agreg.n

$16 f . x \mathrm{~cm}$

BCE

BCP

BCV

CD

CD

$\mathrm{CE}_{\mathrm{pç.n}}$

$\mathrm{CO}_{2}$

DIST

$\mathrm{ECO}_{2}$

$\mathrm{ECO}_{2}$ fáb.pç

$\mathrm{ECO}_{2}$ mp.pç

El

$\mathrm{El}_{\text {fáb.pç }}$

$\mathrm{El}_{\mathrm{IE} . \mathrm{n}}$

$\mathrm{El}_{\text {mp.pç }}$

FC

FE

FET

$\mathrm{m}_{\text {agreg.fáb }}$

$\mathrm{m}_{\text {agreg.n }}$

$\mathrm{m}_{\text {agreg.pç }}$

$\mathrm{m}_{\text {água }}$

$\mathrm{m}_{\text {água.fonte }}$

$\mathrm{m}_{\text {cim.pç }}$

$\mathrm{m}_{\text {h.pc }}$

$\mathrm{m}_{\mathrm{mp} . \mathrm{pc}}$

$\mathrm{m}_{\text {seca.pc }}$

$\mathrm{m}_{\text {seca.total }}$

$M_{\text {transp. }}$

MTT

$\mathrm{m}_{\text {unitária.prod }}$

NV

QTD $_{m p}$

QTD $_{\text {prod }}$

ret.x cm

Und

$\mathrm{V}_{\mathrm{pc}}$

$\mathrm{V}_{\mathrm{TPE}}$
Proporção de cada tipo de agregado

Bloco para pavimento de 16 faces com 6,8 ou $10 \mathrm{~cm}$ de espessura

Bloco de concreto estrutural

Bloco de concreto para pavimento

Bloco de concreto para vedação

Consumo de óleo diesel - mínimo e máximo

Consumo de diesel - mínimo e máximo

Consumo energético de cada tipo de fonte por peça

Dióxido de carbono

Distância de transporte

Emissão de $\mathrm{CO}_{2}$ - mínima e máxima

Emissão de $\mathrm{CO}_{2}$ da fábrica por peça

Emissão de $\mathrm{CO}_{2}$ de cada matéria-prima por peça

Energia incorporada

Energia incorporada da fábrica por peça

Energia incorporada por tipo de insumo energético

Energia incorporada de cada matéria-prima por peça

Fator de consumo de combustível

Fator de emissão de $\mathrm{CO}_{2}$

Fator de emissão de $\mathrm{CO}_{2}$ pelo funcionamento de trem - mínimo e máximo

Massa de agregado total da fábrica

Massa por tipo de agregado

Massa de agregado por peça

Massa de água por peça

Massa de água por origem

Massa de cimento por peça

Massa de água da umidade de equilíbrio com ar por peça

Massa de cada matéria-prima por peça

Massa seca por peça

Massa seca total por tipo produto

Massa de matéria-prima transportada por viagem

Massa total de transporte - mínimo e máximo

Massa unitária do bloco por tipo de produto

Número de viagens

Quantidade total de por tipo de matéria-prima

Quantidade total por tipo de produto

Bloco para pavimento retangular, com 6,8 ou $10 \mathrm{~cm}$ de espessura

Unidade de análise ou de referência

Volume por bloco

Volume total dos produtos selecionados para o estudo 


\section{SUMÁRIO}

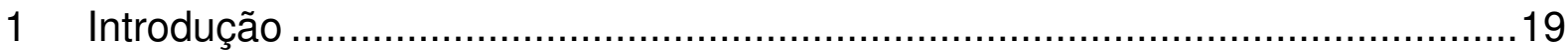

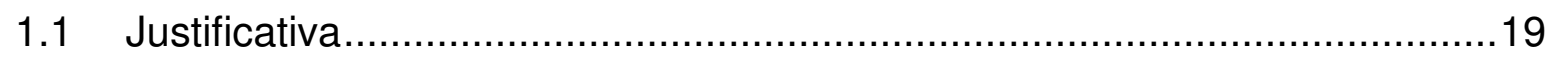

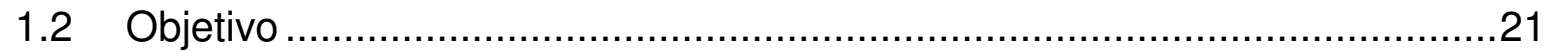

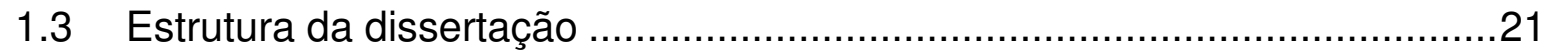

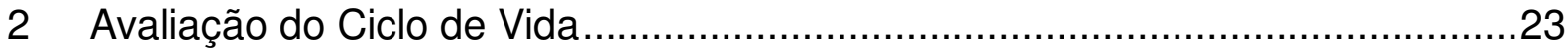

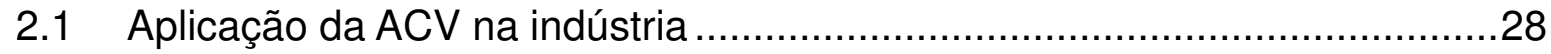

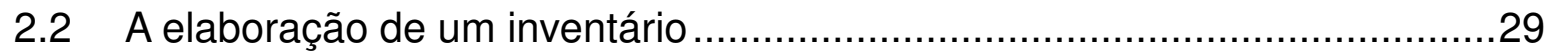

2.3 A necessidade de métodos de ACV mais simples....................................30

2.3.1 Uso de dados secundários ..............................................................

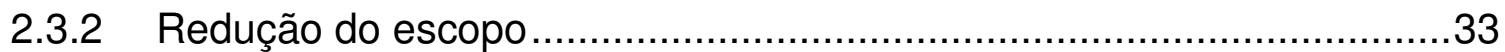

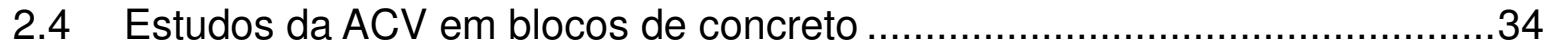

2.5 ACV Modular - características da proposta ...............................................

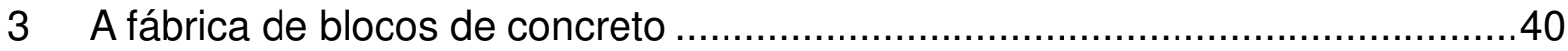

3.1 Controle de dados no processo produtivo ...............................................

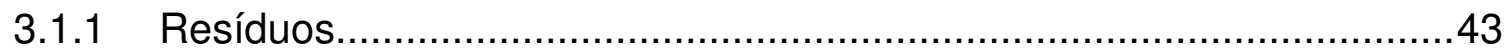

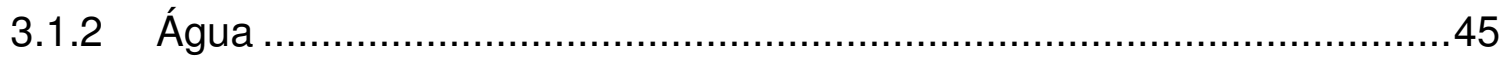

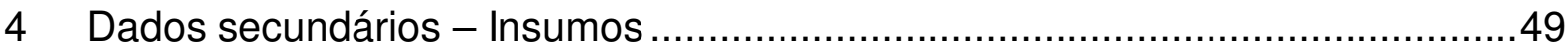

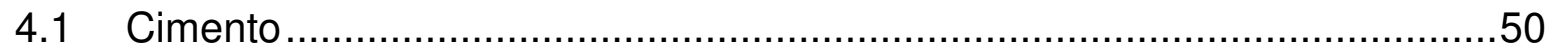

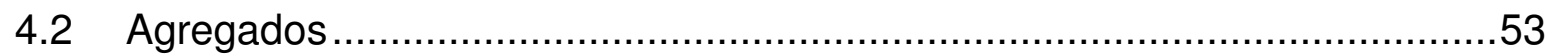

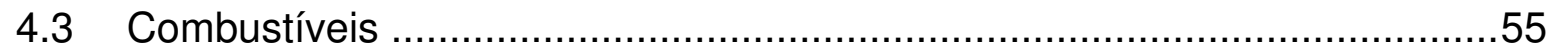

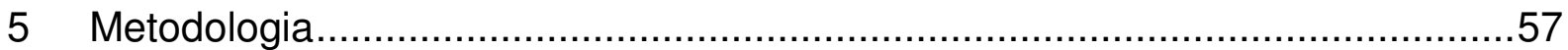

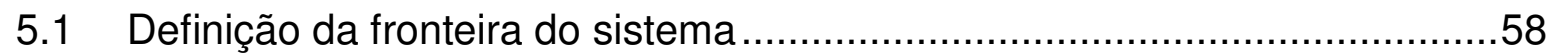

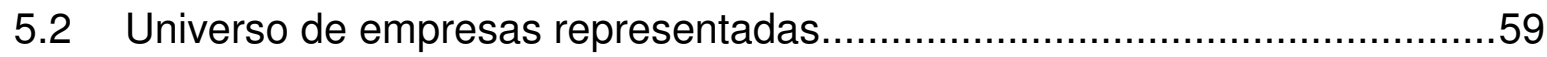

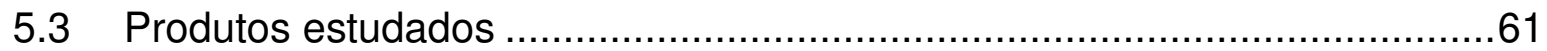

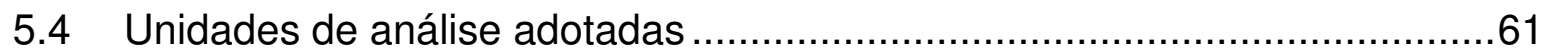

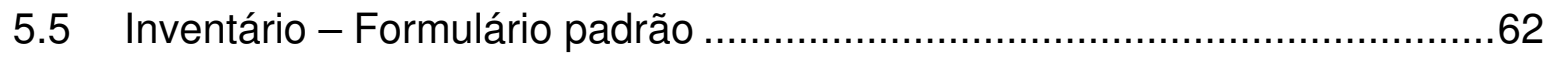

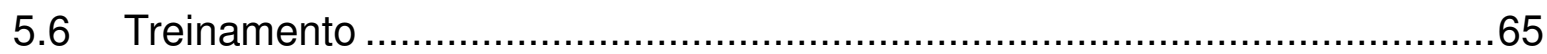

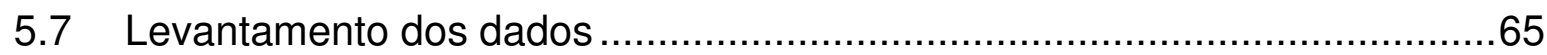

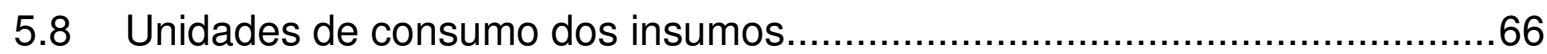

5.9 Conversões de unidades referentes ao processo produtivo .......................68

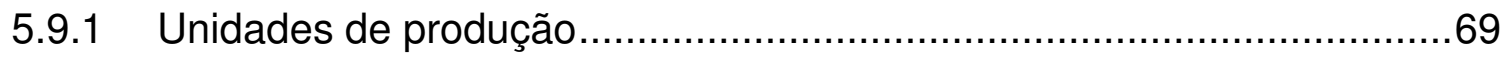

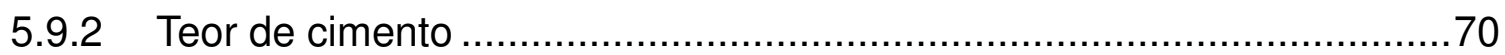

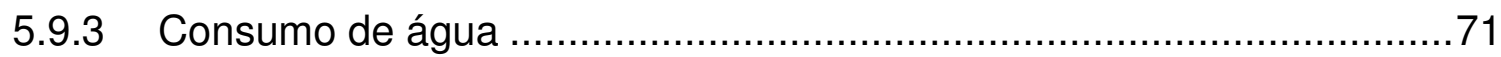

5.10 Estimativa da quantidade total de produtos da fábrica ..........................71 
5.11 Estimativa de combustível do transporte das matérias-primas .73

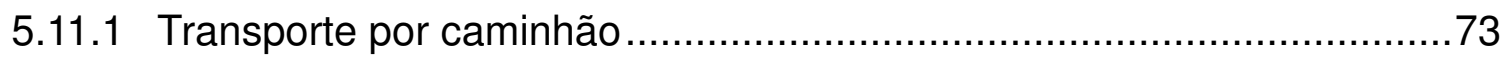

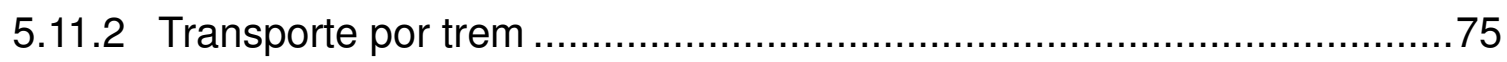

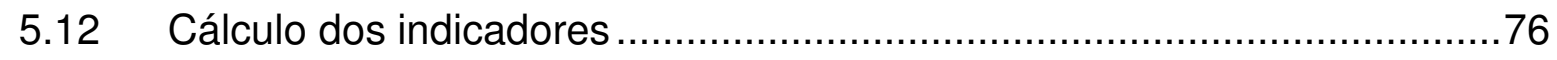

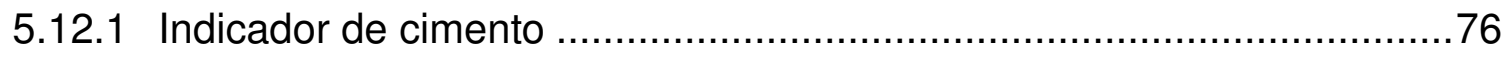

5.12 .2 Indicador de agregados ........................................................ 76

5.12 .3 Indicador de energia incorporada (EI) ..................................... 77

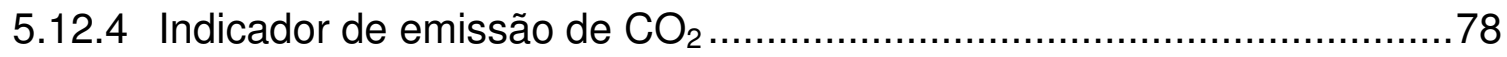

5.12 .5 Indicador de água ............................................................ 79

5.12 .6 Indicador de resíduos/perdas ................................................. 80

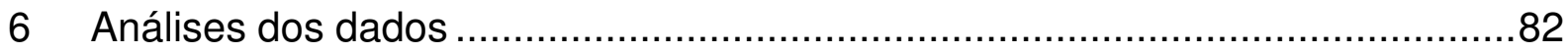

6.1 Balanço de massa entre insumos e produtos informados ..........................82

6.2 Análise da massa informada por peça ................................................... 88

6.3 Análise das perdas e resíduos informados ............................................91

6.4 Tipos de cimentos utilizados e cura térmica ........................................96

6.5 Análise da água informada para a composição do concreto.......................97

6.6 Água consumida pela fábrica ...................................................... 101

6.7 Análise da distribuição acumulada dos indicadores ..............................105

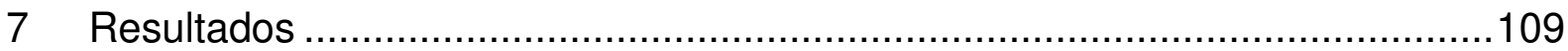

7.1 Indicadores da ACV Modular......................................................... 110

7.1.1 Indicador de energia incorporada ............................................ 110

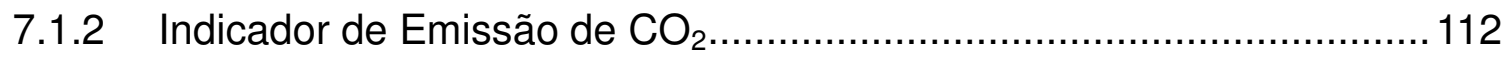

7.1 .3 Indicador de Água.............................................................. 114

7.2 Energia incorporada e emissão de $\mathrm{CO}_{2}$ por tipo de cimento....................120

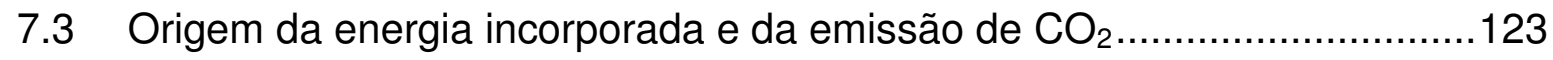

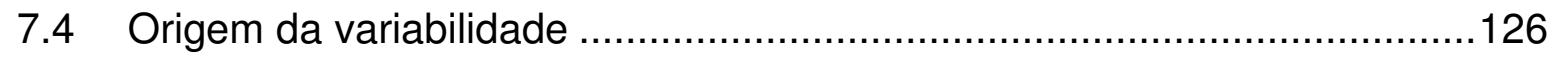

7.5 Influência da distância de transporte ...........................................131

8 Discussões sobre a metodologia da ACV Modular ....................................135

9 Conclusões .................................................................................... 139

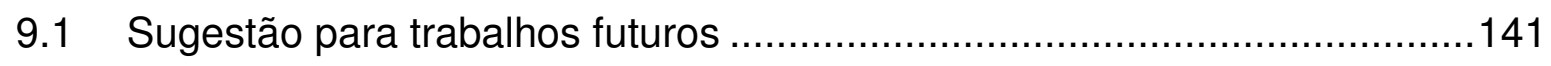

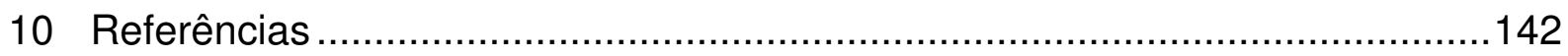

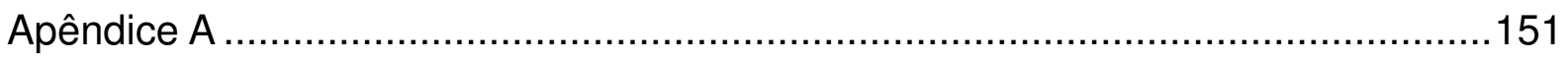

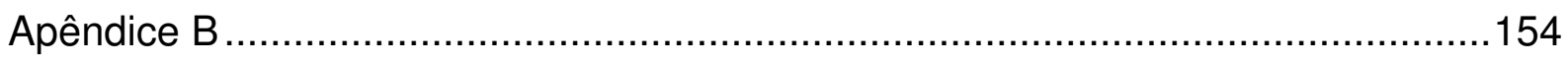




\section{Introdução}

\subsection{Justificativa}

A construção civil gera importantes impactos ao meio ambiente, desde a extração e fabricação de seus insumos até o descarte dos materiais, no final de sua vida útil. O processo produtivo da indústria cimenteira é responsável por $5,3 \%$ das emissões globais de $\mathrm{CO}_{2}$ (QUÉRÉ et al., 2014), sendo que em 2012 foram produzidos 3,7 bilhões de toneladas no mundo (SNIC, 2014). Isso corresponde ao consumo aparente de 22 bilhões de toneladas de agregados e 2,5 bilhões de $\mathrm{m}^{3}$ de água (JOHN; SCRIVENER, Não publicado), sabendo que os agregados são os produtos da indústria mineral que possuem os maiores volumes de comercialização (SERNA; REZENDE, 2009).

Para a extração das matérias-primas, fabricação e transporte dos variados produtos utilizados pelo setor, geralmente são utilizadas máquinas que funcionam pela queima de combustíveis fósseis (não renováveis), responsáveis por aproximadamente $8 \%$ das emissões globais anuais de $\mathrm{CO}_{2}$ (IPCC, 2013). Além disso, resíduos são gerados nos processos de extração, fabricação, uso e no final da vida útil dos bens materiais utilizados pelo setor (ROCHA; JOHN, 2003).

A preocupação com os impactos que as atividades industriais podem causar vem aumentando nos últimos anos no Brasil nos diversos setores, inclusive na construção civil. Por utilizar significativos volumes de recursos naturais, que resulta em grande dano ao meio ambiente, a quantificação de seus impactos é fundamental para que ações de melhorias sejam possíveis. Esse levantamento permitirá analisar como os materiais poderão apresentar maior aproveitamento, de modo a causar menos prejuízos ambientais.

Ferramentas quantitativas confiáveis são necessárias para estimar o desempenho sustentável das ações do homem na natureza (VIÑAS; SILVA, 2012). A avaliação do ciclo de vida $(A C V)$ é uma técnica importante e reconhecida internacionalmente que permite quantificar os impactos ambientais pela análise dos fluxos de entradas e saídas de um sistema de produto durante seu ciclo de vida. Por meio dela é possível identificar, quantificar, analisar e selecionar os aspectos considerados mais relevantes ao sistema. Sua prática tem potencial de melhorar a avaliação dos 
insumos utilizados e das etapas de um processo produtivo, pois pode auxiliar nas tomadas de decisões para melhoria do sistema pela identificação das questões mais críticas, permitindo ações pontuais. Contudo, essa capacidade ainda tem sido pouco explorada no Brasil, já que sua realização necessita de significativos investimentos e tempo, além de pessoal especializado para sua execução.

O Conselho Brasileiro de Construção Sustentável (CBCS) teve a iniciativa de desenvolver um projeto pioneiro para o levantamento dos impactos ambientais causados pela indústria brasileira de materiais de construção de forma simplificada. Chamado de Projeto ACV Modular (ACV-m), o módulo básico foi implementado no setor de blocos de concreto, para pavimento e alvenaria, em parceria com a Associação Brasileira de Cimento Portland (ABCP) e a Associação Brasileira da Indústria de Blocos de Concreto (BlocoBrasil). Essa primeira ação é considerada o piloto para a criação de uma plataforma global de ACV simplificada proposta pelo CBCS (CBCS, 2012).

O conhecimento dos impactos de uma empresa ou setor é possível de estimar apenas pelo levantamento dos fluxos de entrada e saída do sistema. Assim, esse estudo - o Projeto ACM-m de blocos de concreto - visa promover o controle e ações de melhoria de um processo produtivo com critérios de sustentabilidade. O método de levantamento de dados é compatível com o adotado pelo Programa Brasileiro de Avaliação do Ciclo de Vida (PBACV). Como a ACV-m, o PBACV inicialmente considera a análise dos principais materiais do setor secundário da indústria brasileira, com abordagem do berço ao portão, que devem ser mais detalhados em fases posteriores (PBACV, 2009).

A autora desta dissertação teve participação efetiva em todas as etapas do Projeto ACV-m, onde seu desenvolvimento e o desta dissertação ocorreram concomitantemente. As regras estabelecidas pela CAPES (Coordenação de Aperfeiçoamento de Pessoal de Nível Superior), através da Portaria Conjunta nำ 1, foram seguidas para a realização dessa parceria. 


\subsection{Objetivo}

O objetivo dessa dissertação é estimar faixas dos consumos das principais matériasprimas e de água, da energia incorporada, da emissão de $\mathrm{CO}_{2}$ e dos resíduos gerados na produção dos blocos de concreto considerados mais significativos no mercado brasileiro (estruturais, de vedação e para pavimento). Os dados foram levantados em 33 fábricas nacionais, cuja produção corresponde a aproximadamente $50 \%$ do mercado. Os valores extremos das faixas foram definidos pelos menores e maiores valores calculados para cada indicador considerando os dados das empresas participantes.

Os resultados foram levantados por meio de uma avaliação do ciclo de vida simplificada, com a redução do escopo do estudo e o uso de dados secundários, estes referentes aos insumos. A abordagem adotada foi "do berço ao portão", ou seja, da extração das matérias-primas até o portão da fábrica.

\subsection{Estrutura da dissertação}

Essa dissertação é dividida em 10 capítulos, sendo o primeiro esta introdução, que apresenta a justificativa e o objetivo desse trabalho.

O Capítulo 2 contém um embasamento teórico sobre a avaliação do ciclo de vida, assim como os benefícios de sua realização e da simplificação. É apresentada uma introdução sobre a ACV Modular, metodologia desenvolvida nesse estudo.

O Capítulo 3 mostra a descrição geral da fábrica de blocos de concreto e seu funcionamento. São apresentados os itens que possuem maior e menor controle no processo produtivo, sendo dada maior ênfase a estes últimos.

No Capítulo 4 são apresentados os dados secundários de energia incorporada e emissão de $\mathrm{CO}_{2}$ dos insumos levantados na literatura e utilizados no estudo.

No Capítulo 5 a metodologia é descrita. São apresentadas as etapas de desenvolvimento do estudo, com a elaboração dos formulários, o levantamento dos dados, as conversões e estimativas necessárias e, por fim, o cálculo dos indicadores.

O Capítulo 6 apresenta as análises realizadas para verificar a consistência dos dados. As informações levantadas junto às empresas foram avaliadas para garantir a qualidade dos resultados finais. 
No Capítulo 7 são apresentados os resultados, os indicadores selecionados para esse estudo e informações oriundas desses valores.

O Capítulo 8 apresenta uma discussão sobre a metodologia da ACV Modular, sendo apontados aspectos que podem ser melhorados em sua execução. No Capítulo 9 são apresentadas as conclusões desse estudo e sugestões para desenvolvimento de novos trabalhos. Por fim, no Capítulo 10 são apresentadas as referências bibliográficas. 


\section{Avaliação do Ciclo de Vida}

A metodologia da ACV é definida pela NBR 14044 como o inventário e a avaliação dos fluxos de entrada e saída de matéria e energia e dos impactos ambientais potenciais de um sistema de produto, durante seu ciclo de vida (ABNT, 2009a). Por meio dela é possível identificar as atividades de um sistema que possuem maior impacto, com o levantamento das etapas de maior consumo de insumos e geração de resíduos. Isso permite ações de melhorias no processo de forma pontual, além de possibilitar um maior gerenciamento da produção.

Alguns produtos têm como principais responsáveis pelos seus impactos as etapas de produção, transporte e descarte, não a fase de uso (GUINEE et al., 2011). Isso porque além de sua fabricação consumir majoritariamente insumos primários extraídos diretamente da natureza ou com poucas etapas de processamento, sua utilização origina menor impacto do que sua fabricação, além de ter vida útil indefinida. Este é o caso dos blocos de concreto, que possuem como principais insumos cimento, agregados e água e acompanham a vida útil da construção, mas a sua própria deve ultrapassar 100 anos. Nesses casos, a prática da ACV é mais simples quando comparada com a de produtos que dependem de outras ACVs mais complexas para o levantamento dos dados - como eletrônicos e automóveis - e que também possuem impactos significativos na fase de uso, fortemente relacionado à fonte energética necessária para seu funcionamento.

A avaliação do ciclo de vida é apontada como uma sofisticada ferramenta que permite a comparação dos impactos de produtos equivalentes, que possuam a mesma função e diferentes matérias-primas, já que os resultados são apresentados em relação à utilidade do produto, a unidade funcional (BUENO; ROSSIGNOLO; OMETTO, 2012; NICOLAY, 2000). No entanto, na maior parte dos casos, negligencia a importância da comparação entre fabricantes distintos de um mesmo produto. Variações na composição da peça e nos fornecedores das matérias-primas podem resultar em significativas diferenças nos impactos (AGOPYAN; JOHN, 2011). A publicação de declarações ambientais de produtos pelos fabricantes é um instrumento adequado para esta comparação.

Para que os resultados sejam comparáveis, a execução das avaliações devem adotar os mesmos métodos. Considerações diferentes resultam em discrepâncias 
nos resultados, o que não permite concluir se suas causas são devido às diferenças nos produtos analisados ou às diferenças existentes entre os métodos utilizados.

De acordo com a NBR 14040, o estudo da ACV realiza uma análise sistemática composta por quatro fases: definição de objetivo e escopo; inventário; avaliação de impactos e interpretação (ABNT, 2009b). As fases se relacionam para possibilitar constantes atualizações, a depender da necessidade do estudo, como ilustra a Figura 1.

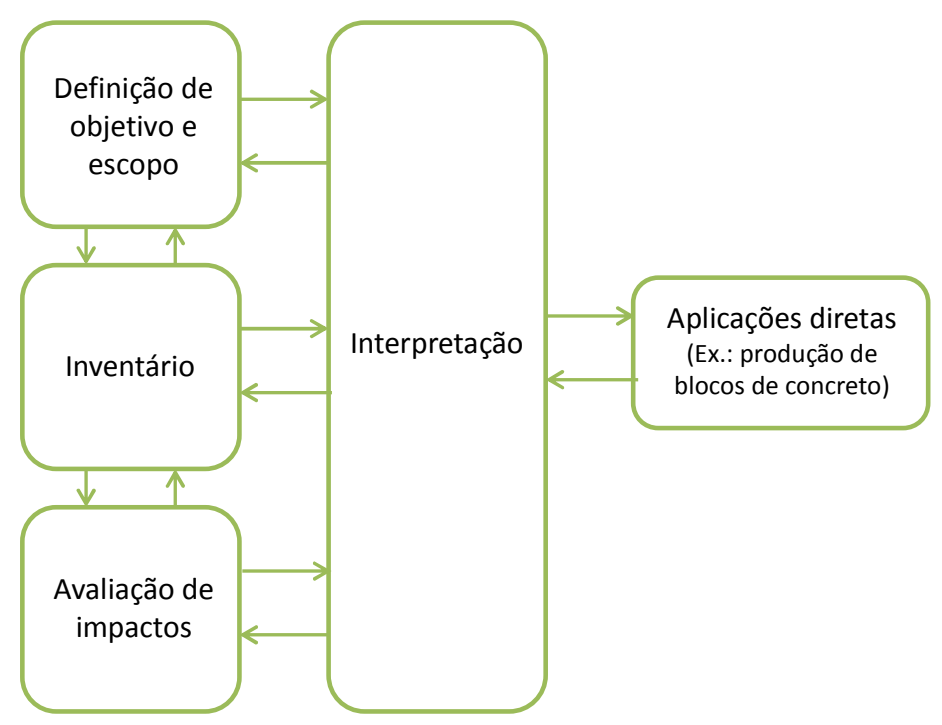

Figura 1 - Esquema das etapas de uma ACV. Fonte: Modificado da NBR 14040 (ABNT, 2009b).

Na primeira fase, o objetivo e o escopo do estudo são definidos, sendo apresentada a aplicação pretendida dos resultados, as razões para o estudo e o público alvo, visto que nessa etapa são definidas as principais questões que terão grande influência na ACV (JENSEN et al., 1997; REBITZER et al., 2004). O sistema a ser estudado, com suas funções e fronteiras, e a unidade funcional adotada precisam ser claramente definidos, além dos tipos de impactos analisados e os métodos de cálculos utilizados (ABNT, 2009b).

Quando o sistema de produção envolve múltiplos produtos é necessário realizar procedimentos de alocação, ou seja, a divisão dos fluxos de entrada e saída entre os produtos. Embora a NBR 14044 aconselhe evitar tais ações quando possível, as considerações adotadas devem ser informadas quando sua realização for inevitável (ABNT, 2009a). Existem diferentes modos de efetuar a alocação - em massa, em volume, por valor econômico - mas nenhum oferece uma solução geral (CURRAN, 2007). O método escolhido necessita ser claramente apresentado, uma vez que 
diferentes tratamentos resultam em diferentes tipos de informação (EKVALL; FINNVEDEN, 2001). A definição de critério de alocação tem considerável influência nos resultados da ACV.

Com o estudo delineado, segue-se para a fase de inventário, onde o levantamento e a validação dos dados são realizados. Quais informações serão coletadas nessa etapa depende da abordagem da $A C V$, que pode ser atribucional ou consequencial (EUROPEAN COMMISSION; JOINT RESEARCH CENTRE; INSTITUTE FOR ENVIRONMENT AND SUSTAINABILITY, 2010), definida na primeira fase da avaliação. Enquanto no primeiro caso o objetivo é analisar os fluxos de um processo ou produto específico durante um período, uma ACV clássica, o propósito do segundo caso é responder como os fluxos e impactos associados a um sistema de larga escala irão responder a diferentes decisões alternativas (CURRAN; MANN; NORRIS, 2005; EUROPEAN COMMISSION; JOINT RESEARCH CENTRE; INSTITUTE FOR ENVIRONMENT AND SUSTAINABILITY, 2010). Como na ACV consequencial há a necessidade de estudo de tendência e projeções de mercado, seus resultados podem ser mais sensíveis e passíveis a incertezas, sendo ainda pouco aplicada (MUNIZ, 2012).

$\mathrm{Na}$ abordagem tradicionalmente utilizada, atribucional, todas as entradas e saídas relevantes dos fluxos de energia e materiais relacionados ao ciclo de vida de um produto são levantadas na fase de inventário (ORTIZ; CASTELLS; SONNEMANN, 2009). Para isso, primeiramente desenvolve-se uma metodologia, com um formulário dedicado para a coleta dos dados. Com o inventário levantado, a análise de consistência das informações coletadas é realizada. Se necessário, são estabelecidos critérios de alocação para alcance dos resultados referentes aos produtos analisados. O processo normalmente envolve ajustes para conversão dos mesmos à unidade funcional definida. Dados de fontes disponíveis para pesquisa precisam ser referenciados e todos os procedimentos de cálculos e hipóteses adotadas devem ser apresentados de forma transparente (ABNT, 2009a). A verificação de consistência das entradas e saídas é necessária para identificar, quantificar, checar e avaliar as informações resultantes do inventário (CURRAN, 2006).

É importante que a representatividade da amostra inventariada seja claramente caracterizada, além de que é indispensável que o período e o local de coleta dos 
dados sejam indicados. As variáveis existentes nos processos produtivos, como tecnologia utilizada, disponibilidade de matérias-primas ou condições climáticas podem originar diferenças importantes nos impactos que um produto pode causar, inclusive em uma mesma região. O tempo mínimo de doze meses é recomendado como sendo considerado suficiente para dissipar os desvios das condições normais de operação de um processo de produção (KULAY; SEO, 2010).

O desenvolvimento do inventário normalmente é a fase de maior trabalho na ACV, pois requer considerável investimento de tempo para seu levantamento. A coleta dos dados implica em medir os fluxos de matéria e energia ao longo do ciclo de vida do produto, que também inclui atividades produtivas da cadeia de fornecedores, incluindo os poluentes gerados. Completeza, precisão/incerteza, metodologia adotada e representatividade são aspectos para serem analisados na avaliação da qualidade dos dados. Somado a isso, também é importante que o inventário seja documentado, para assegurar reprodutibilidade e transparência quanto a sua construção (EUROPEAN COMMISSION; JOINT RESEARCH CENTRE; INSTITUTE FOR ENVIRONMENT AND SUSTAINABILITY, 2010).

A terceira fase, avaliação do impacto do ciclo de vida (AICV), precisa dispor de informações adicionais para ajudar na avaliação dos resultados do inventário (ABNT, 2009a). Os dados levantados são associados aos indicadores de impacto ambiental definidos no início do estudo, que podem ser consumo de recursos naturais, potencial de aquecimento global, destruição da camada de ozônio, eutrofização, acidificação, uso de água, ruído, entre outros (REBITZER et al., 2004; VIÑAS; SILVA, 2012).

A última fase, de interpretação dos resultados, é realizada conforme o objetivo e escopo do estudo, onde também é importante inclur uma avaliação e verificação de sensibilidade dos dados de entrada e saída, assim como dos métodos de cálculos utilizados (ABNT, 2009a). A compreensão do que foi analisado também pode explicar as limitações encontradas e orientar sobre o que é possível realizar para mudar o cenário estudado.

A metodologia da ACV é multidisciplinar, pois sua realização requer conhecimento da área em que será aplicada e sobre o levantamento dos impactos ambientais potenciais, de modo a definir adequadamente os objetivos e o sistema analisado. 
Além disso, permite que a empresa, cujo processo produtivo é estudado, conheçase melhor, já que proporciona a identificação das etapas mais eficientes e as que podem ser aperfeiçoadas. A avaliação do ciclo de vida é um método que se aprende durante sua execução, pois depende do sistema de produto estudado, sendo importante utilizá-lo com discernimento, além de bom conhecimento das suas vantagens e limitações (VENTURA, 2012).

Uma ACV pode ser realizada em diferentes níveis de sofisticação, a depender da aplicação pretendida. Quando o inventário é limitado, considerando apenas aspectos qualitativos, a avaliação pode ser utilizada para auxiliar na identificação de oportunidades para redução de impactos ambiental, social e econômico, conhecida como ACV conceitual ou "Pensar o Ciclo de Vida" (Life Cycle Thinking) (JENSEN et al., 1997). O UNEP (United Nations Environment Programme) e a SETAC (Society for Environmental Toxicology and Chemistry), através da Life Cycle Initiative, tem o objetivo de promover a prática desse modo de pensar no processo produtivo ${ }^{1}$. Esse pode ser o primeiro passo para o levantamento de dados quantitativos.

A ACV tradicional realiza uma abordagem do berço ao túmulo e avalia todas as etapas da vida do produto para estimar seus impactos ambientais (CURRAN, 2006). A simplificação da ACV é realizada principalmente pela redução do escopo e uso de dados secundários (WEITZ et al., 1996), mas essencialmente com mesmo objetivo da tradicional.

Como a simplificação facilita a aplicação, reduz o tempo necessário para realização e possui custo mais baixo que a tradicional, torna-se mais viável o inventário em grande número de processos do sistema estudado. Uma maior abordagem sobre a simplificação é realizada no item 2.3. Na prática é possível, e até necessário, combinar diferentes níveis de ACV simplificada, assim como ampliar progressivamente o inventário de uma avaliação de escopo reduzido, tornando-a gradativamente mais completa.

\footnotetext{
${ }^{1}$ http://www.lifecycleinitiative.org/starting-life-cycle-thinking/what-is-life-cycle-thinking/
} 


\subsection{Aplicação da ACV na indústria}

Estudos de caso de ACV em diferentes áreas da indústria vêm sendo apresentados nos últimos anos (HOFFMAN, 1997; NICOLAY, 2000; ERM, 2001; SALING et al., 2002; HOSPIDO; MOREIRA; FEIJOO, 2003; EARLY et al., 2009; GAMA, 2010; KELLENBERGER; ALTHAUS, 2009; ORTIZ; CASTELLS; SONNEMANN, 2009; SOUZA et al., 2015). A primeira ACV registrada foi realizada no final da década de 1960, para fábrica da Coca-Cola (FERREIRA, 2004). Atualmente algumas grandes empresas do país já utilizam essa ferramenta para auxiliar na solução de problemas, como Braskem (BRASKEM, 2015), O Boticário (GRUPO BOTICÁRIO, 2014) e Natura (NATURA, 2014). Apesar disso, sua aplicação efetiva para embasar decisões do dia a dia ainda vem ocorrendo de forma lenta, sobretudo no Brasil.

A prática da ACV tem sido encorajada por meio de políticas públicas de incentivo ao desenvolvimento sustentável, como a criação de uma base de dados (JENSEN et al., 1997; CONMETRO, 2010). A Comissão Europeia destaca sua importância como ferramenta para avaliar o potencial de melhoria de um produto ${ }^{2}$. A comissão técnica da base de dados francesa, Inies ${ }^{3}$, trabalha em parceria com o governo para garantir a disponibilização de dados com boa qualidade. O Programa Brasileiro de ACV pretende implantar no país um sistema capacitado para organizar, armazenar e divulgar informações sobre a metodologia, além de produzir um inventário com dados da indústria nacional (PBACV, 2011).

Atualmente, maior parte das informações disponíveis é gerada por instituições especializadas, públicas (NREL - National Renewable Energy Laboratory ${ }^{4}$ ) ou privadas (Ecolnvent; ELCD - European Reference Life Cycle Database ${ }^{6}$; BEES ${ }^{7}$; Inies ${ }^{8}$; BEDEC ITeC ${ }^{9}$; Athena Sustainable Materials Institute, 2005), incluindo a academia. Embora seu desenvolvimento seja importante, principalmente referente a insumos primários (combustíveis, por exemplo), ela não deveria ser utilizada como substituição de dados primários gerados de processos produtivos, já que o uso de

\footnotetext{
2 eplca.jrc.ec.europa.eu/?page_id=1058 - acessado em fevereiro de 2015.

${ }^{3}$ www.base-inies.fr/Inies/Consultation.aspx?lang=en-GB - acessado em fevereiro de 2015.

${ }^{4}$ www.nrel.gov; www.lcacommons.gov/nrel/

${ }^{5}$ www.ecoinvent.org/database/

${ }_{7}^{6}$ elcd.jrc.ec.europa.eu/ELCD3/index.xhtml

${ }^{7}$ ws680.nist.gov/Bees/(A(vOTwEAijOAEkAAAAZDk4YmQ0NDAtODIOYi00NjAzLWlyYWMtMTYxNDE0 ZDg2ZDdiakT_bgftmEkONJi_-YvGnCu7jvl1))/AnalysisParametersBuildingProds.aspx ; (LIPPIATT, 2007).

${ }^{8}$ www.base-inies.fr/Inies/Consultation.aspx

${ }^{9}$ itec.es/nouBedec.e/bedec.aspx
} 
dados secundários pode gerar resultados que não correspondem com a realidade do sistema analisado, o que reduz os benefícios esperados da metodologia.

No Brasil a execução de uma ACV tem como obstáculo a falta de uma base de dados secundários nacional. Como em todo o mundo, a divulgação de algumas informações pelas empresas não é fácil, pois alguns dados são considerados segredos de processo. A realização dos inventários é também difícil porque a quase totalidade das empresas não possui a prática de registrar seus fluxos puramente ambientais, pela simples razão que dentro do quadro atual não veem necessidade para tanto. Contudo, apenas através de inventários com dados primários gerados pelas indústrias é possível gerar indicadores que reflitam adequadamente os impactos ambientais, assim como identificar corretamente quais melhorias podem ser realizadas para mudança do cenário. A criação de políticas que incentivem a divulgação de declarações ambientais de produto é um caminho para criar na indústria a cultura de registrar e publicar seus dados.

\subsection{A elaboração de um inventário}

A elaboração do inventário é uma importante etapa da ACV, pois é a partir dos dados levantados que os impactos ambientais do sistema analisado serão estimados. Embora muitos estudos não utilizem uma amostra representativa de empresas para a criação do seu inventário (GAMA, 2010; NICOLAY, 2000; ROSSI; SALES, 2014; SOUZA; SALES, 2012; SOUZA et al., 2015), apesar de não ser seu objetivo, são muito comuns que desta amostra limitada sejam geradas conclusões generalizadas, como se o cenário estudado fosse característico do produto analisado. Além disso, apesar de serem, em geral, ancorados em dados secundários - muitas vezes de bases estrangeiras - são abordados como típicos de um país.

Frequentemente, estudos utilizam um valor único para representar um sistema de produto, abordagem que não revela a incerteza e a variabilidade características de uma ACV (LLOYD; RIES, 2007). A maioria dos processos industriais incluídos na base de dados do ecoinvent, por exemplo, refere-se à média da tecnologia em operação, sendo realizadas análises estatísticas para avaliar as incertezas e variabilidades do processo (FRISCHKNECHT et al., 2005; WEIDEMA et al., 2013). Essas análises são importantes quando os dados considerados não evidenciam essas informações, no entanto não garantem resultados confiáveis, que condizem 
com a realidade (LLOYD; RIES, 2007).

As incertezas, muitas vezes oriundas da imprecisão das medições, da falta de dados e de suposições, podem ser reduzidas através de pesquisas adicionais. Já a variabilidade, inerente das cadeias de produtivas (uso de diferentes tecnologias e entradas e saídas), somente pode ser reduzida por mudanças nos sistemas existentes, ou seja, nas indústrias (HUIJBREGTS, 1998; STEINMANN et al., 2014).

Para caracterização de um setor industrial em um país, o inventário necessita ser realizado em uma amostra representativa de empresas, o que não é fácil de estabelecer. Consequentemente, a definição de um valor característico e indicadores da variabilidade são de difícil obtenção. O alcance de um valor médio ou mediano que represente um produto, assim como a correta dispersão desses valores, somente é possível se obtida a representatividade de dados dentro do setor. Isso não sendo possível, as considerações adotadas para o levantamento das informações precisam ser claramente apresentadas, como número e características das empresas analisadas. Outro caminho que pode estar associado a este é a apresentação dos resultados em uma faixa de valores, que engloba as variabilidade e incertezas associadas a eles (BAILES et al., 2012).

\subsection{A necessidade de métodos de ACV mais simples}

A ACV tradicional é uma metodologia capaz de fornecer uma avaliação mais completa dos impactos ambientais (FRANKL et al., 1998), se todas as orientações das normas forem seguidas, sem qualquer tipo de simplificação. Entretanto, dados específicos são necessários para esse tipo de análise, o que demanda equipe especializada e equipamentos sofisticados para medição por um longo período. Esses itens não estão disponíveis em muitas partes do mundo e sua implantação exigiria elevado investimento e tempo. Estes fatos inviabilizam a ACV em muitas regiões e para pequenas e médias empresas. Mesmo onde sua realização seria possível, a depender do produto, muitas informações (particularmente da cadeia de fornecedores) podem não estar disponíveis nos primeiros estágios de seu desenvolvimento (SUN; RYDH; KAEBERNICK, 2003).

Embora a ACV conceitual seja simples, sua execução gera resultados que são uma estimativa do potencial de melhoria de desempenho, de forma subjetiva, pois seu inventário considera apenas aspectos qualitativos (GRAEDEL; SAXTON, 2002). 
Esse tipo de ferramenta pode ser um caminho para introdução do uso da ACV no dia a dia dos processos produtivos.

A adoção de soluções simplificadoras com base na ACV tradicional é uma imposição da realidade para tornar a metodologia aplicável no cenário atual, tornando sua execução mais acessível à indústria. Elas podem ser realizadas pelo uso de dados secundários, eliminação de alguns fluxos de entrada e/ou saída e redução da fronteira do sistema analisado (TODD; CURRAN, 1999). Essa também é uma alternativa para se iniciar uma avaliação com escopo completo.

A simplificação da ACV é indicada em casos onde não é possível ou desejável investir tempo e recursos no levantamento de dados para se estimar, por exemplo, a acidificação causada pela fabricação de um produto, se a empresa desconhece (e, portanto não controla) seu consumo de água ou a geração de resíduos. O dado não seria relevante para proporcionar mudanças benéficas no processo produtivo em um primeiro momento, pois o fabricante não saberia em que ponto agir para melhorar esse resultado. Outros impactos ambientais são relevantes de serem levantados, mas em uma etapa onde o setor já conhece melhor seus valores primários. As etapas da simplificação precisam ser consistentes com os objetivos do estudo e a função esperada de uma ACV tradicional, além de que é importante que as informações produzidas alcancem as necessidades dos usuários (WEITZ et al., 1999).

\subsubsection{Uso de dados secundários}

Uma simplificação que se tornou regra geral é o uso de dados secundários, valores disponíveis na literatura ou em base de dados que o investigador assume ser representativo do universo de interesse (CURRAN; YOUNG, 1996; RAMPURIA, 2012; WEITZ et al., 1996). Essa é uma alternativa importante quando não é possível levantar valores primários de fluxos elementares fundamentais para o estudo. Além de reduzir o tempo de realização da ACV, isso torna sua execução praticável em muitos casos, particularmente onde a cadeia de fornecedores não dispõe de informações próprias. Na prática é frequente a realização de inventários baseados unicamente em dados secundários, particularmente em trabalhos acadêmicos. Embora inevitável neste momento, o uso desses dados podem gerar resultados incorretos, uma vez que somente em raras situações existem evidências que estes 
são estatisticamente representativos da situação em análise. Hunt et al. (1998) evidenciaram o problema ao comparar os resultados de uma ACV completa (com uso de dados primários) com os de um inventário baseado em dados secundários.

Resultados típicos de ACVs brasileiras divulgam um único valor como representativo do produto analisado, estimado por meio das emissões típicas do país, sem considerar que existem variações entre fabricantes (JOHN; OLIVEIRA; LIMA, 2007). Frequentemente as investigações não evidenciam variáveis como tipo de insumo energético utilizado, eficiência dos equipamentos e materiais disponíveis (KULAY; HANSEN; SEO, 2010; MASTELLA, 2002; SPOSTO et al., 2006).

Quando a incerteza dos dados é analisada, esta é feita apenas por meio de métodos de Monte Carlo e fuzzy. No entanto, como os dados das bases geralmente não são amostras estatisticamente representativas, a média (ou mediana) é o valor selecionado sem medir a variabilidade real do sistema que pretende representar desvio padrão é simplesmente arbitrado.

A hipótese que a rota tecnológica adotada define os impactos gerados ao longo do ciclo de vida de um sistema ou produto é usualmente aceita nos estudos de ACV. Isto implica em assumir que os fluxos de entradas e saídas não variam significativamente nas empresas do setor que possuem igual rota. Em consequência, deve-se aceitar que a capacidade técnica da empresa - relacionada ao nível de investimento em equipe qualificada, presença ou não de estratégias para melhoria contínua do processo produtivo - tem impacto marginal. Tampouco a qualidade das matérias primas naturais, sempre muito variáveis, teria influência. Também seria secundário o impacto da variabilidade na eficiência de equipamentos de diferentes gerações tecnológicas e fornecedores, assim como a renovação e manutenção do maquinário. É importante registrar que até o momento não existem evidências empíricas de que a rota tecnológica é determinante nos impactos ambientais para todos os sistemas produtivos.

Assim, a adoção de apenas um número para representar um produto em um grande mercado precisa ser realizada com muita cautela (HAMMOND; JONES, 2008). Um reconhecimento deste fato é a recomendação de que a elaboração de uma Declaração Ambiental de Produto (EPD - Environmental Product Declaration) apresente a variabilidade (BRE, 2014). No entanto, observa-se que não foi 
encontrada nenhuma aplicação desta orientação.

Por outro lado, na área de materiais cimentícios existem evidências de que uma mesma rota tecnológica pode implicar em enormes variabilidades. Uma metanálise realizada por Damineli et al. (2010) dos fluxos referentes à produção de concretos plásticos, do Brasil e de outros 28 países, indicou que existe considerável variabilidade entre os fluxos de massa e energia para concretos com igual classe de resistência, tipo de cimento e rota tecnológica. Essa variação tem como principal responsável o consumo de cimento, que responde por mais de $90 \%$ das emissões de $\mathrm{CO}_{2}$ (teor variando de 250 a $450 \mathrm{~kg} / \mathrm{m}^{3}$ na produção de concreto com $35 \mathrm{MPa}$ ). Considerando a realidade brasileira, outro motivo para a variabilidade das emissões é a grande faixa permitida pelas normas nacionais para o teor de clínquer por tipo de cimento. Como o real valor usado pelas cimenteiras não é divulgado e varia com o período, isso provoca incerteza quanto à emissão de $\mathrm{CO}_{2}$, visto que diferentes tipos de cimento podem apresentar mesma quantidade de clínquer e, em consequência, mesmo fator de emissão (OLIVEIRA, 2015).

O uso de dados secundários é inevitável quando não é possível levantar informações junto a alguns sistemas. Até que todas as empresas publiquem declarações ambientais de produto baseadas em dados primários, o uso de dados secundários é uma imposição da realidade. No entanto, ela deve ser minimizada gradualmente e as incertezas oriundas dessa abordagem precisam ser apresentas com transparência, de preferência pela adoção de dados em faixas (BAILES et al., 2012).

\subsubsection{Redução do escopo}

A redução do escopo possibilita que se obtenham resultados de forma mais simples, seja pela diminuição das fronteiras, dos fluxos de entrada e saída ou dos aspectos analisados. Essa abordagem torna a execução mais viável e imediatamente relevante, sem que sejam perdidas as características essenciais de uma ACV (CURRAN, 2000).

Ao estudar um sistema produtivo é possível identificar as etapas mais importantes, assim como os fluxos que podem possuir maior significância nos impactos ambientais. Geralmente os levantamentos dos recursos naturais utilizados, da energia incorporada e da emissão de $\mathrm{CO}_{2}$ não são muito complexos e são itens 
relevantes na maioria dos sistemas. Uma alternativa é desconsiderar as etapas de extração das matérias-primas e de eliminação dos resíduos, ou ter sua análise limitada. Outra abordagem, por exemplo, é analisar as etapas que apresentam maior consumo de matérias-primas, normalmente mais significativas na geração de impactos. No entanto, todas essas definições precisam ser apresentadas de forma clara. O importante é que essa redução seja feita tendo em vista o foco do estudo e a compreensão dos resultados pelo público alvo, por aqueles que poderão agir para a melhoria do sistema.

As pegadas de $\mathrm{CO}_{2}$ e água, por exemplo, são casos extremos de redução de escopo. No entanto, são excessivamente limitadas, pois se concentram em apenas um impacto ambiental.

\subsection{Estudos da ACV em blocos de concreto}

Poucos são os estudos que tratam dos impactos ambientais relacionados ao ciclo de vida de blocos de concreto para alvenaria, embora algumas empresas estrangeiras já publiquem suas declarações ambientais (AGGREGATE INDUSTRIES, 2015; ANGELUS BLOCK CO., 2015; EPD, 2009; EPD-NORGE, 2014; YTONG, 2015). No geral, informações referentes ao bloco analisado são limitadas e seus resultados apresentam apenas um valor julgado como representativo, havendo exceção (ANGELUS BLOCK CO., 2015). No caso dos blocos para pavimento, não foram encontradas referências sobre $\mathrm{o}$ assunto.

A divulgação dos resultados de blocos para alvenaria por $\mathrm{m}^{2}$ de parede construída é mais usual, inclusive em base de dados $\left(I n i e s^{10}\right)$, geralmente fazendo comparações com paredes de blocos cerâmicos (QUANTIS, 2012; BUENO et al., 2012; MASTELLA, 2002). A Tabela 1 apresenta alguns dos resultados típicos de emissão de $\mathrm{CO}_{2}$ e consumo energético levantados em estudos de ACV de blocos de concreto.

${ }^{10}$ www.inies.fr : base de dados francesa acessada em março de 2015. 
Tabela 1 - Dados de blocos de concreto levantados em literatura, sendo os seis primeiros estudos nacionais. Os resultados seguem métodos de cálculo diferentes e não podem ser comparados. $O$ número de dígitos significativos é o da publicação.

\begin{tabular}{|c|c|c|c|c|c|c|}
\hline $\begin{array}{l}\text { Dimensões } \\
\quad(\mathrm{cm})\end{array}$ & Und & $\begin{array}{l}\text { Energia } \\
\text { (MJ/Und) }\end{array}$ & $\begin{array}{l}\text { Emissão de } \\
\mathrm{CO}_{2} \\
\left(\mathrm{kgCO}_{2} / \text { Und }\right)\end{array}$ & Fonte & \multicolumn{2}{|c|}{ Observação } \\
\hline $14 \times 19 \times 39$ & $t$ & - & 210 & Costa, 2012 & \multicolumn{2}{|c|}{$\begin{array}{l}\text { Considerado apenas dados de literatura } \\
\text { estrangeira. }\end{array}$} \\
\hline $14 \times 19 \times 39$ & $\mathrm{~m}^{2}$ & 334,32 & $35,82^{*}$ & $\begin{array}{l}\text { Quantis } \\
(2012)\end{array}$ & \multicolumn{2}{|c|}{13 blocos $/ \mathrm{m}^{2}-12$ kg/bloco. } \\
\hline $9 \times 19 \times 39$ & un & 2,90 & - & $\begin{array}{l}\text { Sposto et al., } \\
2006\end{array}$ & \multicolumn{2}{|c|}{$\begin{array}{l}\text { Apenas consumo energético na fábrica; } \\
\text { blocos sem função estrutural. }\end{array}$} \\
\hline & & - & 0,025 & & \multicolumn{2}{|c|}{$\begin{array}{l}\text { Calculado pela autora: transporte das } \\
\text { matérias-primas }\end{array}$} \\
\hline $9 \times 19 \times 39$ & un & - & 0,034 & - Irajano, 2010 & \multicolumn{2}{|c|}{$\begin{array}{l}\text { Calculado através do SimaPro: produção } \\
\text { e transporte das matérias-primas }\end{array}$} \\
\hline $14 \times 19 \times 29$ & $\mathrm{~m}^{2}$ & 217,5 & $36,6^{*}$ & $\begin{array}{l}\text { Bueno et al., } \\
2012\end{array}$ & \multicolumn{2}{|c|}{$\begin{array}{l}\text { UF referente ao } \mathrm{m}^{2} \text { de blocos estruturais } \\
\left(16,67 \text { blocos } / \mathrm{m}^{2}\right) \text {. }\end{array}$} \\
\hline $14 \times 19 \times 29$ & $\mathrm{~m}^{2}$ & 10,62 & - & $\begin{array}{l}\text { Mastella, } \\
2002\end{array}$ & \multicolumn{2}{|c|}{$\begin{array}{l}\text { Apenas consumo de energia elétrica } \\
\text { para produção de } 1 \mathrm{~m}^{2} \text { de blocos. }\end{array}$} \\
\hline $20 \times 20 \times 50$ & $\mathrm{~m}^{2}$ & 1,78 & 0,182 & CERIB, 2014 & \multicolumn{2}{|c|}{$\begin{array}{l}\text { Item da base de dados francesa Inies: } \\
\text { "Mur en maconnerie de blocs en beton". }\end{array}$} \\
\hline - & $\mathrm{t}$ & 76,3 & 6,0 & Littler, 2013 & \multicolumn{2}{|c|}{$\begin{array}{l}\text { Publicação da associação de blocos de } \\
\text { concreto do Reino Unido ( } C B A) \text {. Consi- } \\
\text { dera apenas a energia elétrica. }\end{array}$} \\
\hline $20 \times 20 \times 40$ & un & 12,30 & 1,61 & $\begin{array}{l}\text { Nisbet et al., } \\
2002\end{array}$ & \multicolumn{2}{|c|}{$\begin{array}{l}\text { Publicação da Portland Cement Associa- } \\
\text { tion }(P C A) \text { - dados referentes aos EUA. }\end{array}$} \\
\hline \multirow{6}{*}{$20 \times 20 \times 40$} & \multirow{6}{*}{ un } & 21,31 & 2,103 & \multirow{6}{*}{$\begin{array}{l}\text { - Athena Sus- } \\
\text { tainable Mate- } \\
\text { rials Institute } \\
-(2005)\end{array}$} & \multirow{6}{*}{$\begin{array}{c}\text { Blocos de } \\
18,18 \mathrm{~kg} \mathrm{e} \\
\text { resistência de } 8,27 \\
\text { a } 12,41 \mathrm{MPa} .\end{array}$} & Vancouver, Canadá \\
\hline & & 22,73 & 2,225 & & & Calgary, Canadá \\
\hline & & 24,39 & 2,343 & & & Winnipeg, Canadá \\
\hline & & 22,25 & 2,151 & & & Toronto, Canadá \\
\hline & & 23,67 & 2,255 & & & Montreal, Canadá \\
\hline & & 23,80 & 2,264 & & & Halifax, Canadá \\
\hline
\end{tabular}

*Nota: Dado em kgCO

Entre os seis dados nacionais levantados, Mastella (2002), Sposto et al. (2006) e Trajano (2010) analisaram apenas uma fábrica, respectivamente localizadas em SC, DF e PE. Estes elaboraram seus inventários a partir de dados coletados nas fábricas, sendo que Trajano (2010) também utilizou dados da literatura e disponíveis no software SimaPro (7.1.8F Versão Acadêmica). Nenhum deles informou o período de coleta das informações, no máximo que a produção se refere a um mês. Já Bueno et al. (2012) e Costa (2012) calcularam seus resultados utilizando exclusivamente dados secundários. O estudo de autoria da Quantis (2012), bastante divulgado, gerou seu inventário combinando dados secundários e primários. No entanto, nem a forma de obtenção dos dados primários de blocos de concreto nem a real representatividade setorial foram divulgadas, embora os autores afirmem serem 
característicos da realidade brasileira.

Convertendo alguns resultados da Tabela 1 para a mesma unidade de referência, a unidade de bloco, é possível fazer uma comparação superficial entre eles (Tabela 2). Os dados de Sposto et al. (2006), Trajano (2010), Littler (2013) e CERIB (2014) não foram considerados por não ter sido possível estabelecer uma relação com os demais produtos. Apesar do dado da CBA (LITTLER, 2013) não informar as dimensões do produto, um guia para seleção e especificação de blocos de concreto publicado pela própria associação informa que as dimensões da face do bloco padrão do Reino Unido são 44x21,5 cm (CBA, 2007), diferentes dos demais estudos levantados.

Tabela 2 - Comparação superficial entre os dados de blocos levantados na literatura. Como os estudos consideraram métodos de cálculo diferentes, essa comparação não é correta. O número de dígitos significativos é o da publicação.

\begin{tabular}{|c|c|c|c|c|}
\hline $\begin{array}{l}\text { Dimensões } \\
\quad(\mathrm{cm})\end{array}$ & Características & $\begin{array}{l}\text { Energia } \\
\text { (MJ/bloco) }\end{array}$ & $\begin{array}{c}\text { Emissão de } \mathrm{CO}_{2} \\
\left(\mathrm{kgCO}_{2} / \text { bloco }\right)\end{array}$ & Fonte \\
\hline $14 \times 19 \times 39$ & $\begin{array}{l}\text { Adotada massa igual a } \\
12 \mathrm{~kg} .\end{array}$ & & 2,5 & Costa, 2012 \\
\hline $14 \times 19 \times 39$ & $\begin{array}{l}\text { Blocos de } 12 \mathrm{~kg} ; 13 \\
\text { blocos } / \mathrm{m}^{2} \text { de parede. }\end{array}$ & 25,72 & 2,76 & $\begin{array}{l}\text { Quantis (2012) } \\
\text { (Emissão em kgCO }{ }_{2 e} \text { ) }\end{array}$ \\
\hline $14 \times 19 \times 29$ & Não estrutural & 13,0 & 2,2 & $\begin{array}{l}\text { Bueno et al., } 2012 \\
\text { (Emissão em } \text { kgCO}_{2 \mathrm{e}} \text { ) }\end{array}$ \\
\hline $14 \times 19 \times 29$ & $\begin{array}{l}\text { Estrutural-6 } \mathrm{MPa} \text {; } \\
16,67 \text { blocos } / \mathrm{m}^{2} \mathrm{de} \\
\text { blocos. }\end{array}$ & 0,64 & - & Mastella, 2002 \\
\hline $20 \times 20 \times 40$ & Desconhecidas & 12,30 & 1,61 & $\begin{array}{l}\text { Nisbet et al., } 2002 \\
\text { (PCA) }\end{array}$ \\
\hline \multirow{6}{*}{$20 \times 20 \times 40$} & \multirow{6}{*}{$\begin{array}{l}\text { Estrutural-8,27 a } 12,41 \\
\mathrm{MPa} ; 18,18 \mathrm{~kg} .\end{array}$} & 21,31 & 2,103 & \multirow{6}{*}{$\begin{array}{l}\text { Athena Sustainable } \\
\text { Materials Institute } \\
\text { (2005) }\end{array}$} \\
\hline & & 22,73 & 2,225 & \\
\hline & & 24,39 & 2,343 & \\
\hline & & 22,25 & 2,151 & \\
\hline & & 23,67 & 2,255 & \\
\hline & & 23,80 & 2,264 & \\
\hline
\end{tabular}

Embora os valores de emissão de $\mathrm{CO}_{2}$ sejam semelhantes para o bloco de $14 \times 19 \times 39 \mathrm{~cm}$, considerando que para a produção de blocos de concreto o $\mathrm{CO}_{2}$ é o principal gás do efeito estufa (GEE) e responde pela maior parcela, não é possível concluir que os resultados sejam equivalentes. Para isso, ambos os estudos precisariam ter adotado a mesma metodologia (o que não foi realizado) e os 
produtos teriam que apresentar a mesma classe de resistência (desconhecida para

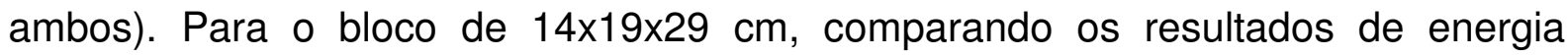
consumida, é evidente que foram adotadas diferentes considerações para os cálculos. Além disso, os blocos analisados possuem diferentes funções, um é estrutural e outro não.

Nisbet et al. (2002) utilizaram uma formulação fornecida pela National Concrete Masonry Association (NCMA) para caracterizar os impactos de um "bloco de concreto padrão" no enorme mercado norte-americano. O mesmo raciocínio é adotado pelo Athena Sustainable Materials Institute (2005), que utilizou apenas uma formulação para representar os blocos de concreto de diferentes regiões do Canadá, variando o tipo de cimento (a energia incorporada no cimento varia entre as cidades analisadas). Comparando os dois estudos, sabendo que todos tratam o setor como homogêneo, observa-se a diferença em um fator máximo de 2 entre eles, o que evidencia que diferentes critérios foram adotados e impossibilita uma comparação.

Apesar dos dados levantados terem sido calculados com base em apenas uma formulação de concreto, não são apresentadas evidências de ela é de fato representativa, assim como não são especificadas características técnicas detalhadas dos produtos, como resistência mecânica na maioria dos casos. Além disso, a variabilidade inerente às diferenças existentes entre os fluxos de entrada e saída de energia e materiais de um sistema não são reportadas.

\subsection{ACV Modular - características da proposta}

A metodologia da ACV Modular (ACV-m) é uma avaliação do ciclo de vida simplificada, realizada pela redução do escopo e uso de dados secundários, estes últimos referentes à energia incorporada e aos fatores de emissão dos insumos. Apresenta uma abordagem evolutiva, que permite que as empresas realizem a ACV em módulos que se complementam progressivamente, formando uma ACV completa. Por esse motivo o termo "modular" foi escolhido, para indicar continuidade e possibilidade de melhoria.

O módulo básico exige que sejam inventariados, com uso de dados primários da empresa, os impactos ambientais considerados críticos para o setor. Este é de simples realização, possível em pequenas e médias empresas. Além de evidenciar os impactos ambientais, esta etapa introduz de forma prática na fábrica o conceito 
de ciclo de vida e de inventário de fluxos ambientais. Por ser de fácil implementação, é esperado que as empresas participantes usem as informações para controlar e intervir continuamente em seu processo produtivo, melhorando seu desempenho e dos seus fornecedores.

A estratégia de implantação prevê que o módulo básico seja realizado simultaneamente por várias empresas de um mesmo setor, que podem trocar experiência. O resultado é um benchmark setorial, que permite evidenciar os potenciais de melhoria e oferece informações valiosas para órgãos governamentais e organizações setoriais estruturarem políticas de produção mais limpa.

Com o ganho de experiência pelas empresas, torna-se mais fácil a evolução do inventário no setor, até que seja atingida uma ACV completa. Assim, é mantida a coerência e os fundamentos do método normatizado, sem que sua característica e relevância sejam perdidas, mas tornando sua realização mais factível pela indústria. Isso porque o método da ACV-m reduz tempo de execução, custo e complexidade, podendo ser considerada uma ferramenta de gestão ambiental de fácil inserção na rotina de uma empresa, uma vez que o objetivo é mostrar ao fabricante e à sociedade o potencial de mitigação de impactos que existe com a tecnologia utilizada.

No primeiro módulo são avaliados cinco indicadores considerados como básicos: consumos de água e de matérias-primas, geração de resíduos, energia incorporada e emissão de $\mathrm{CO}_{2}$. Seus valores mínimos e máximos (faixas) são estimados entre um número razoável de empresas de uma cadeia produtiva. Os dados podem ser inventariados por profissionais das próprias empresas, que preenchem um formulário padronizado, previamente testado, após treinamento sobre os conceitos e a ferramenta.

Uma característica muito importante da ACV-m é não divulgar um único valor como representativo dos impactos ambientais de um setor: os resultados divulgados apresentam somente valores mínimos e máximos do setor (BAILES et al., 2012). Isto torna evidente para os consumidores o potencial de mitigação na escolha do fornecedor. Também evita que o valor médio "rotule" o impacto do produto, o que desestimula a busca de melhoria pelos fabricantes. 
A divulgação de apenas um número como representativo do setor beneficia empresas menos eficientes - que são retratadas por um impacto inferior ao que elas praticam - e prejudica aquelas que possuem maior eficiência ambiental dos seus processos, já que as diferenças entre elas não são reveladas (JOHN et al., 2013). Isso apenas incentiva a competição entre diferentes materiais, que muitas vezes não podem ser substituídos devido às suas propriedades, ao invés de encorajar o investimento em ações de melhorias ambientais entre os fabricantes de um mesmo produto.

Todos os cálculos são apresentados de forma transparente; incluindo conversões e estimativas que se fizerem necessárias. Sempre que dados secundários forem utilizados, geralmente relacionados aos insumos, a incerteza e variação inerente a eles são evidenciadas pela apresentação da faixa do impacto em questão. A não divulgação dos valores reais por seus fabricantes gera um grau de incerteza que é apontado pelo uso dos valores mínimos e máximos levantados. A incerteza somente será reduzida a partir do momento em que os fornecedores divulgarem seus números através de documentos, como uma declaração ambiental de produto auditada.

Alguns erros de conversões e estimativas podem estar incorporados aos resultados, principalmente no módulo inicial, onde algumas empresas ainda não possuem a cultura de registrar seus dados. Eles serão eliminados à medida que os fabricantes passarem a controlar sistematicamente e de forma padronizada seus fluxos de entrada e saída. 


\section{A fábrica de blocos de concreto}

A Figura 2 apresenta o fluxograma geral da fabricação de blocos de concreto. As máquinas utilizadas e o nível de automação da fábrica variam de acordo com o porte da empresa, mas as etapas básicas ilustradas são apresentadas por todas. As principais matérias-primas utilizadas são água, cimento e agregados, variando tipo e granulometria, que depende da formulação do concreto e disponibilidade na região onde se encontra a fábrica.

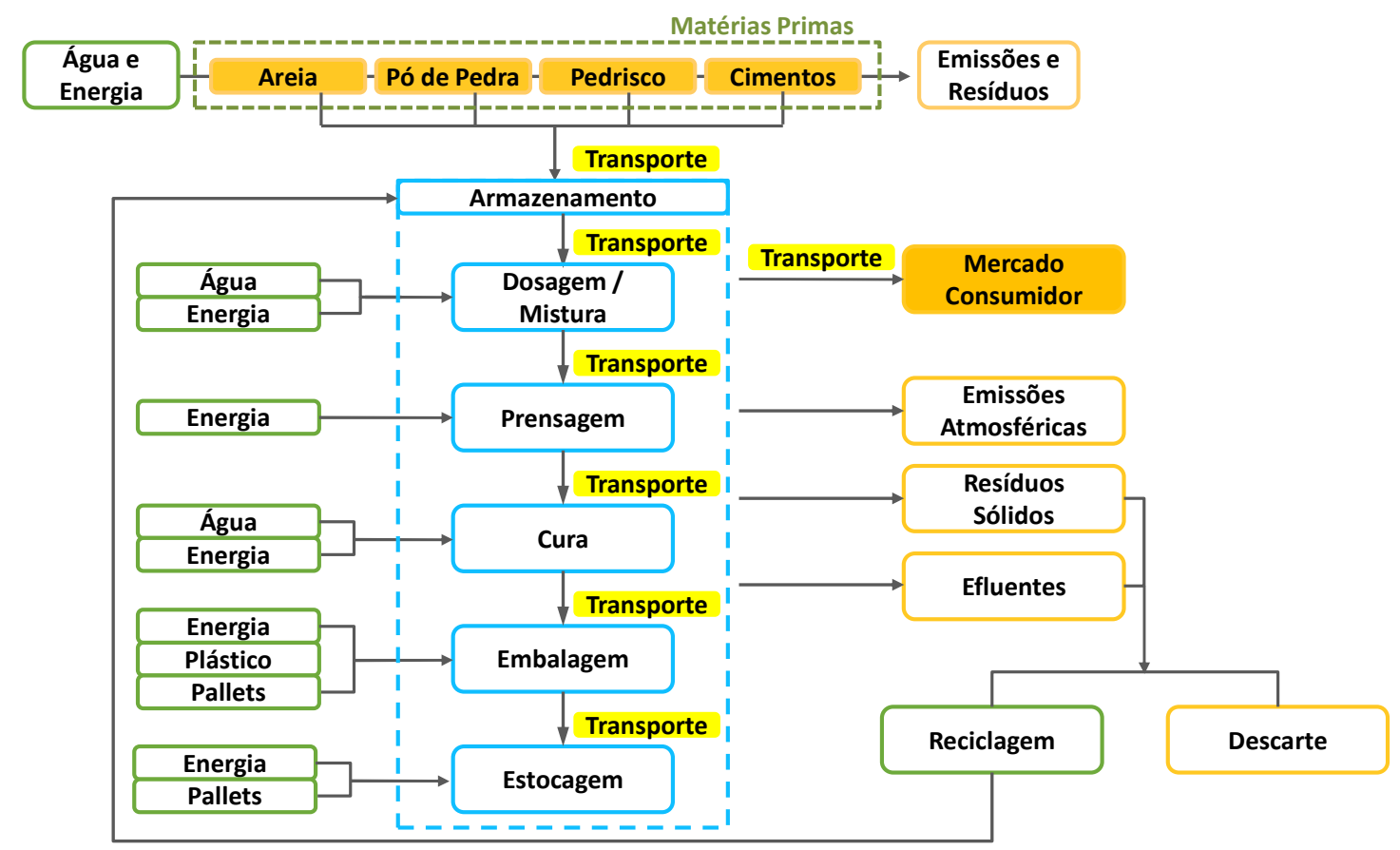

Figura 2 - Fluxograma do processo produtivo de blocos de concreto. Fonte: (JOHN et al., 2014)

Os agregados costumam ser armazenados em baias (com ou sem cobertura) e o cimento em silos próprios. Os insumos são transportados até misturadores, geralmente através de correias, onde é realizada a dosagem do concreto. Durante a mistura é realizado o acréscimo da água necessária para se alcançar a umidade ótima, de modo a atingir a trabalhabilidade adequada para a moldagem. Alguns produtos utilizam pigmentos em sua composição, assim como algum tipo de aditivo para melhorar a consistência do concreto ou facilitar a desmoldagem.

A massa pronta é encaminhada até a vibro prensa, sendo sua tecnologia importante para a qualidade do produto. A resistência adquirida pelo concreto será proporcional ao grau de compactação que a vibro prensa pode conferir à peça e à distribuição granulométrica dos agregados, sendo menor a porosidade da peça quanto melhor for o grau de empacotamento dos grãos. 
Existem no mercado quatro tipos de vibro prensas: mecânica, hidráulica, pneumática e manual (Figura 3). A mecânica apresenta alta produtividade e, pelo grau de compactação que proporciona à peça, permite baixo consumo de cimento. A hidráulica possibilita a fabricação de produtos bem compactos, o que também permite economia no consumo de cimento, mas com tempo de ciclo ${ }^{11}$ maior que a mecânica. Já a pneumática, oferece menor energia de compactação, exigindo maior consumo de cimento para produzir peças análogas às moldadas pela hidráulica. Por fim, a manual pode ser encontrada em fábricas pequenas que praticamente produzem de modo artesanal, que demanda grande consumo de cimento por causa da sua baixa energia de compactação, o que não viabiliza a fabricação de blocos estruturais (ABCP, 2008; FERNANDES, 2013). A distribuição granulométrica e a forma dos grãos podem ser trabalhadas para compensar as deficiências do tipo de máquina utilizado na fábrica, melhorando o empacotamento dos grãos e, assim, reduzindo a porosidade.

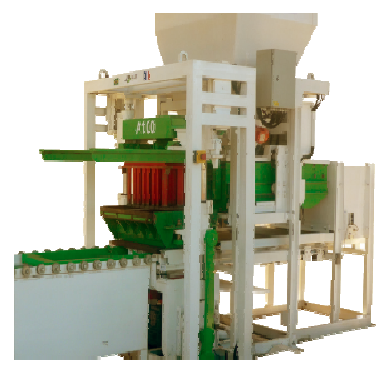

(a) mecânica ${ }^{12}$

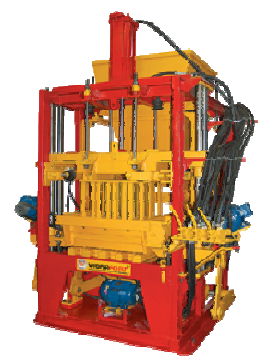

(c) pneumática ${ }^{14}$

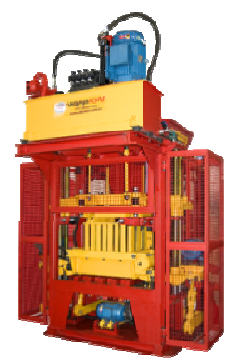

(b) hidráulica ${ }^{13}$

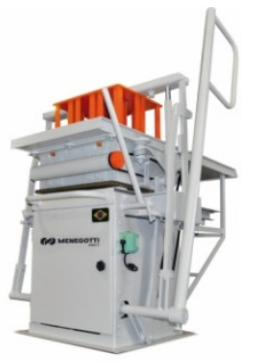

(d) manual $^{15}$

Figura 3 - Tipos de vibro-prensas utilizadas para a produção de blocos e pisos de concreto.

\footnotetext{
11 Tempo de ciclo é o período necessário do preenchimento da forma com concreto até a saída dos blocos.

${ }_{12}^{12}$ Fonte acessada em março de 2015: www.adler-technologies.com/pt/nos-equipements/presses-vibrantes/a100/

${ }^{13}$ Fonte acessada em março de 2015: www.vibrafort.com.br/index.php/portfolio-item/vibro-prensa-hidraulicaautomatica-ou-semi-automatica-vph-2750/

${ }^{14}$ Fonte acessada em março de 2015: www.vibrafort.com.br/index.php/portfolio-item/vibro-prensa-pneumaticasemi-automatica-vfvpp-750/

${ }^{15}$ Fonte acessada em março de 2015: www.menegotti.net/produtos/equipamentos-para-concreto/maquinas-deblocos-e-pavimentos $/ \mathrm{mbm}-3$
} 
Em geral, as formas podem ser modificadas de acordo com o tipo de produto, a depender da fábrica. A desforma ocorre imediatamente após a moldagem das peças, sendo logo em seguida conduzidas a áreas próprias na fábrica para a realização da cura do concreto. Durante a retirada da forma podem ocorrer quebras. Como o concreto ainda está no estado fresco, a massa geralmente retorna ao misturador para ser novamente moldada.

A cura dos blocos normalmente é realizada através de câmaras úmidas. Ela também poder ser executada por vapor de água à pressão atmosférica, com controle de temperatura do ambiente. Esse procedimento é adotado para acelerar as reações de hidratação do cimento e, assim, o bloco alcançar a resistência característica nas idades iniciais (FERNANDES, 2013; PERES, 2006).

Os produtos que não alcançam sua resistência característica podem ser reclassificados para uma categoria inferior ou descartados. Existem empresas que trituram os blocos rejeitados, por defeitos ou quebras, e utilizam o material resultante como agregado na fabricação de outros produtos.

O modo como o produto é preparado para envio ao consumidor é muito variável, sendo realizado com pallets e plástico (Figura 4a), existindo caso em que a empresa otimiza seu processo apenas envolvendo os produtos em plástico (Figura 4b). Por fim, os blocos são encaminhados ao local destinado para estoque. O transporte interno do produto pronto normalmente acontece por meio de empilhadeiras.

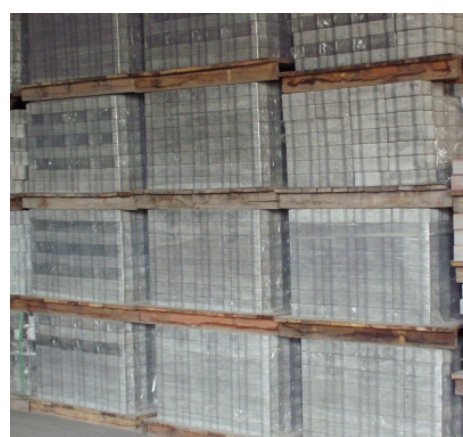

(a)

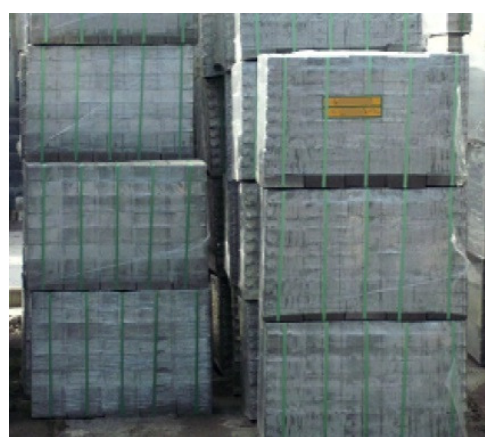

(b)

Figura 4 - Possibilidades de embalagem dos produtos para entrega ao consumidor, registrados entre as empresas participantes do estudo: (a) uso de plástico e pallets; (b) uso de plástico apenas. 


\subsection{Controle de dados no processo produtivo}

Em qualquer processo produtivo, quanto maior o controle das etapas, maiores os ganhos da empresa, tanto referente à qualidade do produto, quanto ao uso eficiente de recursos. No caso da fabricação dos blocos de concreto há significativo controle dos itens que correspondem a maior parte dos custos de produção, que são os consumos de cimento, agregados, eletricidade e combustíveis. No entanto, o controle de alguns itens ainda é precário, de modo que não existem documentos que indiquem como levantá-los, mesmo sendo importantes indicadores de eficiência do processo. Os dois itens identificados como mais problemáticos de registro em uma fábrica de blocos de concreto foram resíduos gerados e consumo de água. Também não há na literatura valores referentes a eles.

\subsubsection{Resíduos}

Resíduo pode ser definido como todo material resultante de um processo produtivo que não o produto final. (JOHN et al., 2014). No entanto, as definições do que é resíduo são variadas, não existindo um padrão.

A norma EN 15804:2012 define resíduo como aquilo que é descartado ou tem intenção de ser descartado pelo proprietário (BRE, 2014). A Cement Sustainability Initative (CSI), ao elaborar a Product Category Rule (PCR) para produtos a base de cimento, definiu resíduo como o que não tem uso definido, não tem valor econômico, não atende a critérios técnicos que permitam seu aproveitamento ou contém substâncias perigosas acima dos limites estabelecidos pelas legislações, causando efeitos ambientais adversos (EPD, 2013). Resumindo, essa PCR considera resíduo tudo aquilo que não possui valor econômico. No entanto, isso é variável, a depender do período e local onde o material se encontre, sendo a escória de alto-forno um exemplo. Inicialmente vista apenas como resíduo da indústria siderúrgica, no início do século XX passou a ser considerada como subproduto na Alemanha, pela sua adição na composição do cimento. No Brasil, embora isso tenha ocorrido no início da década de 1950, a escória começou a possuir valor comercial no RJ e em SP apenas no final dos anos 1990, sendo que em MG continuou sem qualquer valor ainda durante algum período (JOHN, 1995). De fato, observa-se como é difícil se alcançar uma definição que seja adequada às diversas situações.

No caso da produção dos blocos de concreto, considera-se resíduo tudo aquilo que 
sai da fábrica e é destinado a aterro, reciclagem externa ou recuperação de energia. Já tudo que foi reaproveitado dentro da fábrica, mas que não originou o produto final, não pode ser considerado resíduo, mas um subproduto. Esses resíduos e subprodutos podem ter diversas origens, desde materiais cimentícios, como peças defeituosas ou quebradas, até óleos de máquinas, plásticos e pallets, entre outros.

Os blocos que quebram devido a falhas de reologia ou manuseio e o concreto em estado fresco que não foi compactado adequadamente, geralmente são incorporados em novos produtos. Assim, eles não devem ser considerados no levantamento dos resíduos, mas registrados como perdas de processo. Isso porque os insumos utilizados passam por algumas etapas da produção mais de uma vez para fabricar apenas um produto, o que indica uma ineficiência no processo produtivo. O registro dessas perdas não é expressivo dentro de uma $A C V$, já que seu levantamento não representa um impacto, uma vez que retorna ao processo. No entanto, ao setor é um dado interessante por permitir que a fábrica analise sua eficiência. Registrar a parcela de produtos defeituosos que podem retornar ao sistema possibilita que a empresa avalie a qualidade das suas etapas de moldagem, transporte e armazenamento. O bloco que deixou de ser produzido consumiu uma quantidade de energia que foi perdida, mas que apenas pode ser rastreada por meio dessa análise.

A norma NBR 14044 (ABNT, 2009a) não especifica como devem ser realizados os procedimentos de alocação dos impactos ambientais de resíduos quando estes entram em outro sistema de produto como insumo. A atribuição de impacto a resíduos que possuem aplicação de mercado já consolidada para coprodutos ou subprodutos (ex.: escória de alto-forno, cinzas volantes, sucata de aço), é uma tendência na comunidade Europeia (EU, 2008). No Brasil não existem acordos setoriais sobre a alocação de impactos em resíduos, em especial entre as cadeias produtivas dos insumos utilizados em uma fábrica de blocos de concreto.

Não é apropriada a adoção de um critério único de alocação para todos os resíduos, em razão dos diferentes valores que cada um possa apresentar. No entanto, assumir diferentes regras de alocação pode resultar em conclusões muito diferentes (EKVALL; FINNVEDEN, 2001). Até que uma resolução seja definida, uma solução aceita atualmente é que os resíduos apresentam impacto zero oriundo da sua produção, já que se não fossem utilizados como subprodutos ou coproduto seriam 
depositados em aterros (JOHN; ANGULO, 2003; OLIVEIRA et al., 2014).

\subsection{2 Água}

Atualmente não existe uma metodologia consolidada que seja simples e de fácil utilização para a quantificação do consumo de água. A norma ISO 14046 (ISO, 2014), recentemente publicada (julho de 2014), define a pegada de água como um conjunto de indicadores que quantifica os impactos ambientais potenciais relacionados com a água. Nela são especificados princípios, requisitos e orientações para avaliação e informações sobre a pegada de água, sendo aplicada a produtos, processos e organizações com base em ACV. Já para The Water Footprint Network (HOEKSTRA et al., 2009), a pegada de água é definida como o total de água doce utilizada para produzir bens e serviços, que deve ser medida ao longo da cadeia de produção e abastecimento, classificando a água por sua origem.

Alguns documentos possuem orientações para a realização de uma avaliação ambiental, incluindo informações sobre a água. As Product Category Rules possuem regras e requerimentos para a elaboração de uma declaração ambiental de produto $(E P D)$, onde são apresentadas informações sobre impacto ambiental. Na EPD de concreto (EPD, 2013) são descritos como os inventários de água (por tipo de fonte) podem ser elaborados e, apesar de mostrar como realizar o levantamento do consumo de água potável, não informa como a coleta dos dados de consumo dos demais tipos de água pode ser executada.

O Sustainability Reporting Guidelines é a metodologia de avaliação de desempenho ambiental mais popular no mundo, que oferece princípios, conteúdos básicos e um manual de práticas para a elaboração de relatórios de sustentabilidade. Embora registre a quantidade total de água por fonte, não orienta como devem ser realizados os levantamentos dos consumos de água em um processo (GRI, 2013).

Analisando os métodos expostos, pode-se concluir que não há na literatura uma metodologia bem definida para o levantamento do consumo de água, em especial na fabricação de produtos cimentícios. Essa precisa ser construída e estruturada com base no ciclo de vida do produto analisado, considerando os tipos de água por sua origem.

Dados sobre o consumo de água no processamento de blocos de concreto não foram encontrados na literatura. As maneiras como a água é utilizada são variadas, 
assim como as fontes possíveis, sendo o uso dependente da sua qualidade.

Uma utilização fundamental da água na fábrica de blocos é na mistura do concreto, pois ela deve garantir a reação de hidratação do cimento e a trabalhabilidade da massa. De acordo com a $\mathrm{ABCP}^{16}$, a produção de blocos por vibro prensa exige um teor de umidade típico de $6 \%$ da massa de materiais secos. Parte dessa água provém das matérias-primas, que inclui a água indireta (originária do fornecedor) e a água de chuva captada quando o material já está na fábrica, armazenado a céu aberto (caso dos agregados). Também há a água presente nos aditivos e pigmentos.

O processamento de agregados envolve o uso da água no desmonte das jazidas de areia, no abatimento de poeira em operação de desmonte e cominuição da rocha para a produção de agregados artificiais (britas, areia artificial), na lavagem de agregados para remoção de finos, nas operações de limpeza e nos escritórios. Como os agregados são normalmente armazenados ao ar livre, quantidade incerta da água de chuva fica retida nos mesmos. Análises realizadas por Petrucci (2005) referentes à umidade média da areia natural estocada ao ar livre resultaram em teor médio de $4,2 \%$, com desvio padrão de $1 \%$.

Os dados sobre a pegada de água para a produção de agregados são escassos e contraditórios. A Figura 5 apresenta a comparação do consumo de água para a produção de agregados das empresas Lafarge (LAFARGE, 2012) e Holcim (HOLCIM, 2012), referentes ao ano de 2011. Apesar de ambos os relatórios afirmarem adotar a mesma metodologia - Sustainability Reporting Guidelines verifica-se considerável diferença nos consumos levantados. $O$ esperado era que os valores das médias globais das duas empresas estivessem mais próximos. 0 levantamento dessa informação no Brasil ainda encontra barreiras de divulgação por parte dos fornecedores.

No caso do setor produtivo de cimento, que utiliza principalmente método a seco, o uso de água acontece essencialmente para o controle de pó, refrigeração, operações de limpeza e administração. Os relatórios ambientais dos grupos Holcim e Lafarge, também referentes a 2011, apresentam consumos aproximados, ilustrados na Figura 5 (HOLCIM, 2012; LAFARGE, 2012). No entanto, dados nacionais ainda são escassos.

\footnotetext{
${ }^{16}$ Contato com Eng. Claudio Oliveira Silva.
} 


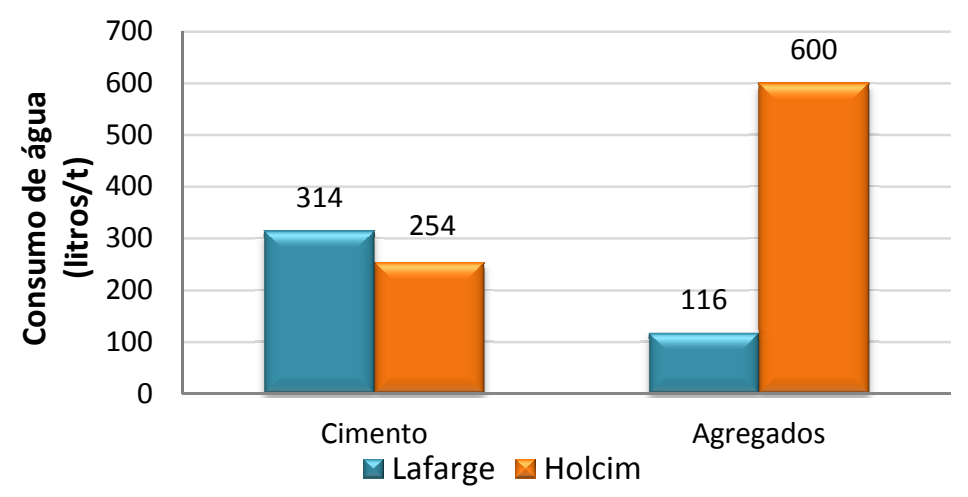

Figura 5 - Comparação entre o consumo de água de dois produtores de agregados e cimento no ano de 2011.

Para a produção de blocos de concreto, a parcela de água que realmente é adicionada ao misturador é inferior à água nominal de mistura. Podem ocorrer situações em que a água presente nos agregados seja suficiente para realizar a mistura. No caso de produtos cimentícios em geral, parte da água de mistura se evapora, parte fica combinada com o cimento e parte permanece como umidade. Com isso, observa-se quão complexa é a análise e levantamento apenas da água utilizada para a produção do concreto. A Figura 6 apresenta o fluxograma do consumo de água dentro da fábrica.

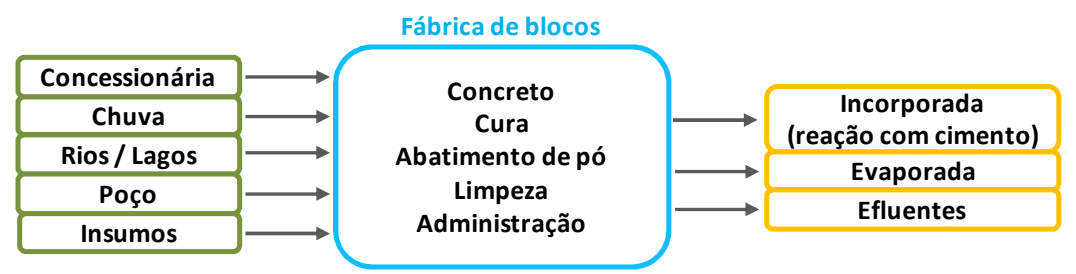

Figura 6 - Fluxograma do consumo de água em uma fábrica de blocos de concreto.

Também é utilizada água na realização da cura dos blocos, pela sua aspersão em câmaras úmidas ou por vapor em ambientes com temperatura controlada. Essa etapa também pode utilizar água captada da chuva pelo material em estoque a céu aberto, mesmo que os mesmos não estejam oficialmente em cura. A água de cura evapora, exceto a retida na umidade de equilíbrio com a atmosfera.

No ambiente da fábrica, para reduzir a quantidade de material disperso no ar por causa do transporte interno e externo, é comum a aspersão de água para o abatimento da poeira. Apesar de não ser usada diretamente no produto, o levantamento desse consumo é importante por seu registro possibilitar uma análise da logística da fábrica, pelo levantamento das áreas que necessitam de maior 
consumo de água para o abatimento do pó. Além disso, o rastreamento das etapas responsáveis pela produção de pó permite a adoção de soluções que minimizem esse tipo de resíduo.

A lavagem de equipamentos (formas e vibro prensas) é necessária no processo produtivo, pois a existência de resíduos pode influenciar na qualidade do produto final. O volume de água que servem à infraestrutura (escritórios, cozinha, banheiros e vestiários) deve ser contabilizado.

A análise de todo o processo produtivo permite levantar as etapas em que a água é utilizada. Com o controle dos consumos é possível determinar a pegada de água de um produto. No entanto, observa-se como essa quantificação é complexa, necessitando de uma metodologia bem definida, dependente do sistema de produto analisado. Ainda não estabelecida para o setor de blocos de concreto. 


\section{Dados secundários - Insumos}

Dados relacionados aos insumos utilizados na produção dos blocos foram levantados na literatura. No entanto, valores referentes à água e aos resíduos provenientes do seu processamento não foram incorporados no estudo pela carência dessas informações, principalmente referências nacionais. Os dados secundários considerados nas análises serão energia incorporada e emissão de $\mathrm{CO}_{2}$.

A energia incorporada pode ser interpretada como a quantidade de energia necessária para processamento e suprimento (HAMMOND; JONES, 2008). Logo, ela é composta pelo consumo energético do processo produtivo e transporte do insumo e, no caso dos combustíveis, também pela energia de combustão. As emissões de $\mathrm{CO}_{2}$, consequentemente, são provenientes dessas mesmas etapas, somada às emissões de transformações químicas. Elas podem ser diretas, oriundas de fontes que pertencem ou são controladas pela empresa, ou indiretas, resultantes das atividades da empresa, mas que não pertencem nem são controladas pela mesma (WBCSD; WRI, 2004).

Nesse estudo, a energia incorporada e as emissões de $\mathrm{CO}_{2}$ foram estimadas com o uso de fatores levantados predominantemente em literatura nacional. Alguns dados, referentes às emissões dos insumos energéticos, foram obtidos de fontes internacionais por falta de dados brasileiros, como será visto mais adiante (item 4.3).

Como a energia incorporada depende do processo produtivo, da disponibilidade de matéria-prima na região, da eficiência de produção e da quantidade de material utilizado (CABEZA et al., 2013), decidiu-se adotar faixas de valores (mínimo e máximo) para os dados referentes às matérias-primas, ao invés de um dado médio. Diferentes características de um mesmo produto também resultam em variações na energia incorporada (MENZIES; TURAN; BANFILL, 2007). Por exemplo, um mesmo tipo de cimento pode apresentar diferentes teores de clínquer de acordo com as normas brasileiras. 


\subsection{Cimento}

$\mathrm{O}$ cimento é responsável por grande quantidade de $\mathrm{CO}_{2}$ emitida para a atmosfera. A indústria cimenteira brasileira é responsável por aproximadamente $6 \%$ das emissões totais de $\mathrm{CO}_{2}$, sem considerar a mudança do uso do solo e das florestas (AGOPYAN; JOHN, 2011). Os principais responsáveis no processo produtivo são os combustíveis fósseis e a descarbonatação do calcário (WORRELL et al., 2001).

A produção do cimento se resume na extração e beneficiamento de suas matériasprimas, onde as principais são argila e calcário. As transformações químicas e físicas desses insumos são realizadas em fornos que podem alcançar até $2.000^{\circ} \mathrm{C}$ (WBCSD, 2011), que resulta na formação do clínquer. Em seguida ocorre a etapa de moagem, sendo a produção finalizada com o acréscimo de outros materiais, a depender do tipo de cimento produzido (CARVALHO et al., 2010).

A etapa de fabricação do cimento representa $95 \%$ das emissões de $\mathrm{CO}_{2}$ do seu ciclo de vida (HABERT; ROUSSEL, 2009 apud LIMA, 2010). A produção do clínquer corresponde a maior parte da energia consumida e da emissão de processo (HUNTZINGER; EATMON, 2009). Aproximadamente $60 \%$ da emissão direta de $\mathrm{CO}_{2}$ do cimento estão associadas à descarbonatação do calcário (WBCSD, 2011).

As emissões de $\mathrm{CO}_{2}$ decorrentes da queima de combustíveis fósseis pelos fornos podem ser reduzidas pela sua substituição por biomassa (MÜLLER; HARNISCH, 2008). Já as emissões oriundas da descarbonatação podem ser minimizadas no cimento pela substituição do clínquer por adições, como escória de alto-forno, pozolana e filler calcário. No Brasil essa substituição é normatizada pela NBR 11578 (ABNT, 1997), NBR 5733 (ABNT, 1991b), NBR 5735 (ABNT, 1991a) e NBR 5736 (ABNT, 1999). A Tabela 3 apresenta os teores permitidos pelas normas. 
Tabela 3 - Composição do cimento de acordo com as normas (\% em massa). Fonte: Oliveira (2015).

\begin{tabular}{|c|c|c|c|c|c|c|}
\hline \multirow{2}{*}{$\begin{array}{c}\text { Normas ABNT } \\
\text { Sigla }\end{array}$} & \multicolumn{3}{|c|}{ NBR 11578/1997 } & \multirow{2}{*}{$\begin{array}{c}\text { NBR } \\
5735 / 1991 \\
\text { CP III }\end{array}$} & \multirow{2}{*}{$\begin{array}{c}\text { NBR } \\
5736 / 1999 \\
\text { CP IV }\end{array}$} & \multirow{2}{*}{$\begin{array}{c}\text { NBR } \\
5733 / 1991 \\
\text { CP V - AR }\end{array}$} \\
\hline & CP II - F & CP II - Z & CP II - E & & & \\
\hline Classe (MPa) & $25 / 32 / 40$ & $25 / 32 / 40$ & $25 / 32 / 40$ & $25 / 32 / 40$ & $25 / 32$ & - \\
\hline Clínquer & $86-90$ & $72-90$ & $52-90$ & $21-61$ & $41-81$ & $91-96$ \\
\hline $\begin{array}{l}\text { Clínquer + } 4 \% \text { de } \\
\text { sulfato de cálcio* }\end{array}$ & 90 a 94 & 76 & 34 & 65 & 85 & 95 a 100 \\
\hline Escória & - & - & 6 a 34 & 35 a 70 & - & - \\
\hline Pozolana & - & 6 a 14 & - & - & 15 a 50 & - \\
\hline Filler & 6 a 10 & 0 a 10 & 0 a 10 & 0 a 5 & 0 a 5 & 0 a 5 \\
\hline
\end{tabular}

*O valor de 4\% de sulfato de cálcio é a média brasileira publicada para 2010 pelo Getting the Numbers Right (WBCSD, 2012).

A variação na quantidade de clínquer permitida no cimento nacional faz com que o consumo energético e a emissão de $\mathrm{CO}_{2}$ na sua produção variem de acordo com a disponibilidade das adições. Com dados da emissão de $\mathrm{CO}_{2}$ média nacional e os teores de clínquer normatizados, Oliveira (2015) estimou as faixas de emissão para os diferentes tipos de cimento. Para o cálculo das faixas de energia incorporada foram adotados os mesmos teores e o valor médio do consumo energético para a produção de clínquer (média de 2008 a 2012) publicado pelo World Business Council for Sustainable Development (WBCSD) ${ }^{17}$. Esses valores são apresentados na Tabela 4. Apesar de algumas empresas divulgarem seus valores médios, os teores exatos de clínquer adotados por tipo de cimento não são conhecidos e podem variar consideravelmente dentro do permitido por norma.

\footnotetext{
${ }^{17}$ Para o cálculo desses valores foi adotado o valor médio do consumo energético para a produção de uma tonelada de clínquer (últimos cinco anos - 2008 a 2012) publicado pelo WBCSD (www.wbcsdcement.org/GNR-2012/Brazil/GNR-Indicator_329-Brazil.html) e os teores de clínquer permitidos pelas normas brasileiras.
} 
Tabela 4 - Energia incorporada e emissão de $\mathrm{CO}_{2}$ unitárias por tipo de cimento. Emissão de $\mathrm{CO}_{2}$ estimada por Oliveira et al. (2014) e energia incorporada calculada a partir dos teores de clínquer permitidos por norma e do consumo energético publicado pelo WBCSD.

\begin{tabular}{ccccc}
\hline \multirow{2}{*}{ Matérias-primas } & \multicolumn{2}{c}{$\begin{array}{c}\text { Fator de Emissão de } \\
\mathbf{C O}_{\mathbf{2}}(\mathbf{k g C O} \mathbf{~} \mathbf{t})\end{array}$} & \multicolumn{2}{c}{$\begin{array}{c}\text { Energia incorporada } \\
(\mathbf{M J} / \mathbf{t})\end{array}$} \\
\cline { 2 - 5 } & Mínima & Máxima & Mínima & Máxima \\
\hline Cimento CP II-F & 735 & 770 & 3.096 & 3.240 \\
\hline Cimento CP II-Z & 616 & 770 & 2.592 & 3.240 \\
\hline Cimento CP II-E & 445 & 770 & 1.872 & 3.240 \\
\hline Cimento CP III & 180 & 522 & 756 & 2.196 \\
\hline Cimento CP IV & 351 & 693 & 1.476 & 2.916 \\
\hline Cimento CP V & 778 & 821 & 3.276 & 3.456 \\
\hline
\end{tabular}

A Figura 7 apresenta 0 gráfico da emissão de $\mathrm{CO}_{2}$ por tipo de cimento (pontos limitados pelas faixas coloridas ilustradas abaixo do gráfico). Observar-se que diferentes tipos de cimento, considerando os teores de clínquer permitidos por norma (Tabela 3), podem apresentar mesma emissão de $\mathrm{CO}_{2}$ (Tabela 4). No gráfico, a reta preta representa os resultados a partir da média brasileira e a faixa cinza os resultados levantados com os valores de emissão de três empresas nacionais que declaram seus dados (Holcim, InterCement e Votorantim). A adoção de apenas um valor médio cria um cenário diferente do real, uma vez que atualmente não é divulgado o teor de clínquer dos cimentos comercializados, que pode variar em razão da disponibilidade de recursos.

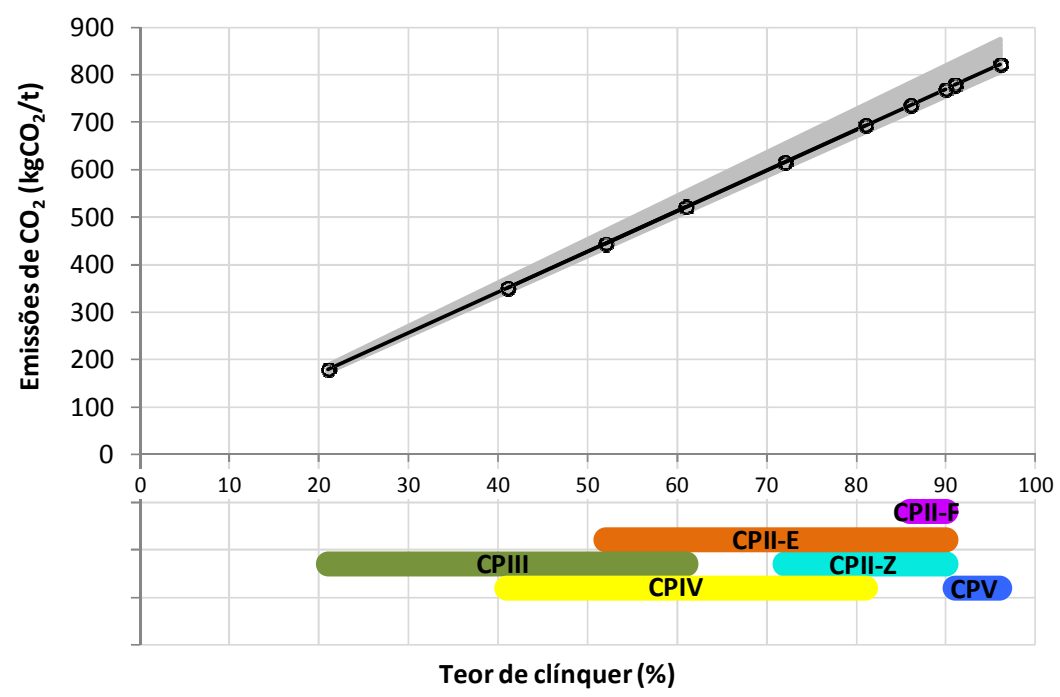

Figura 7 - Emissão de $\mathrm{CO}_{2}$ média brasileira de acordo com o teor de clínquer permitido por tipo de cimento (pontos sobre a reta limitados pelas faixas coloridas) e faixa de emissão média de três empresas nacionais (faixa cinza). Fonte: Oliveira (2015). 


\subsection{Agregados}

Os agregados utilizados na construção civil estão entre os bens minerais mais consumidos pela sociedade, sendo suas reservas abundantes no Brasil. No entanto, estas estão ficando localizadas cada vez mais distantes do centro consumidor devido à urbanização, especialmente no caso da areia (DNPM, 2013). Isso resulta na necessidade de se transportar a matéria-prima em distâncias que podem ser superiores a $100 \mathrm{~km}$ (ALMEIDA; LUZ, DA, 2009).

No Brasil predomina a produção de areia proveniente de leito de rios $(90 \%)$. No maior produtor nacional, o estado de São Paulo, essa relação é de $35 \%$, sendo maior parte produzida em várzeas (45\%) e o restante oriundo de outras fontes (ALMEIDA; LUZ, DA, 2009). Em 2012, sua produção respondeu por $23,3 \%$ do total nacional, seguido de Minas Gerais (11,8\%) e Rio de Janeiro (7,35\%) (DNPM, 2013).

O estado de São Paulo também foi o maior produtor e consumidor de brita em 2012, com $28 \%$ do total nacional, seguido de Minas Gerais, com 12\% (DNPM, 2013). De acordo com a Associação Nacional das Entidades de Produtores de Agregados para Construção Civil (ANEPAC), 14\% do consumo de brita e cascalho está destinado para os pré-fabricados, sendo as concreteiras o setor que apresentam maior parcela, 32\% (ANEPAC, 2013).

A lavra da areia é feita segundo três métodos diferentes, em função do tipo de depósito. Pode ser por dragagem em leitos de rio e em cavas inundadas; desmonte hidráulico em cavas secas e em mantos de alteração de maciços rochosos; e por tiras, em depósitos homogêneos e de maior extensão horizontal (ALMEIDA; LUZ, DA, 2009).

O processo de produção do agregado por meio da britagem inicia-se pela desintegração da rocha através de sua explosão. Em seguida, os matacões são transportados até britadores e, depois de processado, o material resultante é classificado pela sua granulometria, através do peneiramento. A areia artificial é originária desse processo.

A mineração é responsável pela degradação do meio ambiente nas áreas em que há extração da matéria-prima, pois há a destruição da paisagem, a contaminação do solo ou de corpos d'água e o esgotamento do recurso, já que não é renovável. Além disso, há a emissão de gases provenientes do uso de equipamentos para a retirada 
e britagem do material, que majoritariamente utilizam combustíveis fósseis (STACHERA; CASAGRANDE JR., 2007).

No Brasil dados sobre os impactos causados pela produção de agregados são escassos e pouco precisos. Segundo Lima (2010) a análise das emissões relacionadas à mineração e ao transporte dos agregados torna a pesquisa complexa. Uma grande demanda de recursos é necessária para obter tais dados, uma vez que faltam informações sobre alguns fluxos.

As dificuldades em se obter esses números tornam os resultados sobre as emissões dos agregados incompletas. Stachera e Casagrande Jr. (2007) publicaram dados sobre emissão de $\mathrm{CO}_{2}$ na extração da areia no Paraná, no entanto não deixam explícitas quais etapas foram consideradas no levantamento dos dados, além de não citarem informações sobre a produção de brita. Marcos (2009) considerou dado de energia existente na literatura para estimar as emissões de $\mathrm{CO}_{2}$ dos agregados, mas também sem apresentar quais etapas da produção foram analisadas.

Os impactos causados pela produção dos agregados reciclados no Brasil ainda são pouco conhecidos. Discussões que tem o objetivo de comparar os impactos causados pela produção dos agregados reciclados com os agregados minerais estão sendo desenvolvidas em diversos países. Esses resultados mostram que os impactos do processamento podem variar, dependendo dos equipamentos e fontes energéticas utilizadas (BLENGINI; GARBARINO, 2010; COELHO; BRITO, DE, 2012; JULLIEN et al., 2012; MARINKOVIĆ et al., 2010).

A energia incorporada e a emissão de $\mathrm{CO}_{2}$ devido à extração e processamento dos diferentes tipos de agregados levantados nesse estudo são apresentadas na Tabela 5. 
Tabela 5 - Emissão de $\mathrm{CO}_{2}$ e energia incorporada dos agregados levantados nesse estudo.

\begin{tabular}{|c|c|c|c|c|c|}
\hline \multirow[t]{2}{*}{ Matérias-primas } & \multicolumn{2}{|c|}{$\begin{array}{l}\text { Fator de emissão } \\
\text { de } \mathrm{CO}_{2}\left(\mathrm{kgCO}_{2} / \mathrm{t}\right)\end{array}$} & \multicolumn{2}{|c|}{$\begin{array}{c}\text { Energia } \\
\text { incorporada }(\mathrm{MJ} / \mathrm{t})\end{array}$} & \multirow[t]{2}{*}{ Fontes } \\
\hline & Mínima & Máxima & Mínima & Máxima & \\
\hline Areia natural & 4,2 & 9,6 & 55,3 & 109,0 & Souza, 2012 \\
\hline Areia industrial & 1,3 & 1,9 & 17,1 & 42,1 & Falcão et al., 2013 \\
\hline Brita 0 & 1,2 & 1,9 & 13,5 & 55,3 & Rossi, 2013 \\
\hline Cinza volante & 0,0 & 0,0 & 0,0 & 0,0 & Resíduo de outro setor \\
\hline Pedrisco de seixo* & 1,3 & 1,9 & 14,6 & 42,1 & Falcão et al., 2013 \\
\hline Pedrisco & 1,3 & 1,9 & 14,6 & 42,1 & Falcão et al., 2013 \\
\hline Pó de pedra & 1,3 & 1,9 & 17,1 & 42,1 & Falcão et al., 2013 \\
\hline Agregado reciclado & 0,8 & 1,8 & 13,8 & 20,7 & Oliveira et al., 2013 \\
\hline
\end{tabular}

$\mathrm{Na}$ literatura foram levantados os consumos energéticos (eletricidade e combustíveis) por tipo de insumo. Os dados de emissão de $\mathrm{CO}_{2}$ e energia incorporada dos materiais foram calculados com os mesmos fatores adotados nessa dissertação, apresentados no item a seguir.

\subsection{Combustíveis}

Os dados referentes ao fator de emissão de $\mathrm{CO}_{2}$ e à energia incorporada das fontes energéticas desse estudo foram levantados na literatura e são apresentados na Tabela 6. Foi verificado como os dados foram calculados e quais considerações os autores realizaram. Quando possível, o ciclo de vida dos combustíveis para a composição desses dados também foi observado, além das emissões diretas e do poder calorífico resultante do consumo direto desses insumos. Nesse caso se enquadram óleo diesel, gasolina, álcool hidratado, gás natural, lenha, GLP e óleo BPF. 
Tabela 6 - Fator de emissão de $\mathrm{CO}_{2}$ e energia incorporada dos insumos energéticos por unidade de referência (Und).

\begin{tabular}{|c|c|c|c|c|c|}
\hline Fonte & Und & $\begin{array}{c}\text { Energia } \\
\text { incorpora- } \\
\text { da } \\
\text { (MJ/Und) }\end{array}$ & $\begin{array}{c}\text { Emissão de } \\
\mathrm{CO}_{2} \\
\left(\mathrm{kgCO}_{2} / \text { Und }\right)\end{array}$ & $\begin{array}{l}\text { Fonte: Energia } \\
\text { incorporada }\end{array}$ & $\begin{array}{l}\text { Fonte: Fator de } \\
\text { emissão de } \mathrm{CO}_{2}\end{array}$ \\
\hline Diesel & 1 & 37,26 & 3,28 & Silva, 2013 & Silva, 2013 \\
\hline Gasolina & I & 34,84 & 2,66 & Silva, 2013 & Silva, 2013 \\
\hline $\begin{array}{l}\text { Álcool } \\
\text { hidratado }\end{array}$ & I & 21,53 & 0,42 & Silva, 2013 & $\begin{array}{l}\text { Macedo; Seabra; } \\
\text { Silva, } 2008\end{array}$ \\
\hline Gás natural & $\mathrm{m}^{3}$ & 41,26 & 5,38 & $\begin{array}{c}\text { Macedo; Seabra; } \\
\text { Silva, } 2008 \\
\end{array}$ & $\begin{array}{l}\text { IPCC, 2006; Planilha } \\
\text { do GHG Protocol }\end{array}$ \\
\hline \multirow{2}{*}{$\begin{array}{l}\text { Lenha } \\
\text { (plantada torete) }\end{array}$} & \multirow{2}{*}{$\mathrm{t}$} & $6.204,30$ & 689,90 & \multirow{2}{*}{ Punhagui, 2014} & \multirow{2}{*}{ Punhagui, 2014} \\
\hline & & $13.734,30$ & $1.512,20$ & & \\
\hline \multirow{2}{*}{$\begin{array}{l}\text { Lenha (resíduo- } \\
\text { plantada/nativa) }\end{array}$} & \multirow[b]{2}{*}{$t$} & $6.073,00$ & 0,00 & \multirow{2}{*}{ Punhagui, 2014} & \multirow{2}{*}{$\begin{array}{l}\text { Resíduo de floresta } \\
\text { plantada ou nativa }\end{array}$} \\
\hline & & $12.980,00$ & 0,00 & & \\
\hline Eletricidade & kWh & 5,21 & 0,06 & $\begin{array}{l}\text { EPE; MME, } \\
\text { 2013; Goldem- } \\
\text { berg, } 2000\end{array}$ & $\begin{array}{c}\text { MCT - média dos } \\
\text { anos de } 2011,2012 \text { e } \\
2013^{19} \\
\end{array}$ \\
\hline GLP & $\mathrm{t}$ & $56.140,00$ & $3.759,64$ & Silva, 2013 & Silva, 2013 \\
\hline Lixívia (licor negro) & $\mathrm{t}$ & $11.970,00$ & 0,00 & $\begin{array}{l}\text { EPE; MME, } \\
2013\end{array}$ & $\begin{array}{l}\text { Resíduo da indústria } \\
\text { de celulose }\end{array}$ \\
\hline Óleo BPF & $\mathrm{m}^{3}$ & $49.786,00$ & $3.834,99$ & $\begin{array}{c}\text { Macedo; Seabra; } \\
\text { Silva, } 2008 \\
\end{array}$ & $\begin{array}{l}\text { Macedo; Seabra; } \\
\text { Silva, } 2008\end{array}$ \\
\hline Óleo de xisto & $\mathrm{t}$ & $38.100,00$ & $2.792,73$ & IPCC, 2006 & $\begin{array}{c}\text { Planilha do GHG Pro- } \\
\text { tocol }^{18}\end{array}$ \\
\hline
\end{tabular}

Para o cálculo da energia incorporada da eletricidade brasileira, a participação de cada fonte na geração interna de energia elétrica foi ponderada (EPE; MME, 2013). Para isso, foi adotado que a eficiência global de conversão de energia primária em energia útil é igual a 33\% (GOLDEMBERG, 2000). Como as fontes de energia primária representam aproximadamente $22 \%$ na produção nacional de eletricidade, sendo o restante de origem hidráulica e eólica, proporcionalizando suas participações, tem-se que 5,2 MJ estão incorporados em 1,0 kWh ${ }^{20}$.

\footnotetext{
${ }^{18}$ Ferramenta do Programa Brasileiro GHG Protocol: ghgprotocolbrasil.com.br.

${ }^{19}$ www.mct.gov.br/index.php/content/view/321144.html\#ancora.

${ }^{20} 3,6 \mathrm{MJ}$ equivale a 1,0 kWh. Como são utilizadas diversas fontes energéticas para produção da eletricidade brasileira, é necessário fazer a ponderação. A parcela referente às fontes renováveis (hidráulica e eólica) equivale a $(77,7 \%$ × 3,6) e às demais fontes (biomassa, gás natural, derivados de petróleo, nuclear, carvão e derivados) é igual a (22,3\% × 3,6 × 3). A soma das duas parcelas resulta em $5,2 \mathrm{MJ} / \mathrm{kWh}$.
} 


\section{Metodologia}

Neste estudo foi realizado o inventário de água, cimento, agregados, resíduos, perdas, energia e emissão de $\mathrm{CO}_{2}$ de 33 fábricas brasileiras de blocos de concreto, participantes do Projeto ACV-m. Todos os valores são apresentados de forma a evidenciar as variabilidades inerentes a diferenças entre fabricantes e dos modais de transporte e as incertezas provenientes dos fatores ambientais adotados. Todas as conversões e estimativas necessárias são apresentadas.

A coleta de dados foi realizada por formulário desenvolvido em planilha Excel e preenchido pelos próprios fabricantes, treinados em workshops para essa tarefa (item 5.6). As informações levantadas não são divulgadas.

As fábricas foram numeradas sem que um critério fosse seguido para esse procedimento (como ordem alfabética ou localização), sendo essa identificação informada individualmente às empresas. Os resultados referentes a cada fábrica foram revelados apenas para as participantes do estudo. Nessa dissertação somente as empresas responsáveis pelos valores extremos das faixas tem sua numeração apresentada (número presente nos extremos das faixas dos indicadores).

Um termo de confidencialidade sobre os dados coletados foi firmado com toda a equipe envolvida no Projeto ACV-m. Essa conduta foi tomada para deixar as empresas confortáveis ao repassar seus números de produção e consumos, assegurando a elas que seus resultados não seriam divulgados abertamente.

Os impactos são estimados diretamente através dos dados coletados pelo formulário e pelos dados secundários referentes aos insumos. Cada impacto analisado foi representado por um indicador simples, listados a seguir. Energia incorporada e emissão de $\mathrm{CO}_{2}$ são analisadas como impactos nesse estudo, embora se saiba que em ACV estes dados são considerados resultados de inventário para o cálculo das categorias de impacto (ABNT, 2009a).

- Consumo de água: obtido a partir de dados informados pela empresa sobre o consumo de água total na fábrica;

- Energia incorporada: calculado a partir de dados informados pela empresa sobre consumo de eletricidade e de combustíveis na fábrica e da energia estimada para extração, processamento e transporte das matérias-primas; 
- Emissão de $\mathrm{CO}_{2}$ : calculada a partir do consumo de combustíveis fósseis, biomassa, energia elétrica, distâncias de transporte dos insumos e quantidade de $\mathrm{CO}_{2}$ procedente da extração e processamento das matériasprimas;

- Geração de resíduos: obtido através de dados sobre perdas de produção e resíduos da fábrica informados;

- Consumo de materiais não renováveis: obtido através dos consumos das principais matérias-primas selecionadas para a produção dos blocos.

\subsection{Definição da fronteira do sistema}

A fronteira do sistema foi limitada como sendo do berço ao portão, ou seja, da extração das matérias-primas até o produto estar pronto para entrega, como ilustra a Figura 8. Os dados referem-se a um período de 12 meses seguidos, sem a necessidade de ser um ano fechado. Os dados levantados referem-se aos anos de 2012 e/ou 2013.

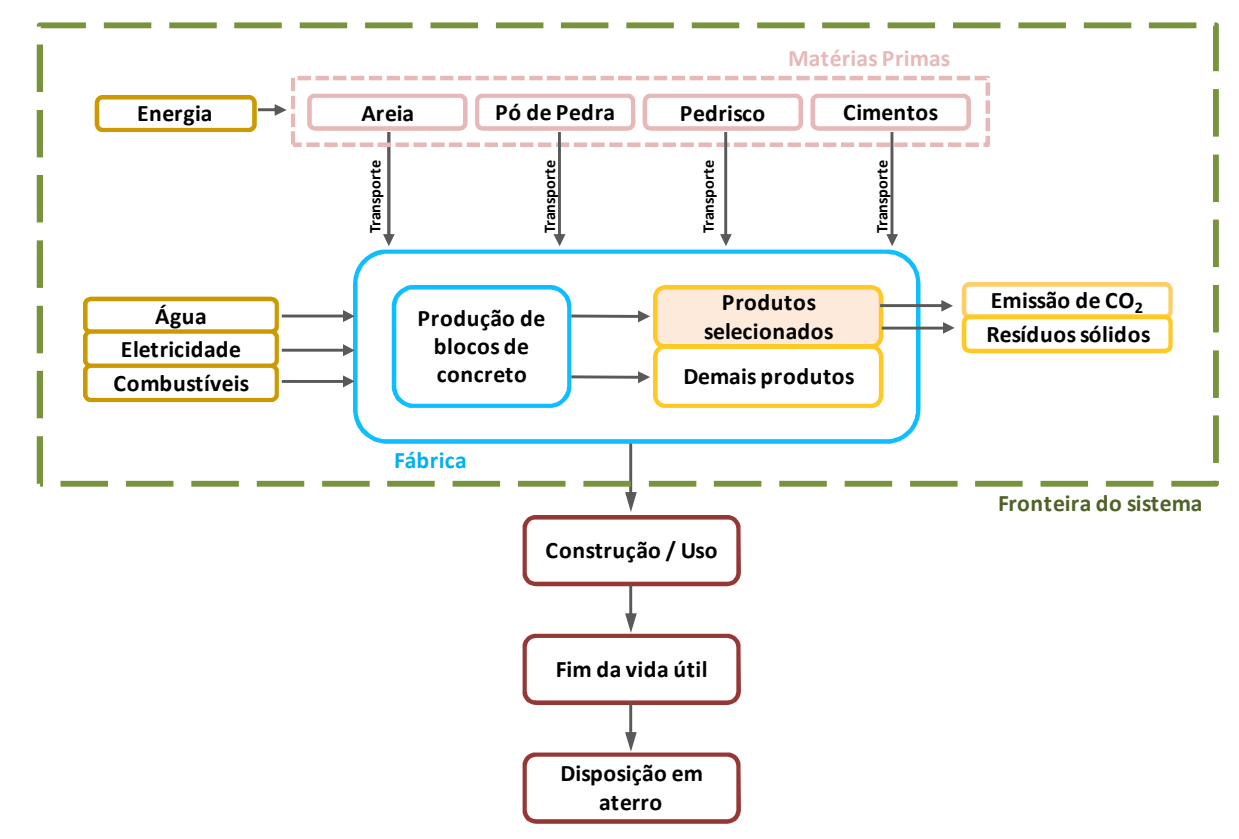

Figura 8 - Delimitação da fronteira do sistema estudado - fabricação de blocos de concreto.

Os impactos foram estimados considerando a extração dos insumos, o transporte das matérias-primas até a fábrica e seu funcionamento. Foram selecionados para o estudo os materiais mais importantes para a produção dos blocos de concreto (cimento, agregados e água). Os consumos de pigmentos e aditivos não foram analisados por serem considerados insignificantes quando comparados à massa dos 
produtos (inferior a 1\%). No entanto, é importante ressaltar que embora estes insumos sejam utilizados em pequenas quantidades, seus impactos podem ser relevantes (o que não foi analisado).

Os impactos causados pelo retorno do caminhão e pela distribuição do produto pronto não foram analisados. No primeiro caso há a incerteza se o veículo retorna vazio ou transportando outro produto, enquanto no segundo são muito variadas as distâncias de transporte possíveis, considerando as dimensões do território brasileiro. Em ambas as análises o levantamento dessas informações junto a cada empresa seria necessário, o que ocasionaria grande complexidade para se alcançar um resultado final.

Dados referentes ao consumo de água e geração de resíduos provenientes do processamento das matérias-primas não puderam ser incorporados aos impactos da produção dos blocos de concreto, embora essas etapas estejam incluídas na fronteira do sistema. Não existem dados confiáveis referentes aos mesmos na literatura, principalmente nacional.

\subsection{Universo de empresas representadas}

O projeto ACV Modular teve a adesão inicial de 45 empresas do setor, que mostraram possuir visão ambiental, com interesse em conhecer seus impactos. No entanto, a falta de uma equipe especializada na empresa para o preenchimento do formulário exigiria muito tempo dos funcionários, já que o ideal seria que os mesmos estivessem vinculados ao processo produtivo. O fato de alguns dados não serem registrados pela fábrica, pode ter sido outro barreira para a efetivação no projeto.

Apesar dessas dificuldades, parcela significativa se efetivou ao projeto pelo envio do formulário preenchido e realização das revisões necessárias. O levantamento dos dados foi realizado por 33 empresas, pioneiras no desenvolvimento de indicadores da construção civil brasileira.

As empresas participantes estão localizadas nas regiões Sul (10), Sudeste (21), Centro-Oeste (01) e Nordeste (01). Para integrar o projeto, a empresa deveria estar associada à BlocoBrasil e possuir o selo de qualidade da ABCP. A Tabela 7 apresenta a lista das empresas participantes, que operam formalmente e possuem sistemas de gestão da qualidade organizados. A carga horária média de 
funcionamento das fábricas é de 45 horas semanais em 94\% das empresas analisadas (funcionam em dois turnos), sendo que as demais trabalham em média 156 horas por semana (operam durante três turnos).

Apesar de ser importante e significativo o número de empresas participantes do Projeto ACV-m, este estudo não possui uma amostra representativa da indústria de blocos de concreto do Brasil. De acordo com o consultor técnico da Associação Brasileira da Indústria de Blocos de Concretos, Carlos Alberto Tauil, as 33 empresas participantes respondem por aproximadamente $50 \%$ da produção nacional. Atualmente são mais de 80 empresas associadas à BlocoBrasil, além de inúmeras empresas informais que também atuam no mercado brasileiro. O estudo não representa a parcela do mercado de empresas menos organizadas, que operam em graus variados de informalidade. Estas tendem a apresentar menor capacidade técnica e administrativa, logo, espera-se que apresentem graus de eficiência ambiental inferiores aos das empresas participantes no estudo.

Tabela 7 - Lista das empresas participantes, por estado da federação.

\begin{tabular}{cc}
\hline Empresa & Estado \\
\hline Arevale & SP \\
\hline Aroucatec & SP \\
\hline Calblock & SP \\
\hline Exactomm & SP \\
\hline Glasser & SP \\
\hline Intercity & SP \\
\hline JB Blocos & SP \\
\hline Oterprem & SP \\
\hline Piuca & SP \\
\hline Prensil & SP \\
\hline Presto & SP \\
\hline Quitaúna & SP \\
\hline Tatu & SP \\
\hline Tinari & SP \\
\hline Blojaf & $\mathrm{MG}$ \\
\hline Sigma & $\mathrm{MG}$ \\
\hline Uni Stein & $\mathrm{MG}$
\end{tabular}

\begin{tabular}{cc}
\hline Empresa & Estado \\
\hline Casalit & $\mathrm{RJ}$ \\
\hline FLG & $\mathrm{RJ}$ \\
\hline Pavibloco & $\mathrm{RJ}$ \\
\hline Pentágono & $\mathrm{RJ}$ \\
\hline Pavimenti - Filial & $\mathrm{PR}$ \\
\hline Pavimenti - Matriz & $\mathrm{PR}$ \\
\hline Tecpaver & $\mathrm{PR}$ \\
\hline Valleblock & $\mathrm{PR}$ \\
\hline Vanderli Gai e Cia. & $\mathrm{PR}$ \\
\hline Kerber & $\mathrm{SC}$ \\
\hline Vale do Selke & $\mathrm{SC}$ \\
\hline Votorantim & $\mathrm{SC}$ \\
\hline Prontomix & $\mathrm{RS}$ \\
\hline Tecmold & $\mathrm{RS}$ \\
\hline Civil & $\mathrm{BA}$ \\
\hline Original & $\mathrm{DF}$ \\
\hline
\end{tabular}

No relatório final do projeto ACV-m de blocos de concreto , a empresa Piuca não foi discriminada por ter deixado de fazer parte da BlocoBrasil durante o andamento do estudo. No mesmo relatório, a empresa Multibloco aparece na lista de participantes, no entanto, devido a problemas com seus dados, não foi possível calcular seus indicadores. Por esse motivo, ela não é apresentada na Tabela 7. 


\subsection{Produtos estudados}

Para o estudo foram selecionados blocos de concreto para pavimento intertravado (BCP) com $35 \mathrm{MPa}$, retangular e 16 faces, e blocos de concreto para alvenaria, estrutural $(B C E)$ e de vedação $(B C V)$. Essa seleção foi realizada pela $A B C P$ e pela BlocoBrasil, sendo esses produtos considerados mais representativos junto ao mercado consumidor brasileiro. As especificações desses blocos encontram-se na Tabela 8 e na Tabela 9.

Tabela 8 - Características dos blocos de concreto para pavimentos selecionados para o estudo.

\begin{tabular}{|c|c|c|c|}
\hline \multicolumn{2}{|c|}{ Formato } & $\begin{array}{l}\text { Espessura } \\
\text { (cm) }\end{array}$ & $\begin{array}{l}\text { Resistência } \\
\quad(\mathrm{MPa})\end{array}$ \\
\hline & & 6 & \multirow{6}{*}{35} \\
\hline & Retangular & 8 & \\
\hline & & 10 & \\
\hline & \multirow{3}{*}{16 faces } & 6 & \\
\hline & & 8 & \\
\hline & & 10 & \\
\hline
\end{tabular}

Fonte das imagens: www.aroucatec.com.br/produtos.php

Tabela 9 - Características dos blocos estruturais e de vedação selecionados para o estudo.

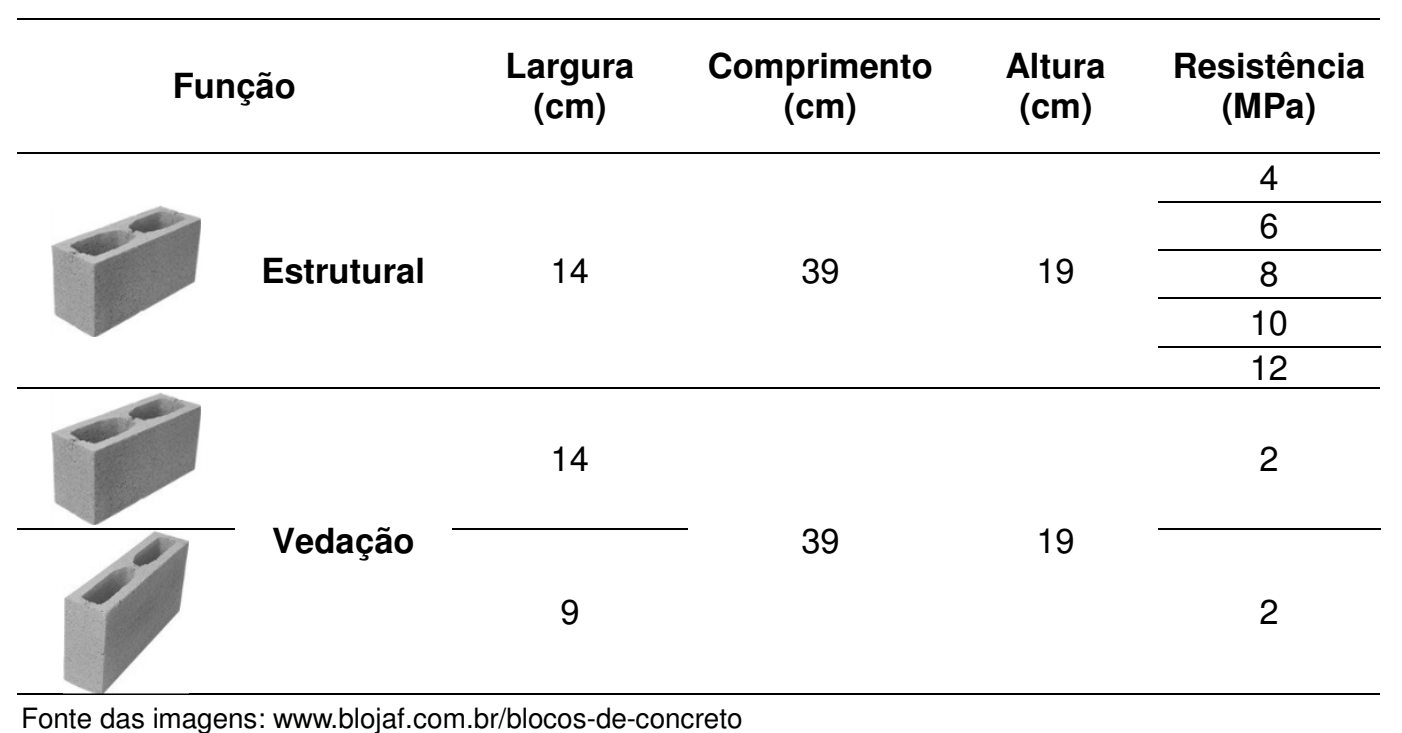

\subsection{Unidades de análise adotadas}

Para o cálculo e divulgação dos resultados decidiu-se pela seleção de duas unidades de análise, uma para cada tipo de produto, de modo a utilizar a mesma linguagem adotada pelo setor, para facilitar a compreensão dos resultados. Assim, para os BCP adotou-se um $\mathrm{m}^{2}$ de blocos e para os BCE e BCV foi escolhida uma unidade de peça. Como a unidade de bloco e o $\mathrm{m}^{2}$ não representam funções do 
produto, nesse estudo as unidades de referências selecionadas não serão tratadas como unidades funcionais.

\subsection{Inventário - Formulário padrão}

A análise do processo produtivo dos blocos de concreto permitiu identificar as principais etapas do sistema. Com base nessas informações, um primeiro formulário padronizado foi desenvolvido para a coleta de dados junto às empresas, em formato Excel, visando fornecer o maior detalhamento possível e verificação de consistência das informações.

Para testar sua funcionalidade, o mesmo foi aplicado em três fábricas localizadas no estado de São Paulo, nas cidades de Campinas, Taubaté e São Paulo. Inicialmente foi previsto o tempo máximo de um mês para retorno do formulário preenchido, no entanto as empresa entregaram-no parcialmente preenchido após três meses. As fábricas apresentaram dificuldades em levantar alguns dados, porque não estavam registrados na forma solicitada ou não realizavam o monitoramento do dado solicitado. Além disso, algumas informações da produção foram consideradas confidenciais, como o traço utilizado na confecção do concreto de cada produto. Como consequência, nenhuma das três empresas retornou com o formulário inteiramente preenchido.

Frente a essas dificuldades, para tornar a metodologia aplicável nos fabricantes de blocos interessados, decidiu-se pela simplificação do formulário, reduzindo-se a quantidade de dados solicitados ao mínimo e diminuindo o leque de produtos analisados. $\mathrm{Na}$ nova versão foram incluídas apenas informações essenciais: consumo dos principais insumos (cimento, agregados, energia e água), geração de resíduos e uso de água total. A Tabela 10 apresenta a comparação de alguns itens do formulário inicial e o formulário utilizado do estudo. 
Tabela 10 - Comparação entre os formulários teste e final para a coleta de dados.

\begin{tabular}{|c|c|c|}
\hline & Formulário Teste & Formulário Final \\
\hline $\begin{array}{l}\text { Quantidade de produ- } \\
\text { tos analisados }\end{array}$ & $\begin{array}{l}\text { todos os blocos produzidos na } \\
\text { fábrica }\end{array}$ & $\begin{array}{l}7 \text { blocos para alvenaria e } 6 \\
\text { blocos para pavimentação }\end{array}$ \\
\hline $\begin{array}{l}\text { Características anali- } \\
\text { sadas por produto }\end{array}$ & $\begin{array}{l}\text { traço, tipo e consumo de cimento } \\
\text { e agregados por fornecedor, } \\
\text { aditivos, pigmentos, água }\end{array}$ & $\begin{array}{l}\text { tipo e teor de cimento, consu- } \\
\text { mo de água }\end{array}$ \\
\hline $\begin{array}{l}\text { Quantidade produzi- } \\
\text { da por produto }\end{array}$ & mensal e total em 1 ano & total em 1 ano \\
\hline $\begin{array}{l}\text { Processo de produ- } \\
\text { ção }\end{array}$ & $\begin{array}{l}\text { algumas especificações, como } \\
\text { tipo de equipamento por etapa }\end{array}$ & não coleta essa informação \\
\hline $\begin{array}{l}\text { Matérias-primas cole- } \\
\text { tadas }\end{array}$ & $\begin{array}{l}\text { todas utilizados, consumos men- } \\
\text { sais por fornecedor (endereço, } \\
\text { distância, especificações sobre o } \\
\text { transporte, entre outras) }\end{array}$ & $\begin{array}{l}\text { principais insumos (definidos } \\
\text { previamente) separados por } \\
\text { fornecedor, apenas cidade e } \\
\text { distância de transporte }\end{array}$ \\
\hline $\begin{array}{l}\text { Matérias-primas - } \% \\
\text { por produto }\end{array}$ & $\begin{array}{l}\text { parcela alocada de cada insumo } \\
\text { por produto }\end{array}$ & não coleta essa informação \\
\hline Consumo - água & $\begin{array}{l}\text { especifica em entradas e saídas } \\
\text { todas as fontes utilizadas, con- } \\
\text { sumos mensais, etapas utilizadas }\end{array}$ & $\begin{array}{l}\text { consumo médio no concreto } \\
\text { por produto e total da fábrica } \\
\text { em } 1 \text { ano }\end{array}$ \\
\hline Equipamentos & $\begin{array}{l}\text { separa por tipo de fonte (eletrici- } \\
\text { dade e combustão), quantidade } \\
\text { de máquinas, potência, horas de } \\
\text { funcionamento, entre outras }\end{array}$ & $\begin{array}{l}\text { uso das principais fontes e- } \\
\text { nergéticas informadas, sem } \\
\text { especificar participação e e- } \\
\text { quipamentos }\end{array}$ \\
\hline Resíduos & $\begin{array}{l}\text { todos os tipos, quantidade total, } \\
\text { parcela reciclada (interna e por } \\
\text { terceiros) e destinada a aterro }\end{array}$ & $\begin{array}{l}\text { \% de perda por produto, resí- } \\
\text { duo total da produção e outros } \\
\text { tipos que a empresa desejas- } \\
\text { se informar }\end{array}$ \\
\hline Transporte - resíduos & $\begin{array}{l}\text { endereço de destinação, tipo de } \\
\text { veículo utilizado }\end{array}$ & $\begin{array}{l}\text { distância de transporte e des- } \\
\text { tinação }\end{array}$ \\
\hline
\end{tabular}

O formulário padrão simplificado foi dividido em quatro partes: Cadastro, Práticas da empresa, Produto e Inventário (Apêndice A - formulários utilizados para a coleta dos dados analisados nesse estudo). Informações da empresa, da unidade produtora e do responsável pelo preenchimento do formulário foram coletadas na planilha "Cadastro". Em "Práticas da empresa" foram levantadas informações classificatórias e qualitativas sobre as atividades da participante, referentes a uma ferramenta desenvolvida pelo $\mathrm{CBCS}^{21}$. A análise deste último não é escopo desse estudo.

Dados relacionados aos produtos selecionados para o estudo foram levantados na planilha "Produto", quanto à composição e quantidade fabricada. As empresas ficaram livres para informar as dimensões de seus BCP, tendo sido fixadas apenas a resistência (35 MPa) e as espessuras $(6,8$ e $10 \mathrm{~cm})$. Para os BCE e BCV foram

\footnotetext{
${ }^{21}$ Critérios para responsabilidade social e ambiental na seleção de fornecedores: Ferramenta desenvolvida pelo CBCS, disponível em http://www.cbcs.org.br/selecaoDeFornecedores/ - acessado em agosto de 2015.
} 
estabelecidas as resistências, com dimensões padronizadas pela NBR 6136 (ABNT, 2007). Nesse formulário foram solicitados dados como tipo e consumo de cimento, consumo de água e perda de produção, referentes a cada produto. Algumas informações da produção total da fábrica também foram solicitadas para possibilitar procedimentos de alocação e permitir a análise de consistência dos dados. A representatividade dos produtos analisados em relação ao total da fábrica foi levantada em porcentagem, além de ter sido solicitada a produção total.

A última planilha, "Inventário", coletou os consumos totais de água, dos insumos energéticos e das principais matérias-primas (cimento e agregados), além de dados referentes aos resíduos procedentes da produção, considerando todos os produtos da fábrica. Através do formulário teste, observou-se que solicitar dados de insumos referentes apenas aos produtos analisados poderiam gerar erros de inventário. Por esse motivo, decidiu-se pelo consumo total dos insumos principais da fábrica e, quando necessário, fazer a alocação pela massa produzida do produto e sua representatividade na produção total da fábrica.

Dados da distância de transporte das matérias-primas foram coletados para se estimar os impactos causados pela sua entrega. Eles foram confirmados por meio da ferramenta online Google Maps, pela cidade de origem do insumo e pelo endereço da fábrica, ambos levantados no formulário. Caso a empresa possuísse mais de um fornecedor para cada insumo, foram solicitadas as quantidades e distâncias referentes a cada um.

O preenchimento do formulário precisou de algumas revisões para confirmação ou retificação de dados, referentes às unidades selecionadas e os valores informados. Essa foi uma preocupação constante para se alcançar resultados plausíveis e com qualidade. Também foi necessário o levantamento de dados individuais complementares via e-mail ou telefone junto aos responsáveis de cada empresa, com objetivo de ampliar e assegurar a análise dos indicadores. Isso ocorreu porque algumas questões importantes foram eliminadas durante o processo de simplificação do formulário. No entanto, durante os cálculos e análises, constatou-se a importância dessas informações para tornar os resultados mais próximos da realidade. Uma delas foi o tipo de transporte utilizado na entrega das matériasprimas, sendo posteriormente solicitado o tipo de veículo que normalmente é utilizado nessa entrega e a quantidade de material entregue em cada pedido. 
Também foram requisitadas informações referentes ao uso ou não de aditivos e quais tipos, além do teor médio da umidade dos agregados. Elas foram utilizadas para auxiliar nas análises de consumo de água por produto levantado no formulário.

O período referente aos dados coletados foi estabelecido como 12 meses, sendo estes seguidos, mas não necessariamente um ano fechado. Essa determinação foi realizada de modo a diluir eventos sazonais e períodos de maior e menor produção. Períodos chuvosos ou secos podem influenciar no processo, pelo aumento ou diminuição nos consumos de energia e água. Empresas que informaram dados referentes a um período menor, não tiveram seus resultados relacionados a ele incorporados nos indicadores.

\subsection{Treinamento}

A divulgação do Projeto ACV-m e esclarecimentos sobre o preenchimento dos formulários ocorreram em quatro workshops, dois realizados na cidade de São Paulo, um na cidade do Rio de Janeiro e um em Florianópolis. Nesses eventos também foram transmitidos aos representantes das empresas os objetivos do projeto e a metodologia da avaliação do ciclo de vida.

Primeiramente foi solicitado que as empresas preenchessem o formulário padrão e enviassem seus dados como confirmação de sua participação no projeto. Esses formulários, considerados preliminares, permitiram observar quais dificuldades as empresas apresentaram no preenchimento, sendo discutidas nos workshops. A participação nesses eventos pelas empresas que enviaram os formulários foi de $65 \%$. Após cada evento, foi solicitado que as empresas revisassem seus dados.

\subsection{Levantamento dos dados}

O levantamento dos dados consumiu mais tempo do que o estimado, que era de um mês. Determinadas informações solicitadas pelos formulários não foram entendidas em um primeiro momento por algumas empresas, alguns valores informados não condiziam com as unidades selecionadas. Diante disso, foram realizadas revisões consideradas imprescindíveis para o alcance dos dados necessários para os cálculos. Como os responsáveis pelo preenchimento dos formulários foram membros da própria empresa, normalmente vinculados ao processo produtivo, as revisões foram realizadas no tempo permitido pelo funcionamento da fábrica. 
Considerando do envio do formulário preliminar, para a participação dos workshops, ao retorno da última revisão para fechamento dos dados, foram consumidos aproximadamente 12 meses para a coleta das informações das 33 empresas. Durante esse período os cálculos dos indicadores foram sendo realizados, de modo a possibilitar análises de qualidade e consistência dos dados levantados.

\subsection{Unidades de consumo dos insumos}

Para facilitar o preenchimento do formulário, algumas unidades de medida foram escolhidas pela empresa. Outras foram fixadas, por serem mais usuais aos insumos a que se referiam, sendo elas as do consumo de água $\left(\mathrm{m}^{3}\right)$, eletricidade $(\mathrm{kWh})$, óleo diesel (litro), gasolina (litro), álcool (litro) e cimento (t).

Para o cálculo dos indicadores, algumas conversões foram necessárias em relação aos insumos informados, de modo a igualar com as unidades de referências da energia incorporada e dos fatores de emissão apresentadas na Tabela 4, na Tabela 5 e na Tabela 6. Na Tabela 11 são apresentadas as unidades adotadas como padrão e os dados considerados para as conversões. 
Tabela 11 - Dados adotados para as conversões das unidades dos insumos informados e as respectivas unidades estabelecidas como padrão para o cálculo dos indicadores.

\begin{tabular}{|c|c|c|c|}
\hline Insumo & $\begin{array}{l}\text { Unidade } \\
\text { adotada }\end{array}$ & $\begin{array}{c}\text { Densidade } \\
\left(\mathrm{kg} / \mathrm{m}^{3}\right)\end{array}$ & Fonte \\
\hline GLP & $\mathrm{t}$ & 552 & \multirow{3}{*}{ BEN 2013 (EPE; MME, 2013) } \\
\hline Gás natural & $\mathrm{m}^{3}$ & 0,74 & \\
\hline Óleo BPF* & $\mathrm{m}^{3}$ & 1.000 & \\
\hline Óleo de xisto & $\mathrm{t}$ & 970 & Empresas Ravato e Betunel $^{22}$ \\
\hline Lenha - eucalipto verde & \multirow{2}{*}{$\mathrm{t}$} & 1.100 & \multirow{2}{*}{ - Punhagui, 2014} \\
\hline Lenha - pinus, eucalipto e nativa & & 970 & \\
\hline Areia natural & $\mathrm{t}$ & 1.460 & Fornecedores Ertcon e Pirâmide ${ }^{23}$ \\
\hline Areia industrial & $\mathrm{t}$ & 1.700 & Sindibrita $^{24}$ \\
\hline Brita 0 & $\mathrm{t}$ & 1.540 & Sindibrita $^{24}$ e fornecedor Ertcon ${ }^{25}$ \\
\hline Pedrisco de seixo & $\mathrm{t}$ & 1.500 & Informado pela empresa que utiliza \\
\hline Pó de brita & $\mathrm{t}$ & 1.530 & Sindibrita $^{24}$ e fornecedor Ertcon ${ }^{26}$ \\
\hline Agregado reciclado & $\mathrm{t}$ & 1.450 & Ryu (2002) \\
\hline
\end{tabular}

*Nota: Adotada a densidade do óleo combustível divulgado pelo BEN 2013.

A densidade da madeira utilizada como lenha pode variar por uma série de motivos, como tipo de madeira e umidade. Com isso, por causa das incertezas em relação à origem da lenha utilizada pelo setor de blocos de concreto, algumas considerações foram necessárias. Entre as fábricas analisadas, cinco informaram que utilizavam lenha em seu processo industrial, sendo que apenas uma informou seu consumo em massa. Entre as que forneceram seu dado em volume, uma informou que utiliza eucalipto, mas não especificou se o valor se encontrava em $\mathrm{m}^{3}$ estéreo (madeira empilhada, considerando os vazios) ou não. Com isso, decidiu-se adotar para essa empresa a pior situação, a densidade do eucalipto verde (com teor crítico de umidade de 60\%), que é de 1,10 t/m³ (PUNHAGUI, 2014). Duas fábricas estimaram a quantidade de lenha consumida através do preço de $1,0 \mathrm{~m}^{3}$ de lenha e do valor total pago pela empresa no período, no entanto, não passaram informações sobre a

\footnotetext{
${ }^{22}$ Empresas: Ravato (www.ravato.com.br/v2/documentos/especificacoes_xisto.pdf) e Betunel (www.betunel.com.br/pdf/oleo_xisto.pdf) - acessos em julho de 2014.

${ }^{23}$ Fornecedores de areia: Ertcon (www.ertcon.com.br/pages/produtos); Pirâmide (www.areiapiramide.com.br/index.php/produtos.html) - acesso em julho de 2014.

24 Dados técnicos do Sindibrita: www.sindibrita.org.br/destaque/svp.htm - acesso em julho de 2014.

${ }^{25}$ Fornecedor de brita 0: Ertcon (www.ertcon.com.br/pages/produtos/p:pedrisco-misto) - acesso em julho de 2014.

${ }_{26}$ Fornecedor de pó de brita: Ertcon (www.ertcon.com.br/pages/produtos/p:po-pedra) - acesso em julho de 2014.
} 
madeira. Assim, decidiu-se utilizar a densidade verde adotada para diferentes tipos e origens de madeira (pinus, eucalipto e nativas), que é de 0,97 t/m³ (PUNHAGUI, 2014). Uma empresa não informou o tipo de lenha utilizada, onde também se decidiu pela adoção deste último valor.

\subsection{Conversões de unidades referentes ao processo produtivo}

De modo a facilitar o preenchimento do formulário, algumas unidades referentes aos processos produtivos foram definidas pela própria empresa. A quantidade de cada produto fabricado no período analisado poderia ser informada em $\mathrm{m}^{2}, \mathrm{~m}^{3}$, tonelada ou mil peças. Algumas adotaram uma unidade para os blocos para pavimento e outra para os demais. Nenhuma empresa informou sua produção por tipo de bloco em volume, apenas a produção total da fábrica.

O consumo de cimento por unidade de produto poderia ser informado em $\%$ da massa, $\mathrm{kg} / \mathrm{m}^{3}$ ou $\mathrm{kg} /$ peça. A quantidade de água de composição do concreto por peça tinha como opções de unidade $\mathrm{m}^{3}$ ou litro, embora algumas empresas tenham informado seus consumos em \% da massa ou litro/m².

Para realizar as análises dos dados e o cálculo dos indicadores, algumas unidades foram estabelecidas como padrão, listadas a seguir. Por isso, algumas conversões e estimativas foram necessárias.

- Produção vendida: número de peças e tonelada;

- Teor de cimento: kg/peça;

- Água: litro/peça.

As tabelas a seguir apresentam as unidades informadas pelas empresas referentes a alguns itens solicitados pelo formulário. A Tabela 12 contém as unidades referentes à quantidade produzida dos blocos analisados. Na Tabela 13 são apresentadas as unidades de consumo de cimento e na Tabela 14 as unidades escolhidas pelas empresas para informar o consumo de água de composição do concreto, ambas por tipo de produto. Os números sublinhados na Tabela 12 apontam as empresas que utilizaram uma unidade para apresentar a quantidade produzida de blocos para pavimento $\left(\mathrm{m}^{2}\right)$ e outra para os blocos para alvenaria (mil peças). 
Tabela 12 - Unidades referentes às produções informadas. Os números sublinhados referem-se às empresas que utilizaram uma unidade para os blocos para pavimentação e outra referente aos blocos para alvenaria.

\begin{tabular}{cc}
\hline $\begin{array}{c}\text { Unidades informadas para } \\
\text { produção }\end{array}$ & Identificação das empresas \\
\hline massa (tonelada) & $3,5,7,12,16,33$ \\
\hline $\begin{array}{c}\text { quantidade de peças (milheiro } \\
\text { ou unidades) }\end{array}$ & $\begin{array}{r}1,2,4,6,8,10,11,13,14,15,18,19,20,21,22,23, \\
24,25, \underline{26}, \underline{27}, 29, \underline{30}, \underline{31}, \underline{32}, 34\end{array}$ \\
\hline $\mathrm{m}^{2}$ & $\underline{15}, 17, \underline{24}, \underline{26}, \underline{27}, 28, \underline{30}, \underline{31}, \underline{32}$ \\
\hline \\
Tabela 13 - Unidades de consumo de cimento informadas por tipo de produto. \\
\hline $\begin{array}{c}\text { Unidades informadas para } \\
\text { consumo de cimento }\end{array}$ \\
\hline $\mathrm{kg} /$ peça \\
\hline$\%$ da massa \\
\hline $\mathrm{kg} / \mathrm{m}^{3}$ \\
\hline
\end{tabular}

Tabela 14 - Unidades de água de composição do concreto informadas pelas empresas por tipo de produto.

\begin{tabular}{cc}
\hline $\begin{array}{c}\text { Unidades informadas para } \\
\text { consumo de cimento }\end{array}$ & Identificação das empresas \\
\hline litro/peça & $1,2,3,4,5,6,7,8,11,12,13,14,15,16,17,18,19$, \\
$20,21,22,23,24,25,28,30,31,32,33,34$ \\
\hline$\%$ da massa & 10,29 \\
\hline litro/m ${ }^{2}$ & 26,27 \\
\hline
\end{tabular}

\subsubsection{Unidades de produção}

Os resultados desse estudo foram calculados tendo como referência as unidades de análise definidas para cada tipo de bloco, $\mathrm{m}^{2}$ para pavimento e unidade de peça para alvenaria. Quando a quantidade total por tipo de produto foi informada em tonelada, para se estimar a quantidade total de peças, a massa informada foi divida pela massa unitária do produto.

A alocação dos consumos de energia (eletricidade e combustíveis) e de água foi realizada em massa. Assim, quando a quantidade total por tipo de produto foi informada em peças, a massa total foi calculada multiplicando o número total de peças pela massa unitária. 
Já quando a produção foi informada em área, a quantidade de peças por $\mathrm{m}^{2}$ por tipo de bloco para pavimento foi levantada junto a cada empresa através de contato via e-mail ou em sua homepage. A quantidade média de peças $/ \mathrm{m}^{2}$ é de 50 unidades para os retangulares e de 40 blocos para os de 16 faces. Para calcular o número total de peças produzidas, multiplicou-se a área total pela quantidade de peças por $\mathrm{m}^{2}$. Com o número de peças calculado, levantou-se a massa total para cada produto selecionado para o estudo multiplicando esse valor pela massa unitária por tipo de bloco.

\subsubsection{Teor de cimento}

O teor de cimento em quilograma por peça foi adotado como unidade de referência para o cálculo dos indicadores. A maioria das empresas informou esse dado nessa unidade. Para o teor de cimento informado em \% da massa, adotou-se a massa seca do bloco para estimar a quantidade de cimento por peça. A massa para cada bloco ( $\left.m_{\text {unitária.prod }}\right)$ é formada por agregados, cimento e água da umidade de equilíbrio com o ar, considerada igual a 5\%. O cálculo dessa massa de água contida na peça $\left(m_{\text {h.p̧̧ }}\right)$ e da massa seca do bloco ( $\left.m_{\text {seca.pç}}\right)$ são expressos pelas equações ( 1 ) e ( 2 ). Assim, a massa de cimento por peça é estimada pela massa seca do bloco multiplicada pelo teor de cimento informado pela empresa em porcentagem.

$$
\begin{gathered}
\mathrm{m}_{\mathrm{h} . \mathrm{pc}}=\mathrm{m}_{\text {unitária.prod }} \times 0,05 \\
\mathrm{~m}_{\text {seca.pç }}=\mathrm{m}_{\text {unitária.prod }}-\mathrm{m}_{\mathrm{h} . \mathrm{pc}}
\end{gathered}
$$

No caso do teor de cimento informado em $\mathrm{kg} / \mathrm{m}^{3}$ foi necessário estimar o volume de cada bloco, já que esse dado não foi solicitado pelo formulário. Diferentes considerações foram adotadas, a depender do formato da peça.

- BCP retangular: o volume do bloco foi calculado com base na geometria informada, por ser uma peça regular.

- BCP de 16 faces: sabendo a quantidade de peças que compõem 1,0 $\mathrm{m}^{2}$, foi possível estimar a área de uma peça. Esse valor multiplicado pelas espessuras selecionadas resultou no volume do bloco. 
- BCE e BCV: o volume de cada peça foi calculado com base na geometria dos blocos selecionados e nas espessuras das paredes, ambos especificados pela NBR 6136 (ABNT, 2007).

A quantidade de cimento por peça foi estimada multiplicando-se o volume de cada peça pelo teor de cimento fornecido $\mathrm{em} \mathrm{kg} / \mathrm{m}^{3}$.

\subsubsection{Consumo de água}

O litro foi a unidade de referência considerada para o cálculo dos indicadores de consumo de água. Quase todas as empresas informaram o consumo por bloco nessa unidade. Quando essa informação foi expressa em porcentagem da massa, foram adotas as mesmas considerações feitas no item 5.9.2. Assim, o consumo de água em massa por peça foi calculado multiplicando-se a massa seca do bloco pelo teor de água informado pela empresa (massa específica da água igual a 1,0 kg/l).

Para a quantidade de água informada em litro $/ \mathrm{m}^{2}$ de produto, o número de peças por $\mathrm{m}^{2}$ foi utilizado. Assim, estimou-se o consumo de água por peça dividindo-se a quantidade de água por $\mathrm{m}^{2}$ pela quantidade de peças por $\mathrm{m}^{2}$.

\subsection{Estimativa da quantidade total de produtos da fábrica}

Para tornar possíveis os procedimentos de alocação e a análise de consistência dos consumos de matérias-primas informados pelas empresas, a produção total da fábrica foi solicitada. O formulário permitiu que esse valor fosse informado em algumas unidades para facilitar seu preenchimento pela empresa: tonelada, mil peças, $\mathrm{m}^{2}$ e $\mathrm{m}^{3}$. A Tabela 15 apresenta a escolha de cada empresa.

Tabela 15 - Unidades de produção utilizadas pelas empresas para informar o total da fábrica. A fábrica 32 não informou sua produção total.

\begin{tabular}{cc}
\hline $\begin{array}{c}\text { Unidade informada para a } \\
\text { produção total }\end{array}$ & Identificação das empresas \\
\hline tonelada & $3,5,7,8,10,12,13,14,16,20,25,26,27,30,33,34$ \\
\hline número de peças & $1,2,4,6,11,18,19,21,22,23,24,29$ \\
\hline $\mathrm{m}^{2}$ & $15,17,28$ \\
\hline $\mathrm{m}^{3}$ & 31 \\
\hline
\end{tabular}


Para possibilitar a alocação dos insumos foram necessárias algumas estimativas, como da massa total de produtos da fábrica nos casos em que as empresas informaram sua produção em unidade diferente da tonelada. Calculou-se também o número total de peças para as produções informadas em massa, área ou volume. Isso foi preciso para permitir o cálculo dos indicadores do estudo nas unidades de análise adotadas ( $\mathrm{m}^{2} \mathrm{e}$ unidade de bloco).

Quando a produção total da fábrica foi informada em $\mathrm{m}^{2}$, o número total de peças produzidas para cada tipo de bloco foi estimado a partir da quantidade de peças por $\mathrm{m}^{2}$, levantada para cada empresa. O número médio de blocos por $\mathrm{m}^{2}$ foi calculado dividindo a quantidade total dos produtos selecionados para o estudo pela área total dos mesmos. Com a área informada como produção total da fábrica e a quantidade média de peças por $\mathrm{m}^{2}$, estimou-se o número total de peças produzidas pela empresa no período analisado pela multiplicação desses dois valores.

No caso em que a produção total da fábrica foi informada em $\mathrm{m}^{3}$, o volume de cada bloco $\left(\mathrm{V}_{\mathrm{pc}}\right)$ foi estimado com base na geometria informada (BCP retangulares), na quantidade de peças por $\mathrm{m}^{2}$ (BCP de 16 faces) ou na geometria e espessura da parede especificadas em norma (BCE e BCV) - ver item 5.9.2. Através desses volumes e do número total de blocos analisados ( $Q T D_{\text {prod}}$ ), o volume total dos produtos do projeto $\left(\mathrm{V}_{\mathrm{TPE}}\right)$ foi estimado (eq. ( 3 )). Em seguida, o volume médio por peça foi calculado dividindo-se o volume total estimado pela quantidade total de produtos selecionados para o estudo. Pela divisão do volume total de produtos fabricados pelo volume médio por peça, estimou-se o número total de blocos produzidos pela fábrica.

$$
\mathrm{V}_{\mathrm{TPE}}=\sum \mathrm{V}_{\mathrm{pc}} \times \mathrm{QTD}_{\text {prod }}
$$

Para a produção total informada em número de peças, a massa total de produtos da fábrica foi estimada a partir da divisão da massa total dos blocos analisados pela quantidade total dos mesmos, sendo calculada uma massa média. Multiplicando-se esse valor e a quantidade total de produtos da fábrica, estimou-se a massa total de produção da fábrica. Já quando a produção total da fábrica foi informada em massa, o número total de blocos da fábrica foi estimado pela divisão dessa massa total de produtos da fábrica pela massa média. 


\subsection{Estimativa de combustível do transporte das matérias-primas}

Para a estimativa do consumo de óleo diesel devido ao transporte das matériasprimas, a distância média de deslocamento e a cidade onde cada fornecedor está localizado foram levantadas pelo formulário (informação verificada pelo Google Maps). No entanto, não foram solicitadas no formulário as quantidades de insumos materiais entregues a cada pedido e o tipo de veículo utilizado nesse transporte. Essas informações foram levantadas em contatos com as empresas via e-mail ou telefone. Nos casos em que não houve sucesso nessa coleta, uma faixa de massa total de transporte (caminhão e carga - valores mínimo e máximo) foi considerada com base nos valores das empresas que retornaram. Para o cimento as massas totais de transporte obtidas variaram de 24 a 73 toneladas e para os agregados a faixa variou de 21 a 64 toneladas.

O transporte das matérias-primas foi realizado majoritariamente por meio de caminhões. Houve apenas um caso em que houve a associação de dois tipos de veículos para o deslocamento do cimento, sendo um trecho realizado por trem e o outro por caminhão.

O consumo de combustível foi obtido em litros por tonelada de matéria-prima. Apenas a entrega da matéria-prima foi considerada. O retorno do veículo não foi estimado, pois foi considerado que o veículo retorna carregado com outro tipo de carga, material ao qual o consumo de diesel deve ser associado.

\subsubsection{Transporte por caminhão}

A partir da divisão da quantidade total de cada matéria-prima, referente a cada fornecedor, pelas quantidades entregues a cada pedido, o número de viagens necessárias para entrega dos insumos materiais foi estimado. A maioria das empresas informou apenas um valor de massa transportada por pedido. Nesses casos a faixa de consumo de combustível (CD - litro/tonelada) foi estimada de acordo com as equações ( 4 ) e ( 5 ). Por causa das diversidades de modelos de caminhões que podem ser utilizados pelo setor, de capacidades de carga e de distâncias de deslocamento (DIST - km), um valor mínimo e um valor máximo foram considerados, ao invés de um valor médio de consumo de diesel. O menor e o maior valor encontrado entre todos os fornecedores de cada insumo foram selecionados para compor os extremos da faixa. 


$$
\begin{aligned}
\mathrm{CD}_{\text {mín }}=\frac{\mathrm{FC}_{\text {mín }} \times \mathrm{NV} \times \mathrm{MTT}_{\text {mín }} \times \mathrm{DIST}}{\mathrm{QTD}_{\text {mp }}} \\
\mathrm{CD}_{\text {máx }}=\frac{\mathrm{FC}_{\text {máx }} \times{\mathrm{NV} \times \mathrm{MTT}_{\text {máx }} \times \mathrm{DIST}}}{\mathrm{QTD}_{\text {mp }}}
\end{aligned}
$$

Onde:

$\mathrm{FC}=$ faixa de consumo de diesel pesquisado na literatura nacional (l/t.km);

$\mathrm{NV}$ = número de viagens necessárias para transportar o total de cada material da fábrica;

MTT = massa total de transporte (carga transportada mais a massa do caminhão em tonelada);

$\mathrm{QTD}_{\mathrm{mp}}=$ quantidade total de matéria-prima $(\mathrm{t})$.

Algumas empresas informaram que a quantidade de material pode variar a cada entrega e, consequentemente, a massa do caminhão. Essas são as de numeração $1,4,11,22,23,25,29,31$ e 32 . As empresas 12, 19 e 33 declararam que apenas a massa de cimento varia a cada pedido. Nesses casos foram consideradas as equações ( 6 ) e ( 7 ) na estimativa do consumo de combustível. Essa diferença foi ponderada porque o caminhão que apresenta maior capacidade de carga realiza menos viagens para entregar a mesma quantidade de material e, portanto, consome menos combustível. O contrário acontece quando o caminhão possui uma carroceria com menor capacidade.

$$
\begin{aligned}
& \mathrm{CD}_{\text {mín }}=\frac{\mathrm{FC}_{\text {mín }} \times \mathrm{NV}_{\text {mín }} \times \mathrm{MTT}_{\text {máx }} \times \mathrm{DIST}}{\mathrm{QTD}_{\text {mp }}} \\
& \mathrm{CD}_{\text {máx }}=\frac{\mathrm{FC}_{\text {máx }} \times \mathrm{NV}_{\text {máx }} \times \mathrm{MTT}_{\text {mín }} \times \text { DIST }}{\mathrm{QTD}_{\text {mp }}}
\end{aligned}
$$

O fator adotado para o consumo de diesel devido ao transporte (FC) realizado por meio de caminhão varia de 0,006 a 0,022 l/t.km, faixa estimada com base em dados de revistas do segmento de veículos de transporte de cargas e pessoas, entrevistas com algumas empresas que comercializam produtos de madeira e comunicação governamental, cujos veículos possuem eficiência variando de 0,8 a $6,5 \mathrm{~km} / \mathrm{l}$ (CAMPOS, 2012). Essas informações foram comparadas com alguns dados referentes ao transporte das matérias-primas utilizadas pelo setor de blocos de 
concreto, onde foi observado que a faixa de consumo de diesel por quilômetro percorrido é equivalente. Como o estudo de Campos (2012) realizou maior levantamento de dados para estimar essa variação, decidiu-se pela adoção de seus resultados.

Como o fator de consumo considera a massa transportada, essa foi determinada com base na quantidade de cada matéria-prima entregue por pedido e no tipo de veículo informado. A massa do caminhão foi levantada em manuais técnicos da Ford (FORD, 2012a, 2012b, 2012c, 2013a, 2013b) e da Volkswagen (VOLKSWAGEN, 2008a, 2008b, 2008c, 2008d, 2008e, 2008f, 2010). A massa das carrocerias foi levantada em manuais técnicos, sites e contatos com fabricantes de implementos rodoviários (Guerra (sem data), Beira Rio ${ }^{27}$, Randon $^{28}$, Brucal $^{29}, \mathrm{Noma}^{30}$ ).

\subsubsection{Transporte por trem}

O consumo de combustível para transporte realizado por trem foi calculado com base na faixa do fator de emissão de $\mathrm{CO}_{2}\left(\mathrm{FET}-\mathrm{kgCO}_{2} / \mathrm{t}\right.$.ku) disponível no $1^{\text {o }}$ Inventário Nacional de Emissões Atmosféricas do Transporte Ferroviário de Cargas (ANTT; IEMA, 2012). Esse valor varia de 0,0049 a 0,0364 $\mathrm{kgCO}_{2} / \mathrm{t} . \mathrm{ku}$, onde $\mathrm{ku}$ corresponde a quilômetro útil (distância percorrida). Primeiramente, calculou-se a quantidade de $\mathrm{CO}_{2}$ total de acordo com as equações ( 8 ) e ( 9 ).

$$
\begin{aligned}
& \mathrm{ECO}_{2 \text { mín }}=\frac{\mathrm{FET}_{\text {mín }} \times \mathrm{NV} \times \mathrm{M}_{\text {transp }} \times \text { DIST }}{\mathrm{QTD}_{\text {mp }}} \\
& \mathrm{ECO}_{2 \text { máx }}=\frac{\mathrm{FET}_{\text {máx }} \times \mathrm{NV} \times \mathrm{M}_{\text {transp }} \times \text { DIST }}{\mathrm{QTD}_{\text {mp }}}
\end{aligned}
$$

Onde:

$\mathrm{M}_{\text {transp }}=$ massa de matéria-prima transportada por viagem ( $\left.\mathrm{t}\right)$;

$\mathrm{NV}$ = número de viagens necessárias para transportar o total de cada material da fábrica.

DIST = distância de transporte $(\mathrm{km})$;

\footnotetext{
${ }^{27}$ E-mail enviado por Carrocerias Beira Rio em novembro de 2013.

${ }^{28}$ www.randonimplementos.com.br/pt/products/detail/carroceria-sobre-chassi/carrocerias/carroceriabasculante\# : acessado em novembro de 2013.

${ }^{29}$ www.brucalimplementos.com.br/silo40_vanderleia.html : acessado em novembro de 2013.

${ }^{30}$ www.noma.com.br/Produtos.aspx? Id=1 : acessado em novembro de 2013.
} 
$\mathrm{QTD}_{\mathrm{mp}}=$ quantidade total de matéria-prima (t), sem considerar a massa do veículo.

No inventário o combustível utilizado para o levantamento do fator de emissão de $\mathrm{CO}_{2}$ é o óleo diesel. Assim, calculou-se a faixa de consumo de combustível (CD - I/t) necessário para o transporte de cada matéria-prima dividindo-se a quantidade total de $\mathrm{CO}_{2}$ estimada e o fator de emissão de $\mathrm{CO}_{2}$ do diesel, informado na Tabela 6 $\left(\mathrm{FE}_{\text {diesel }}-\mathrm{kgCO}_{2} / \mathrm{l}\right)$.

\subsection{Cálculo dos indicadores}

\subsubsection{Indicador de cimento}

A unidade padrão definida para o consumo de cimento foi massa por $\mathrm{m}^{2}\left(\mathrm{~kg} / \mathrm{m}^{2}\right)$ para os BCP e massa por unidade de peça (kg/bloco) para os BCE e BCV. Algumas empresas forneceram seus dados de teor de cimento já em kg/peça, sendo que para os demais casos os consumos foram convertidos, como apresentado no item 5.9.2. Para o cálculo do indicador por $\mathrm{m}^{2}$, multiplicou-se a quantidade de cimento para cada bloco pela quantidade de peças que compõe $1 \mathrm{~m}^{2}$, referente a cada empresa.

\subsubsection{Indicador de agregados}

As quantidades de agregados solicitadas pelo formulário se referiam à produção total da fábrica no período, não apenas aos produtos selecionados para o estudo. Assim, o consumo por tipo de bloco foi estimado com base na massa unitária informada da peça.

Considerou-se que a massa do produto ( $m_{\text {unitária.prod }}$ ) é constituída por cimento $\left(m_{\text {cim.pç}}\right)$, agregados ( $\left.m_{\text {agreg.pç}}\right)$ e água ( $\left.m_{\text {água }}\right)$. Essa última parcela é composta pela água de duas origens, parte da água utilizada na confecção do concreto e a da umidade relativa do ar, como mostra a equação ( 10 ). A quantidade de água que reage quimicamente com o cimento é igual a aproximadamente $20 \%$ da massa de cimento. Já para a quantidade de água da umidade do ar foi adotado como sendo igual a $5 \%$ da massa da peça. Assim, a massa de agregados consumida em cada bloco foi calculada pela equação ( 11 ). Como o indicador de cimento, o indicador de agregados é apresentado em kg/peça para os BCE e BCV e em kg/m² para os BCP.

$$
m_{\text {água }}=20 \%\left(m_{\text {cim.pç }}\right)+5 \%\left(m_{\text {unitária.prod }}\right)
$$




$$
\mathrm{m}_{\text {agreg.pç }}=\mathrm{m}_{\text {unitária.prod }}-\mathrm{m}_{\text {cim.pç }}-\mathrm{m}_{\text {água }}
$$

As empresas utilizam mais de um tipo de agregado na sua composição (areia, brita 0 , pedrisco, pó de pedra, etc.). No entanto, não foi solicitada de cada empresa a proporção de cada tipo contida no produto. Por essa razão, foi necessário estimar a parcela de cada agregado ( $m_{\text {agreg.n) }}$ ) através do consumo total de agregados da

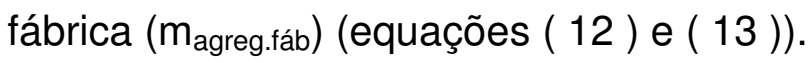

$$
\begin{gathered}
\mathrm{m}_{\text {agreg.fáb }}=\sum_{\mathrm{n}} \mathrm{m}_{\text {agreg.n }} \\
\text { \%agreg.n }=\frac{\mathrm{m}_{\text {agreg.n }}}{\mathrm{m}_{\text {agreg.fáb }}}
\end{gathered}
$$

Multiplicando a massa total de agregados em cada produto e a proporção estimada de cada tipo, estimou-se o consumo de cada tipo de agregado por peça. Essa estimativa foi realizada para determinar quanto do impacto referente a cada matériaprima e seu transporte está direcionado aos blocos.

\subsubsection{Indicador de energia incorporada (EI)}

A energia incorporada por bloco foi estimada considerando três fontes: transporte das matérias-primas (apenas entrega), produção das mesmas e energia consumida pela fábrica. $O$ indicador por peça é calculado pela soma da energia incorporada dessas três parcelas, sendo apresentado em MJ/unidade de referência, ou seja, $\mathrm{MJ} /$ peça para os BCE e BCV e em $\mathrm{MJ} / \mathrm{m}^{2}$ para os BCP.

Com os volumes estimados de óleo diesel para transportar cada tonelada de matéria-prima, considerando a faixa de consumo, calculou-se a quantidade de combustível utilizado para transportar apenas a massa de insumo material contida em uma peça. Para isso, esses dois valores referentes a cada matéria-prima foram multiplicados e, posteriormente, as parcelas foram somadas. Multiplicando esse resultado pelo valor de energia incorporada do óleo diesel (Tabela 6), calculou-se a energia incorporada por peça referente ao transporte das matérias-primas.

A parcela da energia incorporada em razão do consumo de cimento e agregados foi calculada através das respectivas massas estimadas por peça $\left(m_{m p}\right.$.pç $)$, ou seja, por meio dos indicadores de materiais (itens 5.12.1 e 5.12.2), como mostra a equação ( 
14 ). Os diferentes tipos de agregados e cimento foram relacionados às suas respectivas energias incorporadas $\left(\mathrm{EI}_{\mathrm{mp}}\right)$.

$$
\mathrm{EI}_{\mathrm{mp} . \mathrm{pc}}=\sum\left(\mathrm{EI}_{\mathrm{mp}} \times \mathrm{m}_{\mathrm{mp} . \mathrm{pc}}\right)
$$

Os consumos de energia da fábrica foram compostos pelas quantidades de eletricidade e combustíveis utilizados no processo produtivo do bloco. Como esses valores foram informados para toda a produção da fábrica, foi necessário fazer a alocação da energia, realizada em massa de produto. Para isso, primeiro estimou-se a proporção em massa de cada produto selecionado para o estudo, dividindo-se este valor pela massa total de produtos da fábrica. Pela multiplicação desse valor pelo consumo total de cada insumo energético da fábrica, a quantidade de energia relacionada a cada produto foi estimada. A divisão desse valor pela quantidade de

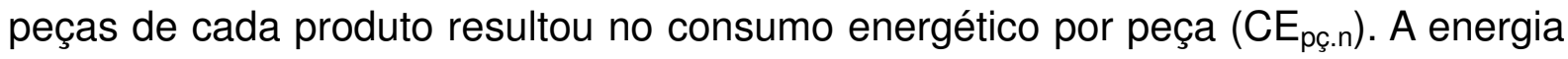
incorporada por peça resultante do funcionamento da fábrica foi calculada através da equação ( 15 ), onde $\mathrm{El}_{\mathrm{IE} . n}$ (Tabela 6) corresponde à energia incorporada referente a cada insumo energético utilizado na fábrica.

$$
\mathrm{EI}_{\text {fáb.pç }}=\sum_{n} \mathrm{EI}_{\mathrm{IE.n}} \times \mathrm{CE}_{\mathrm{pç.n}}
$$

\subsubsection{Indicador de emissão de $\mathrm{CO}_{2}$}

Procedimentos iguais aos adotados para a estimativa do indicador de energia incorporada foram realizados para o cálculo do indicador de emissão de $\mathrm{CO}_{2}$. $\mathrm{A}$ emissão da peça foi calculada pela somatória das emissões oriundas do transporte das matérias-primas (apenas entrega), da extração e processamento das mesmas e da energia consumida pela fábrica. Os fatores de emissão de $\mathrm{CO}_{2}$ dos insumos foram apresentados no item 4. O indicador de emissão de $\mathrm{CO}_{2}$ é apresentado em $\mathrm{kgCO}_{2} /$ peça (BCE e BCV) ou em $\mathrm{kgCO}_{2} / \mathrm{m}^{2}(\mathrm{BCP})$.

Os volumes mínimos e máximos estimados de óleo diesel para transportar cada tonelada de matéria-prima foram utilizados no cálculo do consumo de combustível devido aos materiais de uma peça. Pela multiplicação desses valores com as quantidades de insumos materiais por peça, encontrou-se a quantidade de diesel alocada para transportar apenas uma peça. Multiplicando esse valor pelo fator de 
emissão de $\mathrm{CO}_{2}$ do óleo diesel (Tabela 6), estimou-se a emissão de $\mathrm{CO}_{2}$ por peça por causa do transporte.

A emissão de $\mathrm{CO}_{2}$ do produto devido ao consumo de cimento e agregados foi calculada através das respectivas massas por peça $\left(m_{m p . p ̧}\right)$,como apresentado na equação ( 16 ). Assim como a energia incorporada, os diferentes tipos de cimento e agregados foram relacionados aos seus respectivos fatores de emissão de $\mathrm{CO}_{2}$.

$$
\mathrm{ECO}_{2 \text { mp.pc }}=\sum\left(\mathrm{FE}_{\mathrm{mp}} \times \mathrm{m}_{\mathrm{mp} . \mathrm{pc}}\right)
$$

A emissão de $\mathrm{CO}_{2}$ devido à energia consumida pela fábrica por peça foi calculada através do consumo de eletricidade e combustíveis, estimado da mesma forma como apresentado no item 5.12.3. Estes foram multiplicados aos seus respectivos fatores de emissão de $\mathrm{CO}_{2}\left(\mathrm{FE}_{\mathrm{IE} . n}\right)$, como apresentado pela equação ( 17 ).

$$
\mathrm{ECO}_{2 \text { fáb.pç }}=\sum_{n} \mathrm{FE}_{\mathrm{IE} . \mathrm{n}} \times \mathrm{CE}_{\mathrm{pç.n}}
$$

\subsubsection{Indicador de água}

O formulário solicitou o consumo de água por peça, para formulação do concreto, e o consumo de água total da fábrica. Juntamente com esse segundo dado, solicitouse a origem da água, que poderia ser rede pública, rios ou lagos, poço, pluvial, represa e reúso. Nenhuma empresa indicou que utilizava água das duas últimas fontes.

Em relação ao consumo de água solicitado por peça, diferentes interpretações foram feitas para o preenchimento do formulário. A maioria das empresas (58\%) informou a água total de composição, ou seja, considera a água adicionada e a contida nos agregados; 24\% informaram apenas a água adicionada aos materiais secos e 18\% não especificaram como seu dado foi levantado.

Como o formulário não solicitava o modo como esse valor foi levantado, essa informação foi verificadas através de contato com os responsáveis pelo seu preenchimento. Alguns dos valores analisados apresentaram inconsistências: alguns volumes informados referem-se a água adicionada, mas mostram-se muito elevados; outros especificados como total (adicionada e umidade dos agregados) mostram-se muito abaixo do consumo que deveria ser utilizado para uma peça. 
De acordo com a ABCP, a água de composição representa em média $6 \%$ da massa seca (valor médio produzido pela atividade de controle de qualidade dos blocos certificados realizado pela $A B C P{ }^{31}$ ). Fernandes (2013) indica em seu livro que a umidade final da mistura deve ser próxima a $7 \%$ da massa total de materiais secos. Marchioni (2013) levantou que a umidade para o concreto utilizado em blocos varia de $6 \%$ a $8 \%$ da massa total. No presente estudo decidiu-se pela adoção da umidade informada pela ABCP para a análise dos dados.

Em relação ao consumo de água total da fábrica, foi considerado o mesmo procedimento de alocação adotado para os insumos energéticos da fábrica, proporção em massa por produto. O consumo de água informado para toda a fábrica foi calculado pela soma das quantidades de todas as fontes informadas. Esse valor foi alocado a cada produto pela multiplicação desse valor pela representatividade de cada produto na produção total da fábrica (quantidade do produto analisado dividido pela quantidade total produzida no mesmo período). A divisão desse consumo pela quantidade de peças produzidas para cada tipo de produto resultou no consumo de água da fábrica por peça. $O$ indicador de água da fábrica foi calculado em litro/peça para os BCE e BCV e em litro $/ \mathrm{m}^{2}$ para os $\mathrm{BCP}$.

O indicador de água representa apenas a água total da fábrica, retirada/captada pela empresa. Esse consumo foi analisado como um todo, sem distinguir as etapas de uso. Não foi possível analisar a água consumida por peça no processo de produção do concreto devido às diferentes considerações realizadas pelas empresas durante esse levantamento.

Até o momento também não existem dados disponíveis na literatura sobre os consumos de água no processamento das matérias-primas utilizadas. Por esse motivo, não foram incorporadas nesse indicador as águas provenientes dos insumos utilizados.

\subsubsection{Indicador de resíduos/perdas}

Para estimar a geração de resíduos, o formulário solicitava que cada empresa informasse a porcentagem que é perdida de cada produto e a perda total de produção da fábrica, essa última uma média dos 12 meses analisados. Esta definição não abrange a variedade de resíduos que podem ser gerados (agregados,

${ }^{31}$ E-mail com o Eng. Cláudio Oliveira Silva, da ABCP. 
cimento, embalagens, pallets, perdas - quebras e sobras de produto formulado, seja no estado fresco ou endurecido). Por falha do formulário em definir claramente o que é resíduo e em detalhar sobre quais dados deveriam ser informados, as empresas consideraram os diversos tipos de resíduos, sem que um padrão fosse seguido. Isto ocorreu porque atualmente grande parte das empresas não registra as quantidades de resíduos descartadas ou enviadas para a reciclagem de forma sistemática, o que gerou diferentes informações.

Além disso, parte das perdas de produtos formulados da fábrica, quebras e sobras (estes últimos ainda não hidratados) pode ser reutilizada pelo seu retorno à mistura, o que agrava esse levantamento. Com isso, as perdas incluem resíduo (material que não retorna ao processo) e material reutilizado, que são registrados pelas empresas de forma agregada. Isso ocorre porque o valor total representa perda de produtividade da fábrica, que influencia diretamente nos custos e é representativo para a empresa. No entanto, o dado desagregado não evidenciava informação importante para a empresa até o momento.

Os dados sobre a perda total de produção da fábrica foram comparados com as perdas informadas para os blocos analisados, sendo que a empresa definiu a unidade deste último dado. Algumas passaram seu valor em volume $\left(\mathrm{m}^{3}\right)$, sendo necessária a conversão em massa. Para isso foi adota a densidade aparente média do agregado reciclado $\left(1,45 \mathrm{t} / \mathrm{m}^{3}\right.$ - item 5.8$)$.

Pelos valores de perdas e resíduos totais da fábrica, observou-se falha no formulário para levantar essas informações. Assim, os valores de resíduo levantados não foram conclusivos, o que impossibilitou o cálculo desse indicador.

Por esse motivo, e como o dado de perda de produção é importante para as empresas, decidiu-se criar o indicador de perdas. Para a estimativa da perda de cada bloco selecionado no estudo, a massa total de peças perdidas foi calculada multiplicando a massa total por produto pela porcentagem de perdas informadas por produto. Com a massa total de perda por produto, em quilograma, estimou-se o indicador de perdas por peça dividindo esse valor pela quantidade total de peças referentes a cada produto. $\mathrm{O}$ indicador de perdas para os BCP foi obtido pela multiplicação do resultado por unidade de produto pela quantidade de peças que compõe $1 \mathrm{~m}^{2}$, específico para cada empresa. 


\section{Análises dos dados}

\subsection{Balanço de massa entre insumos e produtos informados}

Os dados levantados pelo formulário foram analisados para verificar sua uniformidade. O objetivo foi comparar os consumos dos produtos selecionados no estudo com o total de materiais que entraram na fábrica. Algumas estimativas foram realizadas de modo a permitir essas análises.

As empresas indicaram a representatividade aproximada dos produtos selecionados em relação a sua produção total. Esse valor foi verificado através dos dados coletados. Nessa comparação, a representatividade das empresas 11, 14, 26 e 27 mostrou-se inferior ao informado e da empresa 18, acima. A empresa 32 não informou a produção total da fábrica, apenas a porcentagem dos produtos analisados em relação ao total. Assim, não foi possível estimar a massa total da fábrica nem verificar sua representatividade em massa.

A empresa 19 não pôde informar a produção total da fábrica no período devido a mudanças em seu banco de dados, apenas sua representatividade. Nas análises de balanço de massa das entradas, constatou-se que os produtos do estudo representavam a produção total da fábrica, o que não corresponde à realidade da empresa, já que ela fabrica outros produtos. Assim, alguns indicadores não puderam ser calculados pela falta da produção total da fábrica (energia, emissão de $\mathrm{CO}_{2} \mathrm{e}$ consumo de água).

As porcentagens de cimento, agregados e de materiais secos referentes aos produtos selecionados foram calculadas através dos consumos informados e das quantidades estimadas por bloco. Os resultados foram comparados com a representatividade da massa total desses produtos em relação à massa total da fábrica para avaliação da qualidade e precisão dos dados.

Para análise do consumo de cimento total da fábrica e o calculado para os produtos analisados, estimou-se a parcela de cimento da fábrica destinada a esses produtos $\left(\mathrm{m}_{\text {cim.prod }} / \mathrm{m}_{\mathrm{cim} . \mathrm{fab}}\right)$. Comparando esse valor com a representatividade dos produtos da fábrica, algumas observações importantes são apresentadas na Tabela 16. Essas informações são ilustradas na Figura 9, sendo os pontos vermelhos os consumos totais de cimento dos produtos analisados e os pontos azuis indicam a representatividade desses produtos na produção total da fábrica (faixa azul). 
Quando os pontos estão próximos, entende-se que a representatividade do consumo de cimento nos produtos em análise está proporcional à desses produtos na produção total da fábrica. Quando esses pontos estão distantes, significa que maior ou menor consumo de cimento de toda a fábrica é destinado apenas à fabricação desses produtos. Se o ponto vermelho está acima do ponto em azul, significa que maior parte do cimento é destinada aos produtos analisados, mas se estiver abaixo do azul, o contrário pode ser suposto. Quando o ponto vermelho está localizado fora da barra azul significa que o consumo calculado para os produtos é superior ao consumo total da fábrica, o que pode indicar erro de inventário.

Tabela 16 - Análises do consumo de cimento: comparação entre consumo total na fábrica e consumo nos produtos analisados.

\begin{tabular}{cc}
\hline Observação & Empresas \\
\hline$\%$ cimento $\approx \%$ produtos & $1,3,4,6,7,8,10,11,12,13,15,16,19$, \\
& $20,21,22,26,27,28,29,30,33,34$ \\
\hline$\%$ produto $(100 \%)>\%$ cimento & 2,5 \\
\hline$\%$ cimento $(\approx 100 \%)>\%$ produtos & 17 \\
\hline$\%$ cimento $(>100 \%)>\%$ produtos & 23,24 \\
\hline$\%$ cimento $(\approx 100 \%): \%$ dos produtos não informada & 32 \\
\hline$\%$ cimento $>\%$ produtos & 14 \\
\hline$\%$ cimento $<\%$ produtos & $18,25,31$ \\
\hline
\end{tabular}

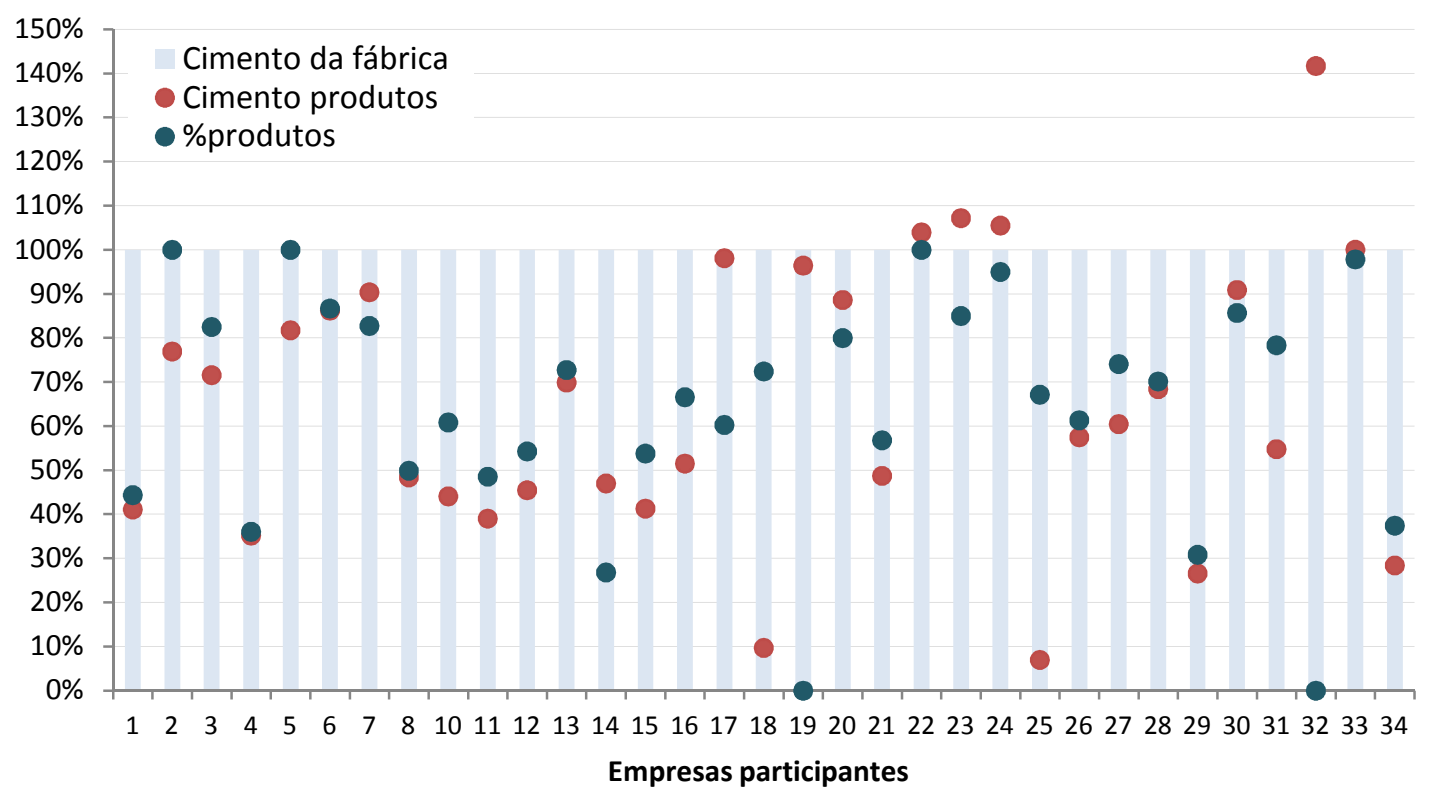

Figura 9 - Comparação entre a massa de cimento utilizada na fabricação dos produtos analisados com a massa de cimento total utilizada na fábrica e a porcentagem que os produtos analisados representam na massa total dos produtos. 
Com o consumo de agregados totais da fábrica e o estimado para os produtos selecionados, calculou-se a parcela de agregados da fábrica ( $\left.m_{\text {agreg.prod }} / m_{\text {agreg.fab }}\right)$. Comparando esse valor com a representatividade dos produtos em análise na fábrica, algumas questões são apresentadas na Tabela 17 e ilustradas na Figura 10. Os pontos em laranja correspondem à porcentagem de agregados estimados nos produtos em análise em relação aos agregados totais da fábrica. Os pontos em azul são as representatividades desses produtos na produção total.

Assim como no consumo de cimento, quando os pontos estão próximos pode-se concluir que a representatividade do consumo de agregados nos produtos em análise está proporcional à porcentagem desses produtos na produção total da fábrica. Já quando estão distantes, pode indicar que mais ou menos de todo agregado consumido pela fábrica é destinado apenas aos produtos em análise. Se o ponto laranja está acima do ponto em azul, significa que são consumidos mais agregados nos produtos analisados do que nos demais produtos, mas quando está abaixo o contrário pode ser concluído. O ponto laranja localizado fora da barra azul significa que o consumo calculado para os produtos é superior ao consumo total da fábrica, o que pode indicar erro de inventário. 
Tabela 17 - Análises de consumo de agregados: comparação na fábrica e nos produtos analisados.

\begin{tabular}{cc}
\hline Observação & Empresas \\
\hline$\%$ agregados $\approx \%$ produtos & $1,3,4,6,7,8,10,11,12,13,15,16$, \\
& $19,21,26,27,28,29,31,33,34$ \\
\hline$\%$ produto $(100 \%)>\%$ agregados & 2,5 \\
\hline$\%$ agregados $(\approx 100 \%)>\%$ produtos & 17 \\
\hline$\%$ agregados $(>100 \%)>\%$ produtos & $20,22,23,24,30$ \\
\hline da agregados $(\approx 100 \%): \%$ dos produtos não informa- & 32 \\
\hline$\%$ agregados $>\%$ produtos & 14 \\
\hline$\%$ agregados $<\%$ produtos & 18,25 \\
\hline
\end{tabular}

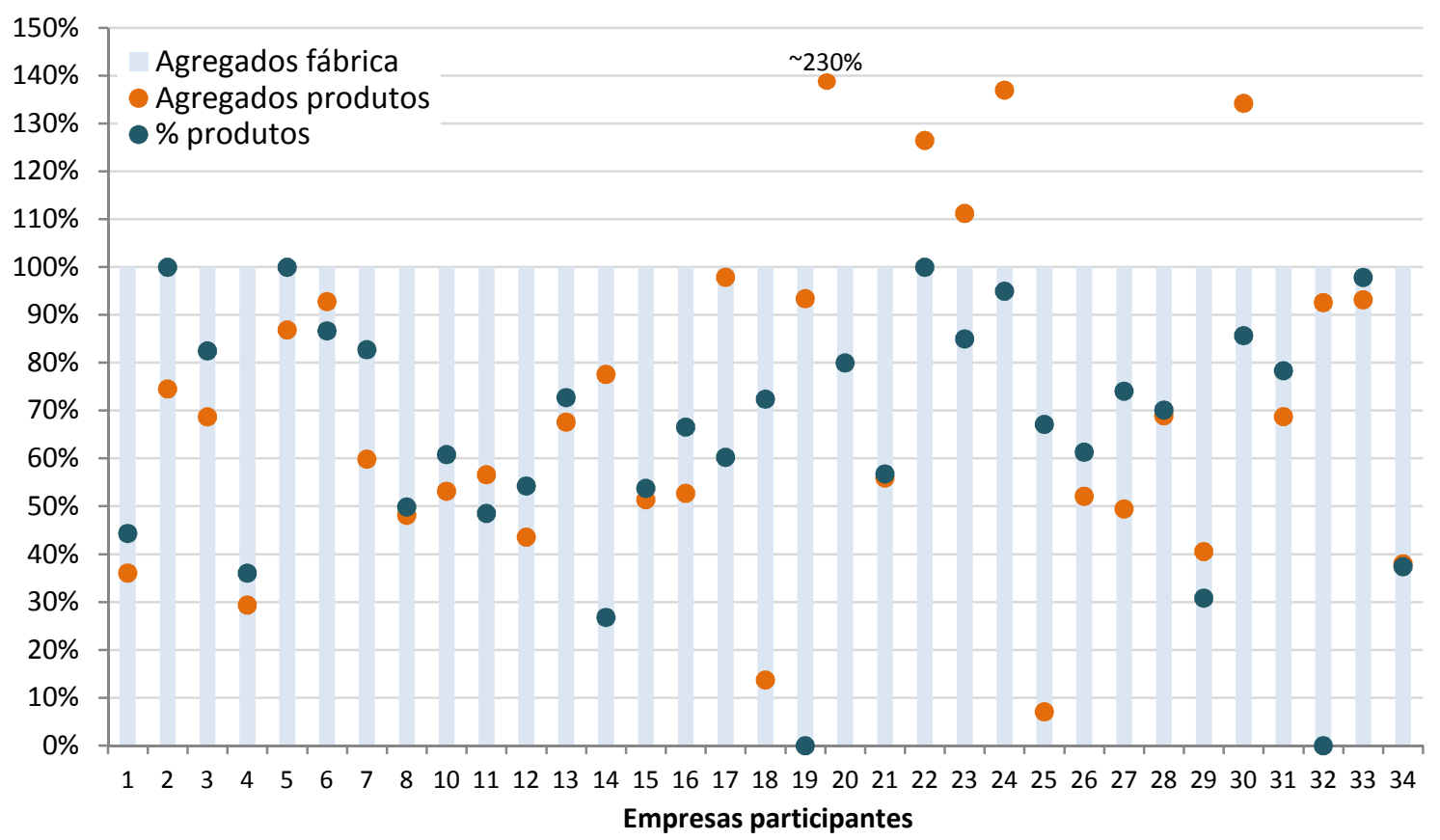

Figura 10 - Comparação entre a massa de agregados utilizada na fabricação dos produtos analisados com a massa total de agregados usados na fábrica e a porcentagem que os produtos analisados representam na massa total dos produtos.

Analisando o consumo de materiais secos totais da fábrica e o estimado para os produtos analisados, que é a somatória da massa de cimento e de agregados, estimou-se quanto da fábrica é destinado a esses produtos $\left(\mathrm{m}_{\mathrm{ms} \text {.prod }} / \mathrm{m}_{\mathrm{ms} \text {.fab }}\right.$ ). Algumas conclusões são apresentadas na Tabela 18 e na Figura 11. Os pontos verdes são os consumos totais de materiais secos estimados para os produtos em análise e os pontos azuis correspondem à representatividade dos mesmos na produção total da fábrica.

A interpretação é similar às análises anteriores. Quando os pontos estão próximos 
significa que a representatividade do consumo de materiais secos nos produtos analisados é proporcional a dos produtos no total da fábrica. Já quando estão distantes, pode-se concluir que maior ou menor quantidade de material seco é destinada apenas à fabricação desses produtos. O ponto verde acima do ponto azul mostra que são consumidas mais matérias-primas nos produtos analisados do que nos demais. Caso o ponto verde esteja abaixo do azul, o contrário pode ser concluído. O consumo de matérias-primas estimado para os produtos é superior ao consumo total da fábrica quando o ponto verde está localizado fora da barra azul, o que pode indicar erro de inventário.

Tabela 18 - Análises de consumo de materiais secos: comparação na fábrica e nos produtos analisados.

\begin{tabular}{cc}
\hline Observação & Empresas \\
\hline$\%$ materiais secos $\approx \%$ produtos & $\begin{array}{c}1,3,4,5,6,7,8,10,11,12,13,15,16, \\
19,21,26,27,28,29,31,33,34\end{array}$ \\
\hline$\%$ produto $(100 \%)>\%$ materiais secos & 2 \\
\hline$\%$ materiais secos $(\geq 100 \%)>\%$ produtos & $17,20,22,23,24,30$ \\
\hline$\%$ materiais secos $>\%$ produtos & 14 \\
\hline$\%$ materiais secos $<\%$ produtos & 18,25 \\
\hline
\end{tabular}

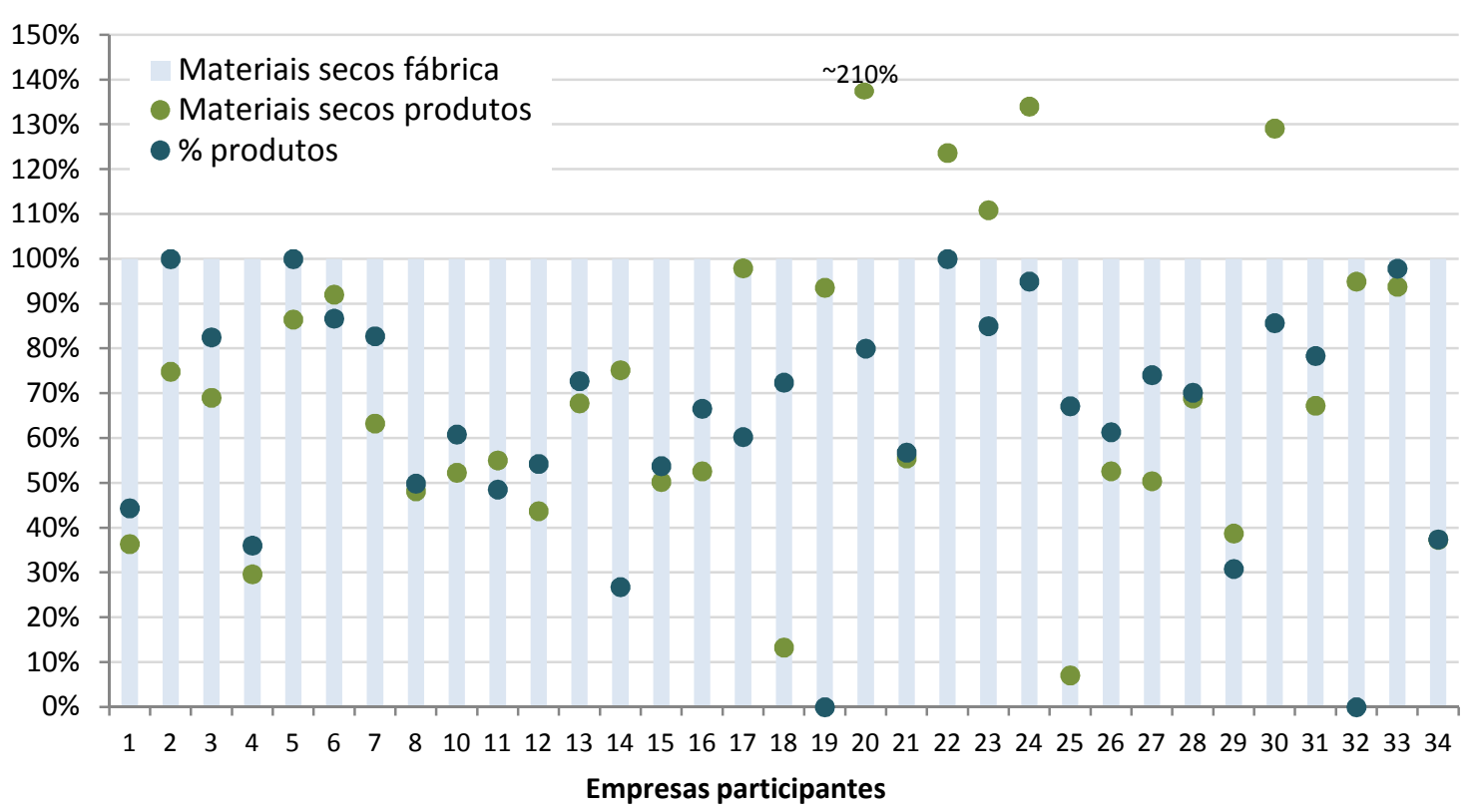

Figura 11 - Comparação entre a massa de materiais secos utilizados na fabricação dos produtos analisados com a massa total de materiais secos utilizados na fábrica e a porcentagem que os produtos analisados representam na massa total dos produtos. 
A massa dos produtos é majoritariamente composta por cimento, agregados e água (umidade relativa do ar e reação com cimento). Logo, a massa total dos produtos selecionados deve ser ligeiramente superior à massa total de matérias-primas usadas em sua produção. Esse valor deve ser próximo ao total de materiais utilizados pela fábrica caso a empresa produza somente os produtos selecionados para o projeto.

As empresas 1, 2, 4, 6, 11, 15, 17, 18, 21, 22, 23, 24, 28, 29 e 31 informaram sua produção total em número de peças, sendo sua massa total de produtos estimada. A empresa 17 informou que os consumos de cimento e agregados inseridos no formulário estão relacionados a toda produção da fábrica. No entanto, as matériasprimas levantadas para os produtos analisados correspondem à mesma quantidade informada para toda fábrica. Já o consumo de materiais referentes aos blocos analisados da empresa 18 é muito inferior ao consumo total da fábrica.

Os consumos de cimento e agregados levantados para as peças selecionadas da empresa 19 são próximos a massa total informada para toda a fábrica. No entanto, apesar de não ter sido informada a produção total no período analisado, sabe-se que são produzidos outros produtos. Assim, pode-se concluir que foram passados dados apenas relacionados aos blocos estudados.

O total de cimento dos produtos analisados da empresa 20 apresentou-se coerente com o consumo total da fábrica, mas o total de agregados está muito acima do total da fábrica. No caso da empresa 22, o consumo de cimento calculado mostrou-se um pouco superior ao total da fábrica. Como foi informado que os produtos selecionados correspondem a $100 \%$ da produção da fábrica, o dado está coerente. Já em relação ao consumo de agregados, observa-se que o consumo estimado está muito acima do total da fábrica.

As empresas 23 e 24 apresentaram os consumos de materiais dos produtos analisados superior aos valores informados como totais da fábrica, apesar dos produtos selecionados não corresponderem à produção total da fábrica. O consumo de materiais estimados para a empresa 25 foi muito inferior ao total utilizado pela fábrica, mesmo considerando que foram fabricados outros produtos.

O consumo de cimento dos produtos estudados da empresa 30 foi coerente com 0 consumo total da fábrica, mas o de agregados apresentou-se superior. O inverso foi 
observado com a empresa 32, que apresentou consumo de cimento superior ao total da fábrica, mas consumo de agregados próximo. No caso dessa fábrica, não se sabe se outros produtos são fabricados, já que a produção total não foi informada.

Deve-se considerar que o único consumo informado referente por tipo de produto foi o de cimento. O consumo de agregados e a proporção de cada tipo foram estimados.

\subsection{Análise da massa informada por peça}

A massa dos blocos informada pela empresa é o dado base para o levantamento do número de peças quando o total produzido é informado em massa, do consumo de cimento quando suas quantidades são informadas em porcentagem e para a alocação dos consumos referentes à toda fábrica. Assim, qualquer distorção do valor da massa por bloco pode ocasionar em erro nos resultados dos indicadores. Por essa razão, uma análise das massas dos produtos foi realizada.

A ABCP forneceu uma tabela contendo a massa de referência de alguns produtos para comparação com as massas informadas pelas empresas ${ }^{32}$. A variação das massas dos BCP retangulares (35 MPa) é apresentada na Figura 12. Há dispersão entre as empresas, apesar de todos os produtos possuírem a mesma resistência e dimensões similares (com diferença máxima de $1 \mathrm{~cm}$ ). Comparando esses dados com os valores da ABCP para as peças de $6 \mathrm{~cm}$ de espessura, verifica-se que todas as empresas encontram-se abaixo da massa de referência. Não foi informada a massa de referência para a peça de $10 \mathrm{~cm}$, mas observa-se que uma empresa apresenta diferença de $50 \mathrm{~kg} / \mathrm{m}^{2}$ em relação à empresa que possui menor massa, cuja variação com as outras empresas é de no máximo $15 \mathrm{~kg} / \mathrm{m}^{2}$.

\footnotetext{
${ }^{32}$ Contato com o Eng. Claudio Oliveira Silva da ABCP: dados da atividade de controle de qualidade realizado pela $A B C P$ dos blocos certificados.
} 


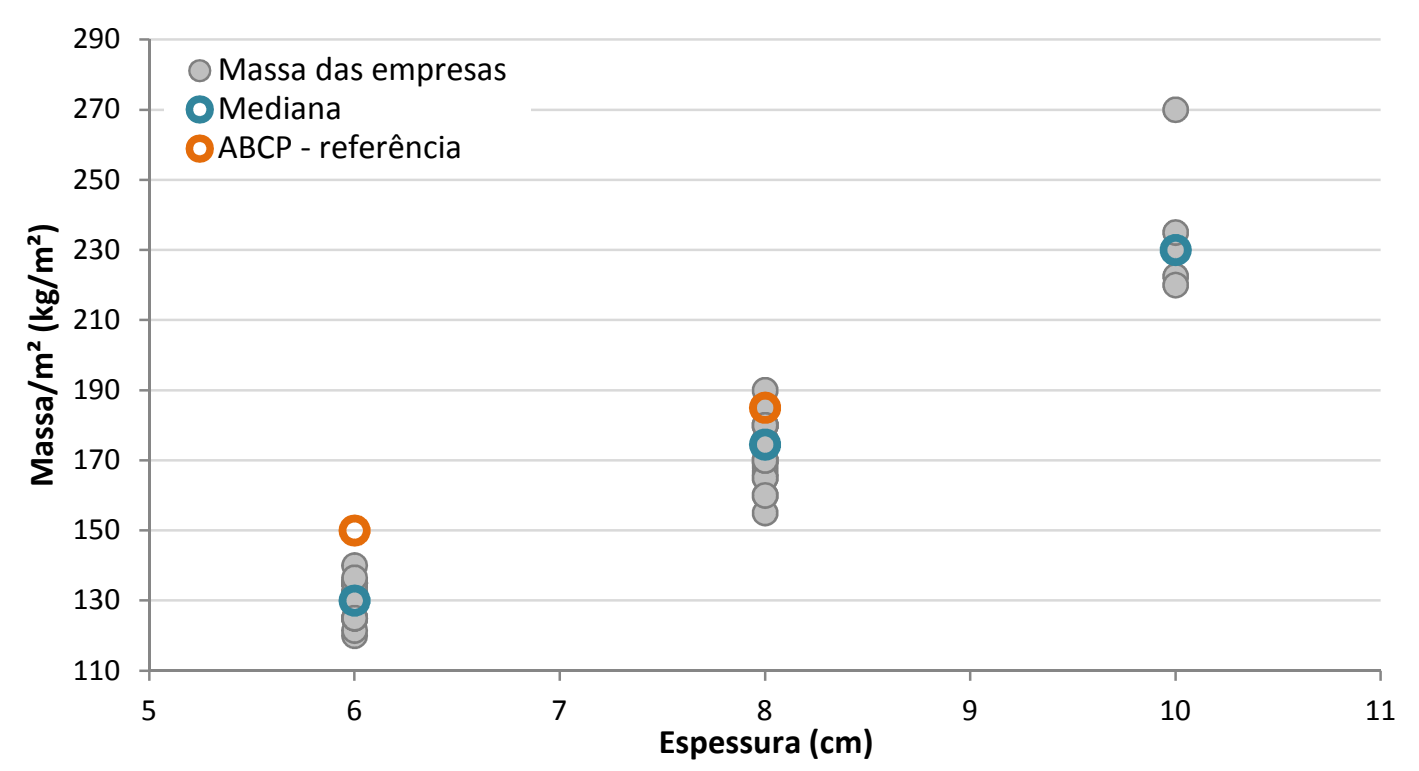

Figura 12 - Variação da massa informada e dado da ABCP - Bloco retangular para pavimento (35 $\mathrm{MPa})$. A variabilidade é função da variação da densidade das formulações e dos agregados.

A Figura 13 apresenta a variação das massas entre as empresas para os blocos $\mathrm{BCP}$ de 16 faces (35 MPa). O mesmo observado nos blocos retangulares é verificado, atentando para maior dispersão entre as empresas. Isso pode ser decorrente da maior variação nas dimensões das peças (diferença de $1,5 \mathrm{~cm}$ na largura e 4,5 no comprimento), pois não há uma padronização, apesar de apresentarem o mesmo formato. Não foram informados dados de massa de referência da $\mathrm{ABCP}$ para essas peças.

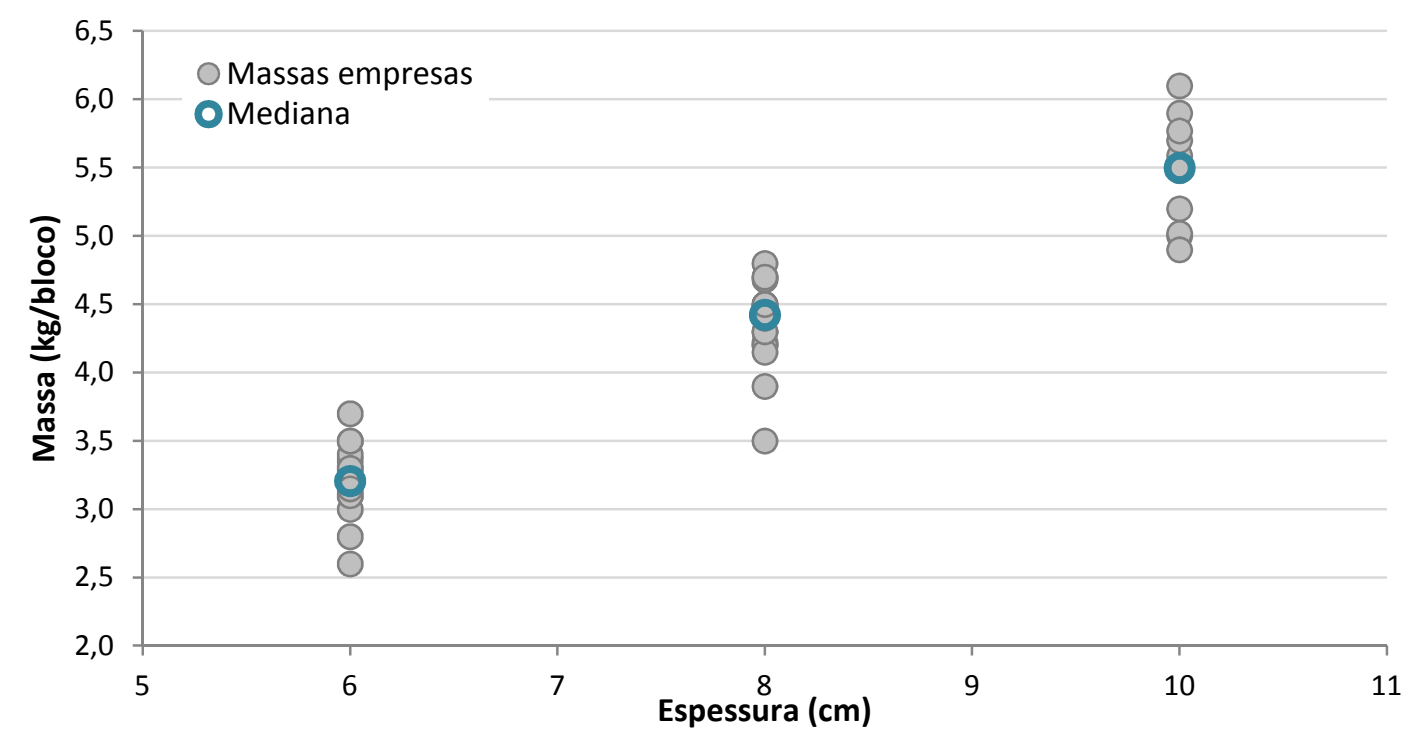

Figura 13 - Variação da massa informada - Blocos para pavimento de 16 faces ( $35 \mathrm{MPa}$ ). A variabilidade é função da variação das dimensões das peças e da variação da densidade das formulações e dos agregados. 
A variação da massa dos blocos estruturais é apresentada na Figura 14. Observa-se que o valor da massa de referência da ABCP é bem próximo da mediana, coincidindo em alguns casos. Há grande variação de massa entre as informações declaradas pelas empresas, apesar dos blocos apresentarem as mesmas resistências e dimensões padronizadas, especificadas pela norma NBR 6136 (ABNT, 2007). Importante observar que as pequenas variações toleradas pela mesma podem ocasionar em considerável variação de massa.

Além disso, o tipo de equipamento utilizado para a moldagem da peça influencia em sua massa, pois quanto mais eficiente for a compactação, menor a quantidade de poros, maior a massa do bloco. Como a resistência mecânica também é controlada pelo teor de cimento e empacotamento dos grãos - que influenciam diretamente na porosidade - a proporção e os tipos de agregados utilizados também são importantes na densidade do bloco.

Algumas vibroprensas não apresentam a eficiência necessária para o alcance da classe de resistência característica desejada pela empresa. Na prática, cada empresa define uma estratégia para obter a resistência mecânica mínima combinando porosidades (via vibração ou formulação) e a espessura das paredes.

A menor massa informada para os blocos de $8 \mathrm{MPa}$ e $10 \mathrm{MPa}$ pertencem à mesma empresa, sendo considerado baixo para as respectivas resistências. Já a maior massa levantada para o bloco de $12 \mathrm{MPa}$ é considerada fora do usual.

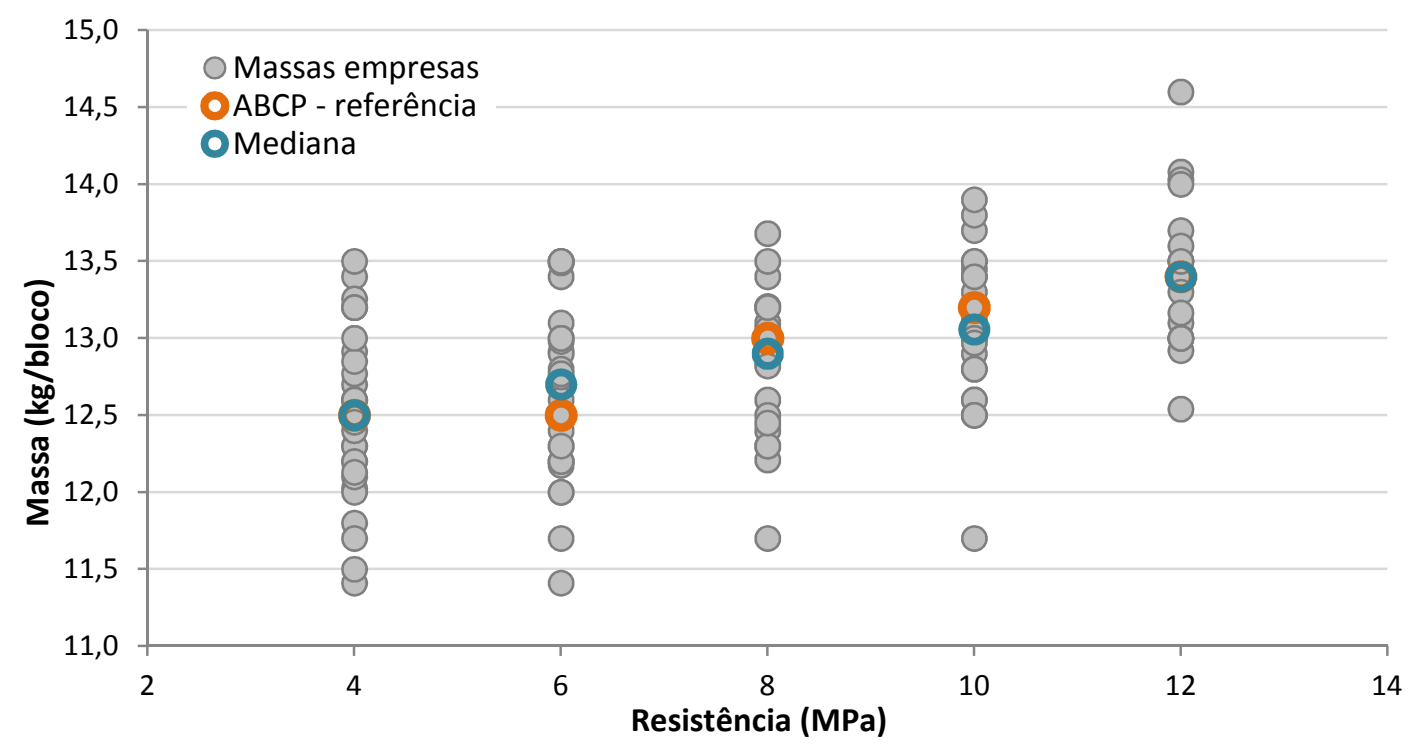

Figura 14 - Variação da massa informada - Blocos estruturais. A variabilidade é função da variação da densidade das formulações e dos agregados. Desgaste de formas é fator importante. 
A Figura 15 apresenta a variação de massa dos blocos de vedação de $2 \mathrm{MPa}$, que possuem diferentes dimensões. Observa-se dispersão maior em comparação com os blocos estruturais, com diferença entre empresas superior a $3 \mathrm{~kg}$. Acredita-se que o maior valor informado para o bloco com largura de $9 \mathrm{~cm}$ esteja incorreto, pois a empresa responsável (19) informou essa mesma massa para o bloco de $14 \mathrm{~cm}$ de largura.

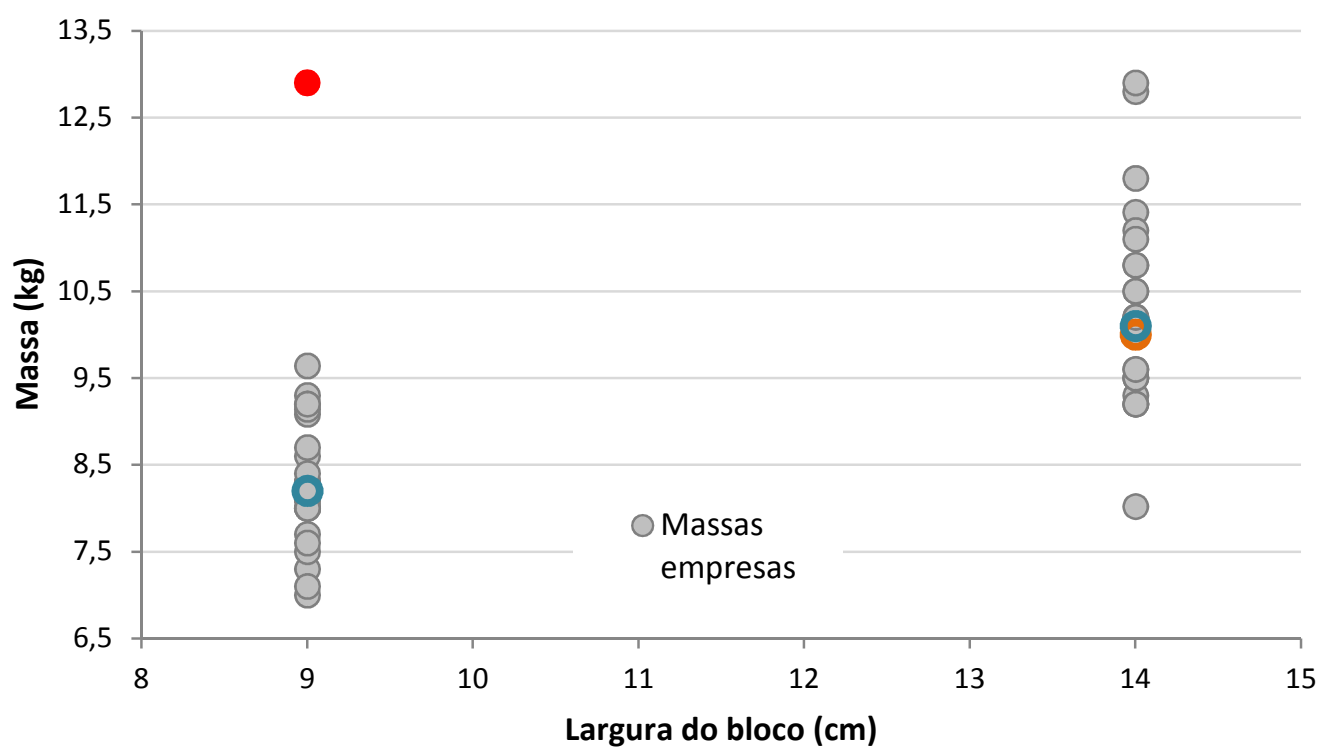

Figura 15 - Variação da massa informada - Blocos de vedação. A variação é associada à espessura de parede, além dos fatores de densidade. $O$ dado referente ao bloco de $9 \mathrm{~cm}$ com massa de $13 \mathrm{~kg}$ pertence à empresa 19, que forneceu o mesmo valor para blocos de 14 e $9 \mathrm{~cm}$ - acredita-se que seja erro de inventário.

\subsection{Análise das perdas e resíduos informados}

A perda total dos produtos selecionados para o estudo foi levantada e comparada com o valor informado como perda/resíduo total da fábrica. Na Tabela 19 observa-se que as empresas $17,20,22,23,24,25$ e 30 apresentam a massa de perdas totais da fábrica inferior à massa de perdas dos produtos analisados. Essa diferença pode ser justificada porque no formulário os termos "perdas" e "resíduos" foram utilizados com o mesmo significado, embora nem toda perda se torne resíduo. Essa inconsistência pode ter origem nas diferentes considerações de levantamento por parte das empresas. Algumas podem ter informado suas perdas, enquanto outras informaram a quantidade de resíduo de produção que sai da fábrica. Essa diferença não ficou definida de forma clara no formulário. 
As empresas 19 e 32 não tiveram suas massas de perdas totais da fábrica analisados por falta de dados. Apesar de a primeira informar sua perda em porcentagem, não pôde informar a massa total de produção do período. A segunda não informou dados de perdas referentes ao período solicitado para estudo (12 meses), apenas referente a dois meses.

As empresas 12, 16, 20 e 22 informaram a perda total da fábrica em volume, sendo adotada a densidade aparente do agregado reciclado $\left(1,45 \mathrm{t} / \mathrm{m}^{3}\right.$ - ver item 5.8$)$ para sua conversão em massa. As empresas 1, 4, 6, 7, 13, 14, 26, 27, 28, 29, 30, 31 e 33 apresentaram suas perdas em porcentagem, sendo suas massas calculadas com base na massa total de produtos das fábricas. As demais empresas informaram suas perdas totais em massa. 
Tabela 19 - Comparação entre as perdas de produção dos produtos analisados e as perdas/resíduos de produção total da empresa. As empresas podem ter feito diferentes considerações neste último valor, incluindo dados referentes a perdas de produção que não se convertem em resíduos.

\begin{tabular}{|c|c|c|c|c|c|}
\hline Empresa & $\begin{array}{c}\text { Perdas dos } \\
\text { produtos } \\
\text { analisados }(t)\end{array}$ & $\begin{array}{c}\text { Perda/resíduo } \\
\text { total da } \\
\text { fábrica (t) }\end{array}$ & $\begin{array}{l}\text { Diferença } \\
\text { (t) }\end{array}$ & $\begin{array}{c}\% \text { das perdas } \\
\text { atribuídas aos } \\
\text { produtos } \\
\text { analisados }\end{array}$ & $\begin{array}{c}\text { \% produtos } \\
\text { analisados na } \\
\text { produção da } \\
\text { fábrica }\end{array}$ \\
\hline 1 & 1.082 & 1.846 & 765 & $59 \%$ & $44 \%$ \\
\hline 2 & 1.107 & 1.326 & 219 & $84 \%$ & $100 \%$ \\
\hline 3 & 967 & 1.172 & 205 & $83 \%$ & $83 \%$ \\
\hline 4 & 400 & 1.110 & 710 & $36 \%$ & $36 \%$ \\
\hline 5 & 565 & 2.200 & 1.635 & $26 \%$ & $100 \%$ \\
\hline 6 & 334 & 531 & 197 & $63 \%$ & $87 \%$ \\
\hline 7 & 179 & 466 & 287 & $38 \%$ & $83 \%$ \\
\hline 8 & 2.474 & 2.535 & 61 & $98 \%$ & $50 \%$ \\
\hline 10 & 262 & 268 & 5 & $98 \%$ & $61 \%$ \\
\hline 11 & 469 & 1.745 & 1.275 & $27 \%$ & $49 \%$ \\
\hline 12 & 724 & 2.400 & 1.676 & $30 \%$ & $54 \%$ \\
\hline 13 & 415 & 560 & 145 & $74 \%$ & $73 \%$ \\
\hline 14 & 243 & 906 & 663 & $27 \%$ & $27 \%$ \\
\hline 15 & 1.151 & 2.160 & 1.009 & $53 \%$ & $54 \%$ \\
\hline 16 & 220 & 436 & 217 & $50 \%$ & $67 \%$ \\
\hline 17 & 622 & 230 & -392 & $>100 \%$ & $60 \%$ \\
\hline 18 & 431 & 6.600 & 6.169 & $7 \%$ & $72 \%$ \\
\hline 19 & 1.802 & 0 & -1.802 & Não informado & Não informado \\
\hline 20 & 1.295 & 1.163 & -132 & $>100 \%$ & $80 \%$ \\
\hline 21 & 84 & 1.000 & 916 & $8 \%$ & $57 \%$ \\
\hline 22 & 613 & 389 & -224 & $>100 \%$ & $100 \%$ \\
\hline 23 & 2.088 & 1.848 & -240 & $>100 \%$ & $85 \%$ \\
\hline 24 & 1.081 & 340 & -741 & $>100 \%$ & $95 \%$ \\
\hline 25 & 67 & 0,8 & -66 & $>100 \%$ & $67 \%$ \\
\hline 26 & Não informado & 110 & 110 & $?$ & $61 \%$ \\
\hline 27 & Não informado & 45 & 45 & $?$ & $74 \%$ \\
\hline 28 & 853 & 1.216 & 363 & $70 \%$ & $70 \%$ \\
\hline 29 & 753 & 2.471 & 1.718 & $30 \%$ & $31 \%$ \\
\hline 30 & 3.287 & 2.050 & -1.237 & $>100 \%$ & $86 \%$ \\
\hline 31 & 273 & 510 & 238 & $53 \%$ & $78 \%$ \\
\hline 32 & 1.528 & 0 & -1.528 & $>100 \%$ & Não informado \\
\hline 33 & 2.054 & 2.267 & 213 & $91 \%$ & $98 \%$ \\
\hline 34 & 159 & 530 & 371 & $30 \%$ & $37 \%$ \\
\hline
\end{tabular}

A Tabela 20 apresenta o destino das perdas da produção, que não são necessariamente resíduos. O material perdido pode ser reutilizado, pela própria empresa ou por terceiros ou descartado em aterros. 
Tabela 20 - Destinação das perdas de produção. As perdas que retornam para a fabricação de outros produtos sem que sofram qualquer processamento (ainda no estado fresco) podem não ter sido classificados de resíduos.

\begin{tabular}{|c|c|c|c|c|c|c|}
\hline \multirow[b]{3}{*}{ 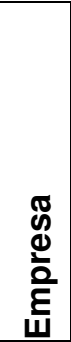 } & \multirow[b]{3}{*}{ 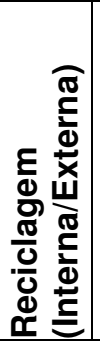 } & \multirow[b]{3}{*}{$\begin{array}{l}\frac{0}{\frac{2}{2}} \\
\stackrel{\text { d }}{<}\end{array}$} & \multirow{2}{*}{\multicolumn{3}{|c|}{$\begin{array}{c}\text { Reciclagem } \\
\text { Uso }\end{array}$}} & \multirow[b]{3}{*}{ Observações } \\
\hline & & & & & & \\
\hline & & & 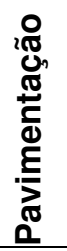 & 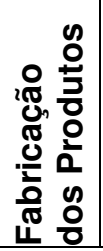 & 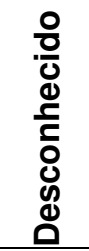 & \\
\hline 1 & $E$ & & & & $\mathrm{X}$ & Doação para Prefeitura Municipal \\
\hline 2 & $\mathrm{I}$ & & $x$ & & & Pavimentação da fábrica \\
\hline 3 & I & & & & $\mathrm{X}$ & Não informa como o material é reciclado internamente \\
\hline 4 & 1 & $10 \%$ & & $90 \%$ & & Fabricação dos produtos e entregue para pedreiras \\
\hline 5 & 1 & & & & $\mathrm{X}$ & Não informa como o material é reciclado internamente \\
\hline 6 & $E$ & & & & $\mathrm{x}$ & Doação \\
\hline 7 & $\mathrm{I}$ & & $\mathrm{X}$ & & & Pavimentação da fábrica \\
\hline 8 & $\mathrm{E}$ & & & & $\mathrm{X}$ & Doação \\
\hline 10 & $\mathrm{I} / \mathrm{E}$ & & & $\mathrm{X}$ & $\mathrm{X}$ & Fabricação dos blocos de vedação e entregue para Prefeitura \\
\hline 11 & $\mathrm{I} / \mathrm{E}$ & & $\begin{array}{l}83 \\
\%\end{array}$ & $17 \%$ & & Fabricação dos produtos e para pavimentação de estradas \\
\hline 12 & 1 & & & & $\mathrm{X}$ & Não informa como o material é reciclado internamente \\
\hline 13 & 1 & & & & $\mathrm{X}$ & Não informa como o material é reciclado internamente \\
\hline 14 & $\mathrm{E}$ & & & & $\mathrm{X}$ & Doação \\
\hline 15 & $\mathrm{E}$ & & $\mathrm{X}$ & & & Entregue para Prefeitura Municipal (pavimentação) \\
\hline 16 & $\mathrm{I} / \mathrm{E}$ & & & & $\mathrm{X}$ & Uso interno na fábrica e entregue para coletores registrados \\
\hline 17 & $\mathrm{E}$ & & & & $\mathrm{X}$ & Reciclagem por terceiros \\
\hline 18 & $\mathrm{E}$ & & & & $\mathrm{X}$ & Reciclagem por terceiros \\
\hline 19 & & & & & & Não informado \\
\hline 20 & $\mathrm{E}$ & & & & $\mathrm{X}$ & Doação \\
\hline 21 & $\mathrm{E}$ & & & & $\mathrm{X}$ & Reciclagem por terceiros \\
\hline 22 & & & & & & Outras (não especificado) \\
\hline 23 & 1 & & & & $\mathrm{X}$ & Não informa como o material é reciclado internamente \\
\hline 24 & $\mathrm{I} / \mathrm{E}$ & & & $20 \%$ & $80 \%$ & Fabricação dos produtos e entregue para Prefeitura Municipal \\
\hline 25 & & $\mathrm{X}$ & & & & Aterro próprio \\
\hline 26 & 1 & & & & $\mathrm{X}$ & Não informa como o material é reciclado internamente \\
\hline 27 & 1 & & & & $\mathrm{X}$ & Não informa como o material é reciclado internamente \\
\hline 28 & & & & & & Apenas informou a cidade de destino \\
\hline 29 & $\mathrm{I}$ & & & & $\mathrm{X}$ & Não informa como o material é reciclado internamente \\
\hline 30 & $\mathrm{I}$ & & & & $\mathrm{X}$ & Não informa como o material é reciclado internamente \\
\hline 31 & 1 & & & & $\mathrm{X}$ & Não informa como o material é reciclado internamente \\
\hline 32 & $\mathrm{I}$ & & & & $\mathrm{X}$ & Não informa como o material é reciclado internamente \\
\hline 33 & $\mathrm{I}$ & & & & $\mathrm{X}$ & Não informa como o material é reciclado internamente \\
\hline 34 & & & & & & Outras (não especificado) \\
\hline
\end{tabular}


Pela Tabela 20 conclui-se que $85 \%$ das empresas reciclam suas perdas de produção e $6 \%$ depositam esse material em aterro. Uma empresa informou que utiliza agregado reciclado produzido a partir das suas perdas, no entanto não indicou a realização de reciclagem interna, apenas que doa esse material.

Nem todas as empresas informaram dados sobre resíduos que não fossem cimentícios. Na Tabela 21 alguns são apresentados, onde RR significa resíduo reciclado ou reutilizado (interna ou externamente) e Des significa resíduo descartado. Nota-se que todo material descartado pode ser reciclado ou reutilizado. 
Tabela 21 - Destinação dos resíduos do processo de produção dos blocos de concreto - RR para resíduo reciclado ou reutilizado e Des para resíduo descartado.

\begin{tabular}{|c|c|c|c|c|c|c|c|c|c|c|}
\hline \multirow{2}{*}{ 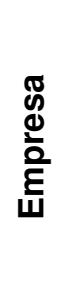 } & \multicolumn{5}{|c|}{ Embalagem } & \multicolumn{3}{|c|}{ Oleosos } & \multirow{2}{*}{ 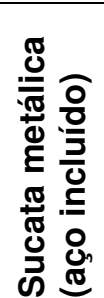 } & \multirow{2}{*}{ 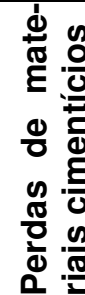 } \\
\hline & $\frac{\frac{\infty}{d}}{\overline{\bar{\sigma}}}$ & $\begin{array}{l}\frac{\pi}{\bar{d}} \\
\frac{\pi}{0} \\
\Sigma\end{array}$ & $\begin{array}{l}0 \\
\stackrel{0}{0} \\
\frac{0}{0} \\
\frac{\pi}{\alpha} \\
\frac{\pi}{\alpha}\end{array}$ & 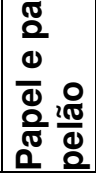 & 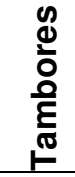 & $\frac{8}{0}$ & $\begin{array}{l}\underset{\mathbb{N}}{\mathbb{N}} \\
\frac{\mathbb{\pi}}{\mathbb{U}}\end{array}$ & $\begin{array}{l}\frac{\pi}{0} \\
\frac{0}{0}\end{array}$ & & \\
\hline 1 & & & & & & & & & & $\mathrm{RR}$ \\
\hline 2 & & & $\mathrm{RR}$ & & & & & & & RR \\
\hline 3 & & & & & & & & & & $\mathrm{RR}$ \\
\hline 4 & & & & & & & & & & Des \\
\hline 5 & $\mathrm{RR}$ & & & & & & & $\mathrm{RR}$ & & $\mathrm{RR}$ \\
\hline 6 & $\mathrm{RR}$ & & $\mathrm{RR}$ & $\mathrm{RR}$ & & $\mathrm{RR}$ & & & $\mathrm{RR}$ & $\mathrm{RR}$ \\
\hline 7 & Des & & $\mathrm{RR}$ & $\mathrm{RR}$ & RR & $\mathrm{RR}$ & & & $R R$ & $\mathrm{RR}$ \\
\hline 8 & $\mathrm{RR}$ & & & & & & & & & $\mathrm{RR}$ \\
\hline 10 & & & & & & & & & & $\mathrm{RR}$ \\
\hline 11 & & & & & & & & & & $\mathrm{RR}$ \\
\hline 12 & & & & & & & & & & $\mathrm{RR}$ \\
\hline 13 & $\mathrm{RR}$ & & Des & & & & & & & $\mathrm{RR}$ \\
\hline 14 & & & & & & & & & & $\mathrm{RR}$ \\
\hline 15 & & & & & & & & & & $R R$ \\
\hline 16 & & & & & & & & & & $\mathrm{RR}$ \\
\hline 17 & & & & & & & & & & $\mathrm{RR}$ \\
\hline 18 & $\mathrm{RR}$ & & $\mathrm{RR}$ & & & & & & & $\mathrm{RR}$ \\
\hline 19 & & & & & & & & & & \\
\hline 20 & & $\mathrm{RR}$ & & & & & & & & $\mathrm{RR}$ \\
\hline 21 & $\mathrm{RR}$ & & & & Des & & & & & $\mathrm{RR}$ \\
\hline 22 & & $\mathrm{RR}$ & & Des & $\mathrm{RR}$ & & & & & \\
\hline 23 & $\mathrm{RR}$ & $\mathrm{RR}$ & & & RR & $\mathrm{RR}$ & $\mathrm{RR}$ & & & $\mathrm{RR}$ \\
\hline 24 & & & & & & & & & & $\mathrm{RR}$ \\
\hline 25 & & & & & & & & & & Des \\
\hline 26 & & & & & & & & & & $\mathrm{RR}$ \\
\hline 27 & & & & & & & & & & $\mathrm{RR}$ \\
\hline 28 & Des & & Des & & & & & & & \\
\hline 29 & & & & & & & & & & $\mathrm{RR}$ \\
\hline 30 & & & & & & & & & & $\mathrm{RR}$ \\
\hline 31 & & & & & & & & & & $\mathrm{RR}$ \\
\hline 32 & & & & & & & & & & $\mathrm{RR}$ \\
\hline 33 & & & & & & & & $\mathrm{RR}$ & & $\mathrm{RR}$ \\
\hline 34 & & $\mathrm{RR}$ & & & & Des & & & & \\
\hline
\end{tabular}

\subsection{Tipos de cimentos utilizados e cura térmica}

Os tipos de cimento utilizados pelas empresas são apresentados na Tabela 22 . Observa-se que uma empresa utiliza mais de um tipo de cimento. Apenas 12 das 33 empresas registraram o uso de cura térmica. Como essa informação estava associada aos insumos energéticos, pode ter tido casos em que a empresa não fez a especificação completa sobre o seu uso. Provavelmente devem ter casos 
intermediários, onde a cura térmica é realizada em períodos de menor temperatura, alta demanda ou apenas em alguns produtos.

Tabela 22 - Tipos de cimento utilizados pelas empresas associado ao uso de cura térmica.

\begin{tabular}{|c|c|c|}
\hline Empresa & Tipos de cimentos & Realiza cura térmica \\
\hline 1 & $\mathrm{CP} V$ & $\mathrm{X}$ \\
\hline 2 & $\mathrm{CPV}$ & \\
\hline 3 & $\mathrm{CPV}$ & \\
\hline 4 & $\mathrm{CPV}$ & \\
\hline 5 & $\mathrm{CPV}$ & \\
\hline 6 & $\mathrm{CPV}$ & $\mathrm{X}$ \\
\hline 7 & CP II-Z & \\
\hline 8 & CP II-Z; CP V & $\mathrm{X}$ \\
\hline 10 & $\mathrm{CP} \mathrm{V}$ & $X$ \\
\hline 11 & CP V & \\
\hline 12 & $\mathrm{CP} \mathrm{V}$ & $\mathrm{X}$ \\
\hline 13 & $\mathrm{CP} \mathrm{V}$ & \\
\hline 14 & $\mathrm{CPV}$ & \\
\hline 15 & $\mathrm{CP} \mathrm{V}$ & \\
\hline 16 & $\mathrm{CP} \mathrm{V}$ & \\
\hline 17 & CP II-E; CP V & \\
\hline 18 & CP IV & $\mathrm{X}$ \\
\hline 19 & $\mathrm{CP} \mathrm{V}$ & \\
\hline 20 & $\mathrm{CPV}$ & $\mathrm{X}$ \\
\hline 21 & $\mathrm{CP} \mathrm{V}$ & \\
\hline 22 & $\mathrm{CPV}$ & \\
\hline 23 & $\mathrm{CPV}$ & \\
\hline 24 & $\mathrm{CP} V$ & $\mathrm{X}$ \\
\hline 25 & CP III; CPV & \\
\hline 26 & $\mathrm{CP} \mathrm{V}$ & $\mathrm{X}$ \\
\hline 27 & $\mathrm{CP} V$ & $\mathrm{X}$ \\
\hline 28 & $\mathrm{CPV}$ & \\
\hline 29 & $\mathrm{CP} \mathrm{V}$ & $\mathrm{X}$ \\
\hline 30 & $\mathrm{CP} V$ & \\
\hline 31 & CP II-Z & \\
\hline 32 & $\mathrm{CP} \mathrm{V}$ & Não informou consumo de combustíveis \\
\hline 33 & $\mathrm{CPV}$ & $\mathrm{X}$ \\
\hline 34 & $\mathrm{CPV}$ & \\
\hline
\end{tabular}

\subsection{Análise da água informada para a composição do concreto}

O consumo da água de composição do concreto por peça foi solicitado em litros. As empresas 10 e 29 forneceram esse dado em porcentagem da massa e as empresas 26 e 27 em litros por $\mathrm{m}^{2}$. Na Tabela 23 e na Tabela 24 são apresentados os consumos de água fornecidos pelas empresas em litro/peça, assim como os valores máximos, mínimos e médios para cada tipo de produto. 
Tabela 23 - Quantidade de água de composição do concreto informada para os blocos para pavimento (35 MPa).

\begin{tabular}{|c|c|c|c|c|c|c|}
\hline \multirow{2}{*}{ Empresa } & \multicolumn{6}{|c|}{ Quantidade de água de composição do concreto por peça (litro/bloco) } \\
\hline & ret. $6 \mathrm{~cm}$ & ret. $8 \mathrm{~cm}$ & ret.10 cm & $16 f .6 \mathrm{~cm}$ & $16 f .8 \mathrm{~cm}$ & $16 f .10 \mathrm{~cm}$ \\
\hline 1 & 0,17 & 0,23 & - & 0,19 & 0,25 & - \\
\hline 2 & 0,15 & 0,20 & - & 0,15 & 0,20 & - \\
\hline 3 & 0,16 & 0,22 & - & 0,21 & 0,27 & 0,36 \\
\hline 4 & - & - & - & - & - & - \\
\hline 5 & 0,15 & 0,20 & - & - & 0,25 & - \\
\hline 6 & 0,15 & 0,19 & - & - & - & - \\
\hline 7 & 0,03 & 0,06 & - & 0,04 & 0,07 & - \\
\hline 8 & 0,10 & 0,14 & - & 0,13 & 0,18 & 0,22 \\
\hline 10 & 0,12 & 0,16 & - & - & - & - \\
\hline 11 & - & - & - & - & - & - \\
\hline 12 & 0,15 & 0,21 & - & - & 0,27 & - \\
\hline 13 & 0,14 & 0,18 & - & - & - & - \\
\hline 14 & - & - & - & - & - & - \\
\hline 15 & 0,16 & 0,20 & 0,27 & 0,18 & 0,26 & 0,30 \\
\hline 16 & 0,16 & 0,21 & - & 0,20 & 0,27 & - \\
\hline 17 & 0,15 & 0,19 & 0,24 & 0,19 & 0,24 & 0,30 \\
\hline 18 & 0,35 & - & - & 0,35 & 0,52 & 0,87 \\
\hline 19 & - & - & - & - & - & - \\
\hline 20 & - & - & - & - & - & - \\
\hline 21 & - & - & - & - & - & - \\
\hline 22 & 0,01 & 0,02 & - & 0,02 & 0,03 & 0,06 \\
\hline 23 & 0,28 & 0,40 & 0,49 & - & 0,53 & - \\
\hline 24 & 0,22 & 0,27 & - & 0,36 & 0,41 & - \\
\hline 25 & 0,40 & 0,40 & 0,40 & 0,40 & 0,40 & 0,40 \\
\hline 26 & 0,09 & 0,12 & - & - & - & - \\
\hline 27 & 0,09 & 0,12 & - & - & - & - \\
\hline 28 & 0,14 & 0,18 & 0,23 & 0,17 & 0,24 & 0,29 \\
\hline 29 & 0,43 & 0,51 & - & 0,53 & 0,70 & 0,91 \\
\hline 30 & 0,20 & 0,30 & - & 0,28 & 0,39 & - \\
\hline 31 & 0,14 & 0,18 & - & 0,15 & - & 0,33 \\
\hline 32 & 0,09 & 0,10 & - & 0,07 & 0,08 & 0,10 \\
\hline 33 & 0,02 & 0,04 & 0,05 & - & 0,04 & 0,05 \\
\hline 34 & - & - & - & - & - & - \\
\hline Máxima & 0,43 & 0,51 & 0,49 & 0,53 & 0,70 & 0,91 \\
\hline Média & 0,16 & 0,20 & 0,28 & 0,21 & 0,28 & 0,35 \\
\hline Mínima & 0,01 & 0,02 & 0,05 & 0,02 & 0,03 & 0,05 \\
\hline
\end{tabular}


Tabela 24 - Quantidade de água de composição do concreto informada para os blocos estruturais e de vedação.

\begin{tabular}{|c|c|c|c|c|c|c|c|}
\hline \multirow[b]{2}{*}{ Empresa } & \multicolumn{7}{|c|}{ Quantidade de água de composição do concreto por peça (litro/bloco) } \\
\hline & $\begin{array}{c}\mathrm{BCE} \\
4 \mathrm{MPa}\end{array}$ & $\begin{array}{c}\text { BCE } \\
6 \mathrm{MPa}\end{array}$ & $\begin{array}{c}\mathrm{BCE} \\
8 \mathrm{MPa}\end{array}$ & $\begin{array}{c}\text { BCE } \\
10 \mathrm{MPa}\end{array}$ & $\begin{array}{c}\text { BCE } \\
12 \mathrm{MPa}\end{array}$ & $\begin{array}{c}B C V \\
14 \mathrm{~cm}\end{array}$ & $\begin{array}{l}\text { BCV } \\
9 \mathrm{~cm}\end{array}$ \\
\hline 1 & 0,82 & 0,82 & 0,88 & 0,88 & 0,89 & 0,67 & 0,54 \\
\hline 2 & 0,55 & 0,55 & 0,55 & 0,55 & 0,55 & 0,40 & 0,35 \\
\hline 3 & 0,78 & 0,79 & 0,79 & 0,85 & - & 0,66 & 0,59 \\
\hline 4 & 1,10 & 1,10 & 1,20 & 1,20 & 1,30 & 1,00 & 0,90 \\
\hline 5 & 0,70 & 0,70 & - & 0,71 & 0,84 & 0,67 & 0,48 \\
\hline 6 & 0,20 & 0,21 & - & - & - & 0,19 & - \\
\hline 7 & 0,14 & 0,18 & - & 0,29 & - & - & 0,09 \\
\hline 8 & 0,63 & 0,63 & 0,64 & - & 0,68 & - & 0,40 \\
\hline 10 & 0,66 & 0,66 & 0,66 & 0,74 & 0,74 & 0,48 & 0,39 \\
\hline 11 & 0,38 & 0,38 & 0,38 & 0,38 & 0,38 & 0,33 & 0,31 \\
\hline 12 & 0,77 & 0,74 & 0,77 & 0,77 & 0,78 & 0,48 & 0,58 \\
\hline 13 & 0,33 & - & - & - & - & 0,30 & 0,22 \\
\hline 14 & 0,29 & 0,30 & 0,35 & 0,41 & 0,65 & 0,24 & 0,21 \\
\hline 15 & 0,77 & 0,72 & 0,82 & 0,83 & 0,85 & 0,63 & 0,46 \\
\hline 16 & 0,81 & 0,82 & 0,83 & - & - & 0,66 & 0,56 \\
\hline 17 & - & - & - & - & - & - & - \\
\hline 18 & 1,35 & 1,35 & 1,42 & 1,46 & 1,79 & 1,36 & 1,36 \\
\hline 19 & 0,32 & 0,32 & 0,32 & 0,32 & 0,32 & 0,32 & 0,32 \\
\hline 20 & 0,20 & 0,25 & 0,25 & 0,30 & 0,30 & 0,20 & 0,20 \\
\hline 21 & 0,28 & - & - & - & - & 0,20 & 0,18 \\
\hline 22 & 0,10 & 0,11 & - & - & - & 0,07 & 0,04 \\
\hline 23 & 1,24 & 1,25 & 1,26 & 1,30 & 1,31 & 0,94 & 0,85 \\
\hline 24 & 0,63 & 0,72 & 0,81 & 0,92 & - & 0,59 & 0,54 \\
\hline 25 & 0,88 & 0,88 & 0,88 & 0,88 & 0,88 & 0,88 & 0,88 \\
\hline 26 & 0,50 & 0,50 & - & - & - & - & - \\
\hline 27 & 0,50 & 0,50 & - & 0,50 & - & - & - \\
\hline 28 & - & - & - & - & - & - & - \\
\hline 29 & 2,00 & 2,08 & 2,11 & 2,14 & 2,18 & - & - \\
\hline 30 & 1,00 & 1,00 & 1,00 & 1,00 & 1,20 & 0,80 & 0,80 \\
\hline 31 & 0,80 & 0,80 & 0,80 & 0,80 & - & 0,67 & 0,67 \\
\hline 32 & 0,32 & 0,34 & 0,34 & 0,35 & 0,35 & 0,33 & 0,33 \\
\hline 33 & 0,04 & 0,05 & 0,07 & 0,09 & 0,12 & 0,03 & 0,02 \\
\hline 34 & 0,44 & 0,43 & 0,44 & 0,42 & 0,42 & 0,47 & 0,44 \\
\hline Máxima & 2,00 & 2,08 & 2,11 & 2,14 & 2,18 & 1,36 & 1,36 \\
\hline Média & 0,63 & 0,66 & 0,76 & 0,75 & 0,83 & 0,52 & 0,47 \\
\hline Mínima & 0,04 & 0,05 & 0,07 & 0,09 & 0,12 & 0,03 & 0,02 \\
\hline
\end{tabular}

Através das quantidades de água por peça (litro/peça) e da massa seca (eq. ( 2 )), calculou-se a proporção de água (eq. ( 18 )).

$$
\text { \%água }{ }_{\text {prod }}=\frac{m_{\text {água.pç }}}{m_{\text {seca.pç }}}
$$


O objetivo dessa avaliação foi comparar os dados informados com o teor de água considerado típico para produção dos concretos secos utilizados nesses tipos de produtos, indicado pela ABCP como 6\% da massa seca ${ }^{33}$. A partir desses dados, foi desenvolvido o gráfico de distribuição acumulada apresentado na Figura 16.

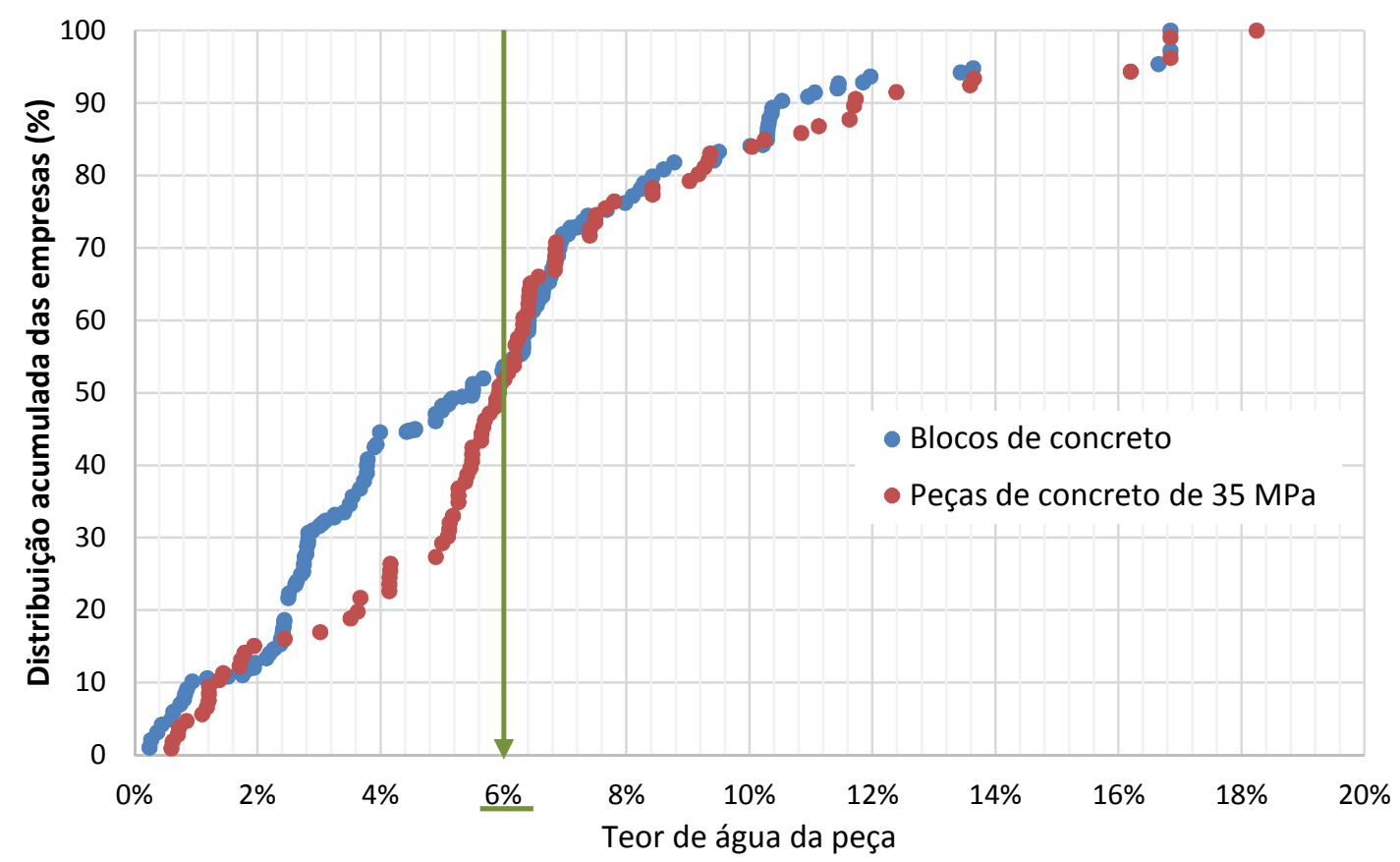

Figura 16 - Gráfico de distribuição acumulada do teor de água de composição do concreto que foi informada pelas empresas. O teor típico para a produção de blocos indicado pela ABCP é de $6 \%$ da massa seca.

Na Figura 16 observa-se que existe grande dispersão entre os resultados. O formato está diretamente associado ao teor de água, pois são pequenas as espessuras das paredes dos blocos para alvenaria, enquanto as peças para pavimento são maciças. Se a massa de concreto possuir quantidade de água superior ou inferior ao ideal para a vibroprensa utilizada, a compactação não será eficiente.

Como são variadas as origens da água contida nos agregados - extração ou chuva o volume adicionado na produção do concreto é normalmente inferior à água de composição necessária. Com isso, presume-se que os consumos de água estejam abaixo de $6 \%$ quando uma empresa informa apenas o que foi adicionado. Considerando que a umidade dos agregados poderia atingir $5 \%$, em uma média anual, e que os agregados são tipicamente $85 \%$ da massa, há a possibilidade de que a água presente nos agregados represente $4 \%$ da mistura, caso onde a

\footnotetext{
${ }^{33}$ Contato com Eng. Claudio Oliveira Silva.
} 
empresa adicionaria apenas 2\%. Entretanto, observa-se que $10 \%$ dos valores informados estão abaixo desse valor.

Por outro lado, quantidades de água acima de 6\% podem acontecer em razão da morfologia de agregados, configuração da prensa, entre outras. $\mathrm{O}$ uso de agregados secos também pode ser uma causa, embora incomum. Entretanto, mesmo neste cenário não é possível justificar teores muito acima de $6 \%$ para a água de composição do concreto. A distribuição revela que mais de $50 \%$ das empresas informaram valores acima de $6 \%$, onde $20 \%$ informou teor acima de $10 \%$. Estes valores são típicos de concretos plásticos e até mesmo argamassas fluidas. Uma explicação aceitável seria o uso de agregados muitos porosos em grande quantidade, como os reciclados. No entanto, considerando os dados de matériasprimas coletados, esse não é o caso. Logo, existe grande inconsistência nestes valores.

O formulário desenvolvido deve ser revisado para aplicações futuras, de modo a tornar bem definidas as considerações que devem ser realizadas no levantamento dos dados, como separar quantidades e origens (água adicionada, água dos agregados, teor de umidade do concreto).

\section{6 Água consumida pela fábrica}

O consumo total de água da fábrica foi solicitado em volume e por tipo de fonte. $A$ Tabela 25 apresenta as origens das águas utilizadas por cada empresa participante. A maioria das empresas utiliza água subterrânea e/ou água da concessionária. Somente três empresas usam água superficial e duas empresas usam água de chuva. 
Tabela 25 - Consumo de água total da fábrica por fonte de origem. A empresa 29 não informou dados sobre o consumo de água pela fábrica.

\begin{tabular}{|c|c|c|c|c|}
\hline Fonte & Superficial & Subterrânea & Chuva & Concessionária \\
\hline 1 & - & $100 \%$ & - & - \\
\hline 2 & $53 \%$ & - & - & $47 \%$ \\
\hline 3 & - & - & - & $100 \%$ \\
\hline 4 & - & $100 \%$ & - & - \\
\hline 5 & $88 \%$ & - & - & $12 \%$ \\
\hline 6 & - & $100 \%$ & - & - \\
\hline 7 & - & $79 \%$ & - & $21 \%$ \\
\hline 8 & - & - & - & $100 \%$ \\
\hline 10 & - & $100 \%$ & - & - \\
\hline 11 & - & $77 \%$ & - & $23 \%$ \\
\hline 12 & - & $100 \%$ & - & - \\
\hline 13 & - & $100 \%$ & - & - \\
\hline 14 & - & $94 \%$ & - & $6 \%$ \\
\hline 15 & - & $82 \%$ & - & $18 \%$ \\
\hline 16 & - & $100 \%$ & - & - \\
\hline 17 & - & $0 \%$ & $97 \%$ & $3 \%$ \\
\hline 18 & - & $100 \%$ & - & - \\
\hline 19 & - & - & - & $100 \%$ \\
\hline 20 & - & $100 \%$ & - & - \\
\hline 21 & $100 \%$ & - & - & - \\
\hline 22 & - & $100 \%$ & - & - \\
\hline 23 & - & - & - & $100 \%$ \\
\hline 24 & - & $51 \%$ & - & $49 \%$ \\
\hline 25 & - & $100 \%$ & - & - \\
\hline 26 & - & $33 \%$ & $23 \%$ & $43 \%$ \\
\hline 27 & - & - & - & $100 \%$ \\
\hline 28 & - & $93 \%$ & - & $7 \%$ \\
\hline 29 & - & - & - & - \\
\hline 30 & - & $100 \%$ & - & - \\
\hline 31 & - & $97 \%$ & - & $3 \%$ \\
\hline 32 & - & $100 \%$ & - & - \\
\hline 33 & - & - & $6 \%$ & $94 \%$ \\
\hline 34 & - & $100 \%$ & - & - \\
\hline
\end{tabular}

A Figura 17 e a Figura 18 apresentam uma análise das fontes de água utilizadas pelas fábricas participantes. A maioria das empresas não tem como fonte principal a água da concessionária, onde 62,7\% utilizam água subterrânea em alguma etapa de seu processo. A empresa 29 não informou a quantidade total de água consumida no período, por isso não possui resultados. 


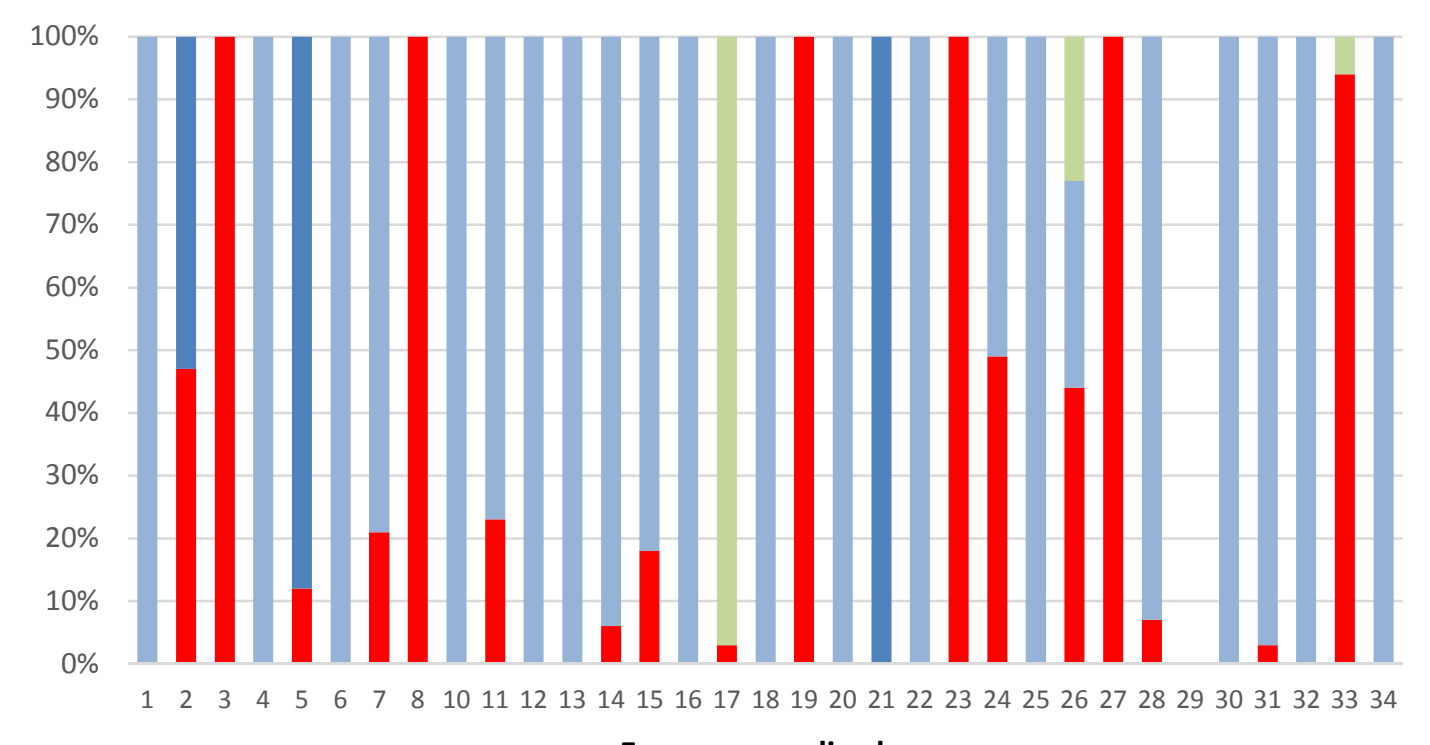

Empresas analisadas

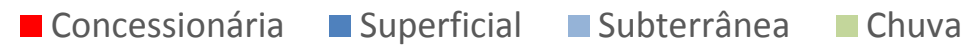

Figura 17 - Fontes de água utilizadas por fábrica participante do projeto. A empresa 29 não informou dados de consumo de água.

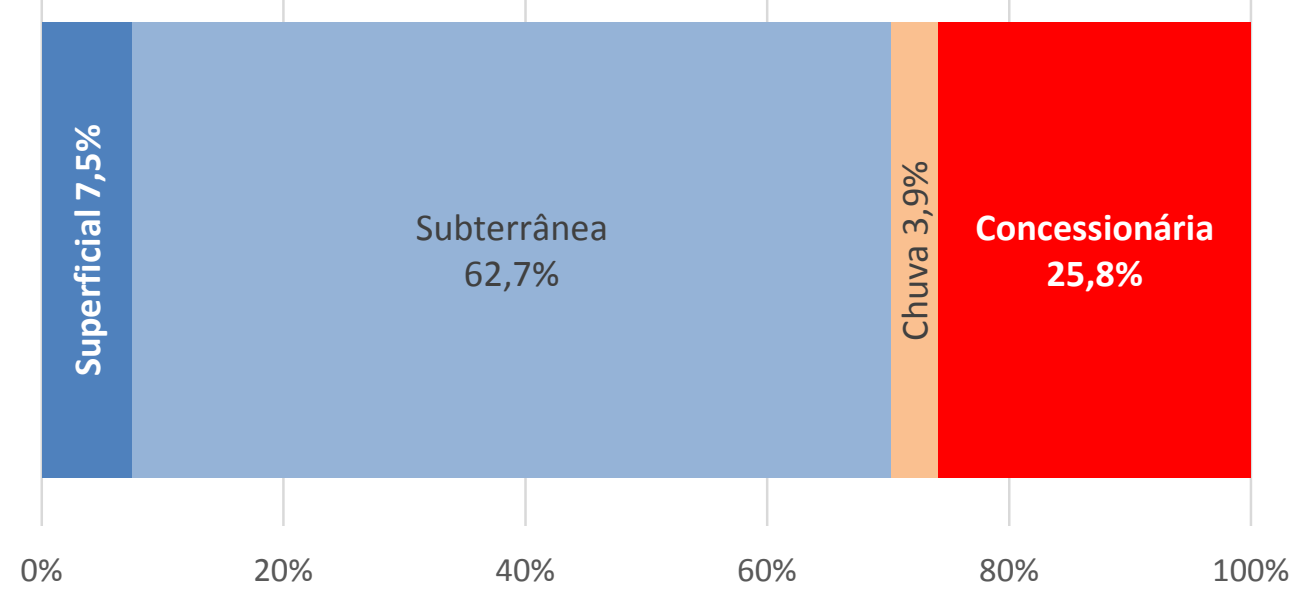

Figura 18 - Fontes de água utilizadas pelas empresas participantes.

Uma análise das parcelas de cada fonte de água por peça foi feita, considerando a massa total seca dos produtos selecionados e o consumo total de água da fábrica alocado nos mesmos ( $m_{\text {água.fonte }} / \mathrm{m}_{\text {seca.total). Esses valores são apresentados na }}$ Tabela 26 junto com o teor médio estimado, baseado no consumo de água informado por peça. Comparando os dois valores, observa-se que algumas empresas (valores em vermelho) apresentam essa relação inferior a $6 \%$, considerado baixo para a moldagem do concreto (ver item 6.5). As empresas $25 \mathrm{e}$ 31 apresentaram valores muito elevados, de aproximadamente $65 \%$, dados que 
podem ter origem devido a erro de inventário.

Se comparado o teor referente ao consumo total da fábrica com o teor para composição do concreto, alguns valores apresentam inconsistência. O consumo no concreto por peça deveria ser inferior ao consumo total da fábrica alocado por bloco, uma vez que esse último considera toda a água utilizada na produção mais a água de composição adicionada. As empresas que apresentam os consumos de toda fábrica marcados em vermelho na Tabela 26 precisariam ser revistos, pois apresentam inconsistência com os consumos de composição do concreto.

Tabela 26 - Comparação da água total da fábrica alocada nos produtos analisados com a água média de composição do concreto informada pelas empresas.

\begin{tabular}{ccccccc}
\hline Empresa & Concessionária & Subterrânea & Superficial & Chuva & $\begin{array}{c}\text { Total da } \\
\text { fábrica }\end{array}$ & $\begin{array}{c}\text { Composição } \\
\text { Média }\end{array}$ \\
\hline $\mathbf{1}$ & - & $7,9 \%$ & - & - & $7,9 \%$ & $7,2 \%$ \\
\hline $\mathbf{2}$ & $4,4 \%$ & - & $5,1 \%$ & - & $9,5 \%$ & $4,9 \%$ \\
\hline $\mathbf{3}$ & $6,8 \%$ & - & - & - & $6,8 \%$ & $6,8 \%$ \\
\hline $\mathbf{4}$ & - & $11,2 \%$ & - & - & $11,2 \%$ & $10,2 \%$ \\
\hline $\mathbf{5}$ & $1,1 \%$ & - & $7,5 \%$ & - & $8,6 \%$ & $5,6 \%$ \\
\hline $\mathbf{6}$ & - & $6,1 \%$ & - & - & $6,1 \%$ & $3,3 \%$ \\
\hline $\mathbf{7}$ & $0,5 \%$ & $1,9 \%$ & - & - & $2,4 \%$ & $1,6 \%$ \\
\hline $\mathbf{8}$ & $5,0 \%$ & - & - & - & $5,0 \%$ & $4,7 \%$ \\
\hline $\mathbf{1 0}$ & - & $4,3 \%$ & - & - & $4,3 \%$ & $5,4 \%$ \\
\hline $\mathbf{1 1}$ & $1,3 \%$ & $4,3 \%$ & - & - & $5,6 \%$ & $3,2 \%$ \\
\hline $\mathbf{1 2}$ & - & $10,6 \%$ & - & - & $10,6 \%$ & $6,3 \%$ \\
\hline $\mathbf{1 3}$ & - & $4,4 \%$ & - & - & $4,4 \%$ & $3,8 \%$ \\
\hline $\mathbf{1 4}$ & $0,3 \%$ & $4,2 \%$ & - & - & $4,5 \%$ & $3,0 \%$ \\
\hline $\mathbf{1 5}$ & $0,7 \%$ & $3,3 \%$ & - & - & $4,0 \%$ & $6,5 \%$ \\
\hline $\mathbf{1 6}$ & - & $11,4 \%$ & - & - & $11,4 \%$ & $6,4 \%$ \\
\hline $\mathbf{1 7}$ & $50,0 \%$ & - & - & $15,2 \%$ & $65,2 \%$ & $5,9 \%$ \\
\hline $\mathbf{1 8}$ & - & $9,3 \%$ & - & - & $9,3 \%$ & $13,0 \%$ \\
\hline $\mathbf{1 9}$ & - & - & - & - & - & $2,5 \%$ \\
\hline $\mathbf{2 0}$ & - & $2,8 \%$ & - & - & $2,8 \%$ & $2,3 \%$ \\
\hline $\mathbf{2 1}$ & - & - & $7,7 \%$ & - & $7,7 \%$ & $2,2 \%$ \\
\hline $\mathbf{2 2}$ & - & $0,3 \%$ & - & - & $0,3 \%$ & $0,8 \%$ \\
\hline $\mathbf{2 3}$ & $3,4 \%$ & - & - & - & $3,4 \%$ & $10,8 \%$ \\
\hline $\mathbf{2 4}$ & $3,5 \%$ & $3,6 \%$ & - & - & $7,1 \%$ & $8,0 \%$ \\
\hline $\mathbf{2 5}$ & - & $65,4 \%$ & - & - & $65,4 \%$ & $9,6 \%$ \\
\hline $\mathbf{2 6}$ & $6,2 \%$ & $4,8 \%$ & - & $3,4 \%$ & $14,4 \%$ & $3,8 \%$ \\
\hline $\mathbf{2 7}$ & $11,8 \%$ & - & - & - & $11,8 \%$ & $3,8 \%$ \\
\hline $\mathbf{2 8}$ & $0,2 \%$ & $2,8 \%$ & - & - & $3,0 \%$ & $5,3 \%$ \\
\hline $\mathbf{2 9}$ & - & - & - & - & - & $16,8 \%$ \\
\hline $\mathbf{3 0}$ & - & $7,7 \%$ & - & - & $7,7 \%$ & $8,8 \%$ \\
\hline $\mathbf{3 1}$ & $1,9 \%$ & $61,9 \%$ & - & - & $63,8 \%$ & $6,4 \%$ \\
\hline $\mathbf{3 2}$ & - & - & - & - & - & $2,9 \%$ \\
\hline $\mathbf{3 3}$ & $1,8 \%$ & - & - & $0,1 \%$ & $1,9 \%$ & $0,8 \%$ \\
\hline $\mathbf{3 4}$ & - & $10,6 \%$ & - & - & $10,6 \%$ & $4,2 \%$ \\
\hline & & & & & & \\
\hline & & - & - & - & - & - \\
\hline
\end{tabular}




\subsection{Análise da distribuição acumulada dos indicadores}

Gráficos de distribuição acumulada foram elaborados para auxiliar a análise da existência de empresas que apresentam dados atípicos quando comparados ao conjunto. A existência destes dados pode ser resultado de uma situação peculiar da empresa, mas também pode ser consequência de erro de inventário. Estes foram o de teor de cimento ( massa $_{\text {cimento }} /$ massa $_{\text {bloco }}$ ); perdas informadas por produto; energia incorporada e emissão de $\mathrm{CO}_{2}$. O eixo vertical apresenta a parcela acumulada das empresas participantes, enquanto o eixo horizontal apresenta o dado analisado.

$\mathrm{Na}$ Figura 19 observa-se que aproximadamente $80 \%$ das empresas que produzem blocos de vedação apresentam teor de cimento entre 4 e $6 \%$. Entre as que fabricam blocos estruturais, em $95 \%$ das empresas o teor varia de 4 a $12 \%$. Os blocos para pavimento apresentaram $50 \%$ das empresas com teor entre 12 e $14 \%$, sendo que essa grande dispersão pode ter como possível causa as diferentes espessuras e dimensões das peças. Menos de $5 \%$ das empresas apresentou teor muito elevado, considerado impraticável.

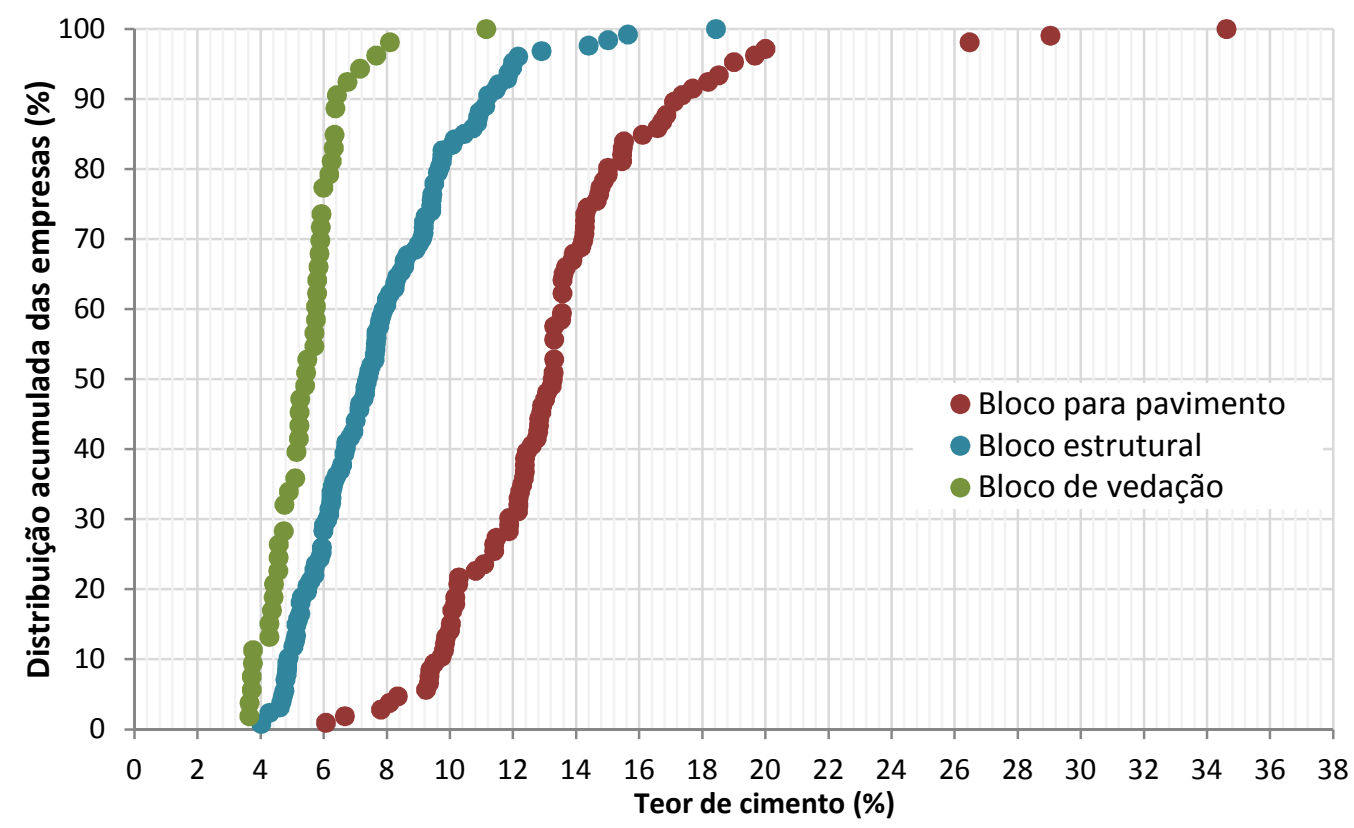

Figura 19 - Distribuição do teor de cimento levantado a partir dos dados informados pelas empresas participantes.

$\mathrm{Na}$ Figura 20 percebe-se que $10 \%$ das empresas informaram que suas perdas encontram-se abaixo de $0,5 \%$. Esse resultado pode ser causado devido à falta de registro desse dado. Mais de $80 \%$ das fábricas apresentaram perdas entre 0,5 e $4 \%$. Menos de $10 \%$ das empresas apresentam valores muito elevados. 
A Figura 21 e a Figura 22 apresentam a variação da energia incorporada, respectivamente mínima e máxima, calculada para os produtos analisados. Entre 10 e $15 \%$ das empresas apresentam valores por bloco muito acima do que pode ser considerado aceitável. Esses resultados não foram considerados na criação da faixa desse indicador.

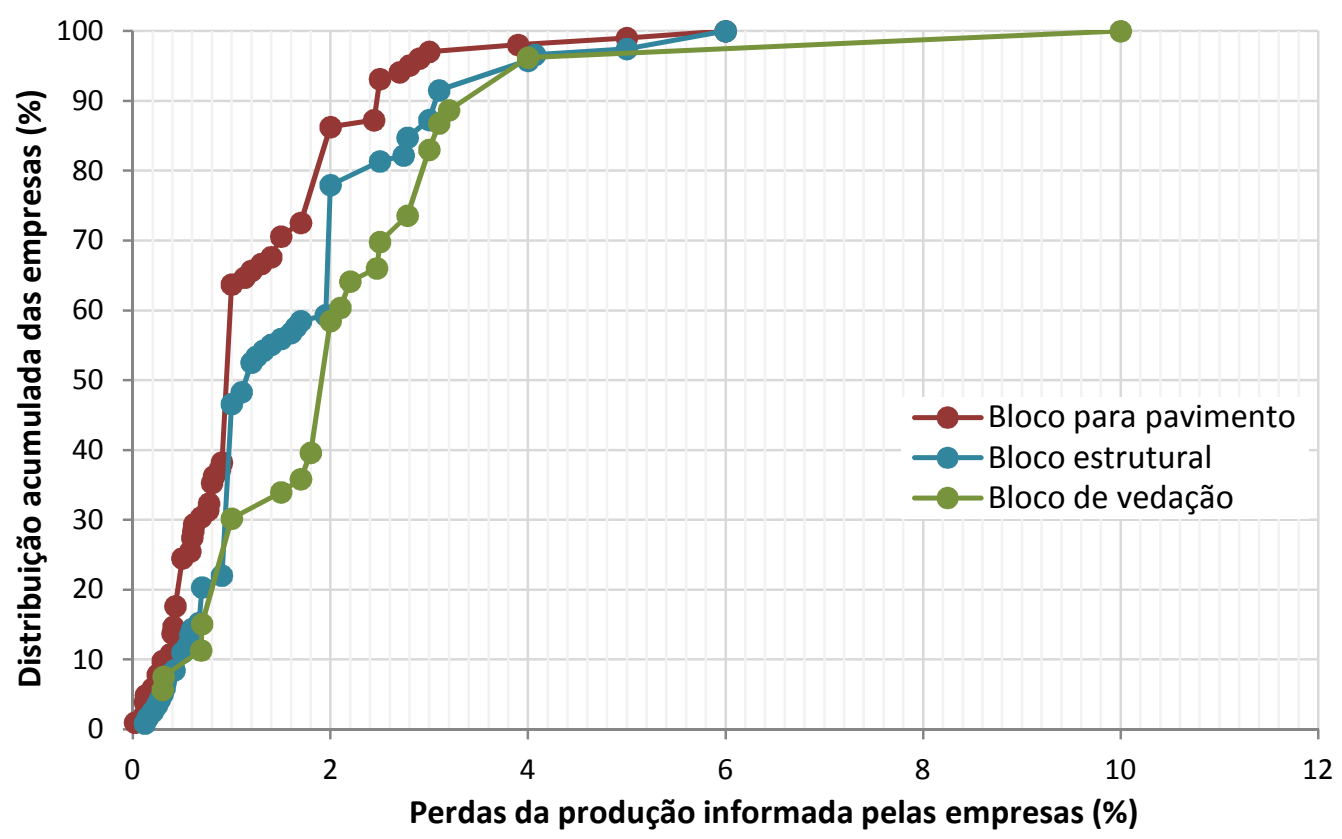

Figura 20 - Distribuição das perdas de produção informadas pelas empresas participantes.

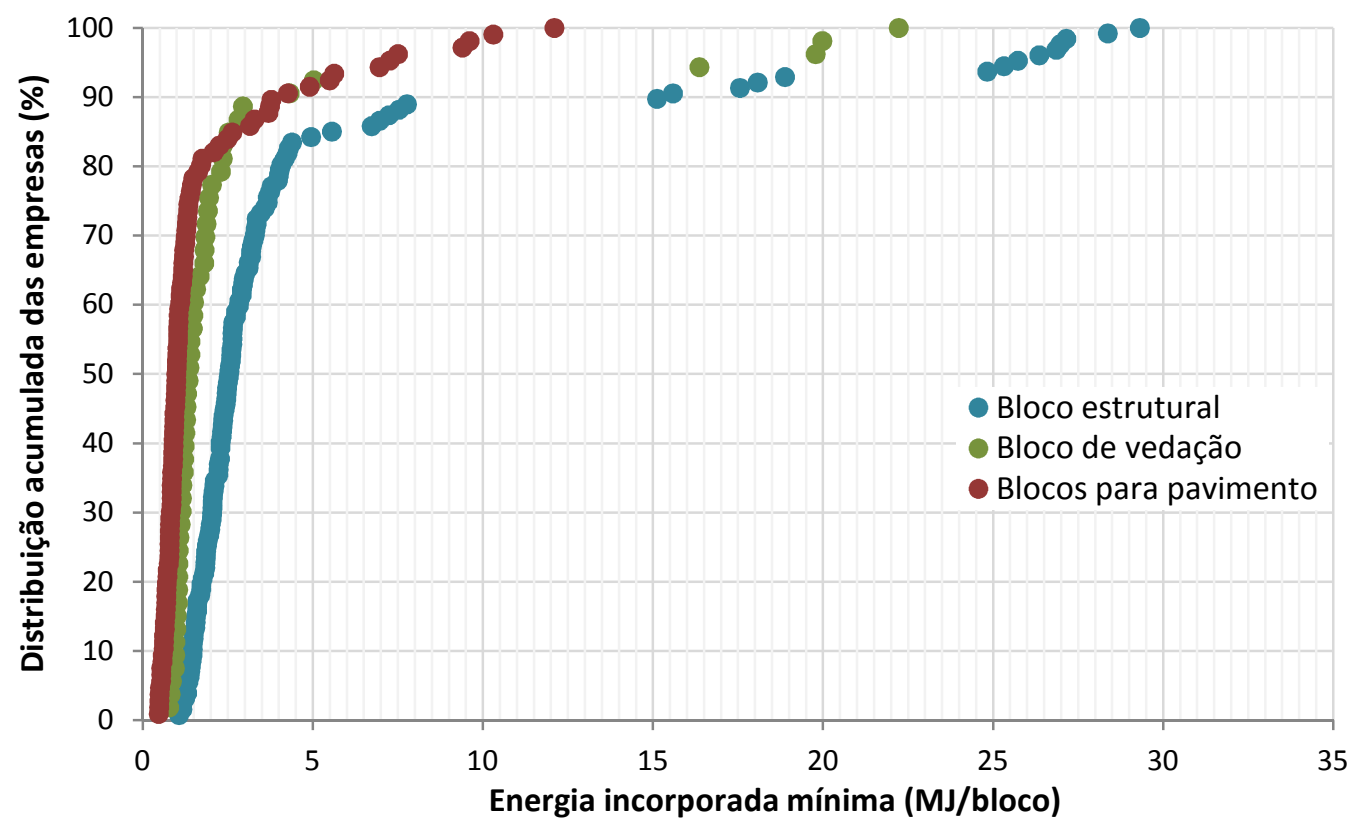

Figura 21 - Distribuição da energia incorporada mínima calculada por bloco. 


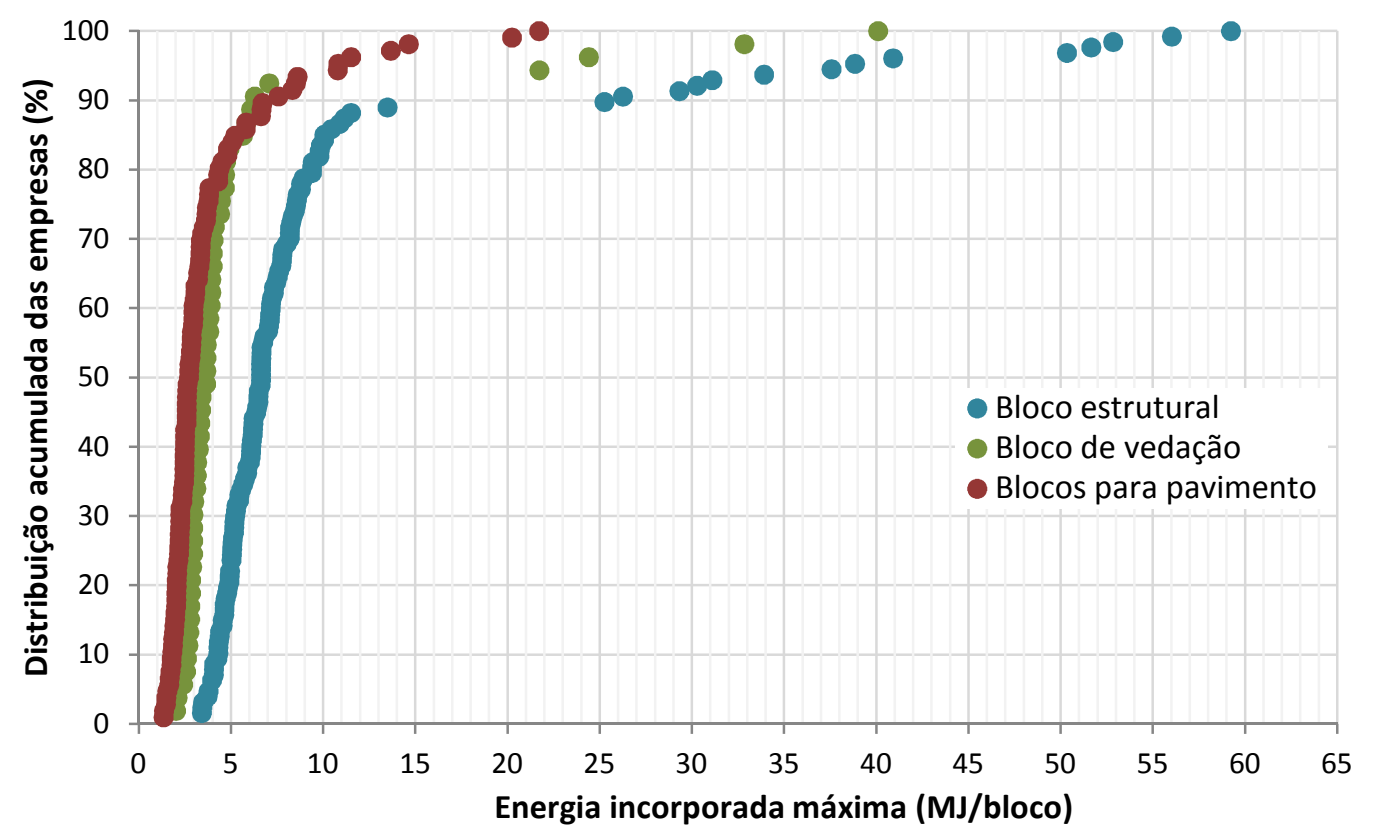

Figura 22 - Distribuição da energia incorporada máxima calculada por bloco.

A Figura 23 e a Figura 24 apresentam a variação da emissão de $\mathrm{CO}_{2}$ calculada para os produtos analisados, mínima e máxima respectivamente. No caso dos blocos estruturais, os resultados de 5 a $10 \%$ das empresas mostraram-se muito altos. Menos de $5 \%$ das fábricas fabricantes de blocos de vedação e de pavimentação apresentaram resultados considerados acima do aceitável.

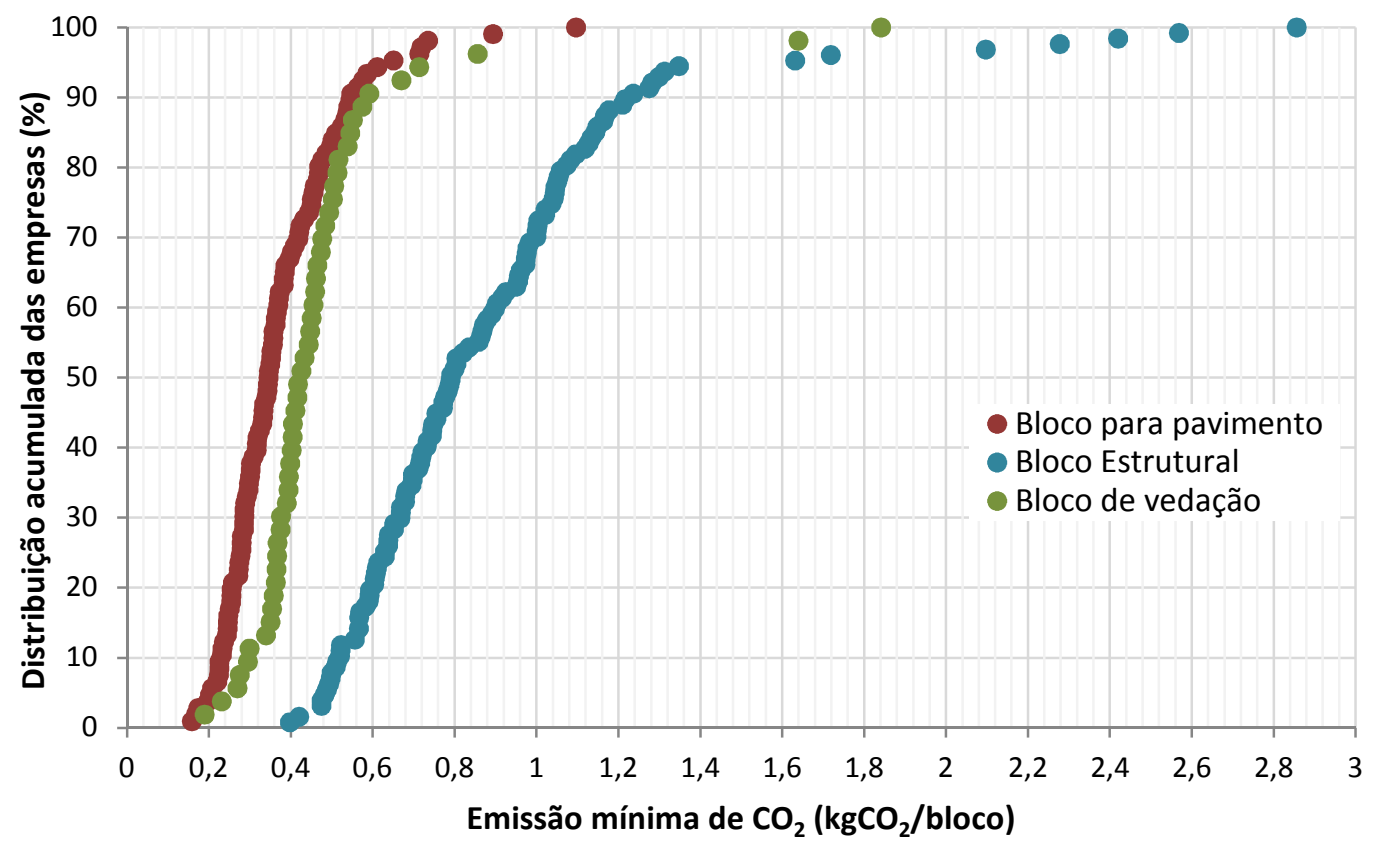

Figura 23 - Distribuição da emissão de $\mathrm{CO}_{2}$ mínima calculada por bloco. 


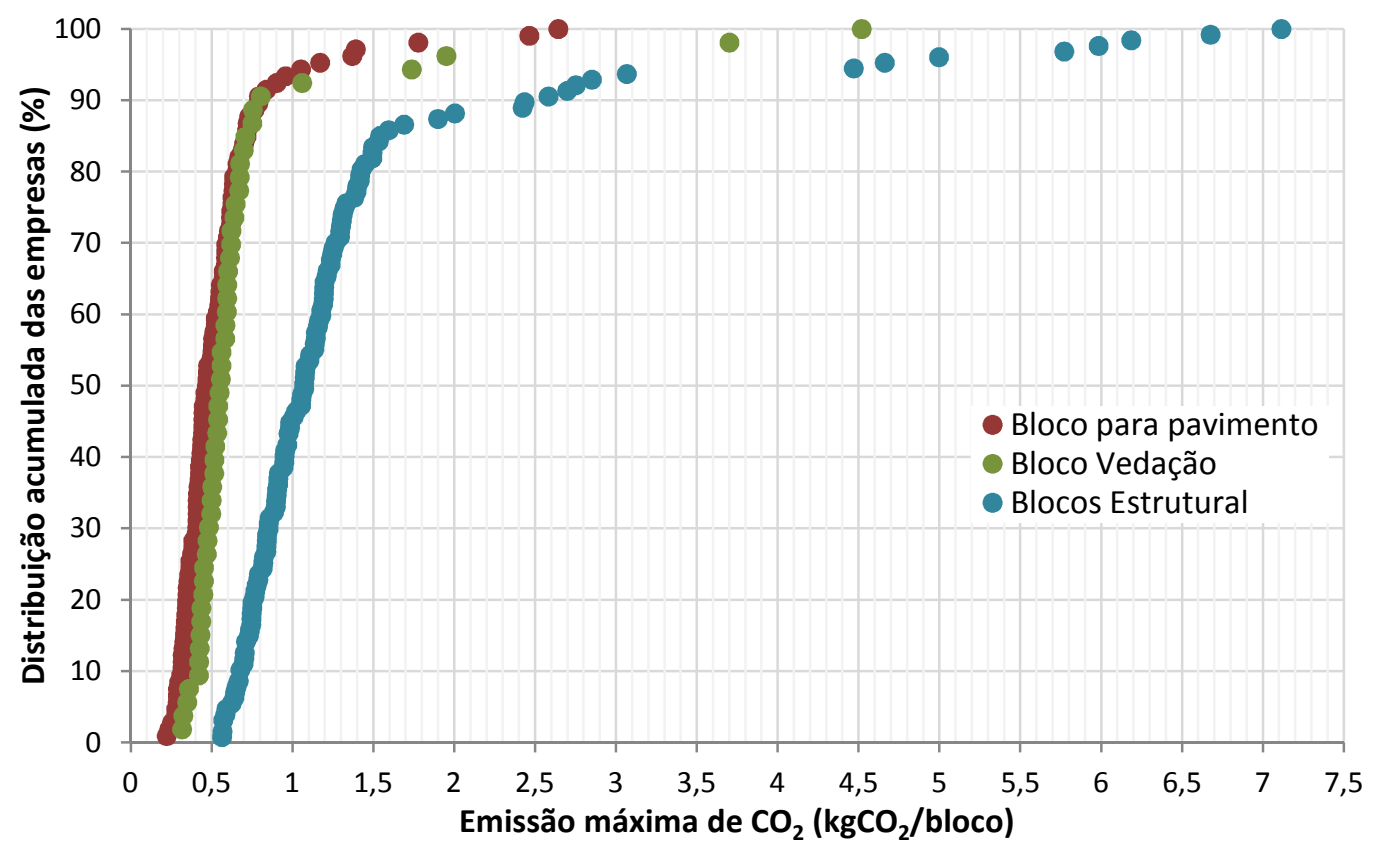

Figura 24 - Distribuição da emissão de $\mathrm{CO}_{2}$ máxima calculada por bloco. 


\section{Resultados}

Os resultados foram divididos em indicadores setoriais e da ACV Modular. Os primeiros indicam para as empresas participantes do estudo a eficiência de seu processo produtivo, comparada com as demais integrantes do projeto. São eles os consumos de agregados e de cimento e as perdas de produção. Os indicadores da ACV-m apresentam os resultados dos outros três indicadores selecionados, consumo de água, energia incorporada e emissão de $\mathrm{CO}_{2}$.

Os indicadores setoriais não são apresentados para preservar informações que podem expor dados considerados confidenciais pelas empresas, sendo divulgados apenas para as mesmas. Isso foi assegurado junto às participantes para que os dados fossem levantados para o estudo. No entanto, vale ressaltar que o consumo de cimento, comparando o mesmo tipo de produto, variou entre as empresas em um fator de 1,6 a 2,6 para os blocos para pavimento e em um fator de 2,1 a 3,1 para os blocos para alvenaria. É uma avaliação importante, uma vez que o cimento possui grande influência na composição dos indicadores de energia e $\mathrm{CO}_{2}$.

Auditorias foram realizadas pela equipe do SENAI RJ em algumas fábricas, a partir de critérios definidos durante as primeiras análises dos dados coletados pelo formulário. No entanto, a metodologia adotada não esclareceu todas as dúvidas nem conseguiu eliminar as inconsistências observadas nas análises. Em razão disso, os dados avaliados como inconsistentes não foram considerados no desenvolvimento dos indicadores.

Como alguns resultados foram calculados com base na massa total de produtos fabricados pela empresa no período analisado, não foi possível calcular os indicadores das empresas 19 e 32. A primeira não pôde informar a massa total de produtos no período e a segunda informou sua produção relativa apenas a dois meses. Assim, entre as 33 empresas participantes do estudo, 26 produzem blocos para pavimento e 31 fabricam blocos para alvenaria. Como alguns resultados foram considerados produtos de erro de inventário, os indicadores de 20 empresas foram incluídos na composição das faixas dos blocos para pavimento e de 25 fábricas na criação das faixas dos blocos para alvenaria.

Os números presentes nos extremos das faixas dos indicadores representam as empresas detentoras dos resultados. Em algumas situações mais de uma empresa 
possui o mesmo valor. Apenas cada empresa conhece sua numeração.

\subsection{Indicadores da ACV Modular}

\subsubsection{Indicador de energia incorporada}

Os indicadores de energia incorporada são apresentados na Figura 25 para os blocos para pavimento e na Figura 26 referentes aos blocos para alvenaria. As faixas são limitadas pelos resultados máximo e mínimo estimado para cada produto. Também são apresentados os resultados calculados para cada empresa (máximos são os círculos vazados em vermelho e mínimos são os círculos vazados em verde).

As faixas expressam as incertezas e variações associadas à energia incorporada dos insumos, às diferenças de formulação do concreto e à variação na distância e modal de transporte das matérias-primas, além da massa do bloco. A variabilidade é significativa, onde a diferença entre o máximo e o mínimo varia em um fator entre 2,5 e 3,0 para os blocos para pavimento e entre 3,5 e 4,1 para os blocos para alvenaria.

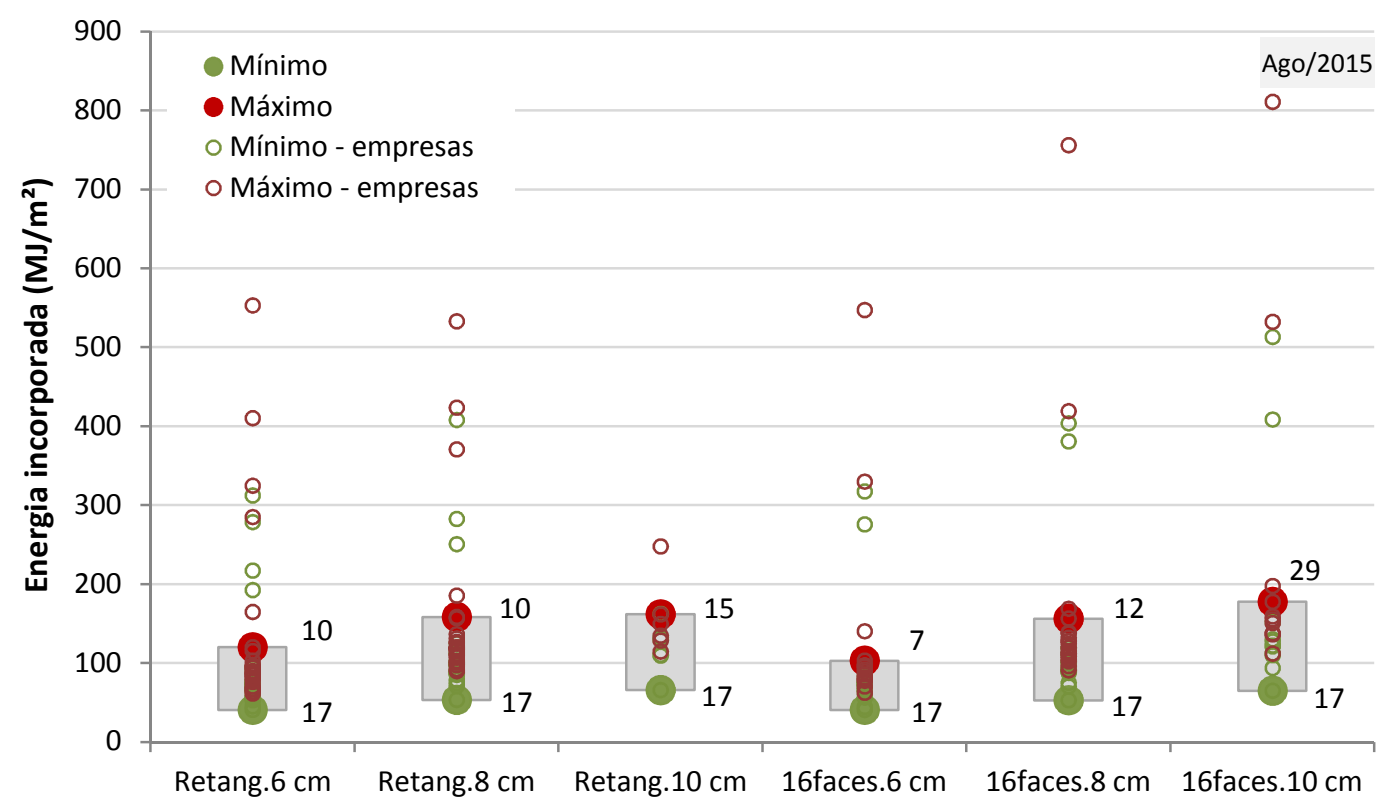

Figura 25 - Indicador de energia incorporada - Blocos para pavimento (35 MPa). Alguns resultados não foram considerados por serem julgados produtos de erro de inventário. 


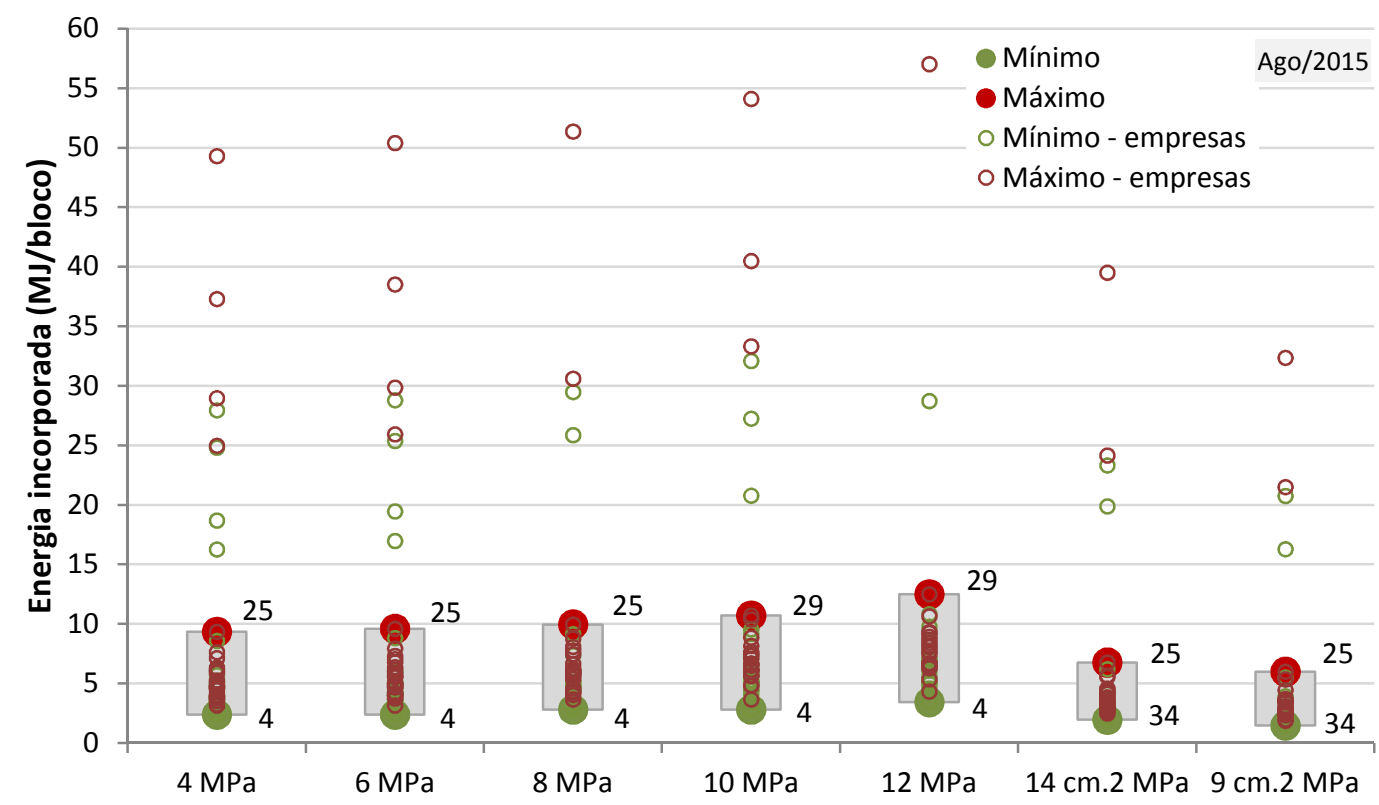

Figura 26 - Indicador de energia incorporada - Blocos estruturais e de vedação. Alguns resultados não foram considerados por serem julgados produtos de erro de inventário.

Os pontos que não estão incluídos na faixa foram considerados produtos de erro de inventário, sendo eles referentes às empresas 3, 18, 26 e 27. Estes resultados indicariam que os blocos de concreto possuem mais energia incorporada do que a necessária para a produção de mesma massa de clínquer, cujo consumo energético de produção é muito alto, na ordem de $3,5 \mathrm{MJ} / \mathrm{kg}^{34}$. Os resultados dos blocos para pavimento da empresa 25 também não foram avaliados por causa da grande influência do consumo de cimento, considerado muito elevado e não incorporado ao indicador de consumo de materiais (setorial).

As empresas 15, 17, 29 e 34, responsáveis por alguns valores extremos das faixas, tiveram a massa total de produção da fábrica estimada. Isso pode ter provocado alguma interferência no cenário, já que a alocação da energia consumida na fábrica foi realizada em massa de produto.

Os resultados de energia incorporada apresentam como principal responsável o consumo de cimento, principalmente os extremos máximos. O tipo de cimento não foi fator determinante, visto que a maioria dos valores mínimos está relacionada ao CP V, como também há um resultado máximo relacionado ao uso de cimento com adições (CP II-Z). No entanto, os valores extremos não estão necessariamente

\footnotetext{
${ }^{34}$ www.wbcsdcement.org/GNR-2012/Brazil/GNR-Indicator_329-Brazil.html - acessado em abril de 2015.
} 
associados aos menores e maiores consumos de cimento, o que revela a dependência não apenas de um mínimo teor de cimento, mas da minimização de outros fatores, como tipo de combustíveis utilizados na fábrica.

Das 12 empresas que informaram realizar cura térmica, os resultados de três não foram considerados na composição das faixas por serem julgados erros de inventário. Entre as demais, os valores de três estão em extremos das faixas, mas nesses casos o principal responsável pelo resultado também foi o consumo de cimento, não o consumo energético da fábrica. Assim, entre as participantes, a realização de cura térmica não foi determinante na quantidade de energia incorporada do bloco.

\subsubsection{Indicador de Emissão de $\mathrm{CO}_{2}$}

$\mathrm{Na}$ Figura 27 são apresentadas as emissões de $\mathrm{CO}_{2}$ dos blocos para pavimento e na Figura 28 as emissões dos blocos para alvenaria. Assim como no indicador de energia, além dos valores que delimitam as faixas, são apresentados os valores máximos (círculos vazados em vermelho) e mínimos (círculos vazados em verde) estimados para cada empresa.

As faixas expressam as incertezas e variações associadas aos fatores de emissão de $\mathrm{CO}_{2}$ dos insumos, à formulação do concreto e à distância e modal de transporte das matérias-primas e à massa do bloco. A variabilidade é significativa, sendo o máximo superior ao mínimo em uma razão que varia de 2,3 a 2,8 para os blocos para pavimento e de 2,6 a 3,3 para os blocos para alvenaria. 


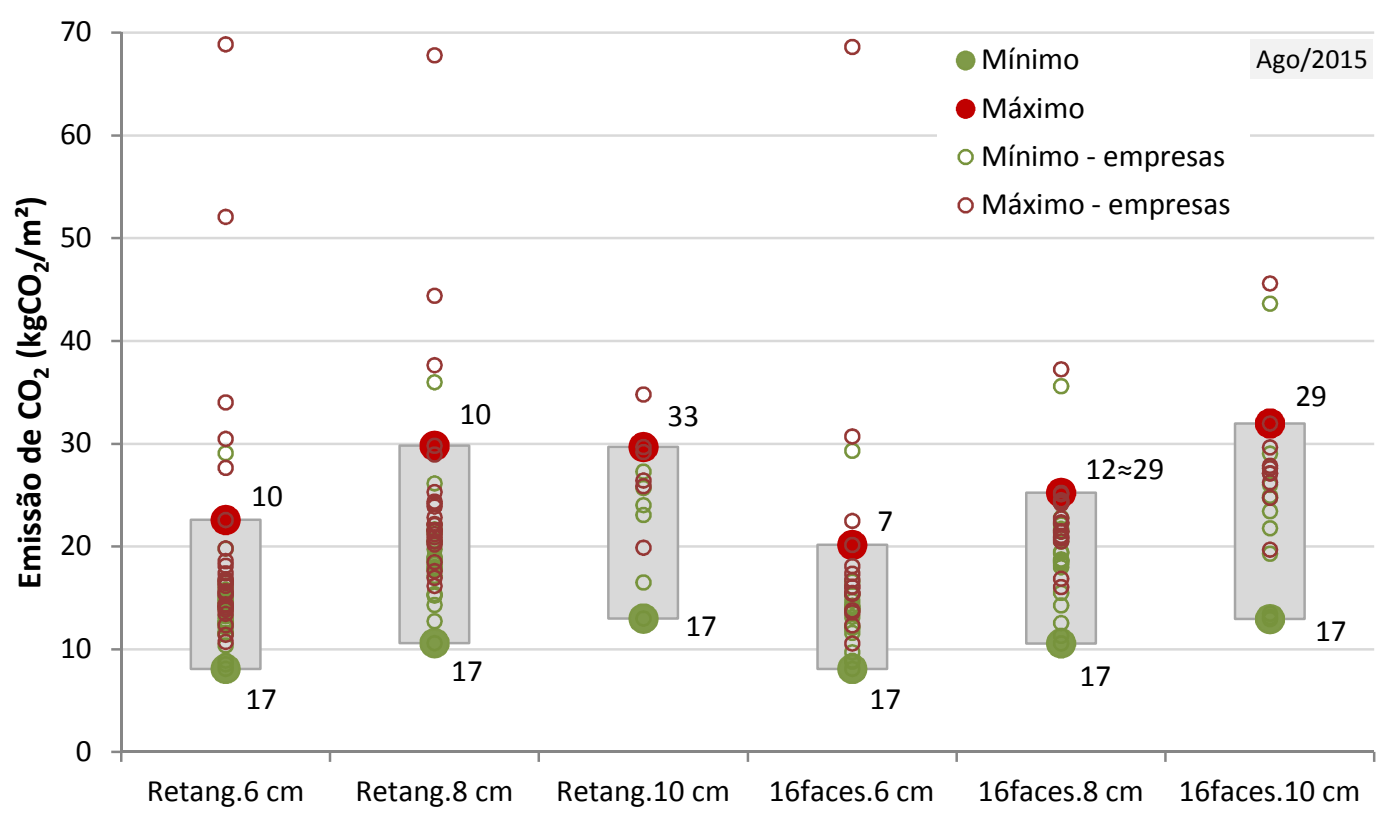

Figura 27 - Indicador de emissão de $\mathrm{CO}_{2}$ - Blocos para pavimento (35 $\left.\mathrm{MPa}\right)$. Alguns resultados não foram considerados por serem julgados produtos de erro de inventário.

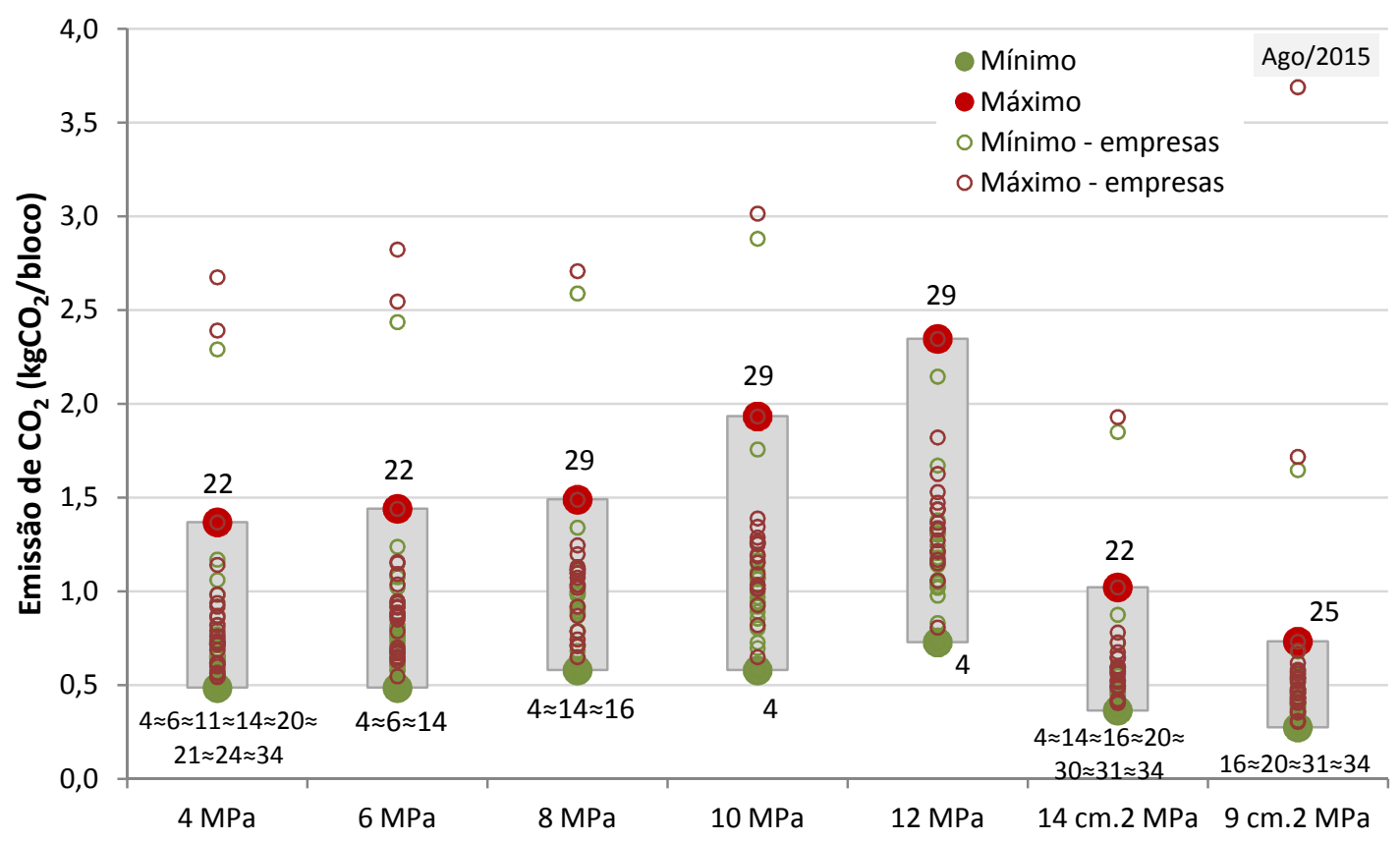

Figura 28 - Indicador de emissão de $\mathrm{CO}_{2}$ - Blocos estruturais e de vedação. Alguns resultados não foram considerados por serem julgados produtos de erro de inventário.

Os resultados das empresas 3, 18, 26 e 27 não compõem a faixa do indicador de emissão de $\mathrm{CO}_{2}$ por serem considerados produtos de erro de inventário. As emissões dos blocos para pavimento da empresa 25 também não foram incluídos devido ao elevado consumo de cimento informado pela mesma. 
O consumo de cimento é um fator importante na emissão de $\mathrm{CO}_{2}$, mas não necessariamente o tipo, assim como aconteceu com o indicador de energia incorporada. Os resultados mínimos de emissão de $\mathrm{CO}_{2}$ dos blocos para pavimentos estão relacionados ao uso de CP II-E e CP V conjuntamente, no entanto os valores mínimos de todos os blocos para alvenaria referem-se ao uso de CP V. Com exceção do bloco de 16 faces com $6 \mathrm{~cm}$ de espessura, fabricado com CP II-Z, os demais resultados máximos relacionam-se à utilização de CP V.

A quantidade de cimento revelou-se como principal responsável pelos resultados, sendo possível mitigar as emissões de $\mathrm{CO}_{2}$ mesmo quando não estejam disponíveis cimentos com menor teor de clínquer (ver Tabela 4). No entanto, assim como no indicador de energia, os valores extremos não estão necessariamente associados aos maiores e menores consumos de cimento. Isso revela que a minimização da emissão de $\mathrm{CO}_{2}$ depende não só de um mínimo teor de cimento, como da minimização de outros fatores.

Entre as empresas responsáveis pelos resultados extremos da faixa, as fábricas 4 , $6,11,17,22,24,29$ e 31 tiveram a massa total de produção estimada. As considerações adotadas podem ter influenciado nos resultados finais, no entanto não se sabe a proporção dessa interferência com o cenário atual.

\subsubsection{Indicador de Água}

As tabelas a seguir apresentam valores médios de consumo de água por fonte na unidade funcional preestabelecida: por $\mathrm{m}^{2}$ para os blocos para pavimento (Tabela 27) e por peça para os blocos estruturais (Tabela 28) e de vedação (Tabela 29 e Tabela 30). As empresas destacadas informaram sua produção total em outra unidade que não em massa, tendo sido necessário estimar esse valor para fazer a alocação da água total informada para a fábrica.

A empresa 29 não informou o consumo total da fábrica no período do estudo. A empresa 32 informou consumos de apenas dois meses, dado insuficiente para análise desse indicador. A empresa 19 não informou sua massa total de produção do período nem outro dado que permitisse sua estimativa, o que não possibilitou a alocação da água total da fábrica nos produtos em análise.

A empresa 28 informou a quantidade de água proveniente da umidade dos agregados, além das fontes de água disponíveis no formulário. Como há grande 
incerteza quanto à origem da água contida nos agregados (chuva, de lavagem, captada durante a extração, etc.) e apenas essa empresa informou esse volume, sabendo-se que as demais também usam essa água incorporada, esse volume não foi considerado no cálculo do indicador.

Tabela 27 - Consumo de água total da fábrica para os blocos para pavimento ( $35 \mathrm{MPa}$ ).

\begin{tabular}{ccccccc} 
& \multicolumn{1}{c}{ Blocos para pavimento - Consumo médio de água (litro/m $\mathbf{m}^{2}$} & \multirow{2}{*}{ Total } \\
\hline Empresa & Concessionária & Subterrânea & Superficial & Chuva & \\
\hline $\mathbf{1}$ & - & 10,57 & - & - & 10,57 \\
\hline $\mathbf{2}$ & 6,34 & - & 7,23 & - & 13,57 \\
\hline $\mathbf{3}$ & 10,46 & - & - & - & 10,46 \\
\hline $\mathbf{4}$ & - & - & - & - & - \\
\hline $\mathbf{5}$ & 1,71 & - & 12,11 & - & 13,82 \\
\hline $\mathbf{6}$ & - & 8,33 & - & - & 8,33 \\
\hline $\mathbf{7}$ & 0,72 & 2,66 & - & - & 3,38 \\
\hline $\mathbf{8}$ & 7,94 & - & - & - & 7,94 \\
\hline $\mathbf{1 0}$ & - & 5,87 & - & - & 5,87 \\
\hline $\mathbf{1 1}$ & - & - & - & - & - \\
\hline $\mathbf{1 2}$ & - & 16,01 & - & - & 16,01 \\
\hline $\mathbf{1 3}$ & - & 6,58 & - & - & 6,58 \\
\hline $\mathbf{1 4}$ & - & - & - & - & - \\
\hline $\mathbf{1 5}$ & 1,13 & 5,23 & - & - & 6,37 \\
\hline $\mathbf{1 6}$ & - & 16,57 & - & - & 16,57 \\
\hline $\mathbf{1 7}$ & 0,76 & - & - & 24,88 & 25,64 \\
\hline $\mathbf{1 8}$ & - & 14,26 & - & - & 14,26 \\
\hline $\mathbf{1 9}$ & - & - & - & - & - \\
\hline $\mathbf{2 0}$ & - & - & - & - & - \\
\hline $\mathbf{2 1}$ & - & - & - & - & - \\
\hline $\mathbf{2 2}$ & - & 0,44 & - & - & 0,44 \\
\hline $\mathbf{2 3}$ & 5,82 & - & - & - & 5,82 \\
\hline $\mathbf{2 4}$ & 4,95 & 5,10 & - & - & 10,05 \\
\hline $\mathbf{2 5}$ & - & 112,60 & - & - & 112,60 \\
\hline $\mathbf{2 6}$ & 9,19 & 7,07 & - & 4,95 & 21,22 \\
\hline $\mathbf{2 7}$ & 17,34 & - & - & - & 17,34 \\
\hline $\mathbf{2 8}$ & 0,36 & 4,82 & - & - & 5,18 \\
\hline $\mathbf{2 9}$ & - & - & - & - & - \\
\hline $\mathbf{3 0}$ & - & 11,12 & - & - & 11,12 \\
\hline $\mathbf{3 1}$ & 2,92 & 97,24 & - & - & 100,16 \\
\hline $\mathbf{3 2}$ & - & - & - & - & - \\
\hline $\mathbf{3 3}$ & 3,25 & - & - & 0,22 & 3,48 \\
\hline $\mathbf{3 4}$ & - & - & - & - & - \\
\hline & & & - & & \\
\hline & & - & - & - & - & - \\
\hline
\end{tabular}


Tabela 28 - Consumo de água total da fábrica para os blocos estruturais.

\begin{tabular}{ccccccc} 
& \multicolumn{2}{c}{ Blocos estruturais - Consumo médio de água (litro/bloco) } & \multirow{2}{*}{ Total } \\
\cline { 2 - 5 } Empresa & Concessionária & Subterrânea & Superficial & Chuva & \\
\hline $\mathbf{1}$ & - & 0,95 & - & - & 0,95 \\
\hline $\mathbf{2}$ & 0,54 & - & 0,62 & - & 1,17 \\
\hline $\mathbf{3}$ & 0,81 & - & - & - & 0,81 \\
\hline $\mathbf{4}$ & - & 1,38 & - & - & 1,38 \\
\hline $\mathbf{5}$ & 0,14 & - & 0,97 & - & 1,11 \\
\hline $\mathbf{6}$ & - & 0,66 & - & - & 0,66 \\
\hline $\mathbf{7}$ & 0,06 & 0,23 & - & - & 0,29 \\
\hline $\mathbf{8}$ & 0,62 & - & - & - & 0,62 \\
\hline $\mathbf{1 0}$ & - & 0,52 & - & - & 0,52 \\
\hline $\mathbf{1 1}$ & 0,16 & 0,55 & - & - & 0,71 \\
\hline $\mathbf{1 2}$ & - & 1,29 & - & - & 1,29 \\
\hline $\mathbf{1 3}$ & - & 0,55 & - & - & 0,55 \\
\hline $\mathbf{1 4}$ & 0,03 & 0,52 & - & - & 0,56 \\
\hline $\mathbf{1 5}$ & 0,08 & 0,39 & - & - & 0,47 \\
\hline $\mathbf{1 6}$ & - & 1,46 & - & - & 1,46 \\
\hline $\mathbf{1 7}$ & - & - & - & - & - \\
\hline $\mathbf{1 8}$ & - & 1,17 & - & - & 1,17 \\
\hline $\mathbf{1 9}$ & - & - & - & - & - \\
\hline $\mathbf{2 0}$ & - & 0,33 & - & - & 0,33 \\
\hline $\mathbf{2 1}$ & - & - & 0,91 & - & 0,91 \\
\hline $\mathbf{2 2}$ & - & 0,03 & - & - & 0,03 \\
\hline $\mathbf{2 3}$ & 0,42 & - & - & - & 0,42 \\
\hline $\mathbf{2 4}$ & 0,39 & 0,40 & - & - & 0,78 \\
\hline $\mathbf{2 5}$ & - & 8,08 & - & - & 8,08 \\
\hline $\mathbf{2 6}$ & 0,79 & 0,61 & - & 0,43 & 1,83 \\
\hline $\mathbf{2 7}$ & 1,51 & - & - & - & 1,51 \\
\hline $\mathbf{2 8}$ & - & - & - & - & - \\
\hline $\mathbf{2 9}$ & - & - & - & - & - \\
\hline $\mathbf{3 0}$ & - & 0,95 & - & - & 0,95 \\
\hline $\mathbf{3 1}$ & 0,22 & 7,23 & - & - & 7,45 \\
\hline $\mathbf{3 2}$ & - & - & - & - & - \\
\hline $\mathbf{3 3}$ & 0,22 & - & - & 0,01 & 0,23 \\
\hline $\mathbf{3 4}$ & - & 1,25 & - & - & 1,25 \\
\hline & & & & & \\
\hline & & - & - & - & - & - \\
\hline
\end{tabular}


Tabela 29 - Consumo de água total da fábrica para os blocos de vedação com $14 \mathrm{~cm}$ de largura.

\begin{tabular}{|c|c|c|c|c|c|}
\hline \multicolumn{5}{|c|}{$\begin{array}{c}\text { Blocos de vedação de } 14 \mathrm{~cm} \text { - Consumo médio de água } \\
\text { (litro/bloco) }\end{array}$} & \multirow[t]{2}{*}{ Tota } \\
\hline Empresa & Concessionária & Subterrânea & Superficial & Chuva & \\
\hline 1 & - & 0,75 & - & - & 0,75 \\
\hline 2 & 0,40 & - & 0,46 & - & 0,86 \\
\hline 3 & 0,66 & - & - & - & 0,66 \\
\hline 4 & - & 0,98 & - & - & 0,98 \\
\hline 5 & 0,13 & - & 0,91 & - & 1,04 \\
\hline 6 & - & 0,66 & - & - & 0,66 \\
\hline 7 & - & - & - & - & - \\
\hline 8 & - & - & - & - & - \\
\hline 10 & - & 0,40 & - & - & 0,40 \\
\hline 11 & 0,13 & 0,42 & - & - & 0,54 \\
\hline 12 & - & 0,81 & - & - & 0,81 \\
\hline 13 & - & 0,47 & - & - & 0,47 \\
\hline 14 & 0,03 & 0,42 & - & - & 0,44 \\
\hline 15 & 0,07 & 0,31 & - & - & 0,38 \\
\hline 16 & - & 1,17 & - & - & 1,17 \\
\hline 17 & - & - & - & - & - \\
\hline 18 & - & 0,93 & - & - & 0,93 \\
\hline 19 & - & - & - & - & - \\
\hline 20 & - & 0,25 & - & - & 0,25 \\
\hline 21 & - & - & 0,79 & - & 0,79 \\
\hline 22 & - & 0,03 & - & - & 0,03 \\
\hline 23 & 0,31 & - & - & - & 0,31 \\
\hline 24 & 0,31 & 0,32 & - & - & 0,64 \\
\hline 25 & - & 5,72 & - & - & 5,72 \\
\hline 26 & - & - & - & - & - \\
\hline 27 & - & - & - & - & - \\
\hline 28 & - & - & - & - & - \\
\hline 29 & - & - & - & - & - \\
\hline 30 & - & 0,70 & - & - & 0,70 \\
\hline 31 & 0,21 & 6,94 & - & - & 7,15 \\
\hline 32 & - & - & - & - & - \\
\hline 33 & 0,19 & - & - & 0,01 & 0,21 \\
\hline 34 & - & 1,03 & - & - & 1,03 \\
\hline
\end{tabular}


Tabela 30 - Consumo de água total da fábrica para os blocos de vedação com $9 \mathrm{~cm}$ de largura.

\begin{tabular}{|c|c|c|c|c|c|}
\hline \multicolumn{5}{|c|}{$\begin{array}{l}\text { Blocos de vedação de } 9 \mathrm{~cm} \text { - Consumo médio de água } \\
\text { (litro/bloco) }\end{array}$} & \multirow[t]{2}{*}{ Total } \\
\hline Empresa & Concessionária & Subterrânea & Superficial & Chuva & \\
\hline 1 & - & 0,60 & - & - & 0,60 \\
\hline 2 & 0,34 & - & 0,39 & - & 0,73 \\
\hline 3 & 0,59 & - & - & - & 0,59 \\
\hline 4 & - & 0,85 & - & - & 0,85 \\
\hline 5 & 0,09 & - & 0,66 & - & 0,76 \\
\hline 6 & - & - & - & - & - \\
\hline 7 & 0,04 & 0,15 & - & - & 0,19 \\
\hline 8 & 0,38 & - & - & - & 0,38 \\
\hline 10 & - & 0,34 & - & - & 0,34 \\
\hline 11 & 0,10 & 0,34 & - & - & 0,44 \\
\hline 12 & - & 0,97 & - & - & 0,97 \\
\hline 13 & - & 0,35 & - & - & 0,35 \\
\hline 14 & 0,02 & 0,37 & - & - & 0,39 \\
\hline 15 & 0,05 & 0,23 & - & - & 0,28 \\
\hline 16 & - & 0,99 & - & - & 0,99 \\
\hline 17 & - & - & - & - & - \\
\hline 18 & - & 0,76 & - & - & 0,76 \\
\hline 19 & - & - & - & - & - \\
\hline 20 & - & 0,19 & - & - & 0,19 \\
\hline 21 & - & - & 0,59 & - & 0,59 \\
\hline 22 & - & 0,02 & - & - & 0,02 \\
\hline 23 & 0,28 & - & - & - & 0,28 \\
\hline 24 & 0,28 & 0,29 & - & - & 0,56 \\
\hline 25 & - & 4,78 & - & - & 4,78 \\
\hline 26 & - & - & - & - & - \\
\hline 27 & - & - & - & - & - \\
\hline 28 & - & - & - & - & - \\
\hline 29 & - & - & - & - & - \\
\hline 30 & - & 0,59 & - & - & 0,59 \\
\hline 31 & 0,14 & 4,82 & - & - & 4,97 \\
\hline 32 & - & - & - & - & - \\
\hline 33 & 0,16 & - & - & 0,01 & 0,17 \\
\hline 34 & - & 0,77 & - & - & 0,77 \\
\hline
\end{tabular}

A Figura 29 apresenta a distribuição das empresas em relação ao consumo de água total da fábrica, estimado pela massa dos produtos. Observa-se grande dispersão dos resultados. Aproximadamente $50 \%$ das empresas apresenta consumo de água total por peça menor ou igual à água de composição informada (aproximadamente $6 \%$ da massa do bloco), enquanto cerca de $10 \%$ apresenta consumo muito elevado. 


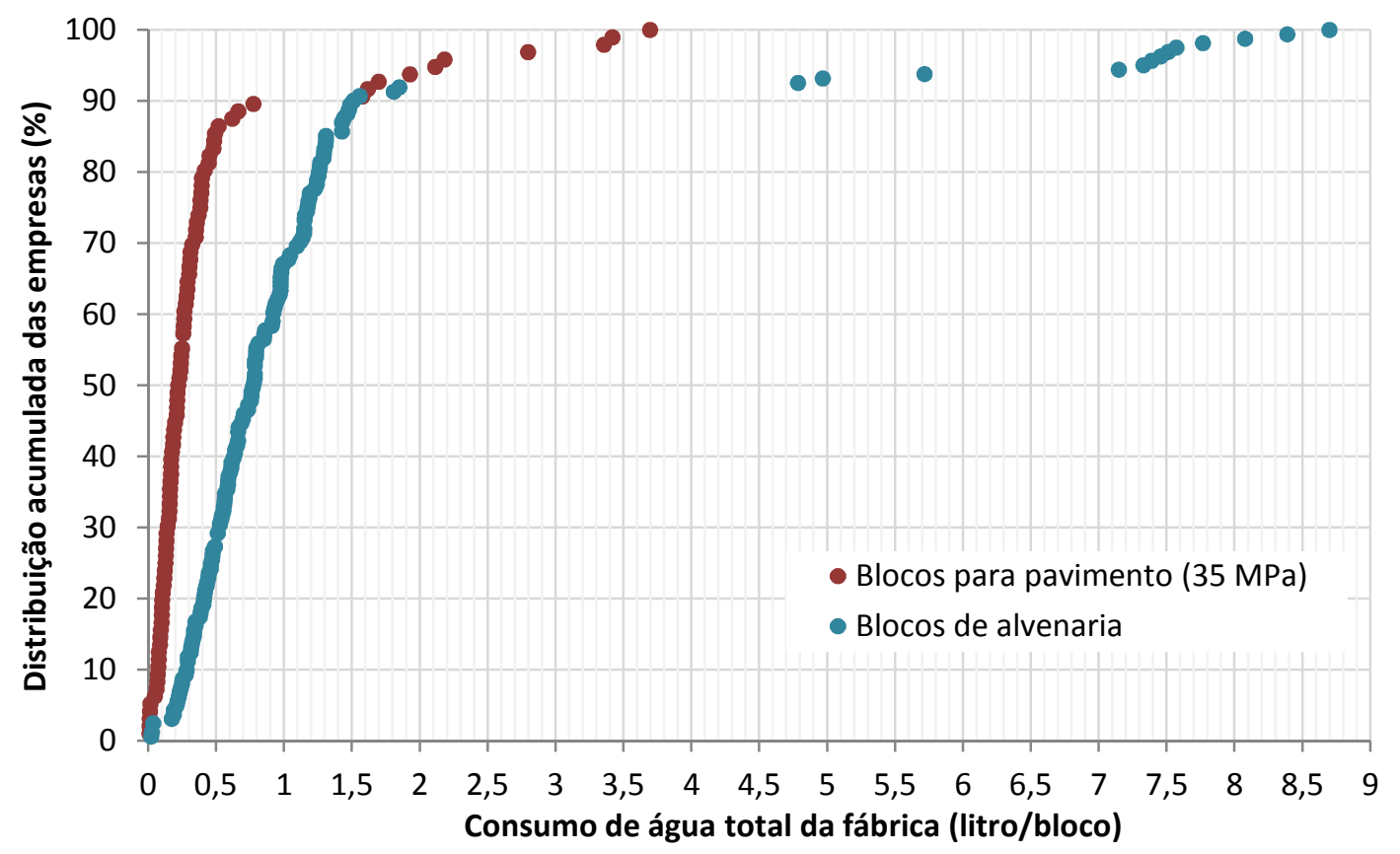

Figura 29 - Gráfico de distribuição do consumo total de água das fábricas alocado nos blocos pela massa da peça.

A Figura 30 e a Figura 31 apresentam a faixa dos indicadores dos consumos de água total estimados para os blocos para pavimento (35 MPa) e para os blocos para alvenaria, respectivamente. Os pontos em cinza representam as empresas.

Como as empresas 19 e 32 não informaram sua massa total de produção, não tiveram seu indicador calculado. As empresas 25 e 31 apresentaram valores de consumo total de água muito elevado quando comparado com as outras empresas, que claramente não pode ser justificado pelas condições operacionais. Por isso, esses resultados não foram considerados para formação da faixa, sendo julgados como produtos de erro de inventário.

Valores muito baixos também podem ser vistos como consequência de falha no inventário. No entanto, preferiu-se não descartar esses resultados devido à falta de um parâmetro para esse corte. Isso porque pode haver casos em que a umidade dos agregados seja elevada ou exista o uso de água captada de chuva, ou outra fonte, que não tenha sido contabilizada.

É necessário desenvolver na cadeia de fornecedores e de fabricantes métodos para a gestão da água consumida, considerando todas as origens, incluindo água de chuva e de reúso. A dispersão observada também é resultado da falta de um procedimento padrão no levantamento dos dados informados pelas empresas. 


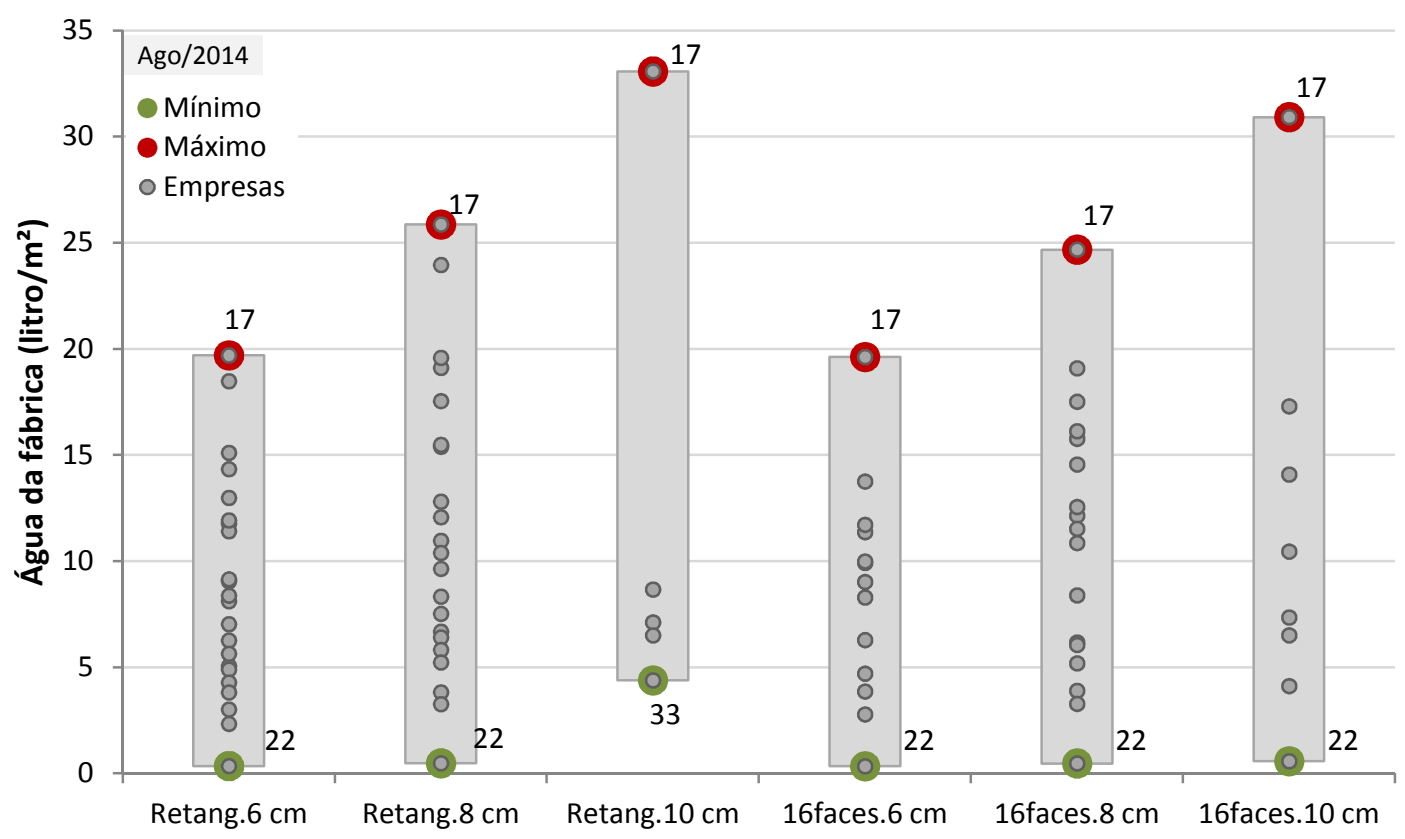

Figura 30 - Indicador de consumo total de água da fábrica dos blocos para pavimento.

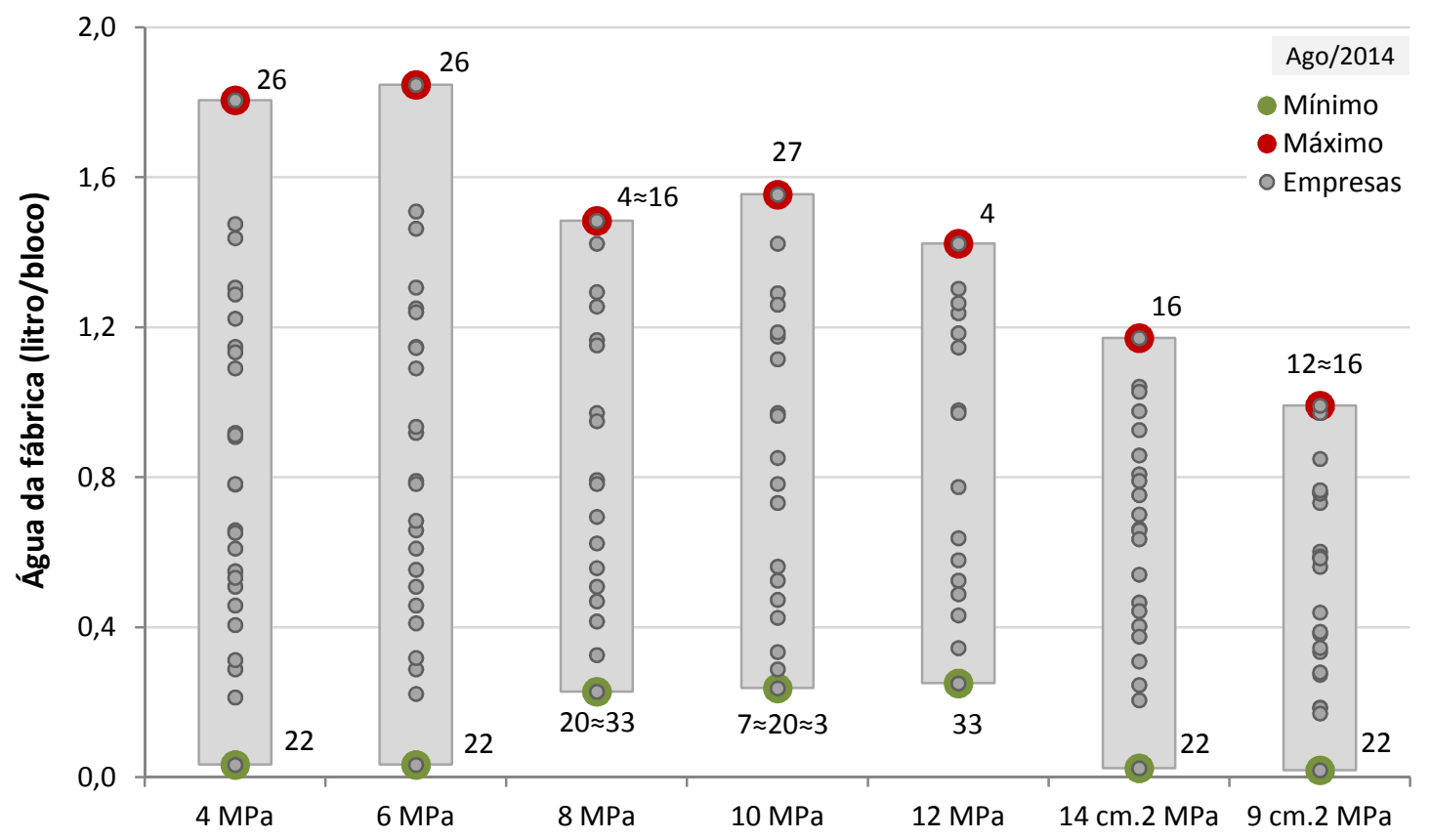

Figura 31 - Indicador de consumo total de água da fábrica dos blocos para alvenaria.

\subsection{Energia incorporada e emissão de $\mathrm{CO}_{2}$ por tipo de cimento}

Para uma análise mais detalhada dos indicadores de energia incorporada e emissão de $\mathrm{CO}_{2}$, a mediana ou a média (quando há apenas uma empresa) por tipo de cimento foram calculadas, sendo apresentadas nas figuras 31 a 34 . Das 20 empresas que compõem as faixas dos blocos para pavimento, 16 utilizam CP V, duas usam CP II-Z, uma CP II-F e uma CP IV. Já entre as 25 empresas que 
constituem as faixas dos blocos para alvenaria, 23 utilizam CP V, uma CP II-Z e uma CP II-F.

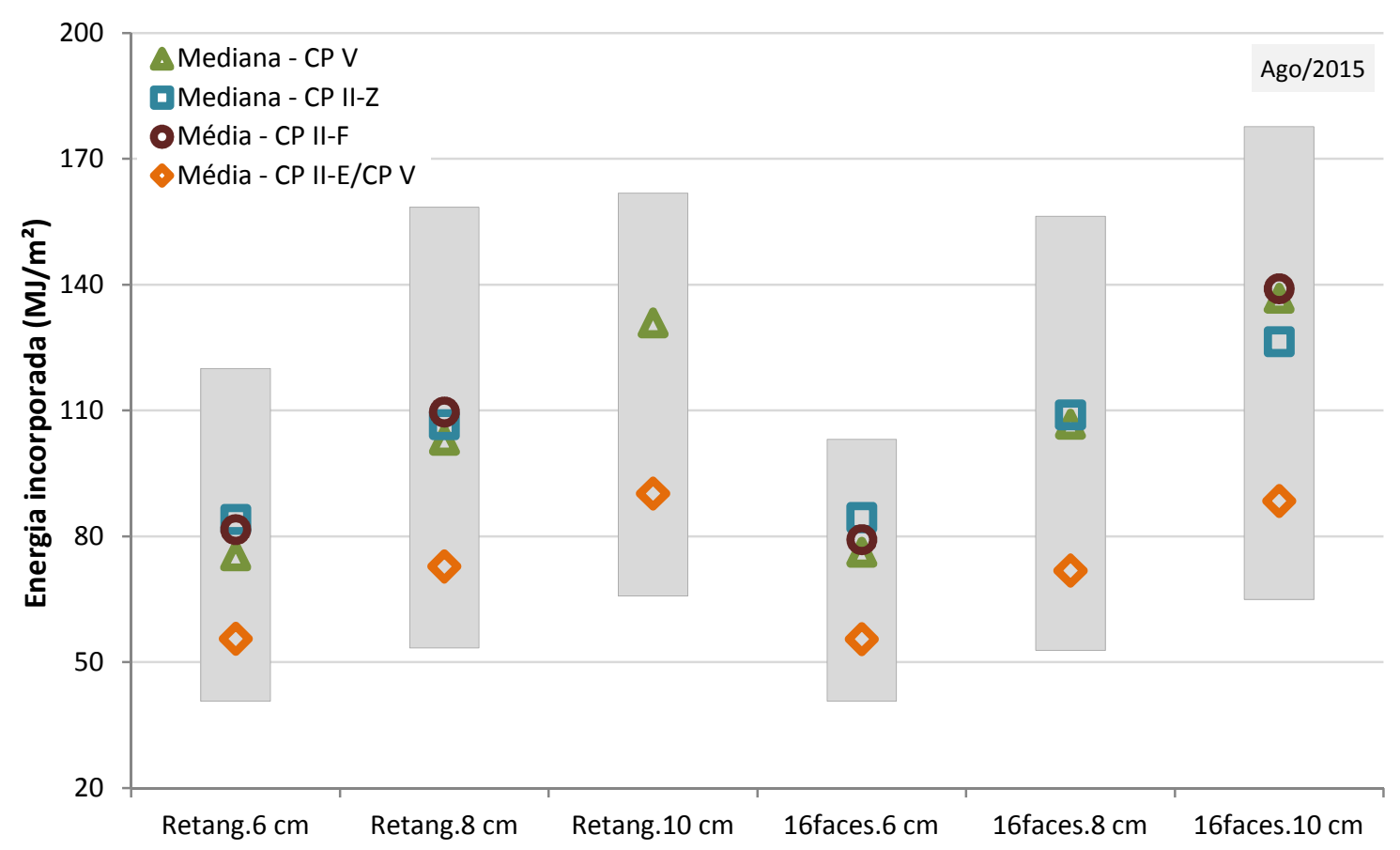

Figura 32 - Faixas da energia incorporada dos blocos para pavimento com mediana/média por tipo de cimento.

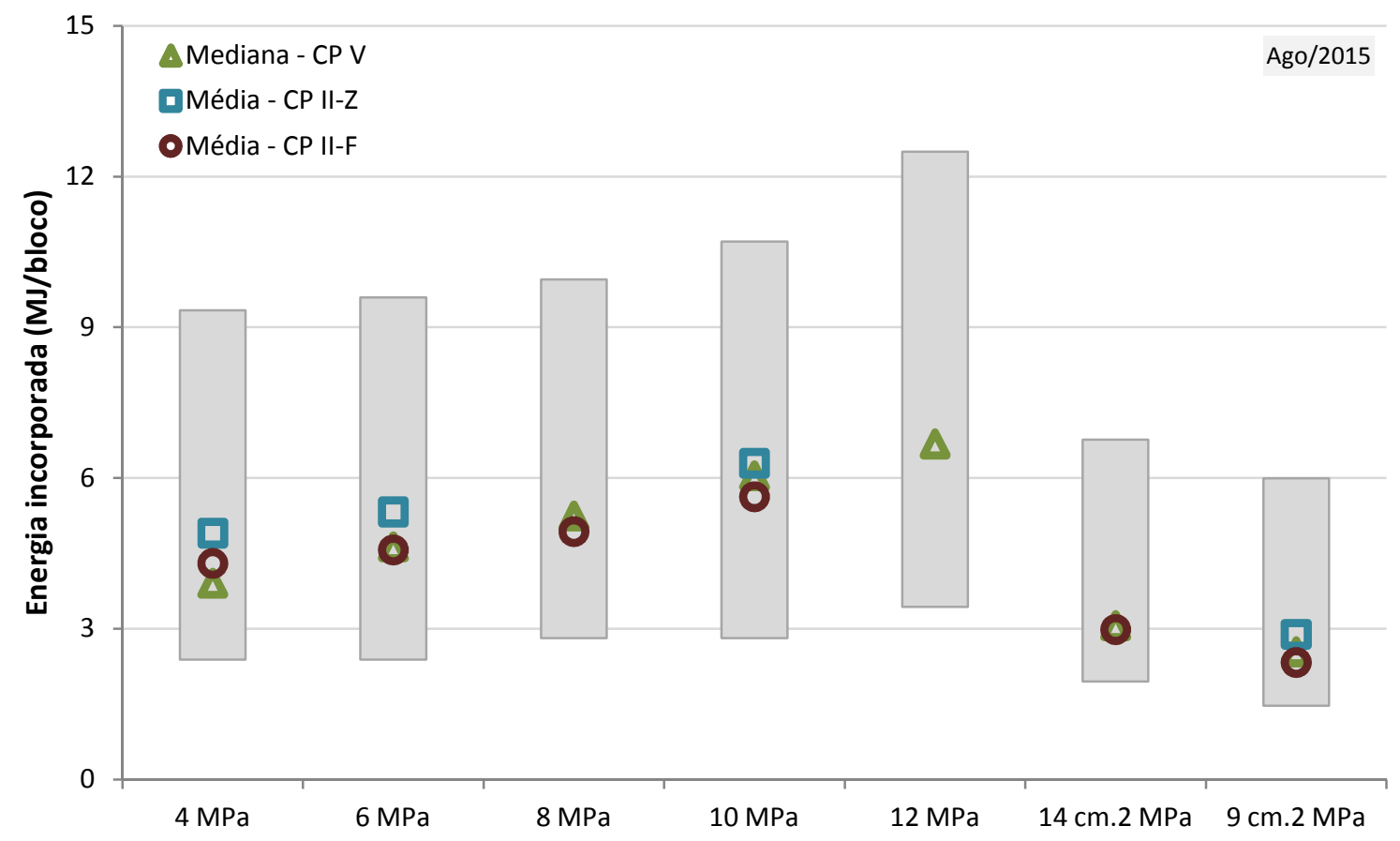

Figura 33 - Faixas da energia incorporada dos blocos para alvenaria com mediana/média por tipo de cimento. 


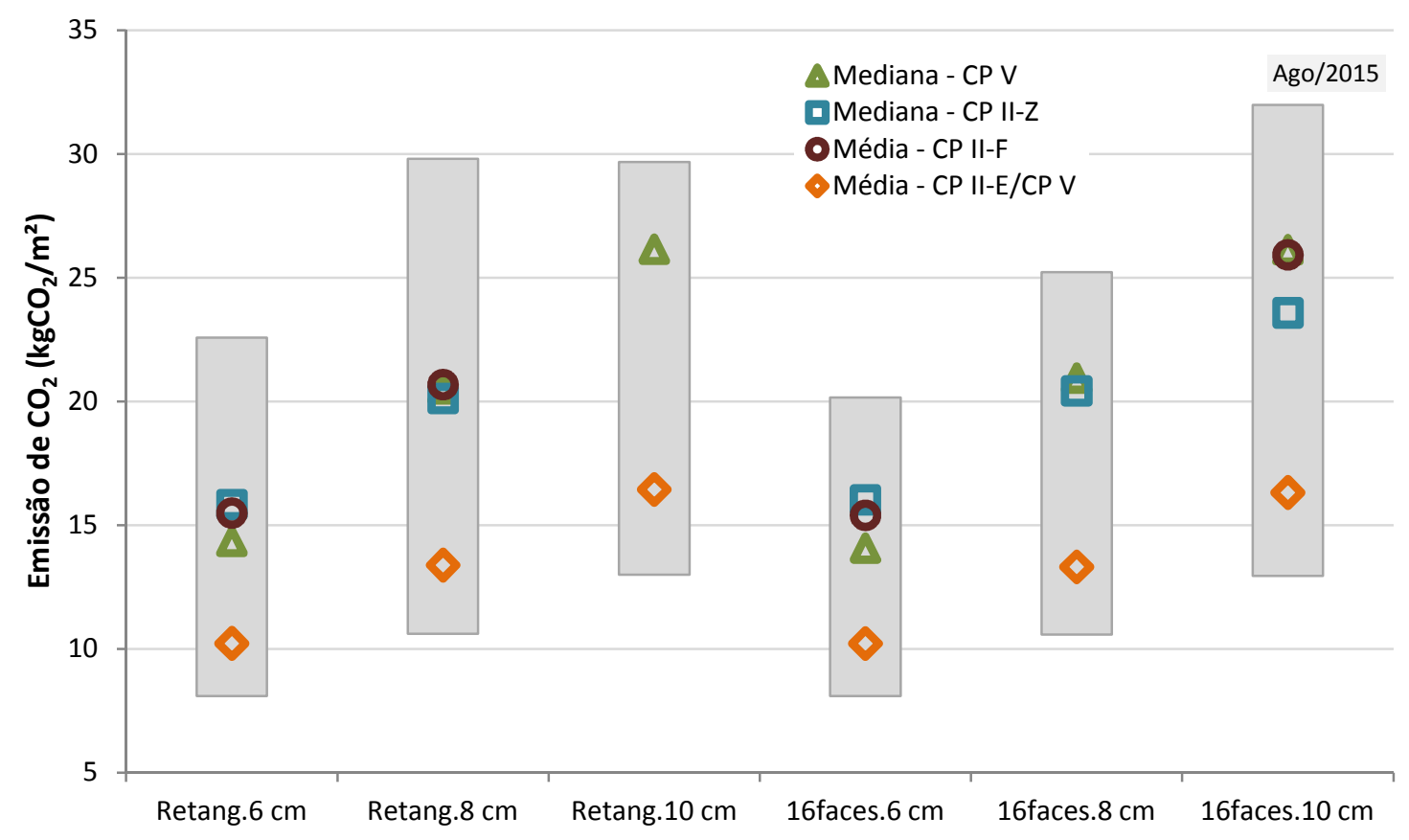

Figura 34 - Faixas da emissão de $\mathrm{CO}_{2}$ dos blocos para pavimento com mediana/média por tipo de cimento.

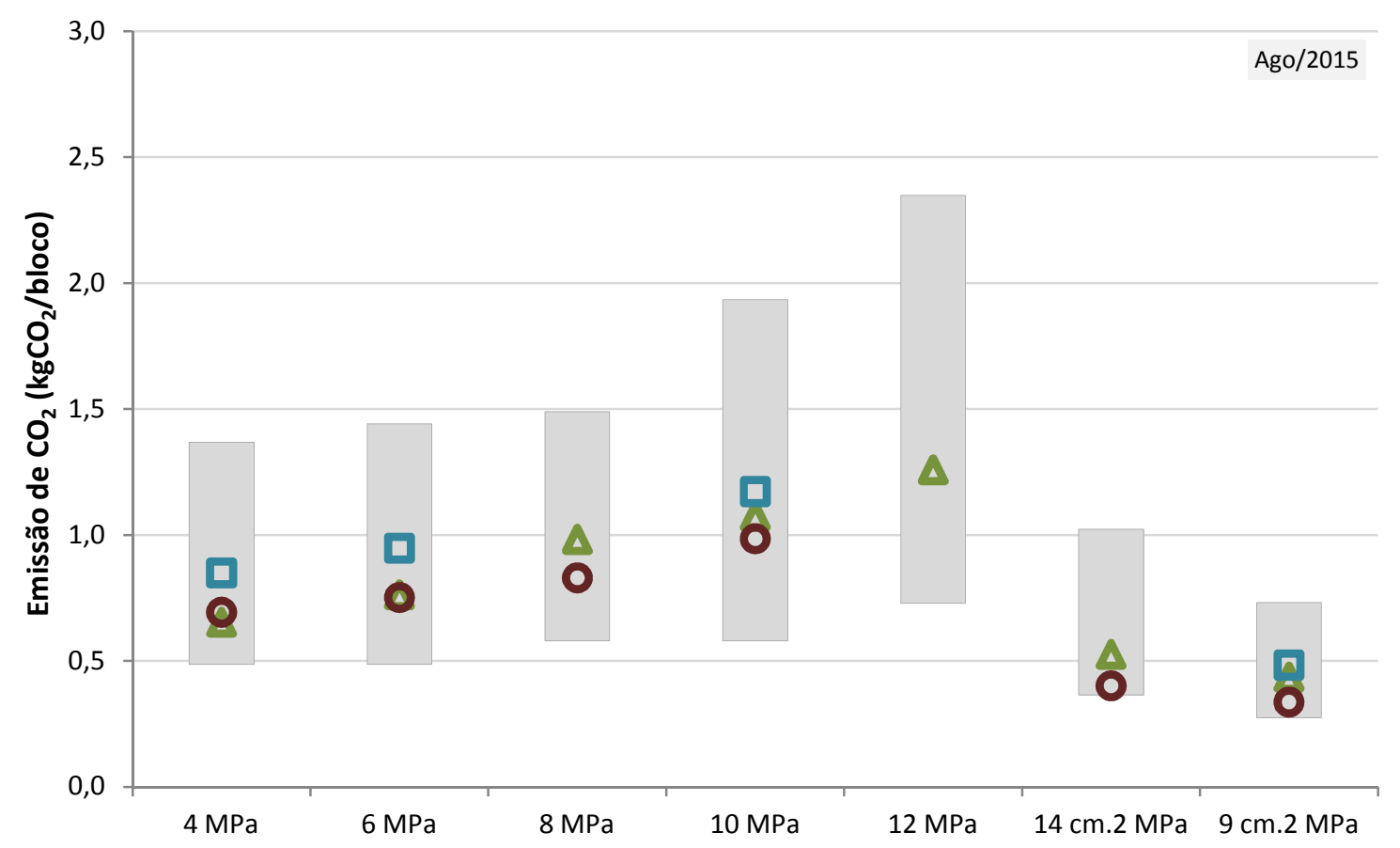

Figura 35 - Faixas da emissão de $\mathrm{CO}_{2}$ dos blocos para alvenaria com mediana/média por tipo de cimento. 
Nas faixas referentes aos blocos para pavimentação (Figura 32 e Figura 34), observa-se que o menor valor observado refere-se à empresa que utiliza CP II-E associado ao CP $\vee$ (empresa 17), responsável por todos os extremos mínimos das faixas. Isso mostra que pelo estudo da formulação do concreto é possível combinar diferentes tipos de cimento para que o produto apresente as características especificadas e baixa emissão de $\mathrm{CO}_{2}$, mesmo usando um cimento com alto teor de clínquer.

Analisando todos os produtos que utilizam CP II-Z e CP II-F, nota-se que suas medianas/médias encontram-se próximas aos valores medianos referentes ao uso apenas de CP V. Embora entre as empresas analisadas poucas utilizem cimentos com adições (apenas 4 entre as que compõem os indicadores), pode-se concluir que no caso em estudo o teor de adições dos cimentos (6-14\% de pozolana e $0-10 \%$ de filler para o CP II-Z e 6-10\% de filler para o CP II-F) não foi o responsável por controlar as emissões de $\mathrm{CO}_{2}$. Embora seja inquestionável que a substituição do clínquer reduza as emissões de $\mathrm{CO}_{2}$ associadas à produção do cimento - uma das principais estratégias adotada pela indústria de cimento (GARTNER, 2004; WORRELL et al., 2001) - ela não automaticamente minimiza as emissões de $\mathrm{CO}_{2}$ de produtos cimentícios, como sugere a literatura (DAMTOFT et al., 2008; ROSKOVIC; BJEGOVIC, 2005) e sistemas de certificação como LEED (KUBBA, 2010; SCA, 2008).

\subsection{Origem da energia incorporada e da emissão de $\mathrm{CO}_{2}$}

A Tabela 31 apresenta a porcentagem de cada parcela do processo produtivo de blocos de concreto responsável pela energia incorporada e pela emissão de $\mathrm{CO}_{2}$ dos produtos analisados. As empresas que não foram consideradas na composição das faixas dos indicadores não estão presentes nessa análise. 
Tabela 31 - Participação de cada etapa da ACV dos blocos de concreto na energia incorporada e na emissão de $\mathrm{CO}_{2}$.

\begin{tabular}{lcccccc} 
& \multicolumn{2}{c}{ Blocos para pavimento } & \multicolumn{2}{c}{ Blocos estruturais } & \multicolumn{2}{c}{ Blocos de vedação } \\
\cline { 2 - 7 } & $\begin{array}{c}\text { Energia } \\
\text { incorporada }\end{array}$ & $\begin{array}{c}\text { Emissão } \\
\text { de } \mathbf{C O}_{2}\end{array}$ & $\begin{array}{c}\text { Energia } \\
\text { incorporada }\end{array}$ & $\begin{array}{c}\text { Emissão } \\
\text { de } \mathbf{C O}_{2}\end{array}$ & $\begin{array}{c}\text { Energia } \\
\text { incorporada }\end{array}$ & $\begin{array}{c}\text { Emissão } \\
\text { de } \mathbf{C O}_{2}\end{array}$ \\
\hline Transporte & 1 a $28 \%$ & 0,3 a $13 \%$ & 1 a $29 \%$ & 0,4 a $16 \%$ & 1 a $29 \%$ & 0,5 a $16 \%$ \\
\hline Fábrica & 3 a 33\% & 0,3 a $14 \%$ & 3 a $62 \%$ & 0,3 a $31 \%$ & 5 a $64 \%$ & 1 a $34 \%$ \\
\hline Materiais & 55 a $96 \%$ & 79 a $99 \%$ & 37 a $95 \%$ & 65 a $99 \%$ & 35 a $92 \%$ & 66 a $99 \%$ \\
\hline - Cimento & 55 a $96 \%$ & 79 a $99 \%$ & 32 a $88 \%$ & 61 a $97 \%$ & 30 a $84 \%$ & 62 a $95 \%$ \\
\hline - Agregados & 0,001 a $1 \%$ & $\begin{array}{c}0,0001 \text { a } \\
0,04 \%\end{array}$ & 2 a $21 \%$ & 1 a $11 \%$ & 4 a $23 \%$ & 2 a $12 \%$ \\
\hline
\end{tabular}

A energia direta, consumida pela fábrica, responde por 3 a $33 \%$ da energia incorporada dos blocos para pavimento (mediana de $10 \%$ ) e de 3 a $62 \%$ no caso dos blocos para alvenaria (mediana de 15\%). Já a energia indireta, que corresponde pelo consumo de materiais e pelo transporte dos mesmos, responde por 36 a $97 \%$ para os BCP (mediana de $90 \%$ ) e por 67 a $97 \%$ para os BCE e os BCV (mediana de $85 \%$ ). Algumas empresas podem realizar o transporte das matérias-primas por veículos próprios, caso onde a energia dessa atividade seria considerada como direta. Essa situação não foi analisada nesse estudo, visto que todo transporte foi considerado como realizado por terceiros.

O consumo de cimento o principal responsável pelo resultado desses indicadores. Entre as empresas participantes houve uma grande variação no consumo de cimento para a produção de blocos com mesmas dimensões e classe de resistência. A razão entre os consumos mínimo e máximo variou em um fator de 1,6 a 2,6 nos blocos para pavimento e de 2,0 a 3,1 nos blocos para alvenaria. As características da vibroprensa utilizada na moldagem do bloco é provavelmente um importante fator na definição do consumo de cimento, que influencia a emissão de $\mathrm{CO}_{2}$ e a energia, pois quanto mais eficiente for a compactação, menor a quantidade de cimento para garantir a resistência mínima.

Mantida a geometria, as características das partículas, agregados (distribuição e forma dos grãos) ou mesmo cimento, o teor de água e aditivos influencia diretamente no grau de compactação obtido com a energia disponível - uma característica da máquina. Assim, estes fatores afetam na quantidade de cimento 
necessária para o alcance da resistência característica especificada e, indiretamente, na energia incorporada e na emissão de $\mathrm{CO}_{2}$. É provável que algumas empresas utilizem estratégias na formulação do concreto, inclusive pela seleção e combinação de agregados, de modo a minimizar o consumo de cimento e, desta forma, a pegada de $\mathrm{CO}_{2}$. Uma das empresas participantes possui seus fornecedores de cimento a distâncias que variam entre 30 e $584 \mathrm{~km}$, sendo que isso deve ser realizado por questões técnicas. Possivelmente ela prefira utilizar CP V transportado por grandes distâncias do que um cimento com menor teor de clínquer, mas que influencie negativamente em sua formulação. Em outros casos, é possível que a qualidade de agregados e cimentos disponíveis na região seja fator limitante, sobre os quais o fabricante tem pouco ou nenhum controle.

A maioria das empresas utiliza o cimento CP V em sua produção, mas os tipos CP IIE, CP II-Z, CP II-F, CP III e CP IV também são utilizados por algumas fábricas, embora os resultados das empresas que utilizam CP III e CP IV não terem sido considerados na composição das faixas (possibilidade de erro de inventário). No entanto, como mostra a Tabela 32, praticamente todos os valores máximos e mínimos de consumo de cimento estão associados ao uso CPV, que tem o maior teor de clínquer, assim como os extremos das faixas de energia incorporada e emissão de $\mathrm{CO}_{2}$, embora não necessariamente eles estejam associados. Assim, a classe do cimento não foi a principal causa das diferenças apresentadas pelos indicadores.

Assim como a minimização da energia e emissão de $\mathrm{CO}_{2}$ depende não só de um mínimo teor de cimento, mas da minimização de outros fatores. As diversas possibilidades para dosagem do concreto, pela variedade de agregados disponíveis por região e pelo teor e reatividade do cimento, as estratégias de cura e as diferenças na eficiência de compactação das vibroprensas são provavelmente os responsáveis por essas variações. 
Tabela 32 - Tipo de cimento associado aos valores mínimos e máximos de consumo de cimento, energia incorporada e emissão de $\mathrm{CO}_{2}$.

\begin{tabular}{|c|c|c|c|c|c|c|}
\hline \multirow{2}{*}{$\begin{array}{l}\text { Tipo de } \\
\text { bloco }\end{array}$} & \multirow{2}{*}{\multicolumn{2}{|c|}{ Característica }} & \multicolumn{2}{|c|}{ Consumo de cimento } & \multicolumn{2}{|c|}{$\begin{array}{l}\text { Energia incorporada } \\
\text { e Emissão de } \mathrm{CO}_{2}\end{array}$} \\
\hline & & & Mínimo & Máximo & Mínimo & Máximo \\
\hline \multirow{6}{*}{$\begin{array}{c}\text { Bloco } \\
\text { para } \\
\text { pavimento } \\
(35 \mathrm{MPa})\end{array}$} & \multirow{3}{*}{ Retangular } & $6 \mathrm{~cm}$ & $\mathrm{CP} \mathrm{V}$ & $\mathrm{CP} \mathrm{V}$ & CP II-E e CP V & $\mathrm{CPV}$ \\
\hline & & $8 \mathrm{~cm}$ & $\mathrm{CPV}$ & $\mathrm{CPV}$ & CP II-E e CP V & $\mathrm{CP} \mathrm{V}$ \\
\hline & & $10 \mathrm{~cm}$ & CP II-E e CP V & CP V & CP II-E e CP V & $\mathrm{CP} \mathrm{V}$ \\
\hline & \multirow{3}{*}{16 faces } & $6 \mathrm{~cm}$ & $\mathrm{CP} V$ & CP II-Z & CP II-E e CP V & CP II-Z \\
\hline & & $8 \mathrm{~cm}$ & CP V & CP IV & CP II-E e CP V & $\mathrm{CP} \mathrm{V}$ \\
\hline & & $10 \mathrm{~cm}$ & $\mathrm{CP} V$ & CP IV & CP II-E e CP V & $\mathrm{CP} V$ \\
\hline \multirow{5}{*}{$\begin{array}{l}\text { Bloco } \\
\text { estrutural }\end{array}$} & \multicolumn{2}{|c|}{$4 \mathrm{MPa}$} & $\mathrm{CP} \vee$ & $\mathrm{CP} \vee$ & CP V & $\mathrm{CP} V$ \\
\hline & \multicolumn{2}{|c|}{$6 \mathrm{MPa}$} & $\mathrm{CP} V$ & $\mathrm{CP} V$ & CP V & $\mathrm{CP} V$ \\
\hline & \multicolumn{2}{|c|}{$8 \mathrm{MPa}$} & $\mathrm{CPV}$ & CP V & $\mathrm{CPV}$ & $\mathrm{CP} V$ \\
\hline & \multicolumn{2}{|c|}{$10 \mathrm{MPa}$} & $\mathrm{CP} V$ & $\mathrm{CP} V$ & CP V & $\mathrm{CP} V$ \\
\hline & \multicolumn{2}{|c|}{$12 \mathrm{MPa}$} & CP V & CP V & CP V & $\mathrm{CP} V$ \\
\hline \multirow{2}{*}{$\begin{array}{l}\text { Bloco de } \\
\text { vedação } \\
(2 \mathrm{MPa})\end{array}$} & \multicolumn{2}{|c|}{$14 \mathrm{~cm}$} & CP IV & CP V & CP V & CP V \\
\hline & \multicolumn{2}{|c|}{$9 \mathrm{~cm}$} & $\mathrm{CP} V$ & $\mathrm{CP} V$ & $\mathrm{CP} V$ & $\mathrm{CP} V$ \\
\hline
\end{tabular}

\subsection{Origem da variabilidade}

As diferenças entre energia incorporada e emissões de $\mathrm{CO}_{2}$ de um mesmo produto dentre as empresas são resultados das incertezas da energia incorporada (EI) e fatores de emissão dos insumos (FE); de fatores internos da fábrica, como massa do bloco, formulação do concreto e tipo de cimento; e das distâncias e modal de transporte das matérias-primas. As variações da energia incorporada e dos fatores de emissão dos insumos (apresentados na Tabela 4 e na Tabela 5) são expostas na Tabela 33, onde a razão entre os valores máximo e o mínimo adotados variou entre 1,1 e 3,0. Observa-se que na ausência da declaração ambiental de produto emitida pelo fabricante, a incerteza estimada para a emissão de $\mathrm{CO}_{2}$ do cimento $\mathrm{CP}$ II-Z é de $25 \%$, enquanto que do CP III é de aproximadamente $200 \%$, em razão dos teores de clínquer permitidos por norma. 
Tabela 33 - Variação dos fatores de emissão de $\mathrm{CO}_{2}$ e da energia incorporada dos insumos.

\begin{tabular}{lcccccc}
\hline \multirow{2}{*}{ Insumo } & \multicolumn{3}{c}{ Emissão de $\mathbf{C O}_{\mathbf{2}}\left(\mathbf{k g C O}_{\mathbf{2}} \mathbf{\mathbf { t }}\right)$} & \multicolumn{3}{c}{ Energia (MJ/t) } \\
\cline { 2 - 8 } & Mínimo & Máximo & $\mathbf{M a ́ x} /$ Mín & Mínimo & Máximo & Máx/Mín \\
\hline Areia natural & 4,2 & 9,6 & 2,3 & 55,3 & 109,0 & 2,0 \\
\hline Areia industrial & 1,3 & 1,9 & 1,4 & 17,1 & 42,1 & 2,5 \\
\hline Brita 0 & 1,2 & 1,9 & 1,6 & 13,5 & 55,3 & 4,1 \\
\hline Pedrisco de seixo & 1,3 & 1,9 & 1,4 & 14,6 & 42,1 & 2,9 \\
\hline Pedrisco & 1,3 & 1,9 & 1,4 & 14,6 & 42,1 & 2,9 \\
\hline Pó de pedra & 1,3 & 1,9 & 1,4 & 17,1 & 42,1 & 2,5 \\
\hline Agregado reciclado & 0,8 & 1,8 & 2,3 & 13,8 & 20,7 & 1,5 \\
\hline Cimento CP II-F & 735 & 770 & 1,1 & 3.096 & 3.240 & 1,0 \\
\hline Cimento CP II-Z & 616 & 770 & 1,3 & 2.592 & 3.240 & 1,3 \\
\hline Cimento CP II-E & 445 & 770 & 1,7 & 1.872 & 3.240 & 1,7 \\
\hline Cimento CP III & 175 & 522 & 3,0 & 756 & 2.196 & 2,9 \\
\hline Cimento CP IV & 351 & 693 & 2,0 & 1.476 & 2.916 & 2,0 \\
\hline Cimento CP V & 778 & 821 & 1,1 & 3.276 & 3.456 & 1,1 \\
\hline Lenha (plantada) & 690 & 1.512 & 2,2 & 6.204 & 13.734 & 2,2 \\
\hline Lenha (resíduo) & 0 & 0 & 0,0 & 6.073 & 12.980 & 2,1 \\
\hline
\end{tabular}

As figuras de 36 a 41 apresentam a origem das variações dos resultados da energia incorporada e da emissão de $\mathrm{CO}_{2}$ das empresas participantes, separando-as em três fontes: (i) diferenças entre empresas em relação às matérias-primas (como tipo de cimento), consumos energéticos, massa do produto e formulação do concreto; (ii) diferenças de distâncias e modal de transporte; e (iii) incertezas da energia incorporada e dos fatores de emissão dos insumos materiais e energéticos.

Primeiramente as faixas dos indicadores foram recalculadas considerando apenas os valores mínimos de FE e El dos insumos, sem incluir o consumo de óleo diesel devido ao transporte. Subtraindo desse valor o resultado mínimo dos indicadores reais dos produtos, tem-se a interferência das variações entre fabricantes (faixa verde nos gráficos). Em seguida, os indicadores foram calculados novamente apenas com os FE e El mínimos, mas agora incluindo o consumo de diesel pelo transporte. A parcela oriunda da variação do transporte resulta da subtração desse resultado pelo valor sem considerar o consumo de óleo diesel (faixa vermelha nos gráficos). Por fim, descontando do resultado máximo do indicador real o valor calculado pelos mínimos FE e El, juntamente com o consumo pelo transporte, temse a influência da incerteza da energia incorporada e do fator de emissão de $\mathrm{CO}_{2}$ dos insumos (faixa bege nos gráficos). 
A incerteza dos fatores de emissão e energia resulta em variação de 1,3 a 3,1 $\mathrm{kgCO}_{2} / \mathrm{m}^{2}$ e de 8,1 a $13,1 \mathrm{MJ} / \mathrm{m}^{2}$ no BCP. Nos BCE a variação é de 0,08 a 0,13 $\mathrm{kgCO}_{2} /$ peça na emissão e de 0,6 a 0,8 MJ/peça na energia incorporada. Já nos BCV a variação é de 0,04 a 0,06 $\mathrm{kgCO}_{2} /$ peça e de 0,3 a $0,4 \mathrm{MJ} /$ peça. Se for considerado que os fabricantes utilizam apenas insumos contendo os menores fatores e energia, mesmo apresentando a mesma rota tecnológica, a emissão de $\mathrm{CO}_{2}$ varia em um fator de 2,1 a 3,2 vezes e a energia em um fator de 2,2 a 3,8.

As diferenças de distância de transporte e a incerteza do modal introduzem uma imprecisão que para os blocos para pavimento varia de 0,5 a $2,7 \mathrm{kgCO}_{2} / \mathrm{m}^{2}$ e de 14,8 a $31,1 \mathrm{MJ} / \mathrm{m}^{2}$. Para os blocos estruturais a variação é de 0,08 a 0,14 $\mathrm{kgCO}_{2} /$ peça e de 0,2 a $1,1 \mathrm{MJ} /$ peça. Já para os blocos de vedação a variação devido a essa incerteza é de 0,01 a $0,10 \mathrm{kgCO}_{2} /$ peça e de 0,1 a 0,2 MJ/peça.

A diversidade entre os fabricantes analisados resulta em variação entre 8,3 e 15,8 $\mathrm{kgCO}_{2} / \mathrm{m}^{2}$ e de 35,9 a $83,5 \mathrm{MJ} / \mathrm{m}^{2}$ para os BCP. Para os BCE a variação é de $0,7 \mathrm{a}$ $1,4 \mathrm{kgCO}_{2} /$ bloco e de 6,1 a $7,2 \mathrm{MJ} / \mathrm{bloco}$ e para os $\mathrm{BCV}$ de 0,4 a $0,5 \mathrm{kgCO}_{2} / \mathrm{bloco}$ e de 4,0 a $4,2 \mathrm{MJ} / \mathrm{bloco}$.

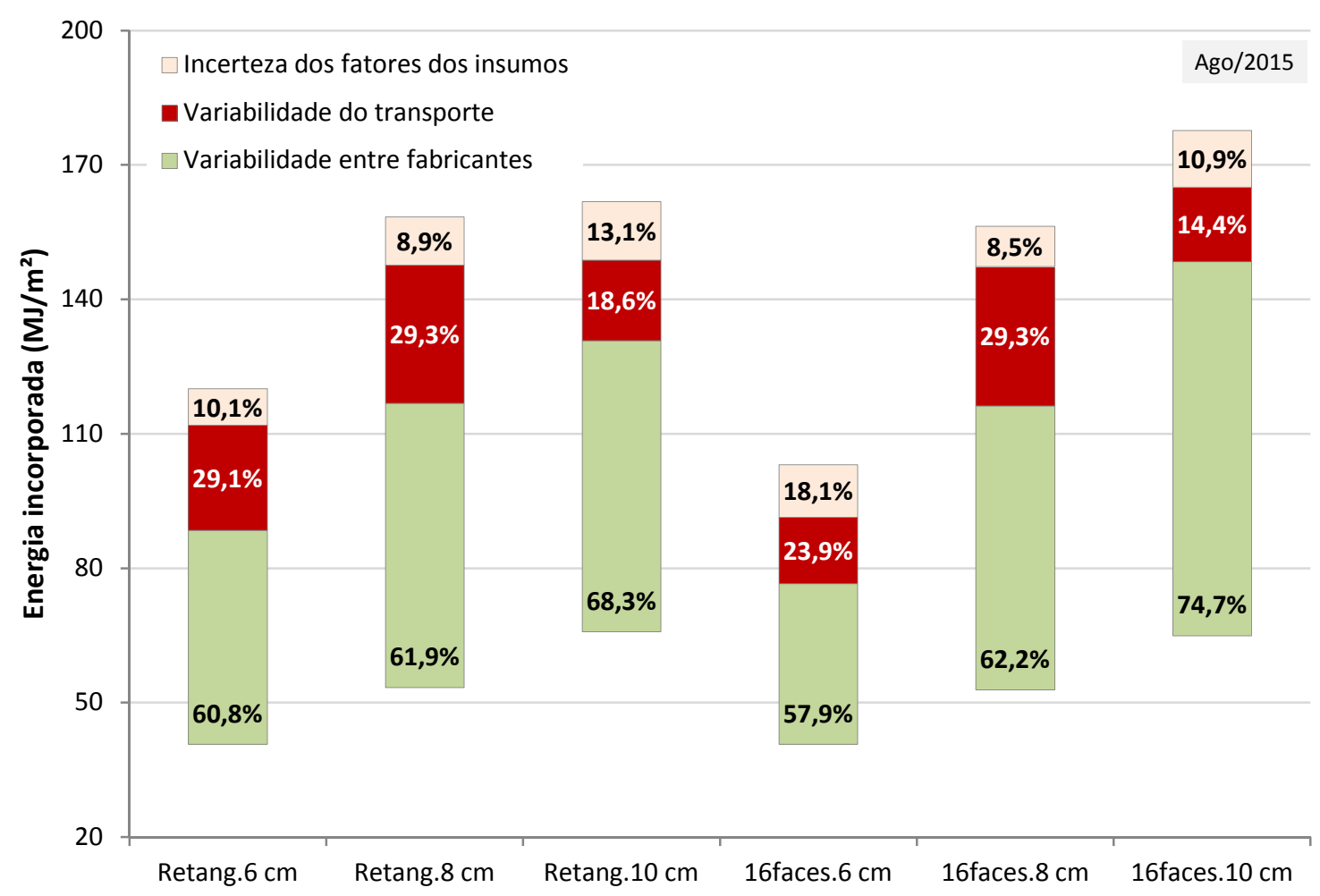

Figura 36 - Faixas da energia incorporada dos blocos para pavimento, considerando a variabilidade entre as empresas e do transporte e as incertezas da energia dos insumos. 


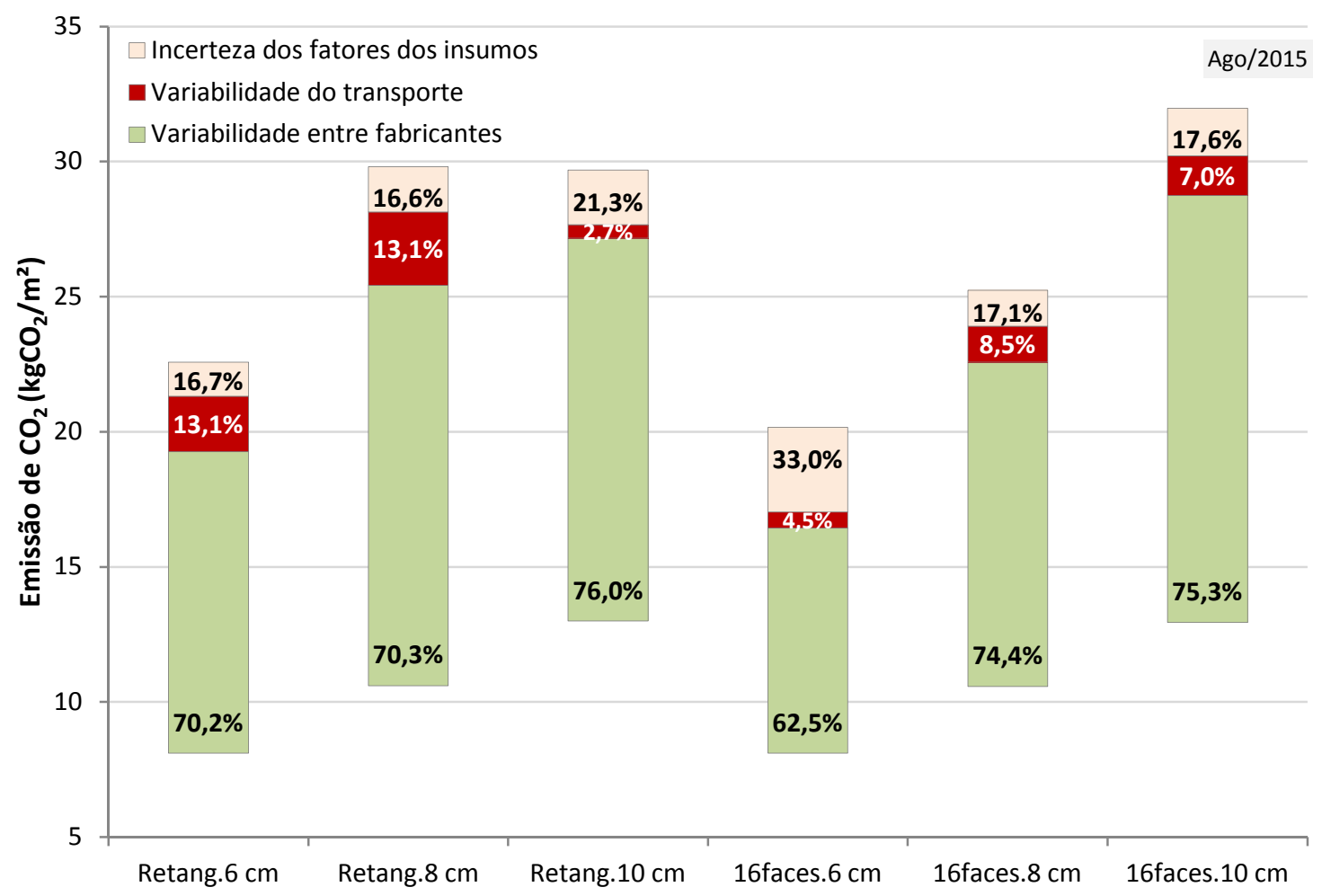

Figura 37 - Faixas da emissão de $\mathrm{CO}_{2}$ dos blocos para pavimento, considerando a variabilidade entre as empresas e do transporte e as incertezas dos fatores de emissão dos insumos.

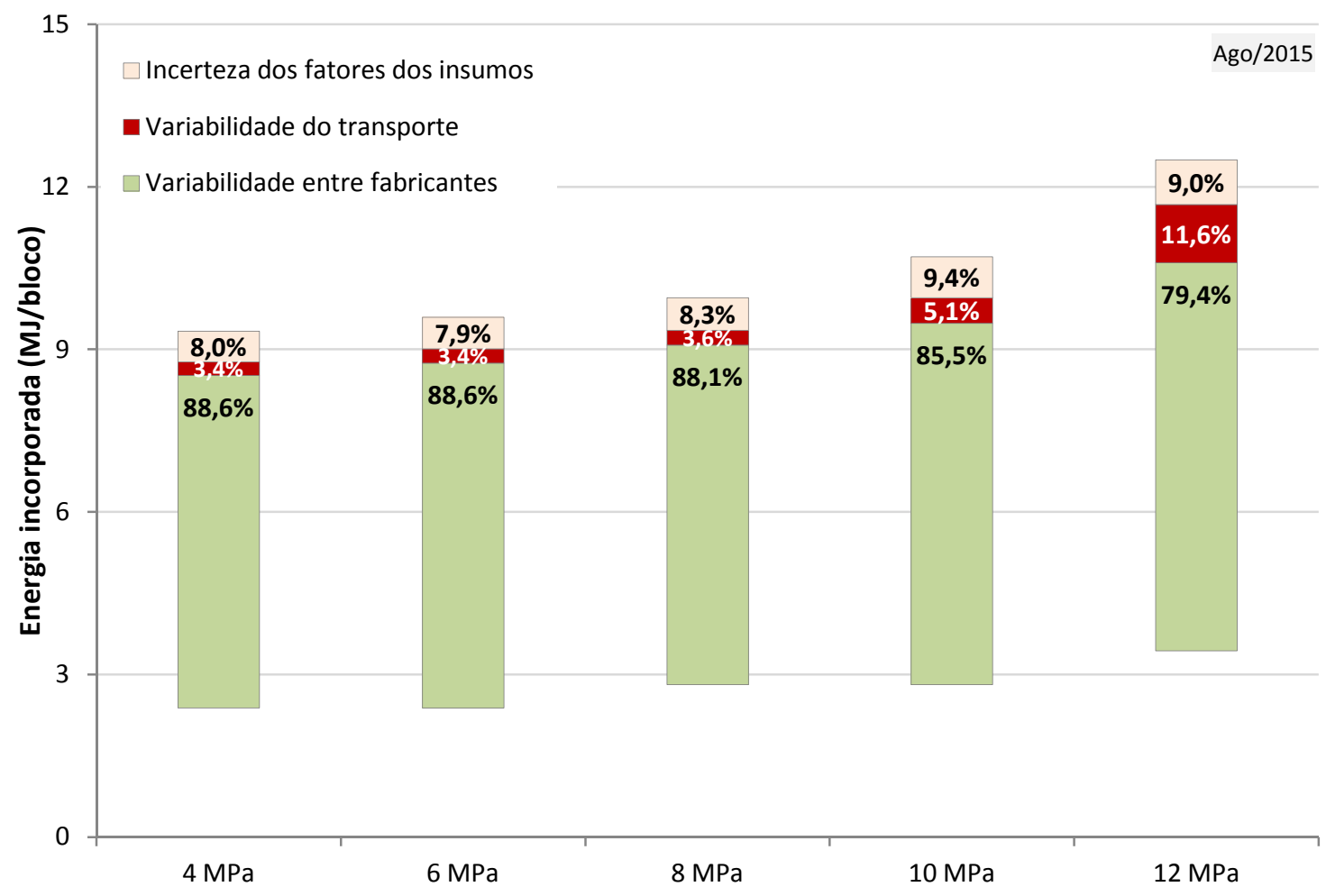

Figura 38 - Faixas da energia incorporada dos blocos estruturais, considerando a variabilidade entre as empresas e do transporte e as incertezas da energia dos insumos. 


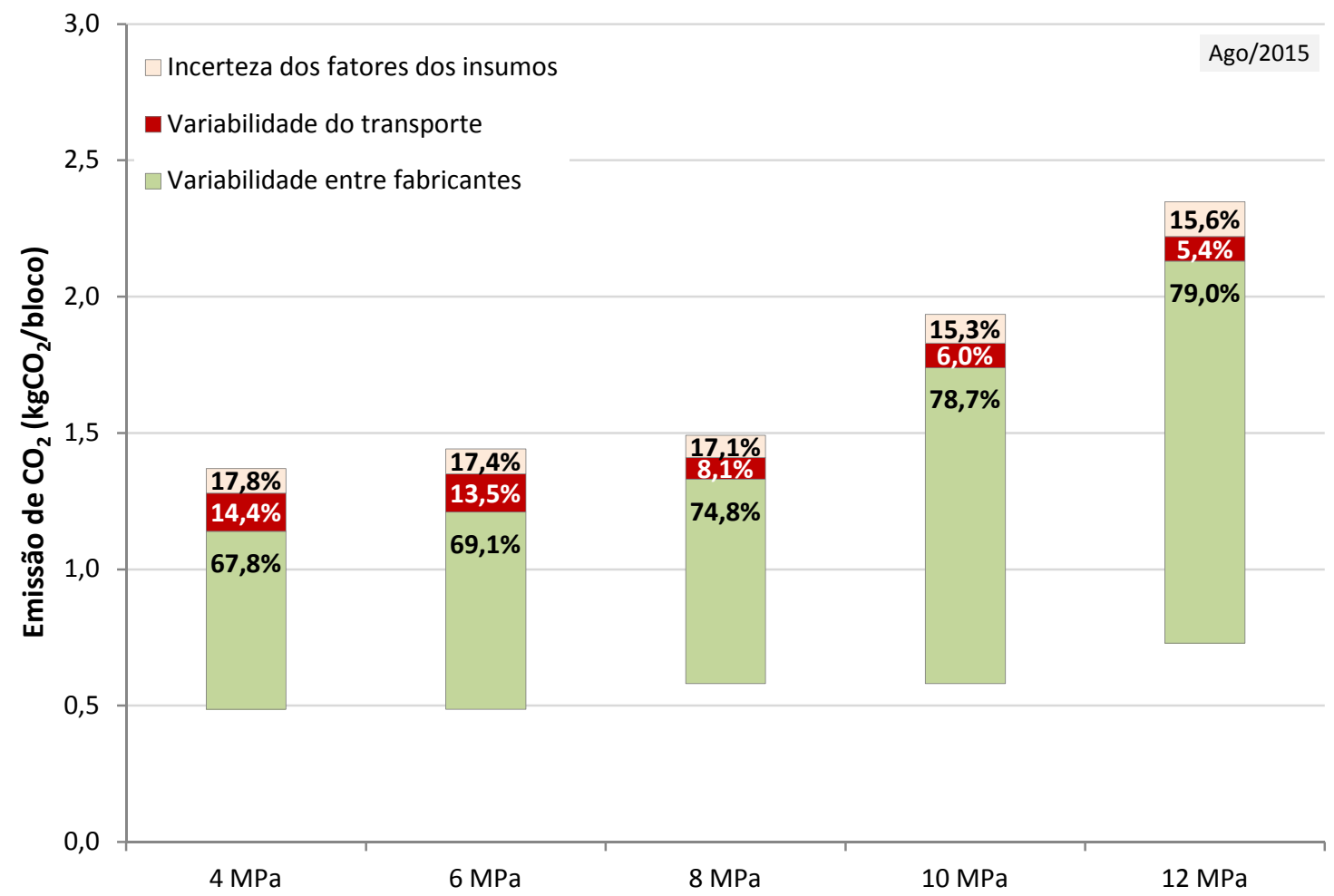

Figura 39 - Faixas da emissão de $\mathrm{CO}_{2}$ dos blocos estruturais, considerando a variabilidade entre as empresas e do transporte e as incertezas dos fatores de emissão dos insumos.

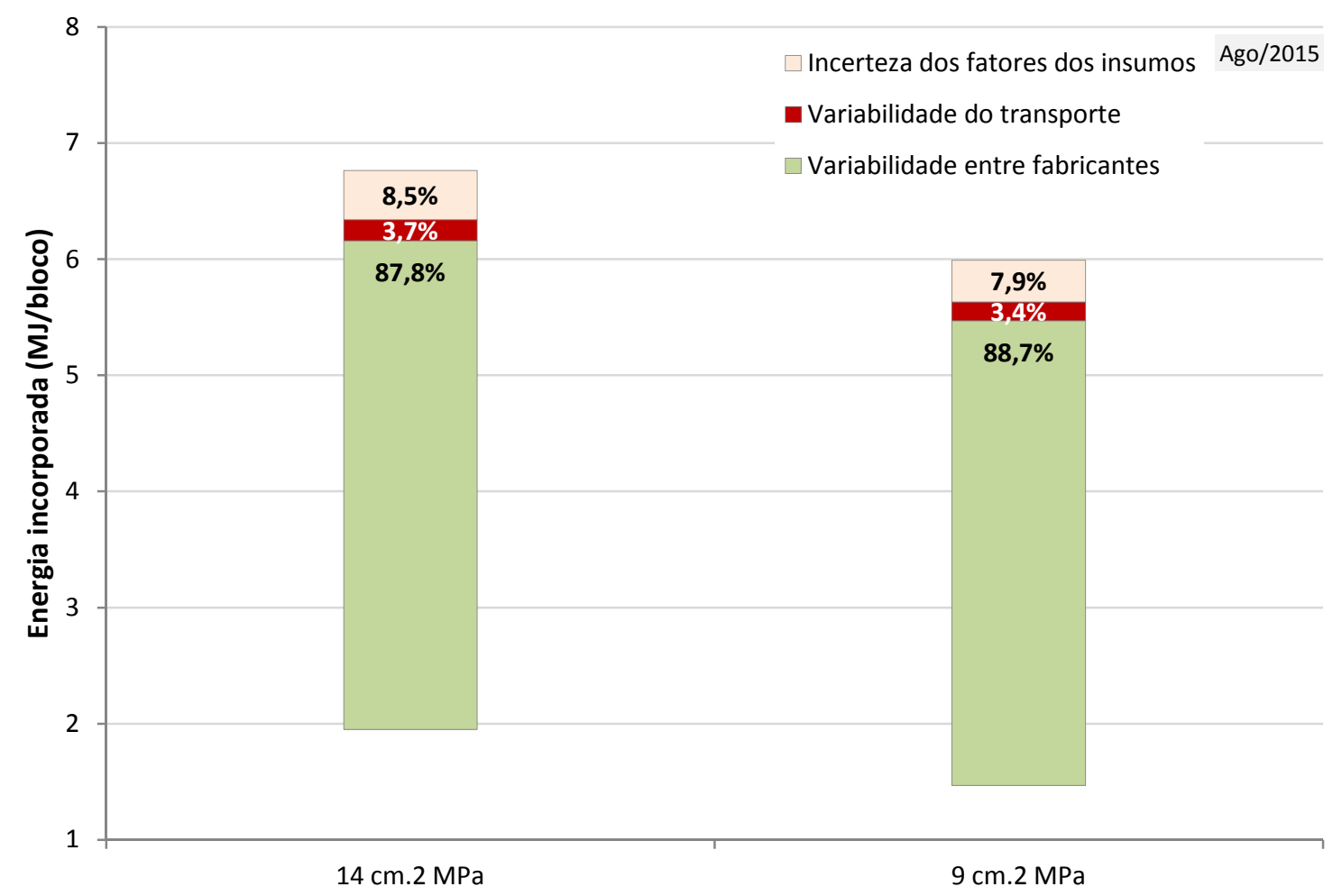

Figura 40 - Faixas da energia incorporada dos blocos de vedação, considerando a variabilidade entre as empresas e do transporte e as incertezas da energia dos insumos. 


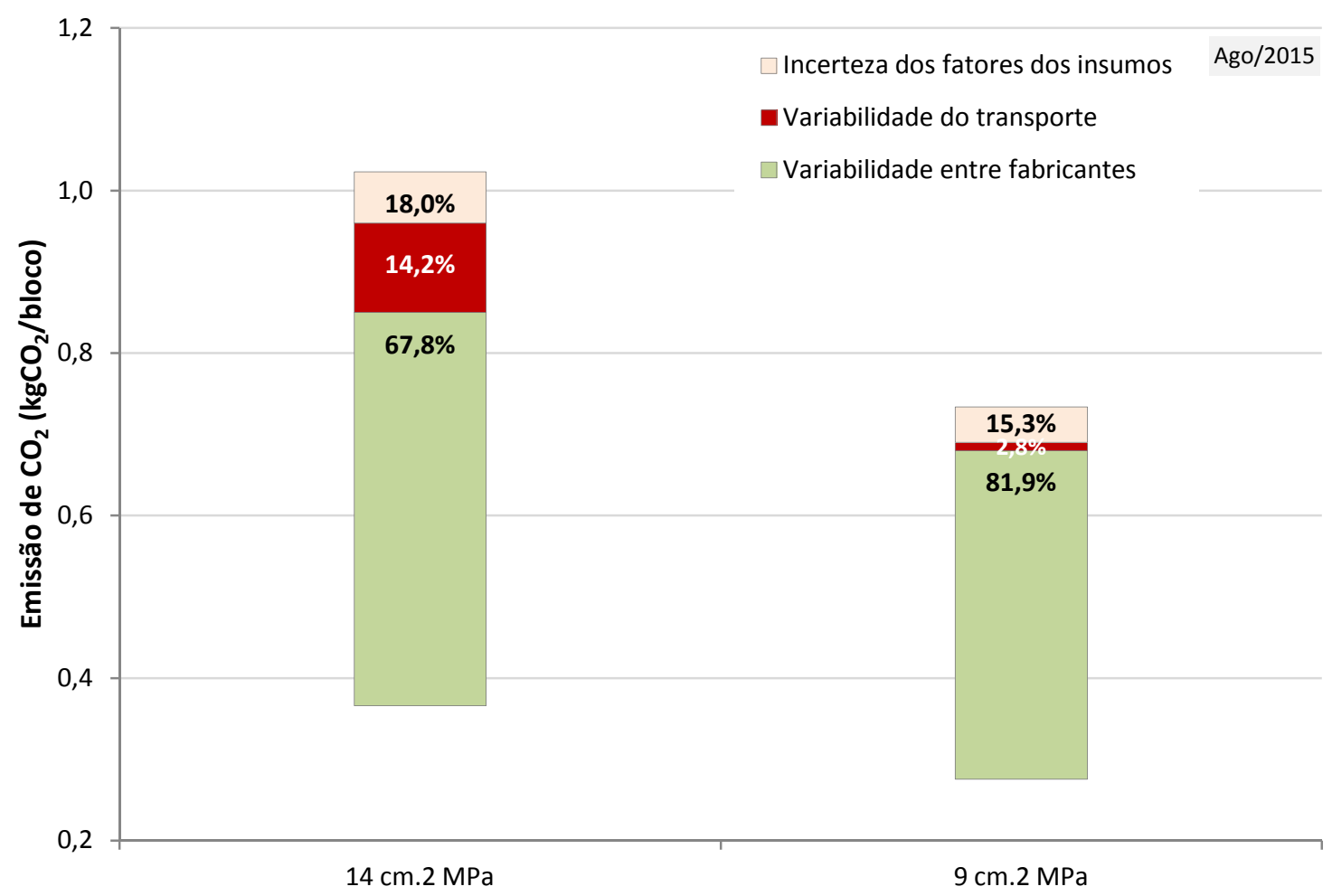

Figura 41 - Faixas da emissão de $\mathrm{CO}_{2}$ dos blocos de vedação, considerando a variabilidade entre as empresas e do transporte e as incertezas dos fatores de emissão dos insumos.

Entre as fabricantes analisadas, os insumos utilizados, a formulação do concreto, a eficiência de compactação da vibroprensa e o sistema produtivo mostraram-se com maior influência nos resultados de energia incorporada e emissão de $\mathrm{CO}_{2}$ do que as incertezas da energia incorporada e dos fatores de emissão dos insumos e as variações quanto ao transporte. Mesmo se essas incertezas não existissem, a dispersão seria enorme - o que não pode ser negligenciado. Isso confirma que não é conveniente utilizar média ou mediana para representar um setor.

\subsection{Influência da distância de transporte}

Nesse estudo foi considerado apenas o transporte das matérias-primas, com o retorno do caminhão carregado. Nesse caso, os impactos gerados após a entrega do material não foram analisados, visto que estes estão associados à outra carga transportada. Se o retorno do veículo vazio fosse incluído na análise, essa etapa aumentaria em média $35 \%$ a energia incorporada e as emissões de $\mathrm{CO}_{2}$ relacionadas ao transporte. No entanto, como se acredita que essa situação é de difícil ocorrência, essa hipótese não foi avaliada.

Entre os dados informados pelas empresas participantes, o cimento foi transportado 
por distâncias que variam de 3 a $771 \mathrm{~km}$ (mediana $390 \mathrm{~km}$ ) e os agregados minerais de 0,3 a $280 \mathrm{~km}$ (mediana $27 \mathrm{~km}$ ). Na Figura 42 é apresentada a distância média ponderada pelas quantidades de cada fornecedor de cimento e de agregados de cada empresa $\left(\sum \%_{\text {fornecedor.n }} \times\right.$ distância $\left._{n}\right)$. Observa-se que entre os agregados a areia é o insumo com maior distância ponderada, que não ultrapassa $150 \mathrm{~km}$, embora a maior distância informada entre as empresas tenha sido $280 \mathrm{~km}$.

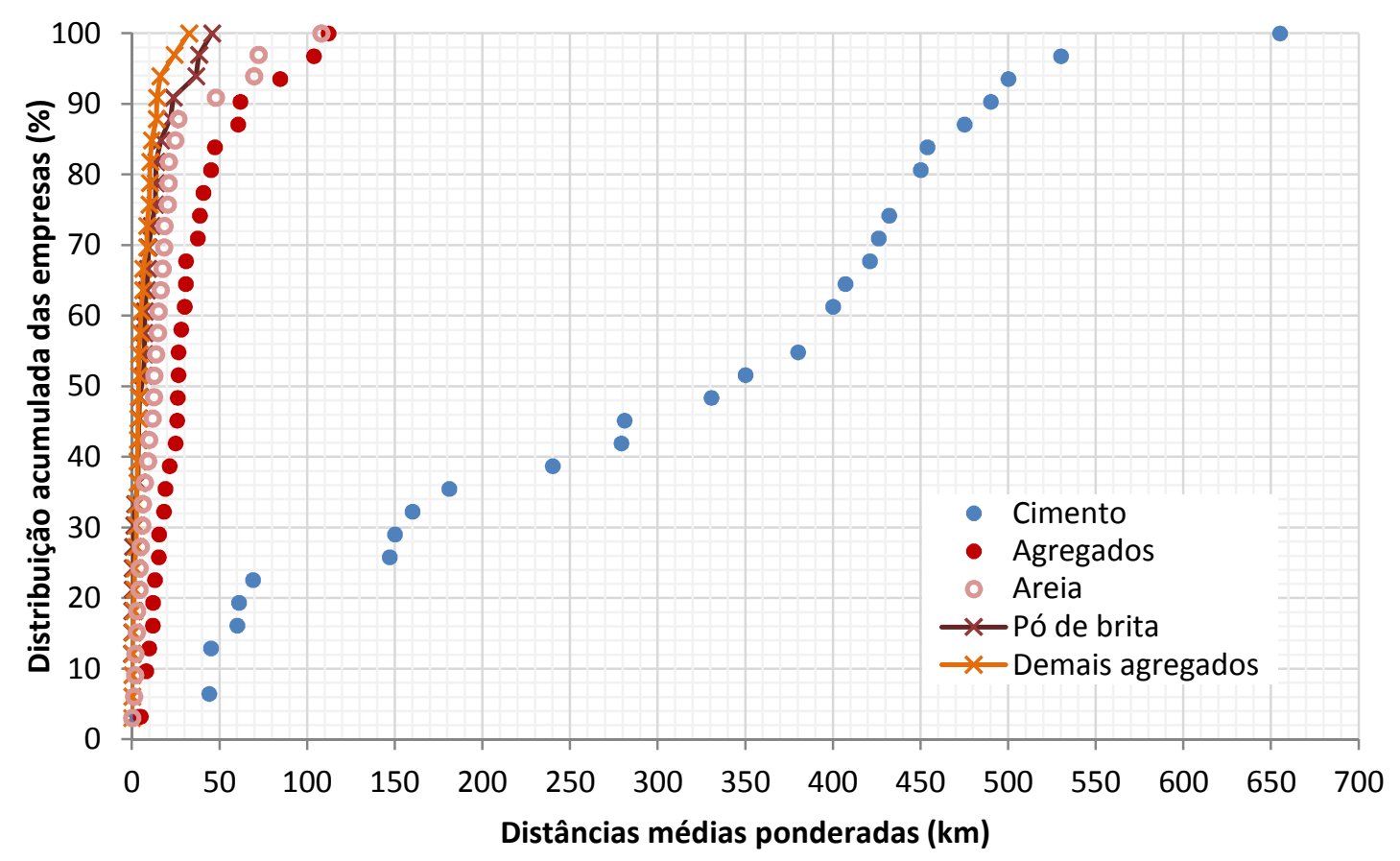

Figura 42 - Curva de frequência acumulada versus a distância média ponderada dos insumos.

No entanto, se as distâncias dos insumos forem ponderadas com as quantidades de cimento e agregado totais calculadas por bloco, as distâncias variam entre 14 e 157 km (mediana de aproximadamente $50 \mathrm{~km}$ ), como mostra a Figura 43. 


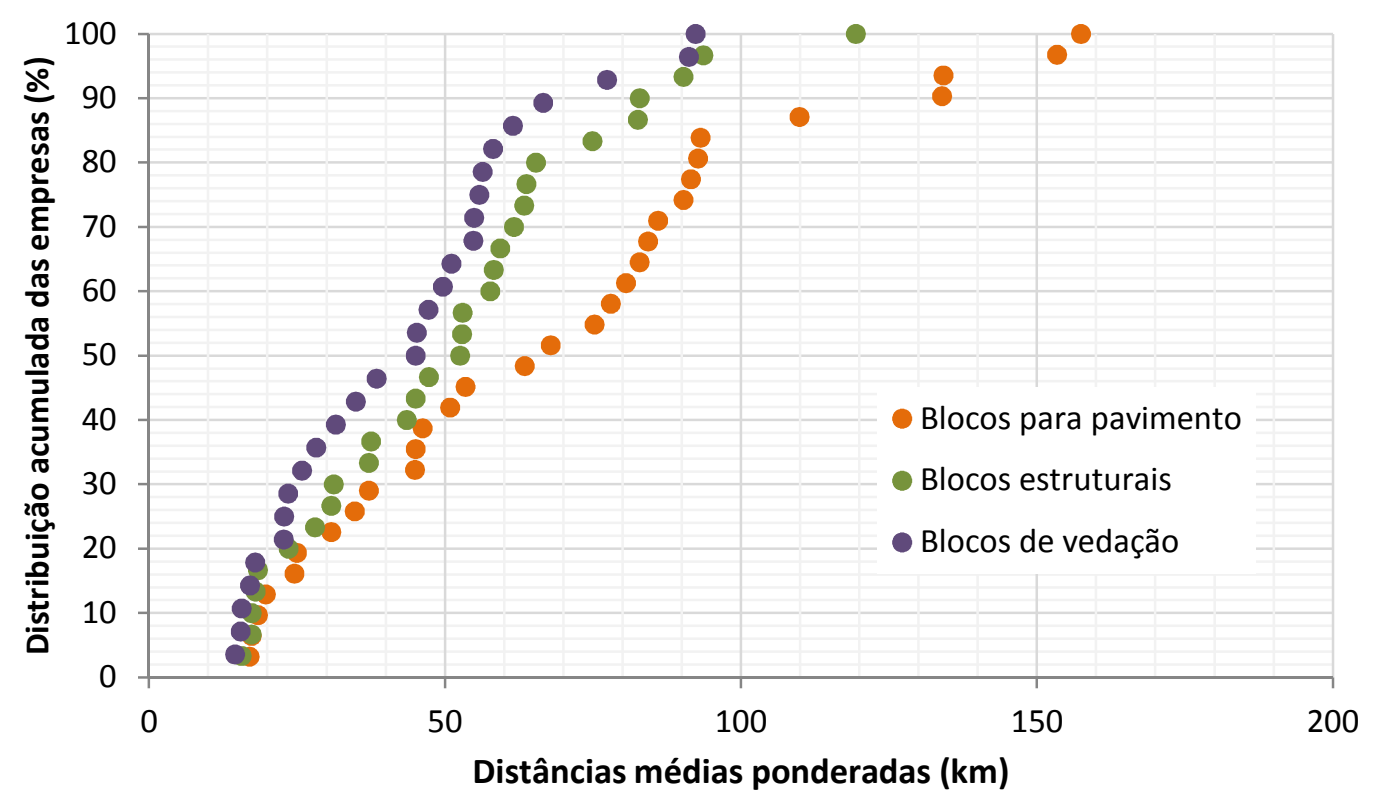

Figura 43 - Distância média ponderada dos insumos pela quantidade utilizada nos blocos.

A influência na distância média de transporte das matérias-primas na relação da emissão de $\mathrm{CO}_{2}$ do bloco é modesta, como é apresentado pela Figura 44. Observase que o coeficiente de correlação $\left(R^{2}\right)$ é muito baixo no caso dos três tipos de blocos analisados (pavimento, estrutural e vedação). 


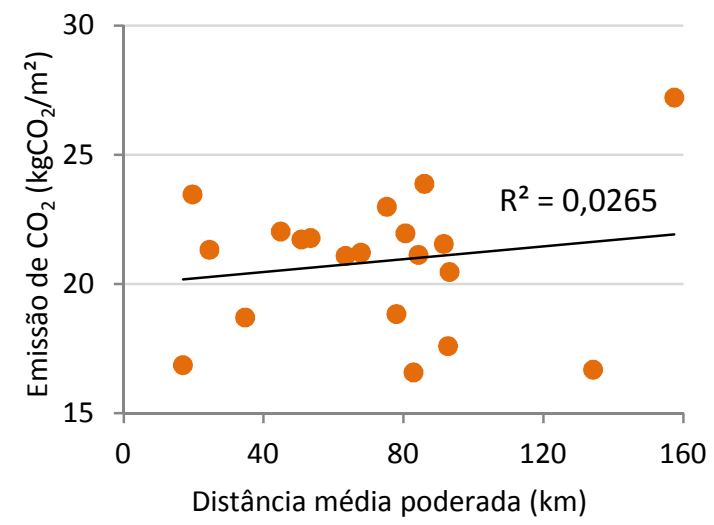

(a)

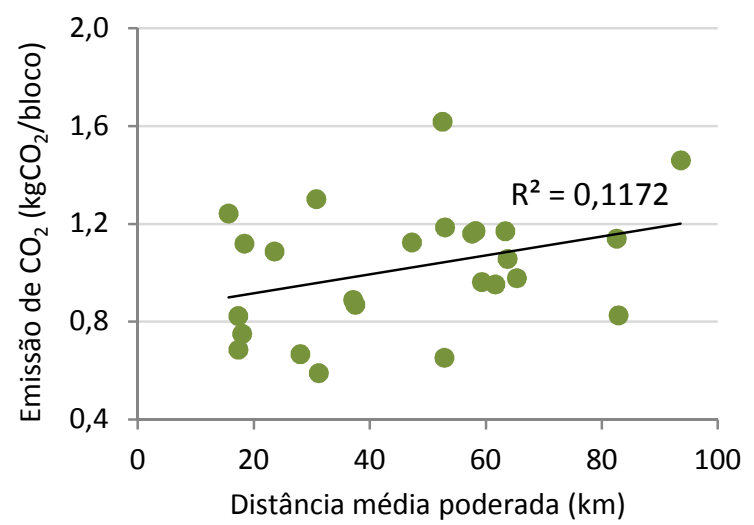

(b)

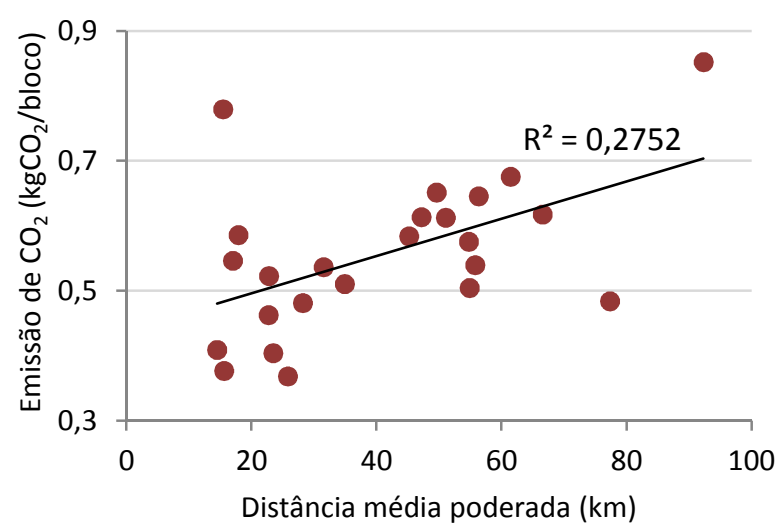

(c)

Figura 44 - Relação entre a distância média ponderada e a emissão de $\mathrm{CO}_{2}$, por $\mathrm{m}^{2}$ para os blocos para pavimento e por peça para os blocos para alvenaria: (a) blocos para pavimento; (b) blocos estruturais; (c) blocos de vedação. 


\section{Discussões sobre a metodologia da ACV Modular}

A seleção de 13 tipos de blocos de concreto para o estudo ocasionou algumas dificuldades durante a execução da ACV. Como a maioria das empresas também fabricava outros produtos, a quantidade de matérias-primas estimadas para os blocos analisados foi comparada com o total de insumo material utilizado pela fábrica. Isso resultou em algumas inconsistências para algumas empresas, como consumo de cimento dos blocos selecionados superior ao consumo total da fábrica, apesar de produzirem outros produtos. A análise possivelmente incorporaria menos erros e seria mais fácil a identificação de falhas do inventário se todos os produtos da fábrica estivessem no escopo do estudo. Isso possibilitaria a realização do balanço de massa, com a comparação entre as entradas de insumos e saídas de produtos e resíduos. O fechamento do ciclo imprimiria maior precisão aos resultados.

Permitir que as empresas definissem a unidade de produção para facilitar o preenchimento do formulário tornou necessária a adoção de alguns fatores de correção, que embutem erros, já que a alocação dos consumos de energia e água da fábrica foi realizada em massa. No caso das empresas que informaram sua produção em unidade diferente da tonelada, e por isso precisaram ter uma massa média calculada a partir dos produtos analisados para a estimativa da massa total de produção (item 5.10), o valor considerado para as análises pode ter sido superior ou inferior ao valor real. Isso pode ter influenciado a quantidade de energia e água alocada aos produtos analisados, informação possível de confirmar apenas com o levantamento da massa real. A padronização dos controles internos da fábrica de todo o setor (criação de metodologias para medições e registro de informações) evitaria a necessidade dessas estimativas.

A comparação entre as massas de blocos equivalentes apontou considerável dispersão entre as empresas participantes. As variações das dimensões das peças, associadas ao desgaste ou não de formas, a densidade dos agregados, a formulação do concreto e o grau de compactação são possíveis causas. Além disso, a variação de massa pode estar associada ao método e condições nas quais a mesma foi medida (produto seco em estufa ou ao ar, produto saturado, etc.), uma vez que não foi especificado como essa medição deveria ter sido realizada. Também é possível que em alguns casos as empresas tenham informado a massa do produto 
que é comunicada à transportadora, quando o mesmo se encontra saturado, para evitar multas por sobrecarga. No estudo foi considerado que a massa do bloco foi medida após estar em equilíbrio com a umidade do ar. Assim, para as empresas que levantaram suas massas em situação diferente, os resultados podem apresentar valores diferentes do cenário real. É, portanto, necessário padronizar as condições de medida da massa dos blocos.

O teor de cimento do produto informado em $\mathrm{kg} / \mathrm{m}^{3}$ por algumas empresas tornou necessária a estimativa do volume de cada peça, para permitir o cálculo da massa de cimento relativa à mesma. $O$ volume dos blocos para pavimento foi estimado com base na quantidade de peças por $\mathrm{m}^{2}$, específico para cada empresa, e na espessura do mesmo. No caso dos blocos para alvenaria, que possuem dimensões normatizadas (admitas tolerâncias), seu volume foi estimado de acordo com a norma NBR 6136 (ABNT, 2007). As empresas que produzem blocos com dimensões maiores ou menores que a padrão, mas dentro dos limites permitidos, podem apresentar consumos de cimento acima ou abaixo do estimado. Isso implica em distorções nos indicadores que dependem da massa de cimento.

As indefinições quanto à água ainda são muitas, apesar da ISO ter lançado recentemente, em julho de 2014, uma norma de pegada de água baseada em ACV. Os consumos não são controlados quantitativamente pelas empresas, particularmente a água captada diretamente pela própria empresa. O formulário solicitava a água de composição do concreto por peça para cada tipo de produto; onde foram realizadas diferentes considerações para esse levantamento. Ainda se tentou estimar o volume dessa água, através de uma pesquisa junto às empresas sobre o teor de umidade médio de seus agregados. No entanto, esse valor não é controlado, uma vez que sensores no misturador do concreto realizam a verificação do alcance da umidade ótimo de dosagem. Esse é um tema que exige o estabelecimento de métodos padronizados para a realização das medições. Por causa dessa incerteza, não foi possível calcular uma faixa para o indicador de consumo de água de composição do concreto, apenas para a água total utilizada na fábrica. No caso desta, também é necessária a criação de metodologias para o seu levantamento, considerando todas as fontes de água. Os resultados do indicador de água mostram que seu levantamento ainda é bastante frágil por parte de algumas empresas. 
Como no processo de simplificação alguns itens foram suprimidos do formulário, a coleta complementar de algumas informações foi necessária para a análise dos impactos devido ao transporte - quantidade de matéria-prima entregue a cada pedido e tipo de veículo utilizado. Como esses dados foram levantados por e-mail ou contatos por telefone, não foi possível ter o retorno de todas as empresas. Para os casos em que não houve resposta, os valores máximo e mínimo levantados entre as que responderam foram adotados. Acredita-se que os resultados reais estejam dentro da faixa de consumo de combustível calculada, sendo que o cenário pode vir a melhorar com a correta especificação por essas fábricas em um novo estudo.

Algumas empresas informaram consumo muito elevado para alguns combustíveis usados no seu processo produtivo, quando comparadas com as demais, em especial GLP e lenha. Entende-se que no levantamento desse dado pode ter havido falha de registro da informação. Por esse motivo, os resultados dessas empresas não foram considerados no desenvolvimento dos indicadores de energia incorporada e emissão de $\mathrm{CO}_{2}$.

Durante a análise dos dados de resíduos da produção, observou-se que no formulário ficou confusa a diferenciação entre o que considerar como resíduos e o que registrar como perdas. As perdas de produção de cada tipo de bloco selecionado para o estudo ficaram bem determinadas, mas não foram bem definidos que dados foram informados como resíduos da fábrica. Pelos valores levantados, algumas empresas provavelmente informaram números relativos aos resíduos que saem da fábrica, enquanto outras passaram seus valores de perdas. Por esse motivo, não foi possível criar o indicador de resíduo. Este é um tema que precisará ser aperfeiçoado, tanto em relação à definição, quanto ao controle dentro da fábrica pelas empresas.

O formulário solicitou também a descrição e as quantidades de outros tipos de resíduos além dos oriundos da produção, sem predefinir os tipos a serem informados. Como consequência, menos da metade das empresas passou esses dados, o que impossibilitou a criação de outro indicador de resíduo, específico por tipo. Isso deixou claro que os dados solicitados pelo formulário devem estar bem estabelecidos para que as empresas informem seus valores. 
A partir da análise dos primeiros resultados, algumas auditorias foram realizadas para verificação dos dados de algumas empresas selecionadas. Entretanto, as dúvidas que existiam permaneceram após as visitas da equipe responsável pela auditoria (SENAI-RJ). A falta de uma metodologia específica para a verificação dos dados levantados pelo formulário do Projeto ACV-m contribuiu para isso. Como alguns dados informados foram estimados, a abordagem para verificação dessa informação deveria ter sido muito específica, para facilitar o detalhamento do levantamento por parte da empresa. A solicitação dos cálculos realizados no preenchimento do formulário foi outro dado importante que deveria ter sido melhor especificado para as empresas.

Embora alguns valores possam não corresponder à realidade, essa primeira ação era necessária para se conhecer os números iniciais, qual o nível de controle do processo que as empresas possuem, quais os pontos que precisam de maior atenção. À medida que o controle de processo aumentar, as faixas podem se tornar mais estreitas, com as empresas alcançando maior capacidade de gerenciamento dos seus fluxos. 


\section{Conclusões}

As faixas do indicador de emissão de $\mathrm{CO}_{2}$ apresentaram uma variabilidade significativa, sendo o máximo superior ao mínimo em uma razão que varia de 2,3 a 2,8 para os blocos para pavimento e de 2,6 a 3,3 para os blocos para alvenaria. 0 mesmo foi observado entre as faixas do indicador de energia incorporada, que apresentou diferença entre máximo e mínimo variando em um fator entre 2,5 e 3,0 para os blocos para pavimento e entre 3,5 e 4,1 para os blocos para alvenaria.

O cimento é um item importante responsável por parcela significativa do $\mathrm{CO}_{2}(61 \mathrm{a}$ 99\%) e da energia incorporada (30 a 96\%) do bloco. O CP V é o tipo mais utilizado entre as fábricas participantes do estudo, mas não necessariamente responde pelos maiores resultados desses indicadores, pois algumas empresas que apresentaram os menores valores também utilizam esse tipo de cimento. No caso em estudo, o teor de clínquer dos cimentos não foi o principal responsável por esses indicadores, mas a quantidade de cimento utilizada no bloco.

Observou-se grande variação nos consumos de cimento entre as empresas em blocos que possuem mesmas características, como classe de resistência. As características da vibro prensa utilizada provavelmente é um importante fator na definição desse consumo, por reduzir a porosidade do bloco. Mas as características das partículas, dos agregados (distribuição e forma dos grãos) ou mesmo do cimento, e o teor de água e aditivos também devem influenciar. A obtenção da formulação ótima do concreto pela seleção e combinação das matérias-primas, pelo empacotamento dos grãos, consegue minimizar o consumo de cimento. No entanto, estas seleções são, por questões de logística e custo, limitadas aos materiais disponíveis na região. Estratégias para a redução no consumo de materiais são importantes como artifícios para a implantação da produção mais limpa.

A minimização da energia e emissão de $\mathrm{CO}_{2}$ depende não só de um mínimo teor de cimento, mas da minimização de outros fatores. As diversas possibilidades para dosagem do concreto, pela variedade de agregados disponíveis por região e pelo teor e reatividade do cimento, as estratégias de cura, assim como as diferenças na eficiência de compactação das vibroprensas, são caminhos importantes para melhoria ambiental. 
As diferenças entre energia incorporada e emissões de $\mathrm{CO}_{2}$ de um mesmo produto são resultados das incertezas da energia e fatores de emissão dos insumos w da variabilidade de fatores internos da fábrica, das distâncias e modal de transporte das matérias-primas. A influência da energia incorporada e dos fatores de emissão dos insumos apresentou uma razão entre os valores máximo e o mínimo que variou de 1,1 a 3,0. Entretanto, entre as fabricantes analisadas - mesmo com igual rota tecnológica - os insumos utilizados, a formulação do concreto, a eficiência de compactação da vibroprensa e o sistema produtivo mostraram maior influência nos resultados de energia incorporada e emissão de $\mathrm{CO}_{2}$. Apesar das distâncias de transporte dos insumos serem grandes, principalmente para o cimento, a influência na distância média de transporte na relação da emissão de $\mathrm{CO}_{2}$ do bloco é modesta.

A análise do inventário poderia englobar menos erros se todos os produtos de cada empresa participante estivessem no escopo do estudo. Essa abordagem possibilitaria a comparação entre as entradas de matérias-primas e saídas de produtos, permitindo também a estimação dos resíduos, ou seja, seria possível realizar o balanço de massa - que não foi possível.

Estabelecer no formulário as unidades dos dados solicitados diminuiria a necessidade de estimativas que podem influenciar nos resultados, como o consumo de cimento no caso de produtos cimentícios, observado para os blocos de concreto. Além disso, fluxos de entrada e saída informados em massa evitariam erros de conversões, o que também facilitaria nos procedimentos de alocação que se fizessem necessários.

As indefinições quanto à água ainda são muitas, apesar do recente lançamento da norma de pegada de água baseada em ACV. Os consumos não são controlados quantitativamente pelas empresas, particularmente a água captada diretamente pela mesma. Aproximadamente $50 \%$ das empresas apresentam consumo de água total da fábrica por peça menor ou igual à água de composição informada, enquanto cerca de $10 \%$ apresentam consumo muito elevado. Métodos para o gerenciamento do consumo de água, assim como para o levantamento dos dados, precisam ser desenvolvidos e implementados juntos às fábricas. 


\subsection{Sugestão para trabalhos futuros}

- Levantar novamente dados do setor de blocos de concreto, mas considerando todos os produtos, de modo a possibilitar o balanço de massa.

- Levantar junto às empresas um detalhamento sobre os consumos de água.

- Definição de uma metodologia para realização das auditorias.

- Analisar a influência da energia de compactação na produção de blocos de concreto com o consumo de cimento.

- Levantar e analisar dados de consumo de combustíveis em diferentes situações do transporte de matérias-primas primárias do setor da construção civil.

- Aplicar a metodologia da ACV modular em outros setores da indústria. 


\section{Referências}

ASSOCIAÇÃO BRASILEIRA DE NORMAS TÉCNICAS. NBR 5735: Cimento

Portland de alto-forno. Rio de Janeiro, 1991.

. NBR 5733: Cimento Portland de alta resistência inicial. Rio de Janeiro, 1991.

NBR 11578: Cimento Portland composto. Rio de Janeiro, 1991.

NBR 5736: Cimento Portland pozolânico. Rio de Janeiro, 1991.

NBR 6136: Blocos vazados de concreto simples para alvenaria -

Requisitos. Rio de Janeiro, 2007.

NBR 14040: Gestão Ambiental - Avaliação do Ciclo de Vida - Princípios e estrutura. Rio de Janeiro, 2007b.

NBR ISO 14044: Gestão ambiental - Avaliação do ciclo de vida - Requisitos e orientações. Rio de Janeiro, 2007a.

AGGREGATE INDUSTRIES. Enviroblock Dense Blocks - EPD for precast concrete blocks. United Kingdom, 2015.

AGOPYAN, V.; JOHN, V. M. O Desafio da Sustentabilidade na Construção Civil. Edgard Blucher Ltda., 2011.

ALMEIDA, S. L. M. DE; LUZ, A. B. DA. Manual de agregados para a construção civil. Rio de Janeiro: Centro de Tecnologia mineral (CETEM) e Ministério da Ciência e Tecnologia (MCT), 2009.

ANEPAC, A. N. DAS E. DE P. DE A. PARA C. C. Agregados. 2013.

ANGELUS BLOCK CO. Environmental Product Declaration - Angelus Block Concrete Masonry Units. Califórnia, 2015.

ANICER. ACV - Avaliação do ciclo de vida do produto cerâmico. 2013.

ANTT; IEMA. $1^{\circ}$ Inventário Nacional de Emissões Atmosféricas do Transporte Ferroviário de Cargas - Relatório Final. Brasília: Agência Nacional de Transportes Terrestres, Instituto de Energia e Meio Ambiente, 2012.

ATHENA SUSTAINABLE MATERIALS INSTITUTE. Cement and structural concrete products: Life cycle inventory update \#2. Ottawa/Canadá, 2005.

BAILES, R. et al. Data Variability and Uncertainty in Greenhouse Gas Life Cycle Assessment. National Petroleum Council/Future Transportation Fuels Study, 2012. v. Topic Paper \#30.

BARBOSA JR., A. F. et al. Conceitos e aplicações de ACV no Brasil. XXVII Encontro Nacional de Engenharia de Produção, 2007.

BLENGINI, G. A.; GARBARINO, E. Resources and waste management in Turin (Italy): the role of recycled aggregates in the sustainable supply mix. Journal of Cleaner Production, jul. 2010. v. 18, n. 10-11, p. 1021-1030.

BRE. BRE Global Product Category Rules for Type III environmental product declaration of construction products to EN 15804:2012+A!:2013 - PN514. BRE Group, 2014.

BUENO, C.; ROSSIGNOLO, J. A.; OMETTO, A. R. Comparative Life cycle assessment: structural masonry of concrete and clay blocks. International 
Symposium on Life Cycle Assessment and Construction, 2012. n. France.

CABEZA, L. F. et al. Low carbon and low embodied energy materials in buildings : A review. Renewable and Sustainable Energy Reviews, 2013. v. 23, p. 536-542.

CAMPOS, É. F. DE. Emissão de $\mathrm{CO}_{2}$ da madeira serrada da Amazônia: o caso da exploração convencional. São Paulo: Escola Politécnica da Universidade de São Paulo, 2012. Dissertação de Mestrado.

CARVALHO, J. O. et al. Emissões fugitivas de gases de efeito estufa na indústria de petróleo e gás natural. Segundo inventário brasileiro de emissões e remoções antrópicas de gases de efeito estufa, 2010. v. Parte I, n. SNIC/ABCP/MCT. CBA, C. B. A. Aggregate Concrete Blocks - A Guide to Selection \& Specification. CBCS, C. B. DE C. S. Plataforma Global de Avaliação do Ciclo de Vida Simplificada para Construção Sustentável.

CERIB, C. D'ETUDES ET DE R. DE L'INDUSTRIE DU B. MUR EN MAÇONNERIE DE BLOCS EN BÉTON - Fiche de Déclaration Environnementale et Sanitaire conforme à la norme NF P 01-010. France: [s.n.], 2014

COELHO, A.; BRITO, J. DE. Influence of construction and demolition waste management on the environmental impact of buildings. Waste Management, mar. 2012. v. 32, n. 3, p. 532-541.

COSTA, B. L. DE C. Quantificação das emissões de $\mathrm{CO}_{2}$ geradas na produção de materiais utilizados na construção civil no Brasil. Rio de Janeiro:

Universidade Federal do Rio de Janeiro, COPPE, 2012. Dissertação de Mestrado.

CURRAN, M. A. Life cycle assessment: An international experience.

Environmental Progress, 1 jun. 2000. v. 19, n. 2, p. 65-71.

CURRAN, M. A. Life Cycle Assessment: Principles and Practice. U.S.

ENVIRONMENTAL PROTECTION AGENCY. Ohio, 2006.

CURRAN, M. A. Co-Product and Input Allocation Approaches for Creating Life Cycle Inventory Data: A Literature Review. The International Journal of Life Cycle Assessment, 2007. v. 12, n. Special Issue 1, p. 65-78.

CURRAN, M. A.; MANN, M.; NORRIS, G. The international workshop on electricity data for life cycle inventories. Journal of Cleaner Production, jun. 2005. v. 13, n. 8 , p. $853-862$.

CURRAN, M. A.; YOUNG, S. Report from the EPA on Streamlining LCA. International Journal of Life Cycle Assessment, 1996. v. 1, n. 1, p. 57-60.

DAMINELI, B. L. et al. Measuring the eco-efficiency of cement use. Cement \& Concrete Composites, 2010. v. 32, n. 8, p. 555-562.

DAMTOFT, J. S. et al. Sustainable development and climate change initiatives. Cement and Concrete Research, 2008. v. 38, p. $115-127$.

DNPM, D. N. DE P. M. Sumário Mineral 2013. 2013.

EKVALL, T.; FINNVEDEN, G. Allocation in ISO 14041-a critical review. Journal of cleaner production, 2001. v. 9, n. 3, p. 197-208.

EPD. EPD Concrete Blocks - KB-BLOK system.2009. 
EPD. Product Category Rules - UN CPC 375 - Concrete. The International EPDßSystem. 2013.

EPD-NORGE. EPD Multi betongblokk, Multi 12, 15 og 19 - Multiblokk. 2014.

EPE, E. DE P. E.; MME, M. DE M. E E. Balanço Energético Nacional 2013. 2013.

ERM, E. R. M. Streamlined Life Cycle Assessment Study - Study Prepared for

Airdri Ltd. and Bobrick Washroom Equipment Inc. United Kingdom, 2001.

EU. DIRECTIVE 2008/98/EC of the European Parliament and of the Council - of 19 November 2008 on waste and repealing certain Directives. 2008.

EUROPEAN COMMISSION; JOINT RESEARCH CENTRE; INSTITUTE FOR ENVIRONMENT AND SUSTAINABILITY. International Reference Life Cycle Data System (ILCD) Handbook - General guide for Life Cycle Assessment - Detailed guidance. Luxembourg: Publications Office, 2010.

FALCÃO, C. M. B. DE B. et al. Análise da qualidade do investimento e emissões de $\mathrm{CO}_{2}$ associadas à produção de agregados reciclados na Região

Metropolitana de São Paulo. São Paulo: Escola Politécnica da Universidade de São Paulo, 2013. Não publicado.

FERNANDES, I. D. Blocos e Pavers - Produção e Controle de Qualidade. 4. ed. São Paulo: Treino Assessoria e Treinamentos Empresariais Ltda., 2013.

FERREIRA, J. V. R. Análise de Ciclo de Vida dos produtos. Gestão Ambiental. Instituto Politécnico de Viseu, 2004.

FORD. Cargo 1723 - Especificações técnicas - Caminhões. 2012.

FORD. Cargo 2629 - Especificações técnicas - Caminhões. 2012.

FORD. Cargo 3133 - Especificações técnicas - Caminhões. 2012.

FORD. Cargo 2042 - Especificações técnicas - Caminhões. 2013.

FORD. Cargo 2842 - Especificações técnicas - Caminhões. 2013.

FRANKL, P. et al. Simplified life-cycle analysis of PV systems in buildings: present situation and future trends. Wiley Online Library, 1998. Online Library.

FRISCHKNECHT, R. et al. The ecoinvent Database: Overview and

Methodological Framework. The International Journal of Life Cycle Assessment, jan. 2005. v. 10, n. 1, p. 3-9.

GAMA, A. G. C. DE O. Análise ambiental e económica da produção de tijolos Caso de estudo: Fábrica Cerâmica. 2010.

GARTNER, E. Industrially interesting approaches to “'low- $\mathrm{CO}_{2}$ "” cements. Cement and Concrete Research, 2004. v. 34, p. 1489-1498.

GOLDEMBERG, J. Pesquisa e desenvolvimento na área de energia. São Paulo em Perspectiva, 2000. v. 14, p. 91-97.

GRAEDEL, T. E.; SAXTON, E. Improving the overall environmental performance of existing telecommunications facilities. The International Journal of Life Cycle Assessment, 2002. v. 7, n. 4, p. 219-224.

GRI. G4 - Sustainability Reporting Guidelines - Reporting principles and standard disclosures. Global Reporting Initiative, 2013. 
GRUPO BOTICÁRIO. Relatório de Sustentabilidade 2013 - Grupo Boticário. [S.I.]: [s.n.], 2014.

GUERRA. Guerra - Linha carga seca. Sem data.

GUINEE, J. B. et al. Life Cycle Assessment: Past, Present, and Future.

Environmental science \& technology, 2011. v. 45, n. 1, p. 90-96.

HAMMOND, G. P.; JONES, C. I. Embodied energy and carbon in construction materials. Proceedings of the Institution of Civil Engineers - Energy, 2008. v. 161, n. EN2, p. 87-98.

HOEKSTRA, A. Y. et al. Water Footprint Manual - State of the Art 2009. Water Footprint Network, 2009.

HOFFMAN, W. F. Recent advances in design for environment at Motorola. Journal of Industrial Ecology, 1997. v. 1, n. 1, p. 131-140.

HOLCIM. Corporate Sustainable Development Report 2011. Holcim, 2012. HOSPIDO, A.; MOREIRA, M. T.; FEIJOO, G. Simplified life cycle assessment of galician milk production. International Dairy Journal, jan. 2003. v. 13, n. 10, p. 783796.

HUIJBREGTS, M. A. J. Application of Uncertainty and Variability in LCA - Part I: A General Framework for the Analysis of Uncertainty and Variability in Life Cycle Assessment. Int. J. LCA, 1998. Uncertainty in LCA. v. 3, n. 5, p. $273-280$. HUNT, R. G. et al. Case Studies Examining LCA Streamlining Techniques. International Journal of Life Cycle Assessment, 1998. v. 3, n. 1, p. 36-42.

HUNTZINGER, D. N.; EATMON, T. D. A life-cycle assessment of Portland cement manufacturing: comparing the traditional process with alternative technologies. Journal of Cleaner Production, maio. 2009. v. 17, n. 7, p. 668-675.

IPCC, I. P. ON C. C. Climate Change 2013 - The Physical Science Basis: Working Group I Contribution to the Fifth Assessment Report of the Intergovernmental Panel on Climate Change. Cambridge, United Kingdom and New York: [s.n.], 2013.

IPCC, T. I. P. ON C. C. 2006 IPCC Guidelines for National Greenhouse Gas Inventories - Volume 2 - Energy. 2006.

ISO. ISO 14046 - Environmental management: Water footprint - Principles, requirements and guidelines. International Organization for Standardization. 2014.

JENSEN, A. A. et al. Life Cycle Assessment (LCA) - A guide to approaches, experiences and information sources. Environmental Issues Series. EEA European Environment Agency, 1997.

JOHN, V. M. Cimentos de escória ativada com silicatos de sódio. São Paulo: Escola Politécnica da Universidade de São Paulo, 1995. Tese de Doutorado.

JOHN, V. M. et al. Strategies to escalate the use of LCA based decision making in the world-wide industry. CBCS - Conselho Brasileiro de Construção Sustentável. 2013.

JOHN, V. M. et al. Projeto Avaliação de Ciclo de Vida Modular de Blocos e Pisos de Concreto - Relatório final para empresas participantes. São Paulo: Conselho Brasileiro de Construção Sustentável (CBCS), 2014. 
JOHN, V. M.; ANGULO, S. C. Metodologia para desenvolvimento de reciclagem de resíduos. Coletânea Habitare, 2003. v. 4, p. 8-71.

JOHN, V. M.; OLIVEIRA, D. P. DE; LIMA, J. A. R. DE. Levantamento do estado da arte: Seleção de materiais. Projeto Finep 2386/04.

JOHN, V. M.; SCRIVENER, K. Low-CO ${ }_{2}$ Eco-Efficient Cement-based Materials Industry - DRAFT (2014). INEP, SBCI, Não publicado.

JULLIEN, A. et al. Variability in the environmental impacts of aggregate production. Resources, Conservation and Recycling, maio. 2012. v. 62, p. 1-13.

KELLENBERGER, D.; ALTHAUS, H.-J. Relevance of simplifications in LCA of building components. Building and Environment, abr. 2009. v. 44, n. 4, p. 818-825.

KUBBA, S. LEED® Practices, Certification, and Accreditation Handbook. Elsevier Inc., 2010.

KULAY, L. A.; SEO, E. S. M. Orientações conceituais para elaboração de inventários de ciclo de vida. INTERFACEHS - Revista de Gestão Integrada em Saúde do Trabalho e Meio Ambiente, jan. 2010. v. 5.

KULAY, L.; HANSEN, A. P.; SEO, E. S. M. Identificação de oportunidades de melhoria de desempenho ambiental em processo de produção de materiais cerâmicos via aplicação da técnica de avaliação de ciclo de vida (ACV). Revista Produção Online [Online], 2010. v. 10, n. 4, p. 912-936.

LAFARGE. Sustainability 11th report - 2011. 2012.

LIMA, J. A. R. DE. Avaliação das consequências da produção de concreto no Brasil para as mudanças c... Tese de Doutorado. Escola Politécnica da USP, 2010. LIPPIATT, B. C. BEES 4.0 - Building for Environmental and Economic Sustainability: Technical Manual and User Guide. National Institute of Standards and Technology, U.S. Department Of Commerce, Technology Administration.

LITTLER, A. Chairman's report. CBA UPDATE, 2013. n. Spring, p. 2-4.

LLOYD, S. M.; RIES, R. Characterizing, Propagating, and Analyzing Uncertainty in Life-Cycle Assessment: A Survey of Quantitative Approaches. Journal of Industrial Ecology, 1 jan. 2007. v. 11, n. 1, p. 161-179.

MACEDO, I. C.; SEABRA, J. E. A.; SILVA, J. E. A. R. Green house gases emissions in the production and use of ethanol from sugarcane in Brazil: The $\mathbf{2 0 0 5 / 2 0 0 6}$ averages and a prediction for 2020. Biomass \& Bioenergy, 2008. v. 32, n. 7, p. 582-595.

MARCHIONI, M. L. Desenvolvimento de técnicas para caracterização de concreto seco para peças de concreto para pavimentação intertravada. Dissertação de Mestrado. São Paulo: Escola Politécnica da Universidade de São Paulo, 2013.

MARCOS, M. H. C. Análise da Emissão de $\mathbf{C O}_{2}$ em Edificações através do Uso de uma Ferramenta CAD-BIM. SIGraDi 2009 sp, 2009.

MARINKOVIĆ, S. et al. Comparative environmental assessment of natural and recycled aggregate concrete. Waste Management, nov. 2010. v. 30, n. 11, p. 22552264.

MASTELLA, D. V. Comparação entre os processos de produção de blocos 
cerâmicos e de concreto para alvenaria estrutural, através da análise do ciclo de vida. Dissertação de Mestrado. Florianópolis: Universidade Federal de Santa Catarina, 2002.

MENZIES, G. F.; TURAN, S.; BANFILL, P. Life-cycle assessment and embodied energy: a review. Proceedings of the Institution of Civil Engineers - Construction Materials, 2007. v. 160, n. CM4, p. 135-143.

MÜLLER, N.; HARNISCH, J. How to Turn Around the Trend of Cement Related Emissions in the Developing World. 2008.

MUNIZ, V. C. F. Análise da fundamentação da avaliação do ciclo de vida consequencial. Dissertação de Mestrado. Departamento de Engenharia Química. São Paulo: Escola Politécnica da Universidade de São Paulo, 2012.

NATURA. Relatório Anual 2014. 2014.

NICOLAY, S. A simplified LCA for automotive sector - comparison of ICE (diesel and petrol), electric and hybrid vehicles. 8th LCA Case Studies Symposium SETAC-Europe, 2000.

NISBET, M. A.; MARCEAU, M. L.; VANGEEM, M. G. Environmental Life Cycle Inventory of Portland Cement Concrete. PCA - Portland Cement Association, 2002.

NISSEN, N. F. et al. Comparison of simplified environmental assessments versus full life cycle assessment (LCA) for the electronics designer. Life Cycle Networks, FL Krause \& Seliger (Eds), Chapman \& Hall, 1997. p. 301-312.

OLIVEIRA, L. S. et al. Emissões de $\mathrm{CO}_{2}$ dos agregados reciclados de resíduos de construção e demolição (RCD): dois estudos de caso. $3^{\circ}$ Encontro Nacional Sobre Reaproveitamento de Resíduos na Construção Civil - ENARC, 2013. p. 15.

OLIVEIRA, V. C. H. C. et al. Estratégias para a minimização da emissão de $\mathbf{C O}_{2}$ de concretos. Associação Nacional de Tecnologia do Ambiente Construído, 2014. v. 14, n. 4, p. 167-181.

OLIVEIRA, V. C. H. C. Estratégias para minimização da emissão de CO2 de concretos estruturais. Mestrado em Engenharia Civil. São Paulo: Escola Politécnica da Universidade de São Paulo, 2015.

ORTIZ, O.; CASTELLS, F.; SONNEMANN, G. Sustainability in the construction industry: A review of recent developments based on LCA. Construction and Building Materials, 2009. v. 23, p. 28-39.

PBACV. Programa Brasileiro de Avaliação do Ciclo de Vida - PBACV Detalhamento. 2011.

PBACV, P. B. DE A. DO C. DE V. Metodologia Padrão para Elaboração de Inventários de Ciclo de Vida da Indústria Brasileira - Documento Consolidado: Projeto "SICV Brasil - Sistema de Inventários do Ciclo de Vida Brasil”. 2009.

PERES, L. D. P. Avaliação de propriedades mecânicas de peças pré-moldadas submetidas à cura térmica pelo método da maturidade: estudo de caso.

Dissertação de Mestrado. Ilha Solteira/SP: Universidade Estadual Paulista, 2006.

PUNHAGUI, K. R. G. Análsis de la Arquitectura en Madera en Brasil bajo aspectos de la sostenibilidad (em andamento). Escola Tècnica Superior d'Arquitectura de Barcelona da Universitat Politècnica de Catalunya e Escola 
Politécnica da Universidade de São Paulo, 2014.

QUANTIS. Análise comparativa do ciclo de vida de paredes construídas com tijolos de cerâmica, blocos de concreto e concreto armado moldado in loco Relatório final. Quantis Sustainability counts, 2012.

QUÉRÉ, C. L. et al. Global carbon budget 2013. Earth Syst. Sci. Data, 2014. n. 6, p. 235-263.

RAMPURIA, A. Enabling streamlined life cycle assessment: materialsclassification derived structured underspecification. Massachusetts Institute of Technology, 2012.

REBITZER, G. et al. Life cycle assessment - Part 1: Framework, goal and scope definition, inventory analysis, and applications. Environment International, jul. 2004. v. 30, n. 5, p. 701-720.

ROCHA, J. C.; JOHN, V. M. Utilização de Resíduos na Construção Habitacional. Porto Alegre: Associação Nacional de Tecnologia do Ambiente Construído (ANTAC), 2003. v. 4.

ROSKOVIC, R.; BJEGOVIC, D. Role of mineral additions in reducing $\mathrm{CO}_{2}$ emission. Cement and Concrete Research, 2005. v. 35, p. 974- 978.

ROSSI, E. Avaliação do ciclo de vida da brita para a construção civil: estudo de caso. Dissertação de Mestrado. São Carlos/SP: Universidade Federal de São Carlos, 2013.

RYU, J. S. An experimental study on the effect of recycled aggregate on concrete properties. Magazine of Concrete Research, 2002. v. 54, n. 1, p. 7-12.

SCA. LEED-NC ${ }^{\mathrm{TM}} 2.1$ Guide: Using Slag Cement in Sustainable Construction. Slag Cement Association. 2008.

SERNA, H. A. DE L.; REZENDE, M. M. Agregados para a construção civil. DNPM - Departamento Nacional de Produção Mineral, 2009.

SILVA, B. V. Construção de ferramenta para avaliação do ciclo de vida de edificações. Dissertação de Mestrado. São Paulo: Universidade de São Paulo, 2013.

SNIC. Relatório anual 2013. Rio de Janeiro: Sindicato Nacional das Indústrias de Cimento, 2014.

SOUZA, D. M. DE et al. Comparative Life Cycle Assessment of ceramic versus concrete roof tiles in the Brazilian context. Journal of Cleaner Production, 2015. n. 89, p. 165-173.

SOUZA, M. P. R. DE. Avaliação das emissões de $\mathrm{CO}_{2}$ antrópico associadas ao processo de produção do concreto, durante a construção de um edifício comercial, na Região Metropolitana de São Paulo. Mestrado em Tecnologia Ambiental. São Paulo: Instituto de Pesquisas Tecnológicas do Estado de São Paulo IPT, 2012.

SPOSTO, R. M. et al. Management and technology for quality and sustainability of masonry components in Brasilia's market. CIB W107 Construction in Developing Countries International Symposium - "Construction in Developing Economies: New Issues and Challenges", Chile, 2006. 
STACHERA, T.; CASAGRANDE JR., E. F. Avaliação de emissões de $\mathrm{CO}_{2}$ na construção civil: um estudo de caso da habitação de interesse social no Paraná. IX ENGEMA - ENCONTRO NACIONAL SOBRE GESTÃO EMPRESARIAL E MEIO AMBIENTE, nov. 2007.

STEINMANN, Z. J. N. et al. A methodology for separating uncertainty and variability in the life cycle greenhouse gas emissions of coal-fueled power generation in the USA. The International Journal of Life Cycle Assessment, maio. 2014. v. 19 , n. 5, p. 1146-1155.

SUN, M.; RYDH, C. J.; KAEBERNICK, H. Material grouping for simplified product life cycle assessment. The Journal of Sustainable Product Design, 2003. v. 3, n. 1, p. $45-58$.

TODD, J. A.; CURRAN, M. A. (Org.). Streamlined Life-Cycle Assessment: A Final Report from the SETAC North America Streamlined LCA Workgroup. Society of Environmental Toxicology and Chemistry (SETAC) and SETAC Foundation for Environmental Education, 1999.

TRAJANO, L. Avaliação do ciclo de vida dos produtos derivados do cimento para habitações de interesse social. Universidade de Pernambuco. 2010.

VENTURA, A. Introduction to the symposium: Life ycle Assessment, in-between Research, standards, regulations and application. Proccedings LCA Construction 2012, 2012.

VIÑAS, R. S.; SILVA, G. A. Critérios de Classificação de Indicadores de Sustentabilidade segundo a Lógica de Ciclo de Vida. III Congresso Brasileiro em Gestão do Ciclo de Vida de Produtos e Serviços, 2012. p. 6.

VOLKSWAGEN. Constellation 19-370 - Especificações técnicas - Caminhões e ônibus. 2008.

VOLKSWAGEN. Constellation 25-370 - Especificações técnicas - Caminhões e ônibus. 2008.

VOLKSWAGEN. Constellation 19-320 - Especificações técnicas - Caminhões e ônibus. 2008.

VOLKSWAGEN. Constellation 25-320 - Especificações técnicas - Caminhões e ônibus. 2008.

VOLKSWAGEN. Constellation 26-260 - Especificações técnicas - Caminhões e ônibus. 2008.

VOLKSWAGEN. Worker 26-220 - Especificações técnicas - Caminhões e ônibus. 2008.

VOLKSWAGEN. Constellation 31-370 - Especificações técnicas - Caminhões e ônibus. 2010.

WBCSD. GNR Project - Weighted average of mineral components and gypsum content in cements used to produce Portland and blended cements - Brazil. 2012.

WBCSD, W. B. C. FOR S. D. Cement Sustainability Initiative (CSI): GNR Project Reporting $\mathrm{CO}_{2} .2011$.

WBCSD, W. B. C. FOR S. D.; WRI, W. R. I. A Corporate Accounting and 
Reporting Standard. The Greenhouse Gas Protocol. 2004.

WEIDEMA, B. P. et al. Overview and methodology. Data quality guideline for the ecoinvent database version 3 (final). St. Gallen: The ecoinvent Centre: [s.n.], 2013.

WEITZ, K. et al. Streamlined Life-Cycle Assessment: A Final Report from the SETAC North America Streamlined LCA Workgroup. Society of Environmental Toxicology and Chemistry (SETAC) and SETAC Foundation for Environmental Education, 1999.

WEITZ, K. A. et al. Streamlining Life Cycle Assessment: Considerations and a Report on the State of Practice. The International Journal of Life Cycle Assessment The International Journal of Life Cycle Assessment, 1996. v. 1, n. 2, p. 79-85.

WORRELL, E. et al. Carbon dioxide emissions from the global cement industry. Annu. Rev. Energy. Environ, 2001. p. 303-329.

YTONG. EPD Ytong® Autoclaved Aerated Concrete. 2015. 


\section{Apêndice A}

Formulário padrão enviado às empresas participantes para coleta dos dados.

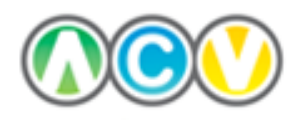

BLOCOS DE CONCRETO

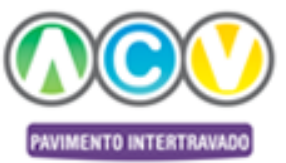

Projeto ACV Modular de Blocos de Concreto

\section{Dados Cadastrais}

\begin{tabular}{|c|c|c|c|}
\hline Razão Social & & & \\
\hline Nome Fantasia & & & \\
\hline CNPJ & & & \\
\hline Endereço & & & \\
\hline Cidade & Estado & & CEP \\
\hline Telefone & & Fax & \\
\hline Site da empresa & & & \\
\hline E-mail de contato & & & \\
\hline
\end{tabular}

\section{Dados sobre a Unidade Produtora}

Endereço da unidade produtora

\begin{tabular}{|l|l|}
\hline Cidade & \\
\hline
\end{tabular}

\begin{tabular}{|c|l|l|l|}
\hline Estado & \\
\hline $\mathrm{h} /$ semana & CEP & \\
\hline & dias/mês & & meses/ano \\
\hline
\end{tabular}

Número de colaboradores (exceto terceirizados)

Número de colaboradores terceirizados

Nome do responsável pelo preenchimento

\begin{tabular}{|l|l|}
\hline Setor & \\
\hline Cargo & \\
\hline Telefone & \\
\hline
\end{tabular}

Email:

Data do preenchimento

Período considerado para o preenchimento dos fomulários (12 meses - mês / ano) Início 


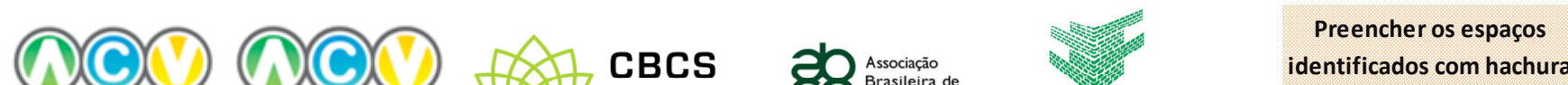 BLocos de conchereto ( laranja = escrever verde $=$ selecionar) .}

Projeto ACV Modular de Blocos de Concreto

\begin{tabular}{|c|c|c|c|c|c|c|c|c|c|c|c|}
\hline \multicolumn{12}{|c|}{ DADOS ESPECÍFICOS DO PRODUTO } \\
\hline Produto & \multirow[t]{2}{*}{$\begin{array}{c}\text { Formato/ } \\
\text { Tipo }\end{array}$} & Largura & Comprimento & Espessura & Resistência & $\begin{array}{c}\text { Massa da } \\
\text { peça }\end{array}$ & \multirow{2}{*}{$\begin{array}{l}\text { Tipo de } \\
\text { Cimento } \\
\text { (CP) }\end{array}$} & $\begin{array}{l}\text { Teor de } \\
\text { cimento }\end{array}$ & $\begin{array}{c}\text { Consumo de } \\
\text { água da } \\
\text { peça }\end{array}$ & $\begin{array}{l}\text { Produção } \\
\text { anual } \\
\text { vendida }\end{array}$ & $\begin{array}{l}\text { Perdas } \\
\text { (resíduos da } \\
\text { produção) }\end{array}$ \\
\hline Unidade & & $\mathrm{cm}$ & $\mathrm{cm}$ & $\mathrm{cm}$ & $\mathrm{MPa}$ & kg & & & & & (\%) \\
\hline \multirow{6}{*}{$\begin{array}{l}\text { Pavimento } \\
\text { de concreto }\end{array}$} & \multirow{3}{*}{ retangular } & & & 6 & 35 & & & & & & \\
\hline & & & & 8 & 35 & & & & & & \\
\hline & & & & 10 & 35 & & & & & & \\
\hline & \multirow{3}{*}{16 faces } & & & 6 & 35 & & & & & & \\
\hline & & & & 8 & 35 & & & & & & \\
\hline & & & & 10 & 35 & & & & & & \\
\hline \multirow{7}{*}{$\begin{array}{l}\text { Bloco de } \\
\text { concreto }\end{array}$} & \multirow{5}{*}{ Estrutural } & 14 & 39 & 19 & 4 & & & & & & \\
\hline & & 14 & 39 & 19 & 6 & & & & & & \\
\hline & & 14 & 39 & 19 & 8 & & & & & & \\
\hline & & 14 & 39 & 19 & 10 & & & & & & \\
\hline & & 14 & 39 & 19 & 12 & & & & & & \\
\hline & \multirow{2}{*}{ Vedação } & 14 & 39 & 19 & 2 & & & & & & \\
\hline & & 9 & 39 & 19 & 2 & & & & & & \\
\hline
\end{tabular}

\begin{tabular}{|c|c|c|c|c|c|}
\hline \multicolumn{6}{|c|}{ Marque um "X" na parcela de participação destes produtos na produção anual da planta total } \\
\hline $100 \%$ a $81 \%$ & $80 \%$ a $61 \%$ & & $60 \%$ a $41 \%$ & $40 \%$ a $21 \%$ & $<20 \%$ \\
\hline Produção comercializada & nentos & Unidade & & Quantidade & \\
\hline
\end{tabular}

* Diferenciar consumo estimado declarado do consumo real declarado (discriminar no campo para observações).

* Descrever como foi realizada a estimativa do valor declarado.

Observações 


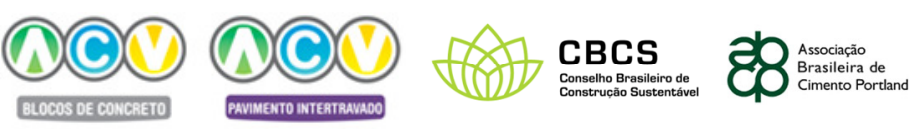

Projeto ACV Modular de Blocos de Concreto

Consumo de INSUMOS da fábrica no período de relatório Os dados de insumos e resíduos da fabricação devem se referir todos à produção comercializável da empresa. A participação dos blocos de concreto e pavimentos na
produção comercializável deve ser discriminada no formulário "PRODUTO"
\begin{tabular}{|l|r|r|r|l|l|}
\hline \multirow{3}{*}{ Cógua } & Ponte & Parcela (\%) & \\
\cline { 2 - 6 } & & Fonte & Parcela (\%) & \\
\cline { 2 - 6 } & & Fonte & & Parcela (\%) & \\
\hline
\end{tabular}

Os dados de insumos e resíduos da fabricação devem se referir todos à produç̃o comercializável da empresa. A participação dos blocos de concreto e pavimentos na

\begin{tabular}{|c|c|c|c|c|}
\hline \multicolumn{5}{|c|}{ Energia } \\
\hline \multicolumn{5}{|l|}{ Consumo total de energia elétrica no período (kWh) } \\
\hline \multirow{9}{*}{$\begin{array}{l}\text { Consumo total de combustível (unidades descritas } \\
\text { para cada tipo de combustível) }\end{array}$} & Fonte & Quantidade & Unidade & Usos \\
\hline & Óleo diesel & & \multirow{3}{*}{ litro } & \\
\hline & Gasolina & & & \\
\hline & Álcool & & & \\
\hline & GLP & & & \\
\hline & Gás Natural & & & \\
\hline & Outro (discrimine) & & & Consumo anual em caldeira de cura térmica \\
\hline & Outro (discrimine) & & & \\
\hline & Outro (discrimine) & & & \\
\hline
\end{tabular}

Matérias-primas

(Se possuir mais de um fornecedor por insumo, entrar em contato com a equipe e informar necessidade)

\begin{tabular}{|c|c|c|c|}
\hline \multicolumn{4}{|c|}{ Matérias-primas } \\
\hline \multicolumn{4}{|c|}{ (Se possuir mais de um fornecedor por insumo, entrar em contato com a equipe e informar necessidade) } \\
\hline \multirow{2}{*}{ Cimento } & \multicolumn{3}{|c|}{ Consumo anual total de cimento na fábrica $(\mathrm{t})$} \\
\hline & \multicolumn{2}{|l|}{ Cidade de origem do cimento } & Distância \\
\hline \multirow{2}{*}{ Areia (1) } & Consumo anual total de areia & Tipo & Unidade \\
\hline & \multicolumn{2}{|l|}{ Cidade de origem da areia } & Distância até a fábrica $(\mathrm{km})$ \\
\hline \multirow{2}{*}{ Areia (2) } & Consumo anual total de areia & Tipo & Unidade \\
\hline & \multicolumn{2}{|l|}{ Cidade de origem da areia } & Distância até a fábrica $(\mathrm{km})$ \\
\hline \multirow{2}{*}{ Brita 0} & \multicolumn{2}{|l|}{ Consumo anual total de brita 0} & Unidade \\
\hline & Cidade de origem da brita 0 & & Distância até a fábrica $(\mathrm{km})$ \\
\hline \multirow{2}{*}{ Pó de brita } & \multicolumn{2}{|c|}{ Consumo anual total de pó de brita } & Unidade \\
\hline & Cidade de origem do pó de brit & & Distância até a fábrica $(\mathrm{km})$ \\
\hline \multirow{2}{*}{ Filler } & \multicolumn{2}{|l|}{ Consumo anual total de filler } & Unidade \\
\hline & Cidade de origem do filler & & Distância até a fábrica $(\mathrm{km})$ \\
\hline \multirow{2}{*}{$\begin{array}{l}\text { Agregado } \\
\text { reciclado }\end{array}$} & \multirow{2}{*}{\multicolumn{2}{|c|}{ Consumo anual total de agregado reciclado }} & Unidade \\
\hline & & & Distância até a fábrica $(\mathrm{km})$ \\
\hline
\end{tabular}

Resíduos da PRODUÇÃO

\begin{tabular}{|l|l|l|l|l|l|}
\hline \multicolumn{7}{|c|}{ Resíduos da PRODUÇÃO } & Quantidade & \\
\hline Perdas anuais TOTAIS estimadas (geração de resíduos DA PRODUÇÃo) & Unidade & Distância até a destinação (km) & \\
\hline Destinação & & . & \\
\hline
\end{tabular}

\begin{tabular}{|l|l|l|l|}
\hline \multicolumn{5}{|c|}{ Outros Residuos } \\
\hline Tipo de Resíduo & Quantidade (informar unidade) & Destinação & Outras informações \\
\hline & & & \\
\hline & & & \\
\hline & & & \\
\hline & & & \\
\hline
\end{tabular}

* Diferenciar consumo estimado declarado do consumo real declarado (discriminar no campo para observações).

* Descrever como foi realizada a estimativa do valor declarado.

* Caso tenho sido realizada alguma conversão entre unidades $\left(\mathrm{kg}, \mathrm{m}^{3}, \mathrm{l}\right.$, etc), descrever os valores utilizados.

* Se houver informações adicionais sobre os itens acima, insumos ou resíduos, descrever no campo observações. 


\section{Apêndice B}

Valores das faixas: extremos das massas dos blocos e dos indicadores de energia incorporada, emissão de $\mathrm{CO}_{2}$ e água.

Variação da massa dos blocos analisados

\begin{tabular}{|c|c|c|c|c|c|}
\hline \multicolumn{2}{|c|}{ Especificação do Bloco } & Unidade & Mínimo & Máximo & Mediana \\
\hline \multirow{3}{*}{ Bloco retangular } & $6 \mathrm{~cm}$ & \multirow{6}{*}{$\mathrm{kg} / \mathrm{m}^{2}$} & 120 & 140 & 130 \\
\hline & $8 \mathrm{~cm}$ & & 155 & 190 & 175 \\
\hline & $10 \mathrm{~cm}$ & & 220 & 270 & 230 \\
\hline \multirow{3}{*}{ Blocos de 16 faces } & $6 \mathrm{~cm}$ & & 111 & 148 & 127 \\
\hline & $8 \mathrm{~cm}$ & & 161 & 187 & 175 \\
\hline & $10 \mathrm{~cm}$ & & 195 & 241 & 219 \\
\hline \multirow{5}{*}{$\begin{array}{l}\text { Bloco estrutural } \\
\qquad(14 \times 19 \times 39)\end{array}$} & $4 \mathrm{MPa}$ & \multirow{7}{*}{ kg/bloco } & 11,4 & 13,5 & 12,5 \\
\hline & $6 \mathrm{MPa}$ & & 11,4 & 13,5 & 12,7 \\
\hline & $8 \mathrm{MPa}$ & & 11,7 & 13,7 & 12,9 \\
\hline & $10 \mathrm{MPa}$ & & 11,7 & 13,9 & 13,1 \\
\hline & $12 \mathrm{MPa}$ & & 12,5 & 14,6 & 13,4 \\
\hline \multirow{2}{*}{$\begin{array}{c}\text { Bloco de vedação } 2 \mathrm{MPa} \\
(\text { esp.x19x39) }\end{array}$} & $14 \mathrm{~cm}$ & & 8,0 & 12,9 & 10,1 \\
\hline & $9 \mathrm{~cm}$ & & 7,0 & 12,9 & 8,2 \\
\hline
\end{tabular}

Indicador de energia incorporada

\begin{tabular}{|c|c|c|c|c|}
\hline \multicolumn{2}{|c|}{ Especificação do Bloco } & Unidade & Mínimo & Máximo \\
\hline \multirow{3}{*}{ Bloco retangular } & $6 \mathrm{~cm}$ & \multirow{6}{*}{$\mathrm{MJ} / \mathrm{m}^{2}$} & 40,7 & 120,2 \\
\hline & $8 \mathrm{~cm}$ & & 53,4 & 158,4 \\
\hline & $10 \mathrm{~cm}$ & & 65,8 & 161,8 \\
\hline \multirow{3}{*}{ Blocos de 16 faces } & $6 \mathrm{~cm}$ & & 40,7 & 103,1 \\
\hline & $8 \mathrm{~cm}$ & & 52,9 & 156,3 \\
\hline & $10 \mathrm{~cm}$ & & 64,9 & 177,7 \\
\hline \multirow{5}{*}{$\begin{array}{l}\text { Bloco estrutural } \\
\qquad(14 \times 19 \times 39)\end{array}$} & $4 \mathrm{MPa}$ & \multirow{7}{*}{ MJ/bloco } & 2,4 & 9,3 \\
\hline & $6 \mathrm{MPa}$ & & 2,4 & 9,6 \\
\hline & $8 \mathrm{MPa}$ & & 2,8 & 10,0 \\
\hline & $10 \mathrm{MPa}$ & & 2,8 & 10,7 \\
\hline & $12 \mathrm{MPa}$ & & 3,4 & 12,5 \\
\hline \multirow{2}{*}{ 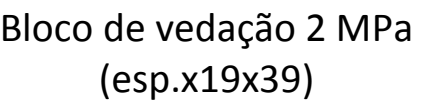 } & $14 \mathrm{~cm}$ & & 1,9 & 6,8 \\
\hline & $9 \mathrm{~cm}$ & & 1,5 & 6,0 \\
\hline
\end{tabular}


Indicador de emissão de $\mathrm{CO}_{2}$

\begin{tabular}{|c|c|c|c|c|}
\hline \multicolumn{2}{|c|}{ Especificação do Bloco } & Unidade & Mínimo & Máximo \\
\hline \multirow{3}{*}{ Bloco retangular } & $6 \mathrm{~cm}$ & \multirow{6}{*}{$\mathrm{kgCO}_{2} / \mathrm{m}^{2}$} & 8,1 & 22,6 \\
\hline & $8 \mathrm{~cm}$ & & 10,6 & 29,8 \\
\hline & $10 \mathrm{~cm}$ & & 13,0 & 29,7 \\
\hline \multirow{3}{*}{ Blocos de 16 faces } & $6 \mathrm{~cm}$ & & 8,1 & 20,2 \\
\hline & $8 \mathrm{~cm}$ & & 10,6 & 25,2 \\
\hline & $10 \mathrm{~cm}$ & & 12,9 & 32,0 \\
\hline \multirow{5}{*}{$\begin{array}{c}\text { Bloco estrutural } \\
(14 \times 19 \times 39)\end{array}$} & $4 \mathrm{MPa}$ & \multirow{7}{*}{$\mathrm{kgCO}_{2} /$ bloco } & 0,5 & 1,4 \\
\hline & $6 \mathrm{MPa}$ & & 0,5 & 1,4 \\
\hline & $8 \mathrm{MPa}$ & & 0,6 & 1,5 \\
\hline & $10 \mathrm{MPa}$ & & 0,6 & 1,9 \\
\hline & $12 \mathrm{MPa}$ & & 0,7 & 2,4 \\
\hline \multirow{2}{*}{ 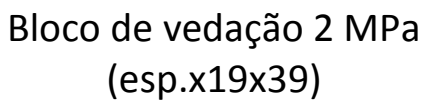 } & $14 \mathrm{~cm}$ & & 0,4 & 1,0 \\
\hline & $9 \mathrm{~cm}$ & & 0,3 & 0,7 \\
\hline
\end{tabular}

Indicador de água

\begin{tabular}{|c|c|c|c|c|}
\hline \multicolumn{2}{|c|}{ Especificação do Bloco } & Unidade & Mínimo & Máximo \\
\hline \multirow{3}{*}{ Bloco retangular } & $6 \mathrm{~cm}$ & \multirow{6}{*}{ litro/m² } & 0,3 & 19,7 \\
\hline & $8 \mathrm{~cm}$ & & 0,5 & 25,9 \\
\hline & $10 \mathrm{~cm}$ & & 4,4 & 33,1 \\
\hline \multirow{3}{*}{ Blocos de 16 faces } & $6 \mathrm{~cm}$ & & 0,3 & 19,6 \\
\hline & $8 \mathrm{~cm}$ & & 0,5 & 24,7 \\
\hline & $10 \mathrm{~cm}$ & & 0,6 & 30,9 \\
\hline \multirow{5}{*}{$\begin{array}{l}\text { Bloco estrutural } \\
\quad(14 \times 19 \times 39)\end{array}$} & $4 \mathrm{MPa}$ & \multirow{7}{*}{ litro/bloco } & 0,03 & 1,8 \\
\hline & $6 \mathrm{MPa}$ & & 0,03 & 1,8 \\
\hline & $8 \mathrm{MPa}$ & & 0,2 & 1,5 \\
\hline & $10 \mathrm{MPa}$ & & 0,2 & 1,6 \\
\hline & $12 \mathrm{MPa}$ & & 0,3 & 1,4 \\
\hline \multirow{2}{*}{ 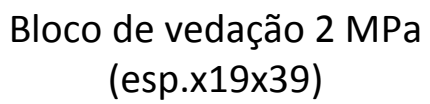 } & $14 \mathrm{~cm}$ & & 0,03 & 1,2 \\
\hline & $9 \mathrm{~cm}$ & & 0,02 & 1,0 \\
\hline
\end{tabular}

